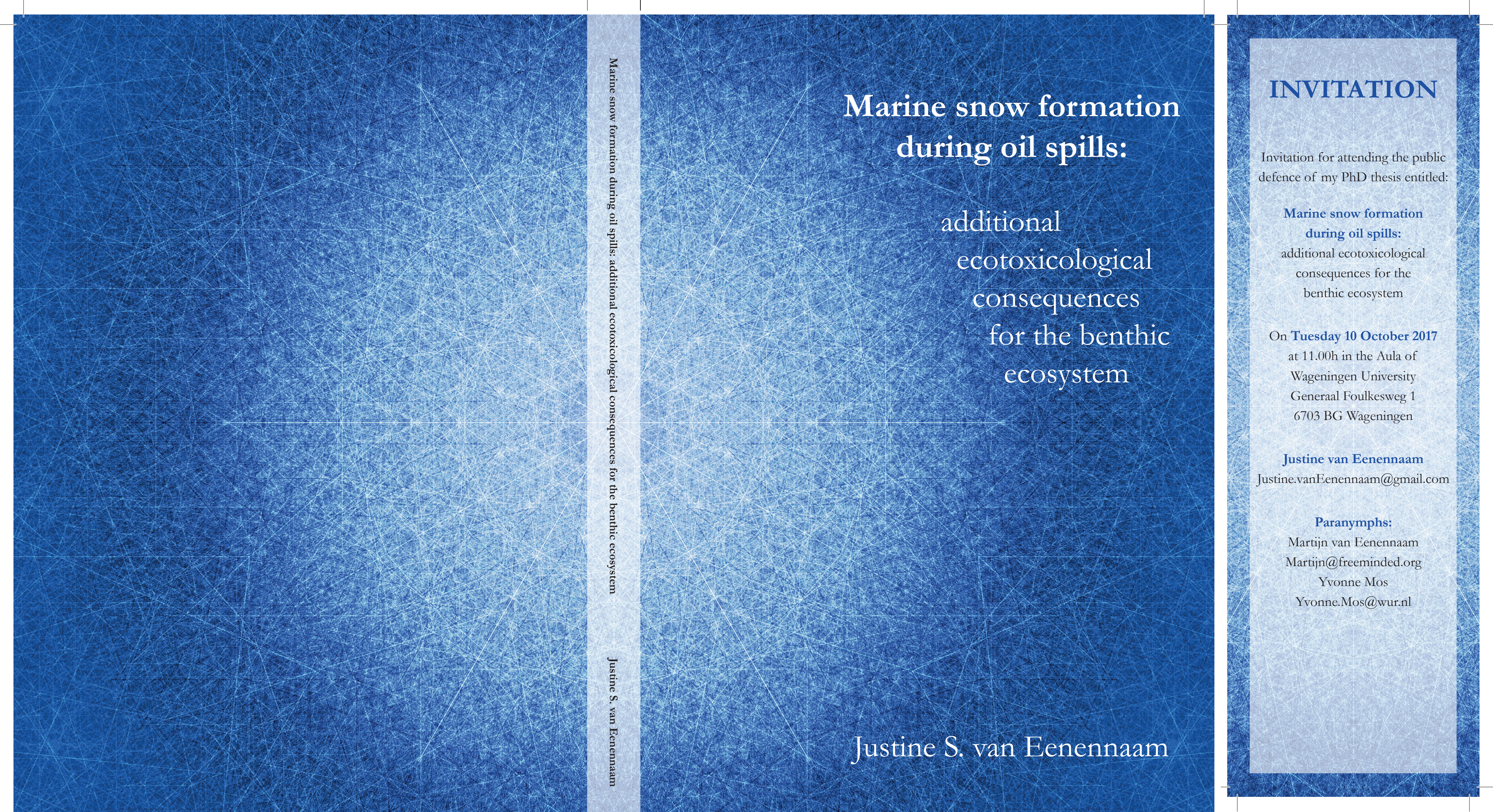




\section{Propositions}

1. The consequences of MOSSFA* events for the benthic ecosystem can be severe and long-lasting and need to be included in spill response decision making.

(this thesis)

2. There is no such thing as a 'good' oil spill response, only 'least bad' responses.

(this thesis)

3. Analogous to 'bappy animals make good science' (Poole 1997, Laboratory Animals 32(2) 116-124), happy PhD students make good science too.

4. The lack of appropriate energy storage systems is the only thing standing in the way of a fossil fuel-free world.

5. The solution to pollution is prevention.

6. The success of all meetings hinges on whether or not someone brought stroopwafels.

7. Scientific articles are to a $\mathrm{PhD}$ student what horcruxes were to Voldemort: pieces of your soul, granting eternal life in bibliographic databases, unless reviewer \#2 destroys them.

Propositions belonging to the thesis, entitled

"Marine snow formation during oil spills: additional ecotoxicological consequences for the benthic ecosystem"

Justine S. van Eenennaam

Wageningen, 10 October 2017.

${ }^{*}$ Marine Oil Snow Sedimentation and Flocculent Accumulation 


\title{
Marine snow formation during oil spills: additional ecotoxicological consequences for the benthic ecosystem
}

\author{
Justine S. van Eenennaam
}




\section{Thesis committee}

\section{Promotor}

Prof. Dr A.J. Murk

Professor of Marine Animal Ecology

Wageningen University \& Research

\section{Co-promotor}

Dr E.M. Foekema

Senior Researcher, Marine Animal Ecology

Wageningen University \& Research

\section{Other members}

Prof. Dr A.J. Hendriks, Radboud University Nijmegen

Prof. Dr P.J. van den Brink, Wageningen University \& Research

Prof. Dr N.M. van Straalen, VU Amsterdam

Dr. M.G.D. Smit, Shell Global Solutions International BV, Rijswijk

This research was conducted under the auspices of the Graduate School for Socio-Economic and Natural Sciences of the Environment (SENSE). 


\title{
Marine snow formation during oil spills: additional ecotoxicological consequences for the benthic ecosystem
}

\author{
Justine S. van Eenennaam
}

Thesis

submitted in fulfilment of the requirements for the degree of doctor

at Wageningen University

by the authority of the Rector Magnificus,

Prof. Dr A.P.J. Mol,

in the presence of the

Thesis Committee appointed by the Academic Board

to be defended in public

on Tuesday 10 October 2017

at 11 a.m. in the Aula. 
Justine S. van Eenennaam

Marine snow formation during oil spills: additional ecotoxicological consequences for the benthic ecosystem, 160 pages.

PhD thesis, Wageningen University, Wageningen, the Netherlands (2017)

With references, with summaries in English and Dutch

ISBN: 978-94-6343-627-4

DOI: $10.18174 / 419549$ 
Table of contents

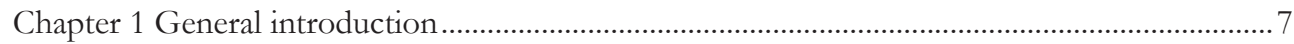

Chapter 2 Oil spill dispersants induce formation of marine snow by phytoplankton-associated

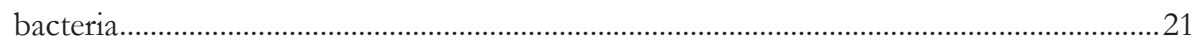

Chapter 3 Marine snow hampers oil biodegradation in a marine sediment layer.......................... 45

Chapter 4 Marine snow enhances the adverse effects of oil on benthic invertebrates.................59

Chapter 5 Ecotoxicological benthic impacts of experimental oil-contaminated marine snow

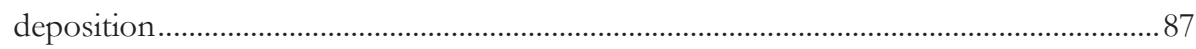

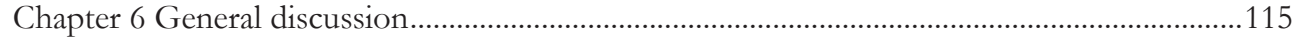

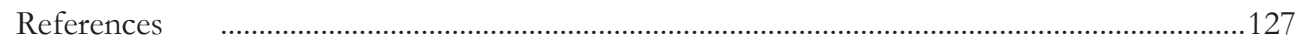

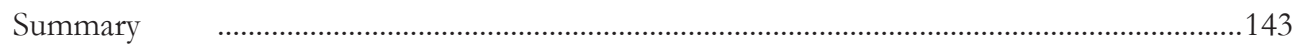

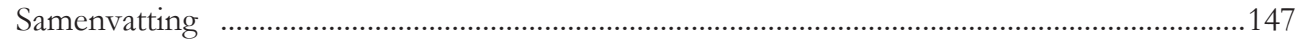

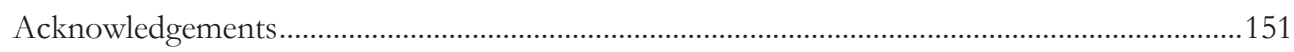

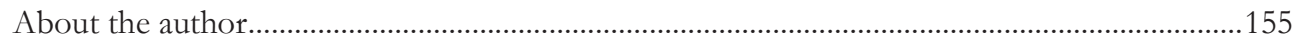

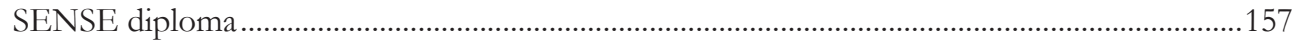


Chapter 1

General introduction 
Oil and petrochemical products are highly important in modern societies, and are still largely considered to be irreplaceable by alternative resources at the moment. As a consequence, global economic value of the petrochemical market is expected to reach around USD 890 billion in 2020 (Market Research Store, 2015). Oil exploration has shifted from easily accessible reserves towards deepwater $(>300 \mathrm{~m})$ and ultra-deepwater $(>1,500 \mathrm{~m})$ reserves (Moerschbaecher and Day Jr., 2011). In the Gulf of Mexico for instance, the average depth of oil wells has increased from $\sim 60 \mathrm{~m}$ in the 1980's to $\sim 120 \mathrm{~m}$ in 2000 (Managi et al., 2005). The world's deepest oil and gas project at the moment is Shell's Stones project, operating in the Gulf of Mexico at a water depth of 2,900 m (Shell, 2016). As oil exploration moves into more challenging environments, the challenges in especially disaster management change as well.

\section{$1.1 \quad$ Oil}

Oil is a mixture of hundreds to thousands different compounds, predominantly hydrocarbons (Fingas, 2011a). The oil hydrocarbons can be grouped according to the SARA classification: Saturates, Aromatics, Resins, and Asphaltenes.

\subsubsection{Saturates, Aromatics, Resins, Asphaltenes}

Saturates are usually the most abundant group of hydrocarbons in oil, and consist of straightchain $n$-alkanes, branched isoalkanes, cycloalkanes, and hopanoids and steroids (Lee et al., 2015). $n$-Alkanes are readily biodegradable, while isoalkanes are more resistant to biodegradation. Cycloalkanes are even more resistant to biodegradation than $n$ - and isoalkanes, while most hopanoids and steroids are non-biodegradable. Hopanoids, especially C30-hopane $(17 \alpha(\mathrm{H}), 21 \beta(\mathrm{H})$-hopane), are often used as conservative biomarker in oil spill studies and to determine the rate of biodegradation of less resistant oil compounds (Aeppli et al., 2014; Prince et al., 1994; Radović et al., 2014).

Aromatics contain at least one benzene ring and are generally more toxic than saturates (Lee et al., 2015). The monoaromatics commonly known as BTEX (Benzene, Toluene, Ethylbenzene, and Xylenes) are volatile, quite water-soluble, acutely toxic, and relatively biodegradable. Benzene is listed as a known carcinogen to humans, and ethylbenzene is a possible carcinogen (IARC, 2017). Polyaromatic hydrocarbons (PAHs) have at least two benzene rings and can be resistant to biodegradation. Out of the 16 priority PAHs defined by the US EPA, one has been listed as carcinogenic to humans (Benzo[a]Pyrene), one as probably carcinogenic, six as possibly carcinogenic, and ten were not classifiable as to their carcinogenicity to humans (IARC, 2017).

Resins are polar hydrocarbons of undetermined individual structures, but they contain one or more nitrogen, sulfur, or oxygen atoms, and are poorly biodegradable (Lee et al., 2015). Asphaltenes are related to resins, but are less polar, have a higher molecular weight, and are even less biodegradable. 
Other compounds that can occur in oil are sulfur, nitrogen, oxygen, mineral salts, as well as trace metals such as iron, nickel, vanadium, and chromium (Fingas, 2011a). Each oil has a different composition of hydrocarbons and other compounds, making oil from each location chemically unique. This property makes it possible to fingerprint the oil, i.e., chemically analyze the oil for its components to identify a particular sample by its uniqueness of its composition (Davis, 2003).

\subsubsection{Classifications}

Crude oil can be classified according to different properties. The petroleum industry classifies oils according to the geographical location of the production site (e.g., North Sea, Arabian, Alaskan North Slope, Louisiana, West Texas Intermediate), since each production site produces oil with specific physicochemical properties (Fingas, 2011a). Based on the API density, the oil industry measure of density, oil can be classified as light, medium, heavy, and extra heavy. Generally speaking, light crude oil is more valuable because it yields higher amounts of gasoline and diesel fuel when refined. The sulfur content of oil is used to divide oil into sweet and sour. Sweet crude oil contains less than $0.5 \%$ sulfur, while sour crude oil contains more than $1 \%$ sulfur (Sheridan, 2006). Sulfur in oil is undesirable because of metal corrosion, the need for additional refining steps, and air pollution from burning of sulfur-rich fuels (Carrales Jr. and Martin, 1975).

\subsubsection{Oil toxicity}

Oil can have many toxic effects: physical, narcotic, or specific. Physical, or mechanical, oil toxicity is mainly relevant in oil spill situations, when birds and marine mammals are physically covered by oil. These images are usually widely reported in the media coverage, and as such physical toxicity is the most visible type of oil toxicity during oil spills (Shigenaka, 2011). Typically, birds and marine mammals are at risk of physical oil toxicity due to oiling of fur or feathers, which reduces insulating capacity and can lead to death from hypothermia or drowning (Bursian et al., 2017; Peterson et al., 2003). Grooming or preening of oiled fur or feathers can also lead to systemic effects due to ingestion of toxic hydrocarbons (Butler et al., 1988). Sessile invertebrates or plants can also be affected by physical oil toxicity: mass mortality occurred among macroalgae and benthic invertebrates due to smothering in the Exxon Valdez oil spill (Peterson et al., 2003). The oil coating prevents access to sunlight, plant nutrients, and planktonic food for filter feeders (Lee et al., 2015). Especially important for plants is the reduced gas exchange and oxygen depletion, which is linked to microbial oil degradation (Mendelssohn et al., 2012). Salt marshes along the coast of the Gulf of Mexico were heavily impacted by oil during the Deepwater Horizon oil spill in 2010 (Michel et al., 2013). For salt marsh plants, oiling of lower parts or roots is more damaging than oiling of leaves and stems (Lee et al., 2015).

Narcotic effects are acute and nonspecific, resulting from direct exposure to high concentrations of hydrocarbons, mostly from volatile BTEX compounds and PAHs due to their high water solubility (Barata et al., 2005; Peterson, 1994). Narcosis is also called baseline toxicity, and is related to the accumulation of hydrocarbons in the tissue of organisms, especially in the 
membrane lipids, thereby affecting functioning of the tissues (Evers et al., 1997). Tissue uptake depends on the hydrophobicity of the compounds (Shigenaka, 2011), reflected in the $\mathrm{K}_{\mathrm{ow}}$ of the compounds. Although narcosis is a reversible process at low concentrations, it might affect feeding or increase the risk of predation if it persists for a longer time, which increases mortality (Almeda et al., 2013).

Specific toxicity is related to the ability of compounds in the oil to interact with specific cellular mechanisms. Of particular interest regarding oil are receptor-mediated mechanisms, such as aryl hydrocarbon receptor (AhR)-mediated effects, and estrogen and androgen receptor-mediated effects (Vrabie et al., 2011; Vrabie et al., 2010; Vrabie et al., 2009). Chronic and sublethal toxicity are associated with more hydrophobic compounds in oil, such as PAHs (Lee et al., 2015). PAHs are known to be genotoxic and have mutagenic and carcinogenic effects through interaction with the AhR (Okey et al., 1994; White, 2002). Although the AhR is ubiquitously present in various animals, the function of AhR seems to differ (Hahn, 1998; Stegeman and Livingstone, 1998). AhR homologs do not seem to be involved in metabolizing xenobiotics in invertebrates (Hahn, 2002). In vertebrates, PAHs bind to the AhR, which activates cytochrome P450 enzymes. The resulting metabolism pathways lead, among other results, to the formation of quinones, which bind to macromolecules such as DNA and can cause genotoxicity (Bolt and Roos, 2008). Especially the cytochrome P450 subfamily CYP1A is involved in specific oil toxicity, and was shown to be induced in birds orally exposed to oil (Alexander et al., 2017).

\subsubsection{Weathering processes}

Oil weathering refers to physical, chemical, and biological transformation processes that change oil properties such as density, viscosity, and chemical composition. Important weathering processes for oil spills at sea are evaporation, emulsification, natural dispersion, photooxidation, sedimentation, and microbial biodegradation (Hollebone, 2011). Evaporation is the main weathering process immediately after the spill. Evaporation of lighter compounds increases the density of the oil, which can lead to sedimentation (Fingas, 2016). Since the more volatile hydrocarbons such as BTEX are generally quite toxic, evaporation can change the toxicity of oil. Evaporated oil contains a larger fraction of resins and asphaltenes, which are polar compounds that are more resistant to biodegradation (Lee et al., 2015). Photooxidation generally increases the oil toxicity, due to formation of reactive oxygen species such as hydroxyl radicals (Tarr et al., 2016), and formation of more water-soluble toxic compounds (King et al., 2014; Larson et al., 1977).

Microbial degradation is the process in which bacteria, archaea, and fungi use oil compounds as food source. Hundreds of species are able to degrade oil, and they can be found widespread in the environment (Atlas and Hazen, 2011). Most oil biodegradation occurs under aerobic conditions, but several species are able to degrade oil under anaerobic conditions as well, although at a much slower rate (Atlas and Hazen, 2011; Atlas et al., 2015). Biodegradation changes the composition of oil compounds in a different way than evaporation (Wang et al., 10 
1998). Particularly the change of compounds relative to hopanoids can be used to distinguish between biodegradation and other weathering processes (Aeppli et al., 2014; Prince et al., 1994; Radović et al., 2014). Enhanced biodegradation, also termed bioremediation, can be used as an alternative clean-up technology in oil-contaminated locations (Das and Chandran, 2011).

\section{$1.2 \quad$ Oil spills}

Oil spills in the marine environment can have far-reaching effects on the ecosystem and economic resources in the vicinity of the spill, such as fisheries, aquaculture, recreation and tourism (Tamis et al., 2012). The impact of adverse effects depends on spill volume, type of oil, weather conditions and the proximity to environmentally, economically or socially sensitive areas.

\subsubsection{Occurrence of oil spills}

Oil spills can be either natural or due to human activities, both intentional and accidental. Natural seeps in the ocean are estimated to account for approximately $45 \%$ of the annual hydrocarbon input in the marine ecosystem (National Research Council, 2003). Intentional discharges of oil (e.g. in ballast water or bilge water) within 50 nautical miles of the coast is prohibited under MARPOL Annex I Regulation 34 of the International Maritime Organization (IMO, 2017), and thus occur mostly at open sea (National Research Council, 2003). However, the intentional spill related to the Gulf war in 1991 remains the largest spill in the last 50 years, with approximately 800,000 tons of oil ( 930 million L) spilled (Fingas, 2016). Accidental spills are mainly related to the petroleum industry: spills can happen at any point and time during extraction, transportation, and consumption of petroleum products (Schmidt-Etkin, 2011). Oil well blowouts and tanker accidents are major sources of spills in aquatic environments, as are pipeline incidents in terrestrial environments. The two largest accidental oil spills are the blowout caused by the explosion of the Deepwater Horizon oil rig in 2010 (see Section 1.3), spilling approximately 4 million barrels of oil ( $\sim 635$ million L) into the northern Gulf of Mexico (U.S. District Court, 2015), and the IXTOC I blowout in 1979, spilling approximately 3.5 million barrels ( $\sim 550$ million L) into the southwestern Gulf of Mexico (Jernelov and Linden, 1981). The Exxon Valdez tanker accident, by contrast, was a fairly small spill (260,000 barrels, 41 million L), but it did cause a major environmental disaster because of the cold weather, proximity to the coast, abundant wildlife in the area, and inadequate clean-up operations (Peterson et al., 2003).

\subsubsection{Oil spill responses}

Contingency planning by oil exploration companies and governmental organizations provide the framework for oil spill responses, including stopping the flow, containing the oil, and the cleanup operations (Fingas, 2011d). Several options are available, and different response options can be applied and combined in different situations. Effectiveness of a certain response option is 
dependent on spill characteristics like the type of oil, its viscosity, and thickness of the oil slick, and on environmental characteristics like wave action, wind speed, water and air temperature, and the presence of ice or debris (Fingas, 2016). Skimming, in situ burning, and the use of chemical dispersants are three often used response options.

Skimming is a mechanical method of removing floating oil slicks from the water surface, and works best in calm sea conditions and with a thick oil slick (Fingas, 2016). A major disadvantage of skimmers is the need for separation, storage, and treatment of collected oil and water fractions.

In situ burning is the controlled burning of an oil slick, usually contained on the water by fireresistant booms (Fingas, 2016). While in situ burning has its advantages, such as the capacity to remove large amounts of oil (Fingas, 2011c) and its applicability in presence of sea ice, it certainly has a major disadvantage in the environmental and human health concerns related to the toxic emissions in the smoke plume (Fingas, 2016). Smoke plume pollutants include volatile organic compounds, nitrogen oxides (NOx), sulfur dioxide, PAHs, carbon monoxide, and particulate matter (Gullett et al., 2017), which can lead to pulmonary inflammation and immune responses when inhaled (Jaligama et al., 2015). Especially spill response workers could be exposed to these compounds since they are close to the source. However, the overall human health risks related to the burning emissions are believed to be small, especially at some distance from the fires (Mullin and Champ, 2003). The unburned oil residue has a higher density than the parent oil and water itself, causing the residues to sink to the sediment (Stout and Payne, 2016a).

Chemical dispersants contain surfactants that reduce the oil-water interfacial tension, which promotes the formation of small oil droplets. Dispersion of oil using chemical dispersants is enhanced by wave action. There are three main reasons for using dispersants: reducing shoreline impacts, reducing impacts on birds and mammals on the water surface, and increasing the potential for oil biodegradation (Fingas, 2011b), although there is dispute whether dispersants really do promote biodegradation or not. Smaller droplet size can provide a larger surface area for oil-degrading bacteria (Lessard and DeMarco, 2000), but smaller droplets also enhance the dissolution of toxic oil compounds such as BTEX into the water, which can inhibit oil-degrading bacteria (Rahsepar et al., 2016). Other matters of concern are the effectiveness of dispersants, and their toxicity. The effectiveness is greatly dependent on environmental conditions during application, like wind speed and wave energy, and on oil properties, like viscosity and density (Fingas, 2016; Zeinstra-Helfrich et al., 2015b). Dispersant toxicity is discussed in Section 1.2.3.

\subsubsection{Toxicity of dispersants and dispersed oil}

Although new generation dispersants are less toxic than in the early days of production (Fingas, 2011b), there is still considerable concern about dispersant toxicity, both to humans and to the environment. The dispersant Corexit was found to be cytotoxic and genotoxic in mammalian cells (Wise et al., 2014), but not mutagenic or endocrine disruptive (DeMarini, 2011) or 
phototoxic (Finch et al., 2017). Aquatic toxicity to a wide range of aquatic organisms was low to moderate for both Corexit 9500 and Corexit 9527, two types of dispersants used during the Deepwater Horizon spill response (George-Ares and Clark, 2000). Corexit 9527 contains 2butoxyethanol (Nalco, 2008), which was found to be genotoxic (Wise et al., 2014). Corexit 9500 does not contain this specific solvent (Nalco, 2005).

Dispersants increase the dissolution of oil components into the water column (Rahsepar et al., 2016; Singer et al., 1998), particularly high molecular weight PAHs (Couillard et al., 2005). This can lead to a temporary spike in toxicity. However, it is expected that due to dilution the toxicity rapidly decreases (Lessard and DeMarco, 2000). Rico-Martínez (2013) reported that there appeared to be a synergistic effect of oil and Corexit 9500 dispersant: the toxicity of dispersed oil to rotifers would be 52 -fold higher compared to that of oil and dispersant alone. However, this was later disputed by Coelho et al. (2013), stating that the methods were not standardized and nominal oil loadings were reported instead of actual exposure concentrations, which is not very informative. They reiterated the need for standardized methods the so-called CROSERF methods (Aurand and Coelho, 2005). CROSERF aimed to "improve the knowledge base related to the toxicity and environmental effects of dispersants and dispersed oil when dispersants are used in oil spill response" ( $\mathrm{p} 1$ of Aurand and Coelho (2005)). In another study, dispersed oil did not show higher toxicity to several aquatic organisms, based on the measured Total Petroleum Hydrocarbons (TPH) concentrations in water with dispersed versus undispersed oil (Clark et al., 2001) and no synergistic toxicity of oil and dispersed oil was found in fish embryos (Adams et al., 2014).

\subsection{Deepwater Horizon}

\subsubsection{The Deepwater Horizon oil spill}

The Macondo prospect (Mississippi Canyon block 252, MC252) is an oil field in the northern Gulf of Mexico, off the coast of Louisiana, USA, at about 1,500 m water depth (Moerschbaecher and Day Jr., 2011). BP leased the semisubmersible drilling rig Deepwater Horizon from Transocean, and it took over work on the Macondo well in January 2010 after Transocean's Marianas rig was damaged in a hurricane (National Commission on the BP Deepwater Horizon Oil Spill and Offshore Drilling, 2011).

On April 20, 2010, an oil well blowout caused an explosion on the Deepwater Horizon rig, killing 11 men, and on April 22, the rig sank. The following oil spill is the largest accidental oil spill in history (Fingas, 2016). After several failed attempts to repair the blowout preventer and a temporary cap of the well which stopped oil flow on July 15, the well was finally declared closed on September 19, 152 days after the start of the blowout (National Commission on the BP Deepwater Horizon Oil Spill and Offshore Drilling, 2011). Already in May 2010, BP committed $\$ 500$ million over a 10 -year period for independent scientific research related to the Deepwater 
Horizon spill. The Gulf of Mexico Research Initiative (GoMRI), an independent scientific organization, used this money to fund eight research consortia in 2011 (GoMRI, 2011). The project of which current $\mathrm{PhD}$ thesis is a final result, was part of the Center for Integrated Modeling and Analysis of Gulf Ecosystems (C-IMAGE) consortium, hosted by the University of South Florida, St. Peterburg, Florida, USA (C-IMAGE, 2017).

\subsubsection{Macondo oil}

The oil in the Macondo well was classified as Louisiana Light Sweet Crude (BP, 2010). It contains $0.261 \%$ sulfur, $\sim 14 \mathrm{~g} \mathrm{~kg}^{-1}$ PAHs, and $\sim 60 \mathrm{~g} \mathrm{~kg}^{-1} \mathrm{TPH}$ (BP Gulf Science Data, 2017b). Because the well was capped, not much source oil is available and therefore, most research efforts undertaken by the GoMRI rely on a surrogate oil from the Dorado Field, collected at the Marlin Platform on November 16, 2011. This surrogate oil was found to be most similar to MC252 oil in terms of hydrocarbon composition and toxicological properties (BP Gulf Science Data, 2017b).

During the spill, 4.0 million (U.S. District Court, 2015) to 4.9 million (Lehr et al., 2010) barrels of oil (approx. 636 million L - 780 million L) are estimated to have spilled into the Gulf of Mexico. The Oil Budget Calculator, developed by The Federal Interagency Solutions Group, Oil Budget Calculator Science and Engineering Team (Lehr et al., 2010), estimated that $17 \%$ of the total spilled oil was directly recovered from the well head, $5 \%$ burned, $3 \%$ skimmed, $16 \%$ chemically dispersed, 13\% naturally dispersed, $23 \%$ evaporated or dissolved, and the remaining $23 \%$ is "other oil" (Lehr et al., 2010). This suggests that the contribution of technical responses, such as skimming, in situ burning, and chemical dispersants, was relatively small compared to the natural processes of dispersion, evaporation, and dissolution. These three technical responses will be further discussed in Section 1.3.3 and 1.3.4. The unknown $23 \%$ is considered to be tar balls, surface slicks, sedimented oil, oil in the surf zone, biodegraded oil, or was cleaned up after it impacted the shoreline. A large part of this "other oil" is now thought to be sedimented on the ocean floor due to the MOSSFA process, which will be discussed in Section 1.4.

\subsubsection{Response operation: skimming and in situ burning}

The Deepwater Horizon spill response operation started just hours after the explosion, with skimmer ships being dispatched after 4 hours (National Commission on the BP Deepwater Horizon Oil Spill and Offshore Drilling, 2011). At the peak of the response operation, there were almost 48,000 people involved in various parts of the operation (FOSC, 2011).

Skimming removed only 3\% of the spilled oil (Lehr et al., 2010), despite hundreds of ships and thousands of people involved in the skimming operations. At its pinnacle, on day 105 (August $2^{\text {nd }}, 2010$ ), there were 835 skimmers working in the spill operations (FOSC, 2011). Many of these skimmers were privately owned ships, employed by BP as 'vessels of opportunity' to help in the spill operations (National Commission on the BP Deepwater Horizon Oil Spill and Offshore 
Drilling, 2011). Skimming operations were halted when Tropical Storm Bonnie entered the northern Gulf of Mexico on July 22, but resumed on July 24 (FOSC, 2011).

In situ burning was used extensively since the $8^{\text {th }}$ day of the spill, since weather and sea conditions did not allow continuous skimming, and skimmers and dispersants could not remove the enormous quantities of oil (FOSC, 2011). In total, 411 controlled burns were performed until July 19, burning an estimated 265,450 barrels (42 million L) of oil (FOSC, 2011). On June 18, the highest single-day quantity of oil was burned: 59,550 barrels (9,5 million L).

\subsubsection{Response operation: chemical dispersants}

Aerial and vessel spraying of dispersants started already on April 22 $2^{\text {nd }}$, two days after the incident. On May 10, day 21 of the spill, the highest single-day quantity of aerial dispersants was applied: 56,220 gallons (213,000 L) (FOSC, 2011). In total, more than 1 million gallons (3.8 million L) of dispersants were applied to the more or less weathered oil at the surface: $80 \%$ was the dispersant type Corexit 9500 and 20\% was Corexit 9527 (BP Gulf Science Data, 2017a). The sub-sea application of chemical dispersants to fresh oil was highly controversial: it had only been tested experimentally six times anywhere in the world, and only in shallow waters (FOSC, 2011). However, lack of success with closing the well and the limited effectiveness of other response options lead the Federal On-Scene Coordinator (FOSC) to approve the sub-sea use of dispersants, which started on May 15 after several test injections in the first two weeks of May (FOSC, 2011). On June 4, day 46 of the spill, the highest single-day quantity of sub-sea dispersants was applied: 20,655 gallons (78,200 L). In total, approximately 770,000 gallons (2.9 million L) of Corexit 9500 were injected over the course of the spill (BP Gulf Science Data, 2017c). The unprecedented volume of dispersants used caused public concern for environmental and human health, even if the FOSC reported that dispersants were an effective response tool that prevented millions of gallons of oil to impact sensitive shorelines (FOSC, 2011). Many people reported health issues that they considered to be due to the use of dispersants, but it is unclear whether those issues were related to the dispersants or to the oil spill itself (Schmidt, 2010; Solomon and Janssen, 2010).

While $16 \%$ of the total spilled oil is estimated to have been chemically dispersed, it is unknown how large the contribution of sub-sea dispersant injection really was. Experts could not reach consensus about the effectiveness of dispersant applications during the spill (Lehr et al., 2010). Dispersion of the oil in the water column limited the amount of oil that could be skimmed, burned, or dispersed at the surface. This reduced the removal of oil out of the marine system and increased the amount of dissolved oil. Sub-sea oil dispersion is also thought to increase weathering processes, making the oil that eventually rises to the surface less susceptible for subsequent surface dispersion (Lehr et al., 2010). The chemically and naturally dispersed oil from the wellhead formed a deep-sea plume of oil droplets and dissolved hydrocarbons, which was detected at a depth of 1099 - $1219 \mathrm{~m}$ at distances of $10 \mathrm{~km}$ (Hazen et al., 2010) to $35 \mathrm{~km}$ from the wellhead (Camilli et al., 2010). The presence of the deep-sea plume coincided with a lower 
dissolved oxygen concentration, most likely due to increased methanotrophic bacterial respiration (Kessler et al., 2011).

The dispersant Corexit is considered to be readily biodegradable at the water surface (Campo et al., 2013). Low temperatures, for example in the deep-sea, greatly slow down Corexit biodegradation (McFarlin et al., 2014). Dioctyl sulfosuccinate (DOSS) is the major surfactant in Corexit 9500 and can be partially degraded by photolysis (Glover et al., 2014; Gray et al., 2014), although this is obviously not relevant when the dispersants are injected sub-sea. DOSS was sequestered in the deepwater plume at 1000-1200 m, and was hardly degraded there (Gray et al., 2014). It was detected up to $300 \mathrm{~km}$ away from the wellhead, 64 days after the end of subsea dispersant injection, indicating negligible degradation (Kujawinski et al., 2011). DOSS was also detected in deep-sea sediments of the Gulf of Mexico (Perkins et al., 2017; White et al., 2014).

\subsection{Marine snow and MOSSFA}

\subsubsection{Marine snow}

Marine snow is a general term for aggregates that include fecal pellets, mineral particles, live and dead bacteria, phytoplankton, and zooplankton (Turner, 2002; Wotton, 2004a), glued together by Extracellular Polymeric Substances (EPS) (Wotton, 2004a). EPS are mainly carbohydrates (Myklestad, 1995; Wotton, 2004a), and can be excreted by a wide variety of microorganisms, ranging from (cyano)bacteria (Arnosti et al., 2015; Fu et al., 2014; Gutierrez et al., 2013; Han et al., 2014; Sohm et al., 2011) and fungi (Jia et al., 2017; Metzger et al., 2009) to diatoms and microalgae (Corzo et al., 2000; Mishra and Jha, 2009; Raposo et al., 2013). EPS has many functions and influences in the oceans, such as aiding the attachment of bacteria in biofilms and protection against stressors (Decho and Gutierrez, 2017; Wotton, 2004a, b). Glycoprotein EPS produced by marine bacteria has emulsifying properties (Gutierrez et al., 2007), indicating that EPS can also be excreted to increase bioavailability of compounds, for example oil, to microbial degradation (Head et al., 2006; Jia et al., 2017; Ziervogel et al., 2012).

\subsubsection{Marine Oil Snow Sedimentation and Flocculent Accumulation: MOSSFA}

During the Deepwater Horizon spill, abnormally large amounts of marine snow were observed at the sea surface (Dell'Amore, 2010; Passow et al., 2012). Most likely, exposure to oil and dispersants lead to increased EPS excretion and marine snow formation. Laboratory experiments with water and indigenous bacteria from the Gulf of Mexico showed that Colwellia sp. were able to create flocs, containing oil and carbohydrates, when exposed to oil and dispersant (Bælum et al., 2012). The marine snow particles observed during the spill were several $\mathrm{cm}$ in diameter, while they usually are only a few $\mathrm{mm}$, and rapidly sank to the bottom of the ocean. It is estimated that the oil aggregates settled at a rate of hundreds of meters per day (Daly et al., 2016), sinking through the entire water column of 1,500 $\mathrm{m}$ in approximately one week (Ziervogel et al., 2012). 
The marine snow particles can trap oil droplets in the sticky matrix, and as such can be a vector for surface and sub-surface oil to the deeper waters and sediment (Passow et al., 2012). The large amount of marine snow as seen during the Deepwater Horizon spill, and the subsequent settling of oil-marine snow aggregates on the sea floor has been named MOSSFA: Marine Oil Snow Sedimentation and Flocculent Accumulation (MOSSFA Steering Committee, 2013). It is estimated that MOSSFA brought at least 14\% of the total spilled oil to the ocean sediment (Daly et al., 2016). Another estimate, based on PAH deposition on the sediment, puts the total oil on the sediment at $21 \pm 10 \%$ (Romero et al., 2017).

There are two proposed mechanisms by which MOSSFA can have effects in the deep-sea ecosystem: the so-called 'dirty blizzard' and 'bathtub-ring' mechanisms (Brooks et al., 2015; Gong et al., 2014; Hollander et al., 2012; Joye et al., 2014; MOSSFA Steering Committee, 2013; Schrope, 2013; Schwing et al., 2014; Valentine et al., 2014; Ziervogel et al., 2016). The dirty blizzard, also called flocculent blizzard or depositional pulse, refers to the massive settling of oilcontaminated marine snow through the water column, leading to oil sedimentation on the ocean floor. The bathtub-ring hypothesis refers to the impingement of the deep-sea plume containing oil hydrocarbons onto the continental slope at a depth of 900-1300 m (Valentine et al., 2014).

The MOSSFA event during the Deepwater Horizon oil spill was unique in a sense that it had not been observed and recognized during a spill before (Vonk et al., 2015). However, it probably has occurred before, during the IXTOC I and Santa Barbara blowouts and subsequent oil spills (Lehr et al., 2010; Vonk et al., 2015). Main drivers that could facilitate a MOSSFA event are high suspended particulate matter, high phytoplankton biomass, EPS excreted by biota, and dispersed oil droplets (Vonk et al., 2015). These factors were all present during the DWH spill: high suspended particulate matter because of the flushing of the Mississippi River (Bianchi et al., 2011), high phytoplankton biomass because of algae blooms (Hu et al., 2011; O'Connor, 2013), EPS and marine snow were observed during the spill (Passow and Ziervogel, 2016; Passow et al., 2012), and dispersed oil droplet were present at the sea surface and in the deep-sea plume (Valentine et al., 2014).

\subsection{MOSSFA and the benthic ecosystem}

The sedimentation of oil in the deep-sea ecosystem after the depositional pulse received quite some attention, since this was the first observation of this phenomenon during a deepwater blowout with sub-sea dispersant injection. Several lines of evidence exist to show that MOSSFA did happen and what the consequences are.

Firstly, the mass accumulation rates based on sedimentological records in sediment cores in the Gulf of Mexico were 4-10 fold higher compared to background sedimentation rates (Brooks et al., 2015; Hastings et al., 2016), and a concurrent 2-3 fold increase in sedimentary PAH concentrations (Romero et al., 2015) showed a clear oil component to the sedimentation. The 
total spatial extent of oil deposition is estimated to range from $3,200 \mathrm{~km}^{2}$ (Valentine et al., 2014) to $24,000 \mathrm{~km}^{2}$ (Chanton et al., 2015) using sedimentary oil indicators, and hydrocarbon deposition at depths $>200 \mathrm{~m}$ was found in $\sim 76,000 \mathrm{~km}^{2}$ (Romero et al., 2017). Oil deposits have been found as far as $256 \mathrm{~km}$ from the wellhead (Mason et al., 2014). With a different method using increased ${ }^{210} \mathrm{~Pb}$ flux, the spatial extent of MOSSFA was estimated to be 12,805 $35,425 \mathrm{~km}^{2}$ (Schwing et al., 2017).

Secondly, changes in sediment redox condition indicated that pore-water oxygen concentration decreased because of the degradation of marine snow (Hastings et al., 2016). Distinct oildegrading microbial communities developed in oil-contaminated sediments compared to uncontaminated sediments (Yang et al., 2016), and these species were highly similar to species that were enriched in the deep-sea plume of oil droplets (Mason et al., 2014).

Finally, benthic biota in the deep-sea around the wellhead showed distinct changes after the oil spill. Benthic foraminifera showed a decline in density and diversity (Schwing et al., 2016; Schwing et al., 2014; Schwing et al., 2015), chronologically related to the depositional pulse. Macro- and meiofaunal abundance and diversity (Montagna et al., 2013) and deep-sea metazoan meiofauna diversity all decreased in contaminated sediments (Baguley et al., 2015). Deepwater corals close to the wellhead showed clear signs of stress and damage, and were covered with oilcontaminated flocculent material (Fisher et al., 2014; Hsing et al., 2013; White et al., 2012).

\subsection{Thesis outline}

Up to now, only field observations of MOSSFA-related effects in GoM have been reported. No mechanistic studies into the effects on the benthic ecosystem have been done. This thesis takes a multi-tiered approach to investigate the effects of oil-contaminated marine snow on benthos. Starting with a more in-depth look into the mechanisms behind dispersant-induced EPS formation, three consecutive microcosm experiments were then designed, each gradually increasing in complexity, to simulate the effect of marine snow on benthic invertebrates.

This thesis has four main research questions:

1) To what extent are dispersants involved in the formation of Extracellular Polymeric Substances (EPS) by phytoplankton and bacteria?

2) To what extent does marine snow affect oil biodegradation?

3) Does marine snow affect benthic invertebrate survival and behavior, and to what extent do benthic invertebrates affect oil biodegradation?

4) How does marine snow affect recovery of benthic ecosystems? 
Chapter 2 describes experiments performed with a marine green algae and a diatom species, exposed to oil spill dispersants, to elucidate the role of dispersants in the formation of EPS. Non-sterile, filtered, and sterilized phytoplankton cultures were used to find out which organisms were responsible for the EPS formation.

Chapters 3 to 5 describe the multi-tiered experimental investigation of the effects of oilcontaminated marine snow in benthic ecosystems. A laboratory scale setup of glass microcosms was used with natural sediments and seawater, to have a controlled test system. The first experiment, in Chapter 3, looked at the effect of marine snow on oil biodegradation, without the presence of benthic invertebrates. Chapter 4 describes the second experiment, which looked at the effects of marine snow and oil on benthic invertebrate survival and behavior, and compared the oil biodegradation in presence of invertebrates to the oil biodegradation without invertebrates (Chapter 3). The third and final experiment is presented in Chapter 5, where the organisms were tested in a more field-realistic scenario of marine snow and oil exposure to assess impact and the recovery of benthic systems under these conditions.

Chapter 6 presents the general discussion of this thesis. Here, the results are summarized and discussed. The additional ecotoxicological consequences of marine snow formation during oil spills for the benthic ecosystem are discussed. Future perspectives for oil spills in the Arctic environment and oil spill response decision making are presented. 


\section{Chapter 2}

\section{Oil spill dispersants induce formation of marine snow by phytoplankton-associated bacteria}

Justine S. van Eenennaama, Yuzhu Wei ${ }^{\mathrm{a}}$, Katja C. F. Grolle ${ }^{\mathrm{a}}$, Edwin M. Foekema ${ }^{\mathrm{b}, \mathrm{c}}$, AlberTinka J. Murk ${ }^{\mathrm{c}}$

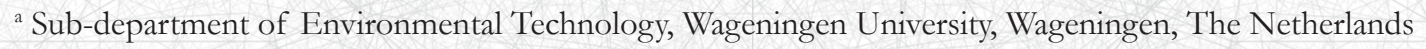

${ }^{\mathrm{b}}$ Wageningen Marine Research, Den Helder, The Netherlands

c Marine Animal Ecology Group, Wageningen University, Wageningen, The Netherlands

This chapter is based on:

van Eenennaam, J.S., Wei, Y., Grolle, K.C.F., Foekema, E.M., Murk, A.J. (2016). Oil spill dispersants induce formation of marine snow by phytoplankton-associated bacteria. Marine Pollution Bulletin, 104, pp. 294-302. 
Oil spill dispersants induce formation of marine snow by phytoplankton-associated bacteria

\section{Abstract}

Unusually large amounts of marine snow, including Extracellular Polymeric Substances (EPS), were formed during the 2010 Deepwater Horizon oil spill. The marine snow settled with oil and clay minerals as an oily sludge layer on the deep-sea floor. This study tested the hypothesis that the unprecedented amount of chemical dispersants applied during high phytoplankton densities in the Gulf of Mexico induced high EPS formation. Two marine phytoplankton species (Dunaliella tertiolecta and Phaeodactylum tricornutum) produced EPS within days when exposed to the dispersant Corexit 9500. Phytoplankton-associated bacteria were shown to be responsible for the formation. The EPS consisted of proteins and to lesser extent polysaccharides. This study reveals an unexpected consequence of the presence of phytoplankton. This emphasizes the need to test the action of dispersants under realistic field conditions, which may seriously alter the fate of oil in the environment via increased marine snow formation. 


\subsection{Introduction}

In April 2010, the drilling rig Deepwater Horizon exploded in the northeastern Gulf of Mexico, killing 11 people and causing crude oil to flow from the Macondo well at $1500 \mathrm{~m}$ depth (National Commission on the BP Deepwater Horizon Oil Spill and Offshore Drilling, 2011). When the well was finally capped in August, 780 million liters of crude oil had spilled into the Gulf of Mexico (National Commission on the BP Deepwater Horizon Oil Spill and Offshore Drilling, 2011). Spill response included skimming, in situ burning, and use of chemical dispersants. An unprecedented volume of dispersants, 6.8 million liters, was used, of which approximately 4 million liters at the sea surface and 2.8 million liters by subsurface injection at the wellhead (BP Gulf Science Data, 2017a, c).

During the spill, an abnormally large amount of marine snow was observed at the sea surface (Dell'Amore, 2010; Passow et al., 2012). The marine snow event resulted in a depositional pulse of particulate matter to the sediment, during which the sediment mass accumulation rates were 10-fold higher than rates observed over the past $\sim 100$ years (Brooks et al., 2015). An estimated 1,200 square miles of deep ocean sediment (NRDC, 2015) was covered with a thick layer of oily material including sea snow and particulates (Brooks et al., 2015), which smothered benthic macrofauna and meiofauna (Montagna et al., 2013) and corals (White et al., 2012). There was a $80-93 \%$ decline in density of benthic foraminifera (Schwing et al., 2015), which could be due to changes in sediment redox conditions and a reduction of pore-water oxygen concentration, or PAHs and other toxic compounds in oil and/or dispersants (Hastings et al., 2016). Vertical mixing in the top layers stopped, indicating a shutdown of bioturbation (Brooks et al., 2015). The flocculent material on the sediment after the depositional pulse contained crude oil and surface materials, including phototrophic organisms (Hollander et al., 2014) and particulate matter. The depositional pulse, mediated by marine snow, brought surface materials down through the water column to the sea floor. This process was named MOSSFA: Marine Oil Snow Sedimentation and Flocculent Accumulation (MOSSFA Steering Committee, 2013). Through the MOSSFA process, marine snow influenced the fate of the dispersed oil by concentrating it on the sea floor (Kinner et al., 2014). In this way, marine snow provides an alternative route by which even the deep-sea benthic organisms can be exposed to dispersed surface oil.

Marine snow generally consists of aggregates including fecal pellets, mineral particles, live and dead bacteria, phytoplankton, and zooplankton (Wotton, 2004a). The separate particles can be glued together into aggregates by Extracellular Polymeric Substances (EPS) from various sources because of the stickiness of EPS (Wotton, 2004a). EPS excretion is a naturally occurring process, which can be performed by a wide variety of microorganisms, ranging from (cyano)bacteria (Arnosti et al., 2015; Fu et al., 2014; Gutierrez et al., 2013; Han et al., 2014) and fungi (Metzger et al., 2009) to diatoms and microalgae (Corzo et al., 2000; Mishra and Jha, 2009; Raposo et al., 2013). 
The main constituents of EPS are carbohydrates (Myklestad, 1995; Wotton, 2004a) although other constituents can include proteins, uronic acid, lipids, and humic substances (Al-Halbouni et al., 2009; McSwain et al., 2005; Wingender et al., 1999). One specific type of EPS are the Transparent Exopolymer Particles (TEP). These are distinct particles that are formed from dissolved carbohydrate polymers excreted by bacteria and algae (Decho, 1990; Passow and Alldredge, 1994; Stoderegger and Herndl, 1999). TEP can also be formed when bacteria hydrolyze mucus on the surface of diatoms (Smith et al., 1995). TEP are very sticky (Passow, 2002), and thus greatly contribute to the formation of marine snow (Alldredge et al., 1993). Larger marine snow flocs can form when TEP stick together, aggregate with other material such as organic compounds and clay particles, and eventually become negatively buoyant and sink (Simon et al., 2002; Wotton, 2004a).

Wotton (2004a, b) described several causes for EPS excretion, such as attachment of bacteria in biofilms and protection against stressors. Excreted EPS protects bacteria and phytoplankton against several stressors, including extremely high or low salinity (Liu and Buskey, 2000; Mishra and Jha, 2009), other changes in the physico-chemical environment such as desiccation and light availability (De Philippis and Vincenzini, 1998; Han et al., 2014; Hill et al., 1994; Wotton, 2004a), exposure to oil and other chemicals (Passow et al., 2012) and silver nanoparticles (Joshi et al., 2012). Excess photosynthesis products due to overflow metabolism or nutrient limitation can be released via EPS (Corzo et al., 2000; Staats et al., 2000). EPS and marine snow are food sources for many pelagic and deep-sea organisms since they consist of proteins and easily degradable carbohydrates (Decho, 1990). In this way, EPS and marine snow form a link in mass and energy transfer towards the deep-sea ecosystems (Beaulieu, 2002; Simon et al., 2002; Wotton, 2004a).

Marine snow formation is a natural process that occurs widely, but has never been reported as excessively as was seen during the Deepwater Horizon oil spill. The unexpected massive production during the spill raises questions about its cause. One suggested explanation is that oil-degrading bacteria excrete EPS as dispersant to better degrade weathered oil by emulsification (Passow et al., 2012). However, pilot experiments in our laboratory showed that the production of EPS seemed to be connected to the presence of phytoplankton, and also dispersant application without oil addition induced marine snow production by phytoplankton communities. This leads to the hypothesis that the unprecedented use of chemical dispersants in the presence of phytoplankton has induced the highly increased marine snow formation during the oil spill. The composition of the produced EPS will determine its nutritional value and physical characteristics, and may also influence the interaction with the oil, affecting its ultimate fate and degradation rate in the oily sludge layer that settled on the sediment. Also, nutrient flows and oxygen use in the marine system will be impacted by the massive production of EPS and marine snow. 
In this study, we investigate the EPS formation by marine phytoplankton cultures upon exposure to dispersants. We tested the roles of phytoplankton and associated bacteria with two types of marine phytoplankton: the green algae Dunaliella tertiolecta and the diatom Phaeodactylum tricornutum. The phytoplankton cultures with and without sterilization by antibiotics were exposed to dispersant. In addition, the phytoplankton-associated bacteria alone were tested after filtering out the phytoplankton. This filtrate too was tested with and without subsequent filtersterilization. The formation and appearance of dispersant-induced EPS was studied and the composition of the EPS was biochemically characterized.

\subsection{Materials and methods}

\subsubsection{Phytoplankton culture and treatment}

Non-sterile cultures of Dunaliella tertiolecta (green algae, Chlorophyceae; hereafter called 'Dunaliella') and Phaeodactylum tricornutum (diatom, Bacillariophyceae; hereafter called 'Phaeodactylum') were provided by IMARES, part of Wageningen UR, Den Helder, The Netherlands. The cultures were grown on $\mathrm{f} / 2$ medium (according to the recipe provided by Culture Collection of Algae and Protozoa, Argyll, Scotland, United Kingdom), which was made with autoclaved artificial seawater $\left(32 \mathrm{~g} \mathrm{~L}^{-1}\right.$ AquaHolland artificial sea salt in demi water). The cultures were kept at $20{ }^{\circ} \mathrm{C}$ on a shaker (New Brunswick Innova 44, Eppendorf AG, Germany) at $80 \mathrm{rpm}$ under continuous light of nine 15W F15T8 Plant \& Aquarium Fluorescent tubes (GE, Cleveland, OH, United States). Once a week the phytoplankton cultures were refreshed by transferring $40 \mathrm{~mL}$ into 200 $\mathrm{mL}$ fresh $\mathrm{f} / 2$ medium.

In order to create axenic cultures, phytoplankton cultures were treated with antibiotics $(20 \mathrm{~mL}$ $\mathrm{L}^{-1}$ PenStrep Glutamine, Gibco by Life Technologies, Paisley, United Kingdom) for at least 7 days. Cell density was measured with a CASY cell counter Model TT (Roche Innovatis AG, Reutlingen, Germany). After selecting optimal absorbance and validation (Annex S2.1), absorbance at $670 \mathrm{~nm}$ was used to determine initial cell densities, measured with a Tecan Infinite M200 PRO spectrophotometer (Tecan Trading AG, Männedorf, Switzerland).

\subsubsection{EPS formation experiments}

All experiments were performed in $20 \mathrm{~mL}$ glass tubes with phytoplankton in an exponential growth phase. Autoclaved fresh f/2 medium $(5.5 \mathrm{~mL}$ ) was combined with $4 \mathrm{~mL}$ of the phytoplankton cultures or filtrates in autoclaved glass tubes. A dispersant dilution of $10 \mathrm{~mL} \mathrm{~L}^{-1}$ Corexit (Corexit EC9500A, kindly provided by Nalco, Sugar Land, Texas, USA) was prepared in $\mathrm{f} / 2$ medium. This was then filtered-sterilized through a $0.2 \mu \mathrm{m}$ filter to remove any bacteriological contamination that could be in the Corexit stock, and $0.5 \mathrm{~mL}$ of the dispersant filtrate was added to each tube to make an experimental dispersant concentration of $0.5 \mathrm{~mL} \mathrm{~L}^{-1}$ in each tube. In pilot experiments (Annex S2.2), it was determined that a concentration of 0.5 
$\mathrm{mL} \mathrm{L} \mathrm{L}^{-1}$ Corexit induced rapid and consistent EPS formation in phytoplankton cultures. Considering an application rate of 1870 - 9354 liter per square $\mathrm{km}$ (2-10 US gallons per acre) (U.S. EPA, 1995) and taking into account that application will not be homogeneous, this concentration could be reached in the upper centimeters of the water column after surface application of dispersants. Since we were primarily interested in the mechanism of EPS production and its composition, we have chosen a relatively high dispersant concentration of which we were confident that EPS was produced. The tubes were capped with an aluminum cap, mixed, and placed at $20^{\circ} \mathrm{C}$ under continuous light of a $90 \mathrm{~W}$ red-orange-blue-purple LED lamp (LEDSPECTRUM, Drunen, The Netherlands). The tubes were manually shaken twice a day and every day the visible EPS formation was noted (starting time of EPS appearance).

The following experimental conditions were tested for both phytoplankton species (Figure 2.1): non-sterile phytoplankton culture (containing phytoplankton and associated bacteria; hereafter called 'non-sterile phytoplankton'), antibiotic treated phytoplankton culture (containing only phytoplankton; hereafter called 'antibiotic treated phytoplankton'), filtrate from non-sterile cultures (containing only bacteria, made by filtering through $0.45 \mu \mathrm{m}$ filter to separate water with bacteria from algal cells; hereafter called 'phytoplankton filtrate'), and phytoplankton filtrate which was then filter-sterilized ( $0.2 \mu \mathrm{m}$ filtered; hereafter called 'filter-sterilized phytoplankton'). In addition to the EPS formation experiments with phytoplankton, a free-living $n$-alkane degrading bacteria (Rhodococcus qingshengii TUHH-12) was tested for Corexit-induced EPS formation. This was tested because oil-degrading bacteria have been suggested to produce EPS upon exposure to oil, but their response to Corexit exposure has not yet been tested. Bacterial suspension in the exponential growth phase $(1 \mathrm{~mL})$ was diluted to $10 \mathrm{~mL}$ total volume of $\mathrm{f} / 2$ medium with $0.5 \mathrm{~mL} \mathrm{~L}^{-1}$ Corexit.
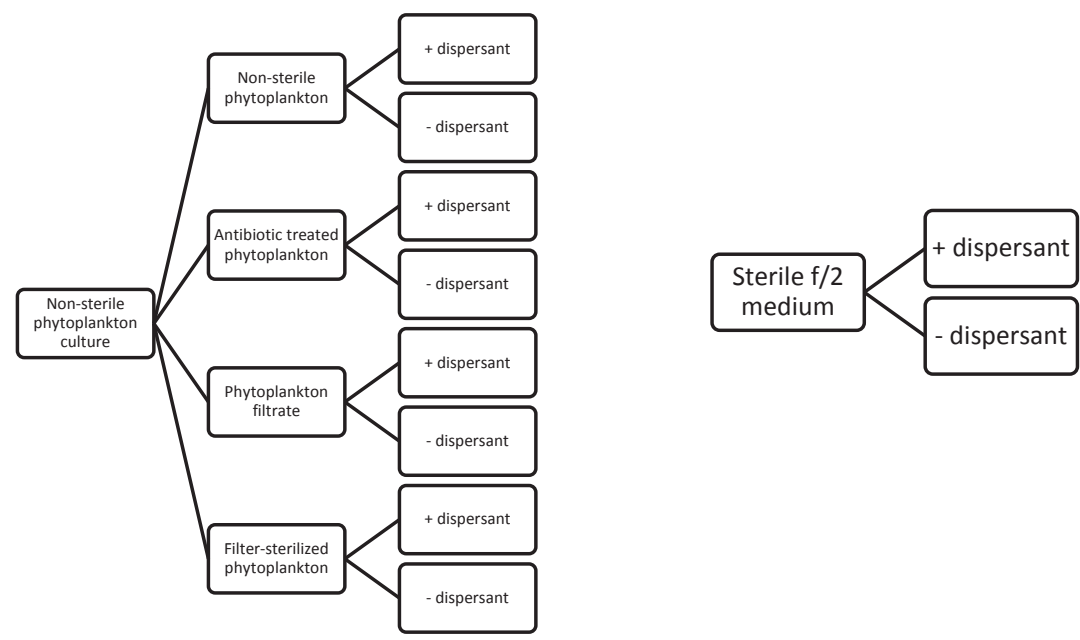

Figure 2.1: Experimental setup of EPS formation experiment. All treatments were performed with two species of marine phytoplankton, Phaeodactylum tricornutum and Dunaliella tertiolecta, in triplicate. 


\subsubsection{EPS characterization}

EPS was characterized visually, physically (dry weight) and biochemically (protein and polysaccharide content).

EPS for biochemical analyses was produced in $500 \mathrm{~mL}$ Erlenmeyer flasks with silicone stoppers with air exchange membrane. The flasks were autoclaved with $55 \mathrm{~mL}$ of f/2 medium. Then, 5 $\mathrm{mL}$ of a $10 \mathrm{~mL} \mathrm{~L}^{-1}$ dispersant dilution, which was $0.2 \mu \mathrm{m}$ filter-sterilized, and $40 \mathrm{~mL}$ phytoplankton or $40 \mathrm{~mL}$ of phytoplankton filtrate was added. The final dispersant concentration was $0.5 \mathrm{~mL} \mathrm{~L}^{-1}$. The flasks were incubated under the same conditions as the tubes during the EPS formation experiments. After 7 days, the EPS flocs were collected manually with a glass pipette. EPS from several flasks was combined and washed at least three times with demi-water to remove as much salt and phytoplankton cells as possible. The washed EPS was dried overnight in aluminum cups at $60^{\circ} \mathrm{C}$. Dry weight was measured by weighing aluminum cups containing EPS after drying and subtracting the weight of the empty cups. EPS production was expressed as ng dry weight per $\mathrm{mL}$ of exposure medium in the flasks.

Total carbohydrate content of dried EPS was measured with a phenol-sulfuric acid method based on Masuko's microplate adaptation of Dubois (Masuko et al., 2005). In short, the concentrated sulfuric acid hydrolyses all carbohydrates to monosaccharides, which then react with phenol. The absorbance of the reaction products is measured at $490 \mathrm{~nm}$. We optimized the method by using a longer incubation time of 40 minutes to allow full hydrolysis of the dried EPS samples. The microplates were measured on a Tecan Infinite M200 PRO spectrophotometer (Tecan Trading AG, Männedorf, Switzerland), and D-Glucose was used as standard. All samples were tested in triplicate.

Monosaccharide composition of dried EPS was determined in a pilot test using orcinol-sulfuric acid hydrolysis and high performance anion exchange chromatography (HPAEC). Further analysis and quantification was done according to the method described by Englyst and Cummings (1984). Pre-hydrolysis in $72 \%$ (w/w) $\mathrm{H}_{2} \mathrm{SO}_{4}\left(30^{\circ} \mathrm{C}, 1 \mathrm{~h}\right)$ was followed by hydrolysis in $1 \mathrm{M} \mathrm{H}_{2} \mathrm{SO}_{4}\left(100{ }^{\circ} \mathrm{C}, 3 \mathrm{~h}\right)$. The monosaccharides formed upon hydrolysis were derivatized to alditol acetates and analyzed by gas chromatography (GC) using inositol as an internal standard. The colorimetric $m$-hydroxydiphenyl assay (Ahmed and Labavitch, 1978) was used to determine the total uronic acid content. Samples were tested in duplicate, except the non-sterile Dunaliella sample where one duplicate was discarded for analysis because of problems with the internal standard and uronic acid measurement.

The protein content of dried EPS was determined with the Dumas method (Schwenzfeier et al., 2011), which is based on combustion of the sample at high temperature, because of practical limitations when using common colorimetric protein assays for EPS. Protein assays such as Lowry and Bradford are incompatible with samples containing Corexit because of background fluorescence. The Pierce $660 \mathrm{~nm}$ protein kit in combination with Ionic Detergent Compatibility 
Reagent (ThermoScientific Pierce Biotechnology, Rockford, Illinois, USA) was compatible with samples containing Corexit. However, as the dried EPS could not be fully homogenized and dissolved, the Pierce protein assay could not be applied either. Therefore, the Dumas method was chosen. In this assay, the total nitrogen content was measured with a Flash EA $1112 \mathrm{~N}$ analyzer (Thermo Fisher Scientific Inc., Waltham, MA, USA) according to the manufacturer's protocol, with D-methionine as standard. The conventional ratio of nitrogen to protein of 6.25 was used (Schwenzfeier, 2013) since a specific ratio is not known for EPS. All samples were analyzed in duplicate.

Protein composition of EPS produced by non-sterile Phaeodactylum was visualized using SDSPAGE under reducing conditions with $\beta$-mercaptoethanol. Bio-Rad Mini-PROTEAN ${ }^{\circledR}$ TGX ${ }^{\mathrm{TM}}$ Any kD ${ }^{\mathrm{TM}}$ gels were run at $120 \mathrm{~V}$ on a Mini-PROTEAN® Tetra Cell system (Bio-Rad Laboratories Inc., Hercules, CA, USA). Protein standards of 10-250 kDa were used (Precision Plus Protein ${ }^{\text {TM }}$ All Blue, Bio-Rad) and gels were stained with InstantBlue ${ }^{\text {TM }}$ (Expedeon Protein Solutions, San Diego, CA, USA). Then, gels were scanned with a Bio-Rad GS-900 ${ }^{\mathrm{TM}}$ Calibrated Densitometer.

\subsubsection{Software and data analysis}

SDS-PAGE results were analyzed with Image Lab ${ }^{\text {TM }}$ 5.1. GraphPad Prism 5 was used to make graphs. Statistics were performed with IBM SPSS Statistics version 23. ANOVA tests and posthoc Tukey tests were considered significant when $p<0.05$.

\section{$2.3 \quad$ Results}

\subsubsection{Phytoplankton culture}

Both phytoplankton species grew well under the growth conditions provided (Annex S2.1). The biomass grew exponentially until the maximum density was reached after one week. The phytoplankton used for the EPS formation experiments was taken from the cultures 3 days after medium refreshment, so the phytoplankton was in the exponential growth phase.

\subsubsection{EPS formation}

Non-sterile cultures of both phytoplankton species exposed to $0.5 \mathrm{~mL} \mathrm{~L}^{-1}$ Corexit produced EPS flocs after $\sim 3$ days of incubation (Table 2.1). The flocs were fragile and fell apart upon shaking (Figure 2.2).

Phytoplankton filtrates of both species, without phytoplankton cells, produced EPS similar to the non-sterile cultures, with the phytoplankton cells still present, in terms of shape, size, and onset of floc formation. The amounts produced, however, were less in the filtrates than in the non-sterile cultures (Table 2.1, Figure 2.3). In contrast, neither of the axenic cultures (antibiotic 
treated phytoplankton or filter-sterilized phytoplankton) produced EPS in any of the experiments. The free-living oil-degrading bacteria did not produce any EPS either.

Dry weight of the EPS formed per $\mathrm{mL}$ exposure medium ranged from $8 \mathrm{ng}$ (Phaeodactylum filtrate) to $18 \mathrm{ng}$ (non-sterile Phaeodactylum) (Table 2.1). For both species, dry weight of EPS produced by the non-sterile phytoplankton samples was consistently higher than those of the filtrates.

\subsubsection{Biochemical composition of EPS}

Table 2.1 shows the biochemical composition of dispersant-induced EPS produced by phytoplankton. Total carbohydrate content did not differ between EPS produced by non-sterile Phaeodactylum and Phaeodactylum filtrates (one-way ANOVA, $\mathrm{p}=0.433$ ). For Dunaliella, however, the phytoplankton samples had higher carbohydrate content than the filtrates (oneway ANOVA, $\mathrm{p}=0.001)$. The total EPS monosaccharide content determined with the GC-based alditol acetates method was similar to the total carbohydrate content determined with the platebased phenol-sulfuric acid method. However, non-sterile Dunaliella EPS had a carbohydrate content 5 times higher with the monosaccharide specific alditol acetates method than with the total carbohydrate phenol sulfuric acid method (20.8\% of dry weight vs $4.6 \%$, Table 2.1$)$. It should be noted, however, that this higher percentage was based on a single measurement instead of duplicate measurements, due to a technical problem. The main difference in monosaccharide composition between non-sterile Dunaliella and the other three samples is the significantly higher relative and absolute glucose content (Figure 2.4; Table S2.4; one-sample T-tests, $p<0.001$ ). Non-sterile Dunaliella EPS also had significantly higher uronic acid and galactose content (onesample T-tests, $p<0.007$ and $p<0.012$ respectively) than the other three samples.
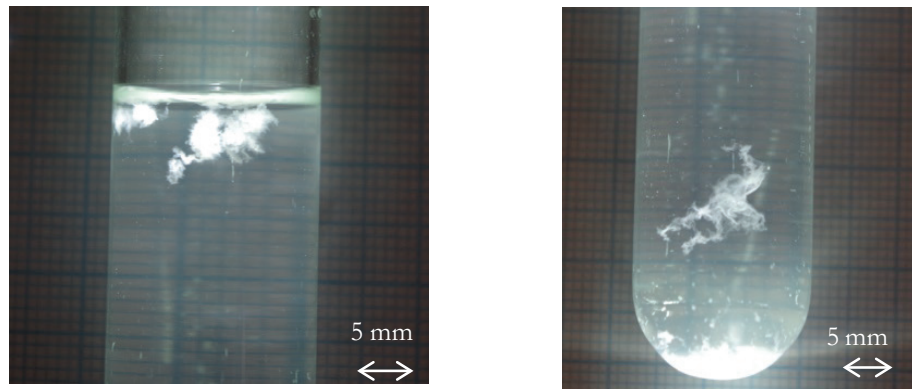

Figure 2.2: EPS flocs, formed by Phaeodactylum tricornutum filtrate. The flocs were floating at the surface (left) and at the bottom of the tube (right) while part of the EPS flocs had settled. The fragile flocs fell apart upon vortexing. 

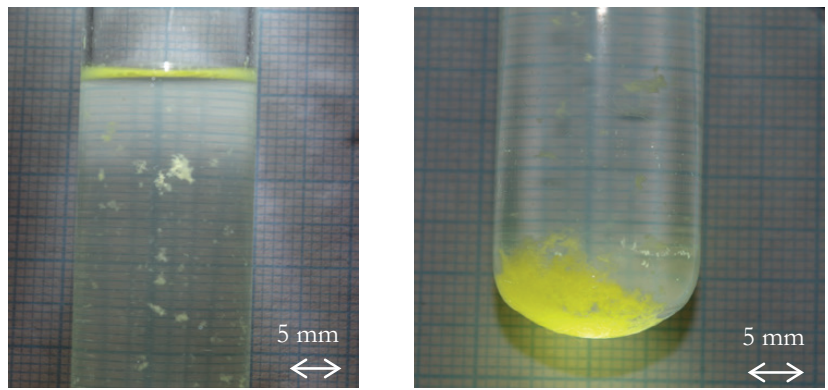

Figure 2.3: EPS flocs, formed by non-sterile Dunaliella tertiolecta. The flocs were floating at the surface (top picture) and at the bottom of the tube (bottom picture). Tube was slightly shaken before taking the picture. the green color is an artefact produced by the camera lighting; in reality the flocs at the bottom were more brown in color.

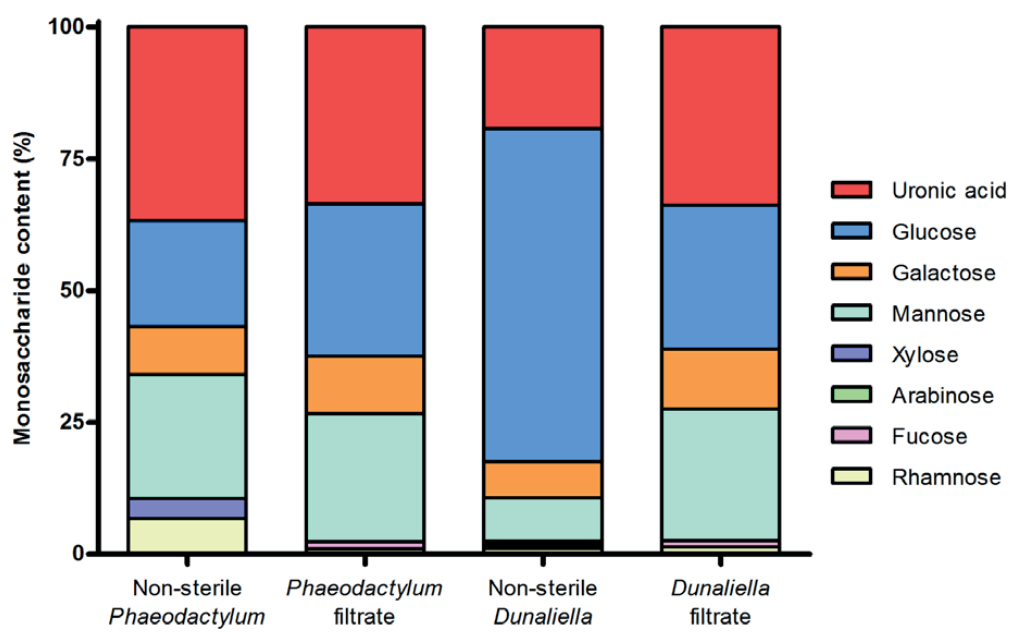

Figure 2.4: Relative monosaccharide composition (\% of total monosaccharide content) of EPS produced by filtrates and non-sterile Phaeodactylum tricornutum and Dunaliella tertiolecta. 

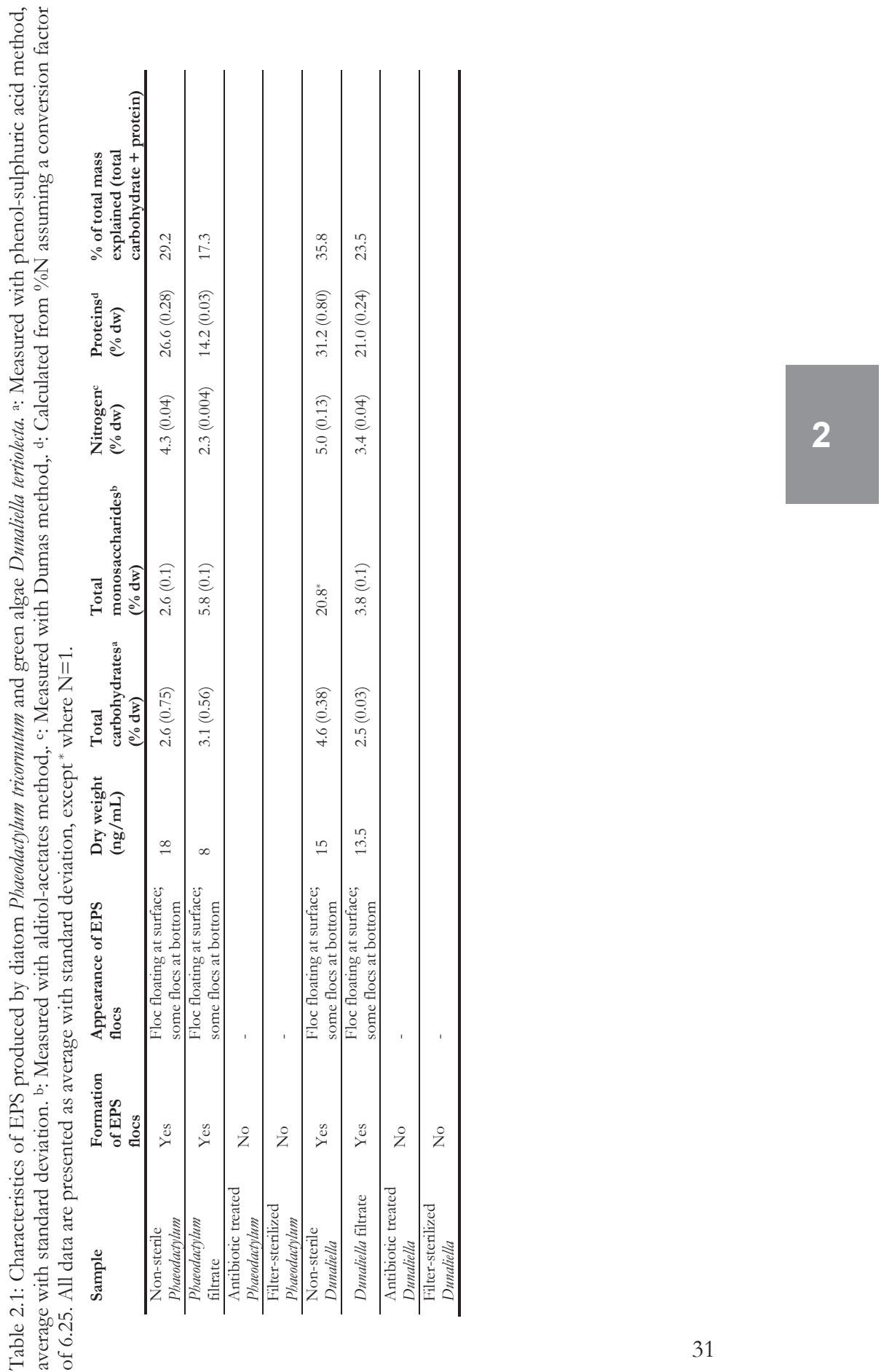
Mannose was significantly higher in non-sterile Dunaliella EPS compared to the non-sterile Phaeodactylum EPS (one-sample T-tests, $p<0.011$ ). Characteristic of the non-sterile Phaeodactylum EPS was the presence of fucose and rhamnose (Figure 2.4). Arabinose is only found in nonsterile Dunaliella EPS. In the filtrates, xylose was not found and rhamnose was present in minor amounts (Figure 2.4, Table S 2.4). The chromatogram from the pilot experiment using HPAEC (Figure 2.5) shows, in a qualitative way, that EPS from both non-sterile species in general looked very similar. However, not all monosaccharides that were quantified using the alditol acetates method, were detected using HPAEC. A small fucose peak, however, was identified in the chromatogram for the non-sterile Phaeodactylum EPS while no fucose could be detected in the sample using alditol acetates method. The protein content of the non-sterile phytoplankton EPS was significantly higher than the protein content of the EPS from filtrates for both species (Table 2.1; one-way ANOVA with post-hoc Tukey test, $p<0.002)$. Dunaliella EPS had significantly higher protein content than Phaeodactylum EPS. SDS-PAGE indicated that most of the EPSproteins produced by Phaeodactylum (32-48\%, Table 2.2) were polypeptide chains with apparent molecular mass of $110 \mathrm{kDa}$ (Figure 2.6). Other bands with high intensity appeared at molecular masses of about 64, 43 and $17 \mathrm{kDa}$. These molecular masses are in concordance with Czaczyk and Myszka (2007), who state that EPS proteins have molecular masses between $10 \mathrm{kDa}$ and $200 \mathrm{kDa}$. The band at $250 \mathrm{kDa}$ reflects non-protein particles that did not penetrate the SDSPAGE gel. At $10 \mathrm{kDa}$, the analysis program calculated a relative mass of $43.6 \%$ and $27.2 \%$ for the replicates. However, no clear bands can be seen in Figure 2.6, so we consider these values as not representative of a specific protein mass.

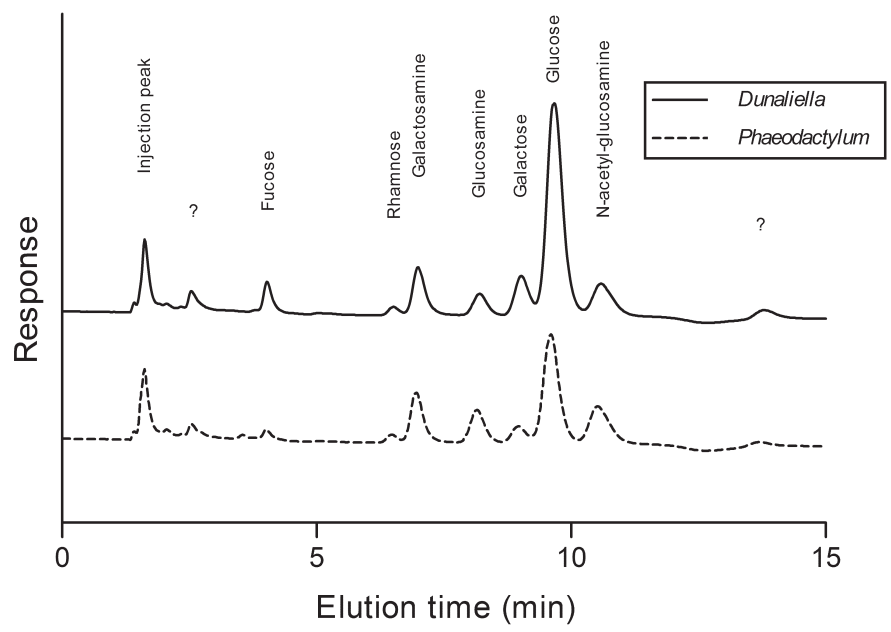

Figure 2.5: HPAEC chromatograms of non-sterile Dunaliella (solid black line) and Phaeodactylum (dotted black line) EPS. A question mark indicates that this peak was not identified. 
Table 2.2: Relative protein content of Phaeodactylum tricornutum EPS sample, based on band intensity on SDS-PAGE gel. Table shows how much of the total intensity corresponded to the molecular masses of the bands. R1 and R2 are replicates of the same EPS sample.

\begin{tabular}{ll|lc}
\hline \multicolumn{2}{c|}{ R1 } & \multicolumn{2}{c}{ R2 } \\
\hline $\begin{array}{l}\text { Molecular } \\
\text { mass (kDa) }\end{array}$ & Molecular \\
\hline 250.0 & 10.6 & 250.0 & 11.0 \\
\hline 110.2 & 31.9 & 108.4 & 48.4 \\
\hline 63.9 & 2.1 & 63.4 & 4.1 \\
\hline 42.6 & 6.9 & 41.1 & 3.3 \\
\hline 37.5 & 0.6 & 31.0 & 4.1 \\
\hline 31.2 & 0.9 & 17.1 & 27.2 \\
\hline 17.2 & 3.4 & 10.0 & \\
\hline 10.6 & 43.6 & & \\
\hline
\end{tabular}

\subsection{Discussion}

This study shows that EPS is produced by marine phytoplankton cultures upon exposure to the dispersant Corexit EC9500A. This EPS production does not occur in axenic cultures, while bacteria separated from the phytoplankton also produced EPS, although to a lesser extent. They especially produced less protein, and had a different monosaccharide profile.

\subsubsection{Role of bacteria in EPS production}

Our experiments reveal that bacteria associated with the phytoplankton are the organisms responsible for the actual formation of the EPS, and the amount of EPS formed is greater in the combined presence with phytoplankton. In situ, phytoplankton always occurs in combination with bacteria, either in symbiosis or more loosely connected. Fu et al. (2014) found marine snow production when seawater, containing both bacteria and phytoplankton, was exposed to oil and dispersant separately and in combination. As they did not include a bacteria-only or phytoplankton-only treatment, they could not yet distinguish between roles of phytoplankton and bacteria. Our experiments demonstrate that the bacteria living in association with the phytoplankton cultures are responsible for the actual formation of the EPS, while phytoplankton seems to provide (additional) energy for the EPS production by the bacteria. The free-living oildegrading bacteria we tested (Rhodococcus qingshengii TUHH-12) were not capable of producing 
EPS. It has been shown that other free-living bacteria can produce EPS, but they always need a source of energy. From freshwater bacteria it is known that they can produce EPS such as alginate from waste water (Lin et al., 2010; Lin et al., 2013). Possibly, free-living oil-degrading bacteria use oil as energy source to produce EPS, as suggested by Passow and colleagues (Passow et al., 2012).

Possibly, Corexit acted as an energy and carbon source for the filtrate with bacteria in our experiments. Corexit contains hydrocarbons in amounts up to 30\% w/w (Campo et al., 2013; Fu et al., 2014; García et al., 2009; Nalco, 2005). Halomonas species are both oil-degrading and EPS-producing (Gutierrez et al., 2013), and were present in oil-aggregates produced during the Deepwater Horizon oil spill, together with other Gammaproteobacteria (Arnosti et al., 2015). Both groups of bacteria produce EPS, possibly as dispersant to be able to enhance degradation of weathered oil.

\subsubsection{Composition of the EPS}

With the methods applied, around 35\% of the EPS mass could be accounted for. This incomplete mass balance could be due to either the suitability of methods for quantification of the polysaccharides and proteins present in EPS, or additional compounds that are present besides polysaccharides and proteins. These issues are discussed below.

\subsubsection{Quantification of polysaccharide and protein content}

In the spectrophotometric analysis of the phenol-sulfuric acid method, different sugar monomers have different absorption characteristics. This means that this method provides the most accurate results when applied to samples containing only the carbohydrate that is used as standard (Brummer and Cui, 2005). D-Glucose was used as a standard in our assay. As a consequence, polysaccharides are expressed as glucose-equivalents. The choice for glucose as standard can greatly influence the results if most carbohydrates present are not glucose. As can be seen in Figure 2.4 and Table S 2.4, glucose accounts for 20\% (Phaeodactylum) - 63\% (Dunaliella) of all monosaccharides. Relating all carbohydrates to glucose underestimates the actual amount of sugars in the EPS. Ideally, every monosaccharide should be known and would have its own standard, but for practical reasons that is unfeasible. The alditol acetates method provides more information about the polysaccharide content and monosaccharide composition, but only for seven monosaccharides and uronic acid, so it does not provide a full monosaccharide characterization. So this too will underestimate the monosaccharide content.

Proteins were determined using the Dumas method based on the total nitrogen content. Because a protein-specific conversion factor was not available, a general nitrogen-to-protein conversion factor of 6.25 was applied to determine the total protein content. This factor of 6.25 is the widely accepted general value, assuming that protein contains $16 \%$ nitrogen and an insignificant amount of non-protein nitrogen (NPN) (Conklin-Brittain et al., 1999). Many studies and food guidelines 
continue to use this default factor (Mariotti et al., 2008), even though there are indications that this is not appropriate for many materials (Diniz et al., 2001; Lourenço et al., 2004; Mariotti et al., 2008), in particular for plant material. Plants contain a significant amount of NPN, increasing the nitrogen content to up to $23 \%$ instead of the assumed $16 \%$ (Conklin-Brittain et al., 1999). The general conversion factor of $6.25(100 / 16)$ will then overestimate the amount of protein. Assuming a nitrogen content of $23 \%$, a conversion factor of $4.35(100 / 23)$ would give a better estimate. Using 4.35 lowers the protein content in our samples from 14.2-31.2\% (Table 2.1) to 9.9-21.7\%. However, without data about NPN and actual nitrogen content of our EPS samples there is no justification to use any other conversion factor than the general factor. Also, we do not expect a lot of plant material in the EPS produced, especially not in the filtrates without phytoplankton. An underestimation of the amount of protein is made when the percentage nitrogen in proteins is less than $16 \%$. However, this seems unlikely because almost all of the conversion factors (for foodstuffs) published are below 6.25 (Mariotti et al., 2008). The FAO considers the error in using the general factor compared to specific factors to range from - $2 \%$ to $+9 \%$ (FAO, 2003). For our samples, the range of protein content would change from 14.2$31.2 \%$ to $14.0-30.5 \%$ (lower estimate, $-2 \%$ ) and $15.5-34.0 \%$ (higher estimate, $+9 \%$ ).

Considering all the uncertainties about using the general conversion factor, and without information about specific N-to-protein factors for proteins in EPS, the colorimetric methods are most suitable since the assumed conversion factor can be avoided. This method, however, only is applicable to dissolved EPS but not to dried EPS flocs that do not dissolve. Also, the SDS-PAGE results serve as an indication that peptides are present in the sample, but it is not possible to identify specific proteins in the sample based on this method. To calculate specific conversion factors, information about the amino acid composition of the EPS is necessary. Amino acid composition can be determined by more advanced proteomics techniques (reviewed by Miller et al. (2014)), and, for example, Ultra High Performance Liquid Chromatography (UHPLC) separation and mass spectrometry detection (Nemkov et al., 2015).

\subsubsection{Possible other EPS contents}

Polysaccharides often are considered to be the main components of EPS produced by microorganisms in general (Myklestad, 1995; Wotton, 2004a). However, using the phenolsulfuric acid method, we found that only a minor part of the dry weight of EPS was polysaccharides ( $<5 \%$ of dry weight) and a larger part was proteins (up to $31.2 \%$ of $\mathrm{dw}$ ). Microbial EPS can also consist of proteins, glycoproteins, lipoproteins, nucleic acids and lipids (Gutierrez et al., 2007; Wingender et al., 1999). For practical reasons, we could only analyze polysaccharides and proteins in this study. It is recommended for future studies to also analyze other possible components.

In addition, components might be captured in the EPS matrix such as salt and phytoplankton cells. A high salt content will reduce the polysaccharide and protein content relative to the dry weight of EPS. However, our conductivity measurements of the water collected from the 
washing steps showed that three washing steps removed $>97 \%$ of salt, and four washing steps removed $>99 \%$ of salt. Since at least three, but mostly four or more, washing steps were used, it is not expected that the presence of salt contributed significantly to the total EPS mass. No phytoplankton cells were seen microscopically after four washing steps, even though the washed Dunaliella EPS had a distinct green color (Figure S 2.3 in Annex S2.4). Therefore, it cannot be excluded that chlorophyll was still present in the EPS and contributed to the total EPS mass.

\subsubsection{A specific category of EPS: alginate}

Alginates are a family of sugar polymers produced by seaweeds and bacteria of several genera, such as Pseudomonas and Azotobacter (Hay et al., 2010; Remminghorst and Rehm, 2006). Alginates contain mannuronic acid $(M)$ and guluronic acid $(G)$ units arranged in irregular patterns of MM, MG, and GG blocks (Lin et al., 2013). Although not chemically analyzed, our EPS samples closely resemble the alginate-like exopolysaccharides (ALE) found in flocculent aerobic sludge from a wastewater treatment plant with an estimated $M / G$ ratio and an ALE yield of $20 \pm 2 \%$ of $\mathrm{dw}$ (Lin, personal communication).

Lin et al. (2010) found that when D-glucose was used as standard in the phenol-sulfuric acid assay, the carbohydrate content of alginate would be underestimated by $62.6 \%$ compared to using sodium alginate as standard. Taking this underestimation into account increases the total polysaccharides found in our sample from $2.5-4.6 \%$ of dw to $4.1-7.5 \%$ of dw.

\subsubsection{Dispersant concentrations after application}

Our experimental dispersant concentration was $0.5 \mathrm{~mL} \mathrm{~L}^{-1}$ which, as explained before, is a high but feasible concentration in the field. After aerial application of dispersant, a maximum concentration of about $0.01 \mathrm{~mL} \mathrm{~L}^{-1}(13 \mathrm{ppm})$ Corexit was measured at $0.6 \mathrm{~m}$ depth (GeorgeAres and Clark, 2000). Dioctyl sodium sulfosuccinate (DOSS) is the major surfactant component in Corexit (Kujawinski et al., 2011). DOSS was found during the Deepwater Horizon oil spill at a maximum of $229 \mu \mathrm{g} \mathrm{L}^{-1}$ at the surface, $0 \mathrm{~m}$ depth (Gray et al., 2014). Given that DOSS represents $10 \%$ of the total Corexit formulation applied, this equals $2.42 \mu \mathrm{L} \mathrm{L}^{-1}$ Corexit at the surface. As no information was provided about the time between application and sample taking, the concentration of $0.01 \mathrm{~mL} \mathrm{~L}^{-1}$ at $0.6 \mathrm{~m}$ depth indicates our experimental concentration is within a realistic range after dispersant application. It would be interesting to study both the gradient of dispersant concentration over the water column, hours and days after application. The lowest effect concentration of dispersant to induce EPS formation still needs to be studied, and will also depend on factors like species and density of algae and symbiotic bacteria, light intensity (turbidity of the water), nutrient availability, temperature, salinity, etc. This is very important for oil spill responders to know, but was beyond the scope of this study. 


\subsubsection{Consequences of increased EPS formation in the marine environment}

Increased formation of EPS and marine snow can have serious consequences in the field situation, both for the fate and transport of oil, as well as for the ecological impacts after an oil spill. As was seen during the Deepwater Horizon oil spill, marine snow can aggregate with dispersed oil droplets and suspended particles (Passow et al., 2012). These aggregates are negatively buoyant and sink to the sea floor. One of the response measures taken during the Deepwater Horizon spill was to flush the Mississippi river to limit influx of oil into estuaries (Bianchi et al., 2011). This increased both the amount of suspended particles and the nutrients in the GoM, increasing the likelihood for a MOSSFA event (Vonk et al., 2015). This can explain the effects at the local and regional benthic community level (Montagna et al., 2013; Schwing et al., 2015).

Since phytoplankton and bacteria are ubiquitous in the marine environment, marine snow formation can potentially occur whenever large amounts of dispersant are used during algal bloom periods. Vonk et al. (2015) reviewed 52 large oil spills, and found indications that also during two other large oil spills the MOSSFA process has occurred, namely the IXTOC I blowout in the Gulf of Mexico in 1979-80, and possibly the Santa Barbara blowout near California in 1969. Sediment core sampling at these locations can reveal depositional pulses which can be related to a specific event by isotope dating, as was demonstrated for the Deepwater Horizon blowout (Brooks et al., 2015). In the Summer of 2015, a cruise of the CIMAGE consortium went to the site of the IXTOC I blowout and sampled both sediments and biota (fish) to look for evidence of MOSSFA processes, and indeed found evidence for such an event during this spill (Vonk et al., 2015). This suggests that MOSSFA processes were not unique to the Deepwater Horizon blowout but occurred more widespread in situations with massive dispersant application than previously thought. This also highlights the need to include sampling of the benthic community during and after oil spills, and preferably before oil drilling takes place as well to get baseline data. Even deep-sea benthic communities can be damaged following oil spills, and their ecological relevance still is hardly known. In addition, analysis of protein and polysaccharide concentrations in sediment cores which show depositional pulses can give further insight in the role of EPS and marine snow in this deposition.

Our findings demonstrate that phytoplankton and their associated bacteria can rapidly produce large amounts of EPS when exposed to chemical dispersant. This mechanism is highly relevant to take into account for the spill response decision makers. Basing field applications of dispersants solely on efficacy tests performed under standard laboratory conditions in pure seawater without phytoplankton and suspended particles can have unexpected and unwanted consequences. Dispersants should not only be tested for their oil-dispersing effectiveness and for their direct toxicity, but also indirect effects on, for example, benthic ecosystems should be considered, as well as their performance under less standard (e.g., arctic, including ice) conditions. Potential side-effects of applying oil spill dispersants, like increased marine snow 
formation and subsequent transport of oiled marine snow with particles to the benthic system, should therefore be considered in the decision making process.

\section{Acknowledgements}

This research was made possible in part by a grant from The Gulf of Mexico Research Initiative (Grant Contract \#SA 12-10/GoMRI-007), and in part by the Wageningen UR TripleP@Sea innovation Program (KB-14-007). Data are publicly available through the Gulf of Mexico Research Initiative Information \& Data Cooperative (GRIIDC) at https://data.gulfresearchinitiative.org/data/R1.x135.119:0003/.

We thank Mohammad Asadi and Gladys Manyika for their practical assistance; Ben van den Broek of Food and Biobased Research of Wageningen UR for the HPAEC sugar analysis; Emma Teuling, Rianne Willems, and Maxime Bohin of the Food Chemistry department of Wageningen UR for the Dumas, SDS-PAGE, and alditol acetates sugar analyses; and Yuemei Lin of TU Delft for the alginate analysis. 


\subsection{Annex to Chapter 2}

S2.1: Absorbance - Density relationship

Figure S2.1

S2.2: Pilot experiments

Tables S2.1 - S2.3

S2.3: Monosaccharide composition

Table S2.4

S2.4: Photos of EPS tubes

Figures S2.2 - S2.3 


\section{S2.1: Absorbance - Density relationship}

Algae in culture grew well under the growth conditions provided. Using the haemocytometer, CASY cell counter, and spectrophotometer, the relationship between absorbance and cell density was produced for the two species (Figure S 2.1). These relationships were subsequently used to calculate the starting densities of the experiments.

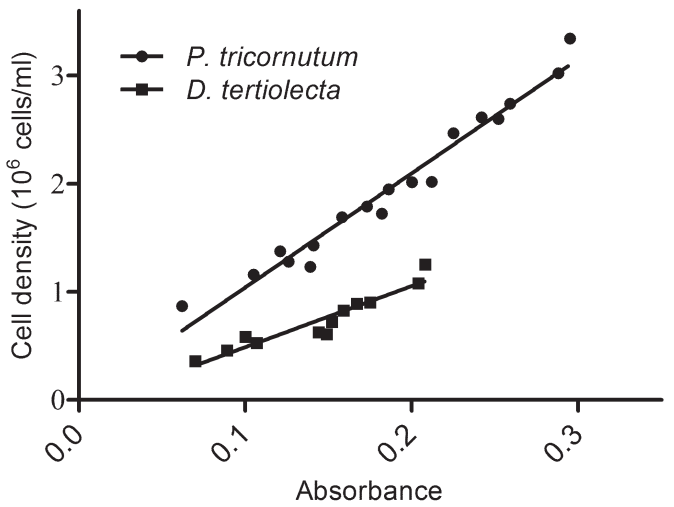

Figure S 2.1: Relationship between absorbance at $670 \mathrm{~nm}$ and cell density for Phaeodactylum tricornutum (circles; trend line with linear regression: $y=10.56 x-0.1364, \mathrm{R}^{2}=0.966$ ) and Dunaliella tertiolecta (squares; trend line with linear regression: $\left.\mathrm{y}=5.654 \mathrm{x}-0.07640, \mathrm{R}^{2}=0.8985\right)$. 


\section{S2.2: Pilot experiments}

Table S 2.1: Observations of pilot experiment, day 2 after start. Three different dispersant concentrations were tested for EPS production by two batches of green algae Dunaliella tertiolecta.

\begin{tabular}{|l|l|l|l|l|}
\hline Species & Batch ID\# & $\begin{array}{l}\text { Dispersant concentration } \\
\left(\mu \mathbf{L ~ L}^{-1}\right)\end{array}$ & $\begin{array}{l}\text { EPS formed } \\
(\text { Yes } / \mathbf{N o})\end{array}$ & Additional notes \\
\hline Dunaliella tertiolecta & 34 & 30 & $\mathrm{~N}$ & \\
\hline Dunaliella tertiolecta & 34 & 100 & $\mathrm{~N}$ & \\
\hline Dunaliella tertiolecta & 34 & 500 & $\mathrm{Y}$ & Some small flocs appear \\
\hline Dunaliella tertiolecta & 39 & 30 & $\mathrm{~N}$ & \\
\hline Dunaliella tertiolecta & 39 & 100 & $\mathrm{~N}$ & \\
\hline Dunaliella tertiolecta & 39 & 500 & $\mathrm{Y}$ & Some small flocs appear \\
\hline
\end{tabular}

Table S 2.2: Observations of pilot experiment, day 5 after start. Three different dispersant concentrations were tested for EPS production by two batches of green algae Dunaliella tertiolecta.

\begin{tabular}{|l|l|l|l|l|}
\hline Species & Batch ID\# & $\begin{array}{l}\text { Dispersant concentration } \\
\left(\mu \mathbf{L ~ L}^{-1}\right)\end{array}$ & $\begin{array}{l}\text { EPS formed } \\
(\text { Yes } / \mathbf{N o})\end{array}$ & Additional notes \\
\hline Dunaliella tertiolecta & 34 & 30 & $\mathrm{~N}$ & \\
\hline Dunaliella tertiolecta & 34 & 100 & $\mathrm{~N}$ & $\mathrm{Y}$ \\
\hline Dunaliella tertiolecta & 34 & 500 & $\mathrm{~N}$ & Big flocs, water clear \\
\hline Dunaliella tertiolecta & 39 & 30 & $\mathrm{~N}$ & \\
\hline Dunaliella tertiolecta & 39 & 100 & $\mathrm{Y}$ & Big flocs, water greenish \\
\hline Dunaliella tertiolecta & 39 & 500 & & \\
\hline
\end{tabular}


Table S 2.3: Observations of pilot experiment, day 5 after start. Three different dispersant concentrations and four different antibiotic concentrations were tested for EPS production by cultures of diatom Phaeodactylum tricornutum.

\begin{tabular}{|c|c|c|c|c|c|}
\hline Species & $\begin{array}{l}\text { Batch } \\
\text { ID\# }\end{array}$ & $\begin{array}{l}\text { Dispersant } \\
\text { concentration } \\
\left(\mu \mathrm{L} \mathrm{L}^{-1}\right)\end{array}$ & $\begin{array}{l}\text { Antibiotics } \\
\left.(\mathrm{mL} \mathrm{L})^{-1}\right)\end{array}$ & $\begin{array}{l}\text { EPS formed } \\
\text { Y/N }\end{array}$ & Additional notes \\
\hline Phaeodactylum tricornutum & 17 & 30 & - & $\mathrm{N}$ & \\
\hline Phaeodactylum tricornutum & 17 & 100 & - & $\mathrm{N}$ & \\
\hline Phaeodactylum tricornutum & 17 & 500 & - & $\mathrm{Y}$ & $\begin{array}{l}\text { A lot of EPS, water clear, brown } \\
\text { diatoms at bottom of tube }\end{array}$ \\
\hline Phaeodactylum tricornutum & $17 \mathrm{x}$ & 30 & 10 & $\mathrm{~N}$ & \\
\hline Phaeodactylum tricornutum & $17 \mathrm{x}$ & 100 & 10 & $\mathrm{~N}$ & \\
\hline Phaeodactylum tricornutum & $17 \mathrm{x}$ & 500 & 10 & $\mathrm{Y} / \mathrm{N}$ & Very tiny flocs observable \\
\hline Phaeodactylum tricornutum & $17 \times 1.5$ & 30 & 15 & $\mathrm{~N}$ & \\
\hline Phaeodactylum tricornutum & $17 \times 1.5$ & 100 & 15 & $\mathrm{~N}$ & \\
\hline Phaeodactylum tricornutum & $17 \times 1.5$ & 500 & 15 & $\mathrm{~N}$ & \\
\hline Phaeodactylum tricornutum & $17 \times 2$ & 30 & 20 & $\mathrm{~N}$ & \\
\hline Phaeodactylum tricornutum & $17 \times 2$ & 100 & 20 & $\mathrm{~N}$ & \\
\hline Phaeodactylum tricornutum & $17 \times 2$ & 500 & 20 & $\mathrm{~N}$ & \\
\hline
\end{tabular}




\section{S2.3: Monosaccharide composition}

Table S 2.4: Monosaccharide composition of EPS produced by diatom Phaeodactylum tricornutum and green algae Dunaliella tertiolecta. Measured with alditol-acetates method, \% of dry weight, average and standard deviation ( $\mathrm{N}=2$, except Non-sterile Dunaliella $\mathrm{N}=1$ ).

\begin{tabular}{|l|l|l|l|l|}
\hline & Non-sterile Phaeodactylum & Phaeodactylum filtrates & Non-sterile Dunaliella & Dunaliella filtrates \\
\hline Rhamnose & $0.18(0.01)$ & $0.06(0.01)$ & 0.23 & $0.05(0.005)$ \\
\hline Fucose & - & $0.08(0.01)$ & 0.08 & $0.05(0.01)$ \\
\hline Arabinose & - & - & 0.09 & - \\
\hline Xylose & $0.10(0.01)$ & - & 0.12 & - \\
\hline Mannose & $0.62(0.002)$ & $1.41(0.04)$ & 1.7 & $0.96(0.03)$ \\
\hline Galactose & $0.24(0.01)$ & $0.64(0.02)$ & 1.41 & $0.44(0.03)$ \\
\hline Glucose & $0.53(0.01)$ & $1.68(0.02)$ & 13.17 & $1.05(0.03)$ \\
\hline Uronic acid & $0.97(0.05)$ & $1.96(0.02)$ & 4.03 & $1.30(0.01)$ \\
\hline Total & $2.64(0.08)$ & $5.83(0.07)$ & 20.84 & $3.85(0.09)$ \\
\hline
\end{tabular}




\section{S2.4: Photos of EPS tubes}

Washed EPS from non-sterile Dunaliella tertiolecta and Phaeodactylum tricornutum (Figure S 2.3) and from $0.45 \mu \mathrm{m}$ phytoplankton filtrates (Figure S 2.2). EPS from several replicate flasks was combined in one tube; more flasks were combined in Figure S 2.3 than in Figure S 2.2.

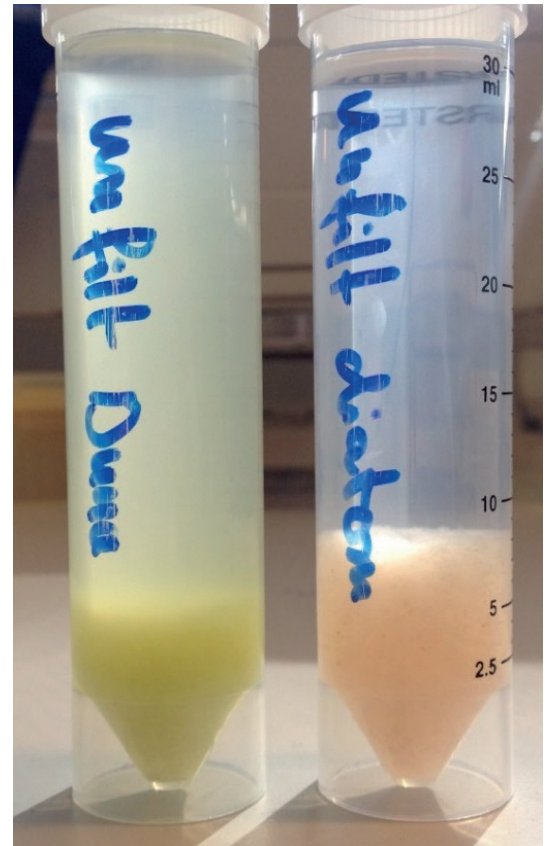

Figure S 2.3: EPS from non-sterile cultures

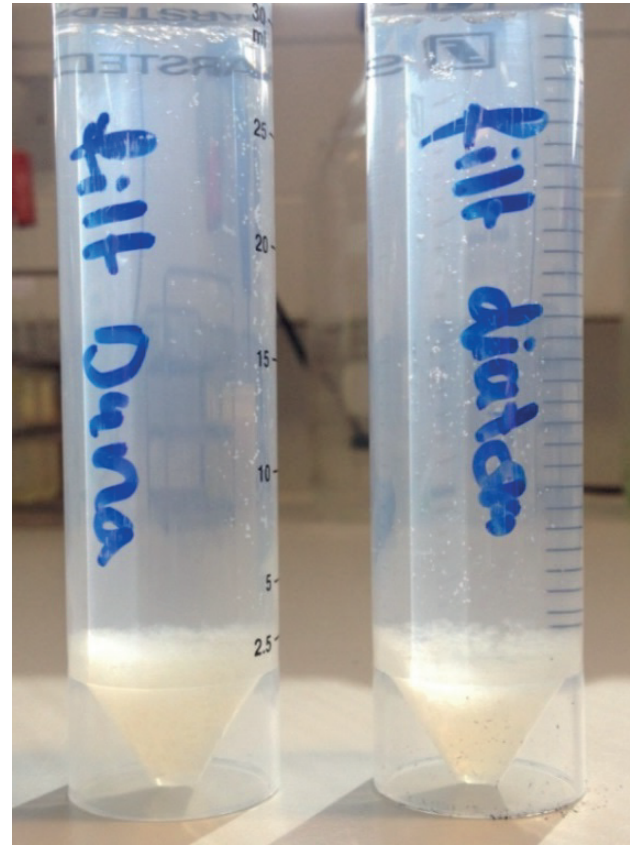

Figure S 2.2: EPS from filtrated cultures 


\section{Chapter 3}

\section{Marine snow hampers oil biodegradation in a marine sediment layer}

Shokouh Rahsepara , Justine S. van Eenennaamª, Jagoš R. Radovićb ${ }^{\text {, Thomas B.P. Oldenburg }}{ }^{b}$, Huub H.M. Rijnaarts ${ }^{\mathrm{a}}$, Albertinka J. Murk ${ }^{\mathrm{c}}$, Edwin M. Foekema ${ }^{\mathrm{c,d}}$, Alette A.M. Langenhoff ${ }^{\mathrm{a}}$

a Sub-department of Environmental Technology, Wageningen University, Wageningen, The Netherlands

b PRG, Department of Geoscience, University of Calgary, Calgary, Canada

${ }^{c}$ Marine Animal Ecology Group, Wageningen University, Wageningen, The Netherlands

${ }^{\mathrm{d}}$ Wageningen Marine Research, Den Helder, The Netherlands

This chapter is based on:

Rahsepar, S., van Eenennaam, J.S., Radović, J.R., Oldenburg, T.B.P., Rijnaarts, H.H.M., Murk, A.J., Foekema, E.M., Langenhoff, A.A.M. Marine snow enhances the adverse effects of oil on benthic invertebrates (submitted manuscript). 


\section{Abstract}

During the Deepwater Horizon $(\mathrm{DwH})$ oil spill, an excessive production of marine snow was observed and it was estimated that as much as $14 \%$ of the oil was transferred to the ocean floor by MOSSFA (Marine Oil Snow Sedimentation and Flocculent Accumulation). MOSSFA is an important pathway of transferring oil to the ocean floor. We performed experiments at laboratory scale in 15 microcosms, representing 5 exposures of marine snow with or without oil, oil plus clay, and controls with only clay or sediment. Results showed that the presence of marine snow reduces the depletion of oil alkanes by $40 \%$ due to preferred biodegradation of marine snow organics. Biodegradation of marine snow reduces the oxygen concentration which might result in an anaerobic layer in the sediment at the ocean sea floor, reducing the oil biodegradation rate. Our results show that marine snow hampers benthic oil biodegradation. 


\subsection{Introduction}

The Deepwater Horizon (DwH) oil drilling rig in the Gulf of Mexico (GoM) exploded on April 2010 , causing the release of roughly $500,000 \mathrm{~m}^{3}$ of Macondo well oil over the course of 87 days (McNutt et al., 2012). In an effort to reduce the oil slick and enhance oil degradation, chemical dispersants (Corexit EC9500A and EC9527A) were applied as the main response (Pietroski et al., 2015), of which $60 \%$ were applied to the ocean surface, and $40 \%$ to the $\mathrm{DwH}$ wellhead at a depth of $1500 \mathrm{~m}$ close to the ocean floor (Beyer et al., 2016; Kujawinski et al., 2011). Dispersants reduce the oil-water interfacial tension (Lee et al., 2002), thereby breaking oil into smaller and more stably suspended droplets than by natural dispersion (Brooks et al., 2015; Zeinstra-Helfrich et al., 2015a). The resulting larger oil-water surface area increases oil bioavailability for biodegrading bacteria (Geng et al., 2013; Reddy et al., 2012).

The exceptional formation of marine snow reported during the DwH oil spill (Daly et al., 2016; Ziervogel et al., 2012) is due to extracellular polymeric substances (EPS) produced either by free living oil degrading microorganisms as natural oil dispersant, and also as a stress response to the presence of chemical dispersants on microorganisms living in symbiosis with phytoplankton (Daly et al., 2016; Hastings et al., 2016; Passow et al., 2012; Sohm et al., 2011; van Eenennaam et al., 2016). Marine snow is naturally occurring in oceans, and consists of aggregates of smaller particles including bacteria, suspended particles and phytoplankton glued together by EPS (Wotton, 2004a). EPS glues organic material and suspended minerals forming marine snow that interacts with dispersed oil droplets in the water column and settles as marine snow-associated oil on the ocean floor (Brooks et al., 2015; Gong et al., 2014; Mason et al., 2014; Passow, 2016; Passow et al., 2012; Romero et al., 2015; Valentine et al., 2014). This was an important pathway of transferring the oil to the ocean floor in the case of the DwH oil spill (Hastings et al., 2016; Romero et al., 2015).

Marine snow plays an important role in transferring suspended particles from the water column to the ocean floor by gravitational settling. The process of deposition of marine snow-associated oil is called Marine Oil Snow Sedimentation and Flocculent Accumulation (MOSSFA). Within $256 \mathrm{~km}$ of the DwH oil rig, deposition of marine snow-associated oil was observed as 1-6 cm thick oily deposits along the northeast GoM slope (Brooks et al., 2015). It is estimated that after the DwH oil spill up to $14 \%$ of the total spilled oil was transferred to the ocean floor by the sedimentation of marine snow-associated oil (Daly et al., 2016). Mass accumulation rates increased from pre-spill to after the oil spill during 2011 and 2012 by respectively 0.05 to 0.16 $\mathrm{g} / \mathrm{cm}^{2} /$ year to $0.48-2.40 \mathrm{~g} / \mathrm{cm}^{2} /$ year (Daly et al., 2016).

The oxygen concentrations at a depth of $1000-1200 \mathrm{~m}$ such as in the GoM are generally in the range of $2.57 \pm 0.5 \mathrm{mg} \mathrm{L}^{-1}$. This concentration is enough for aerobic processes to take place (Jochens et al., 2005), such as aerobic degradation of oil. Aerobic processes in the sediment layer will deplete the dissolved oxygen and continued oxygen consumption in the sediment depends 
on diffusion of oxygen from the water column into the sediment (Joye et al., 2011). There are various papers that describe a MOSSFA event and the transfer of oil to the sediment layers at the ocean floor (Daly et al., 2016; Mason et al., 2014), however, the fate and biodegradation of hydrocarbons in the deposited marine snow-associated oil is not well studied.

We hypothesize that such increases in organic matter content will increase the oxygen consumption at the ocean floor, which affects the degradation of oil. The aim of this study is to elucidate how marine snow affects the biodegradation of oil components in marine sediment layers. The degradation of oil was studied in 15 microcosms with natural marine sediment in combination with artificial marine snow with or without oil, oil plus clay, and controls with only clay or sediment. The degradation of alkanes in these microcosms was studied during an incubation period of 42 days.

\subsection{Materials and methods}

\subsubsection{Experimental setup}

Oil biodegradation experiments were performed in 15 microcosms of $25 \times 25 \times 25 \mathrm{~cm}$, representing five different exposure conditions in triplicate (Table 3.1). Full glass microcosms were used to avoid the oil absorption by silicone rubber. Climate was controlled at $14{ }^{\circ} \mathrm{C}$, with a day-night light regime of $16 \mathrm{~h}$ light and $8 \mathrm{~h}$ dark. The microcosms contained a $5 \mathrm{~cm}$ layer $(\approx$ $3,2 \mathrm{~L})$ of sieved $(1 \mathrm{~mm})$ natural uncontaminated sediment and a $15 \mathrm{~cm}$ layer $(\approx 9.4 \mathrm{~L})$ of filtered $(0.45 \mu \mathrm{m})$ natural seawater, originating from the Netherlands (see 3.2.2). The sediment and seawater were added to the microcosms one day prior to the exposure day (day 1) to settle. At the exposure day, depending on the exposure conditions, a $1 \mathrm{~cm}$ layer of marine snow with or without oil, or $3.15 \mathrm{~g}$ of clay with or without oil was applied on top of the sediment layer, as described in detail in Section 3.2.2. The concentration of oil in the oil containing microcosms was $0.63 \mathrm{~g}$ oil per $625 \mathrm{~cm}^{2}$, which is equivalent to $10 \mathrm{~g} \mathrm{~m}^{-2}$ per microcosm. This is the highest concentration of oil found in the sediment layer of GoM, which makes it a worst-case scenario (Romero, personal communication). The microcosms were covered with acrylic plastic covers to minimize water evaporation, and air was bubbled in the top $5 \mathrm{~cm}$ of the water column through two glass Pasteur pipettes per microcosm via an air pump. Seawater level was maintained by adding approximately $300 \mathrm{~mL}$ demi-water per week to the microcosms to correct for evaporation. The incubation period of the microcosms was 42 days.

Table 3.1: Overview of the exposure conditions for the microcosm experiment. ' + ' indicates present in the microcosm and '-' indicates absent from the microcosm.

\begin{tabular}{cccc}
\hline Exposure description & Marine snow & Oil & Kaolin clay \\
\hline Sediment control & - & - & - \\
\hline Clay control & - & - & + \\
\hline Snow & + & - & + \\
\hline Oil & - & + & + \\
\hline Snow+Oil & + & + & + \\
\hline
\end{tabular}


Sediment core samples for chemical analysis were taken from each microcosm at days 1, 16, 30 and 42. In order to avoid disturbance of the surrounding sediment, a $2 \mathrm{~cm}$ diameter glass tube was pushed vertically into the sediment before sampling and then a $1.5 \mathrm{~cm}$ diameter glass tube was placed inside the bigger tube to extract the sediment under vacuum. The outer tubes were left in the microcosms until the end of the experiment, to avoid disturbance of the remaining sediment and water column. Water level inside the tubes was adjusted with filtered seawater after the sample was taken to prevent drawing surrounding water into the outer sampling tubes. At each sampling time, 4 samples were taken from different locations in one microcosm which were pooled to get a representative sample per microcosm. The samples were kept in a $300 \mathrm{~mL}$ glass jar at $4{ }^{\circ} \mathrm{C}$ in the dark for 3 days to allow the sediment to settle. After settling, the overlaying water was carefully removed with a glass pipette and the sediment samples were freeze-dried using a Christ Alpha 2-4 LDplus freeze dryer (Martin Christ Gefriertrocknungsanlagen GmbH, Osterode am Harz, Germany), followed by extraction for chemical analysis (see 3.2.4).

\subsubsection{Exposure conditions of the microcosms}

We used surrogate Macondo oil in our experiment, kindly provided by BP, a light oil chemically similar to the Macondo oil of the DwH oil spill (BP Gulf Science Data, 2017b). The oil was weathered for $24 \mathrm{~h}$ in the dark at room temperature while stirring with a magnetic stirrer to allow the evaporation of lighter hydrocarbons. Using weathered oil for our experiment gives a more realistic scenario than using fresh oil since the marine snow-associated oil aggregates during the MOSSFA event were also weathered due to evaporation and dissolution (Zhanfei et al., 2012). The oil added to our experiments showed the typical unimodal distribution peaking at $\mathrm{n}$-C17, which is characteristic of light oils, such as Macondo well oil.

Uncontaminated sediments were collected from the top $10 \mathrm{~cm}$ of an intertidal mudflat in the Dutch Wadden Sea (N $52^{\circ} 56.112$ E 004 ${ }^{\circ}$ 59.976) at low tide. Collected sediments were transported to the laboratory and sieved over a $1 \mathrm{~mm}$ sieve to remove larger organisms and particles. The sediment did contain background levels of $n$-alkanes and isoprenoid alkanes, however, they showed distribution characteristic of natural biogenic input (i.e. odd over even preference), such as algae (Gelpi et al., 1970; Weete, 1976).

Uncontaminated natural seawater was collected from the Eastern Scheldt, The Netherlands, filtered over a $0.45 \mu \mathrm{m}$ filter and stored in a tank in the laboratory.

In order to kick-start the biodegradation of oil, two oil-degrading microorganisms were added to the water column at day 1. Rhodococcus qingshengii TUHH-12 (DSMZ No. 46766) was used as an alkane-degrading culture, isolated by the Technical University of Hamburg, Germany from a seawater sample (Schedler et al., 2014). Pseudomonas putida F1, an aromatic degrading culture, was purchased from the German collection of microorganisms and cell cultures (DSMZ, No. 6899). $1 \mathrm{~mL}$ of Rhodococcus qingshengii TUHH-12 (Optical density of 0.98 ), and $1 \mathrm{~mL}$ of Pseudomonas putida 
F1 (Optical density of 0.30) (Rahsepar et al., 2016) was added to each microcosm on day 1. All the exposures contained bacteria.

EPS, including proteins and polysaccharides, was produced in our laboratory by exposing phytoplankton communities to chemical dispersants (van Eenennaam et al., 2016). However, in this way it was not feasible to produce sufficient amounts of EPS for the amount of marine snow needed for this study. Therefore, a method was developed to produce artificial marine snow which resembles the natural marine snow. Based on the natural marine snow composition reported for the MOSSFA event during the DwH oil spill (Daly et al., 2016), the following essential ingredients for production of the artificial marine snow were defined; alginate-like exopolysaccharides (van Eenennaam et al., 2016), phytoplankton biomass (Hu et al., 2011; O'Connor, 2013) and mineral particles (Bianchi et al., 2011). This artificial marine snow was used to study the effect of association of oil with marine snow on oil biodegradation in this study.

Artificial marine snow was prepared by adding $22.5 \mathrm{~g}$ of commercially available alginate (alginic acid sodium salt, CAS 9005-38-3 Sigma Aldrich), a gelling and nontoxic anionic polysaccharide, to $1.1 \mathrm{~L}$ of filtered natural seawater while stirring. Then, $9.45 \mathrm{~g}$ of kaolin clay (hydrated aluminum silicate, CAS 1332-58-7, Sigma Aldrich) and $19 \mathrm{~g}$ of fresh weight of phytoplankton biomass (Chlorella pasta, Ingepro BV, Borculo, The Netherlands) were added to the solution. Separately, $188 \mathrm{~g}$ of $\mathrm{CaCl}_{2}$ (CAS 10043-52-4, Fluka Analytical) was dissolved in $13 \mathrm{~L}$ of demi-water and this solution was added to the alginate solution while stirring. The calcium causes coagulation of the alginate and precipitation of $600 \mathrm{~mL}$ marine-snow-like flocks. The overlying liquid was poured off and the artificial marine snow divided into three equal parts for the three microcosm replicates.

To prepare each replicate of Snow-only exposure, $200 \mathrm{~mL}$ of this artificial marine snow was added to the microcosms resulting in an approximately $1 \mathrm{~cm}$ thick layer on top of the sediment. For the Snow+Oil exposure, the procedure was similar as described above except that the kaolin clay was first mixed with $1.9 \mathrm{~g}$ of oil and $100 \mathrm{~mL}$ demi water before adding it to the alginate solution. For each replicate of the Clay control, the kaolin clay was mixed with approximately $500 \mathrm{~mL}$ seawater from the microcosm to form a suspension and then added to the microcosms. The clay settled on top of the sediment in a homogenous layer of approximately $0.5 \mathrm{~mm}$ thick. The Oil-only exposure was prepared per microcosm by mixing $3.15 \mathrm{~g}$ of kaolin clay with $0.63 \mathrm{~g}$ of oil and $100 \mathrm{~mL}$ of demi water to form a homogenous slurry that was added to the microcosm. To the Sediment control microcosms nothing extra was added.

\subsubsection{Monitored water parameters}

Dissolved oxygen $\left(\mathrm{mg} \mathrm{L}^{-1}\right), \mathrm{pH}(-)$, temperature $\left({ }^{\circ} \mathrm{C}\right)$, and salinity $(\% 0)$ were monitored weekly during the experiment in the water phase at $10 \mathrm{~cm}$ above the sediment. The $\mathrm{pH}$ was measured with a Mettler Toledo $\mathrm{pH}$ probe, and the dissolved oxygen, temperature and salinity with a Hach HQ40d multimeter using dissolved oxygen, salinity and temperature probes. 


\subsubsection{Chemical analyses}

For chemical analysis, $5 \mathrm{~g}$ of freeze-dried sediment was extracted with $8 \mathrm{~mL}$ dichloromethane. An aliquot of the whole extract was first analyzed using GC-MS to check if the oil fingerprint is present. Then, the whole extract was separated into saturate and aromatic fraction, by loading onto a silica gel (0.6 g, 70-230 mesh) column, pre-washed with pentane, and eluting with $2 \mathrm{~mL}$ of pentane to obtain the saturate fraction, followed by elution with $2 \mathrm{~mL}$ of dichloromethane and isopropyl alcohol, respectively, to obtain the aromatic fraction. The temperature program for the GC-MS analysis included a hold of $5 \mathrm{~min}$ at $40{ }^{\circ} \mathrm{C}$, followed by a $4{ }^{\circ} \mathrm{C} \mathrm{min}^{-1}$ ramp up to $325^{\circ} \mathrm{C}$, and finishing with an isothermal hold at $325^{\circ} \mathrm{C}$ for 15 minutes. Separation was performed on a HP-5MS capillary column $(30 \mathrm{~m} \times 0.25 \mathrm{~mm} \times 0.25 \mu \mathrm{m})$, and helium was used

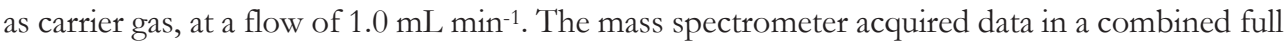
scan/selected ion monitoring (SIM-SCAN) mode. SIM trace at $\mathrm{m} / \mathrm{z} 85$ was used to integrate the areas of $n$-alkanes (C13-C30) and isoprenoid alkanes (pristane and phytane). Integrated areas were then normalized to the area of C30-hopane $(17 \alpha(\mathrm{H}), 21 \beta(\mathrm{H})$-hopane) at SIM trace $\mathrm{m} / \mathrm{z} 191$. C30-hopane is considered a conservative biomarker due to its recalcitrance to weathering (Prince et al., 1994). This normalization approach is typically used in oil spill studies to detect and compare compositional changes due to evaporation, biodegradation, and other weathering processes (Aeppli et al., 2014; Radović et al., 2014).

To demonstrate the stability and persistence of C30-hopane during our experiments and to confirm the validity of C30-hopane normalization, additional batch experiments were performed. The concentration of C30-hopane was followed during 42 days in 4 batches $(1 \mathrm{~L})$, similar to the microcosm exposure Snow+Oil. The whole content of two bottles was extracted at day 0 and the other 2 extracted at day 42. The samples were analyzed using GC-MS as described above, and the C30-hopane was quantified against an internal standard of cholestane$d_{4}$, assuming a relative response factor of 1 (Bennett and Larter, 2000).

\subsubsection{Statistical analysis}

GraphPad Prism 5 was used to perform statistical analysis using two-way ANOVA with Bonferroni multiple comparisons post-test.

\subsection{Results}

\subsubsection{Physical parameters in the water phase}

In the absence of marine snow, the oxygen concentration in the water column $10 \mathrm{~cm}$ above the sediment layer was stable during the incubation time of 42 days $\left(8 \pm 0.3 \mathrm{mg} \mathrm{L}^{-1}\right)$. In the marine snow only exposure, the oxygen concentration in the water phase dropped with $37 \%$ to $5.3 \pm 0.3$ $\mathrm{mg} \mathrm{L^{-1 }}$ at day 6 , followed by a rebound to the initial value at day 10 (Figure 3.1). 


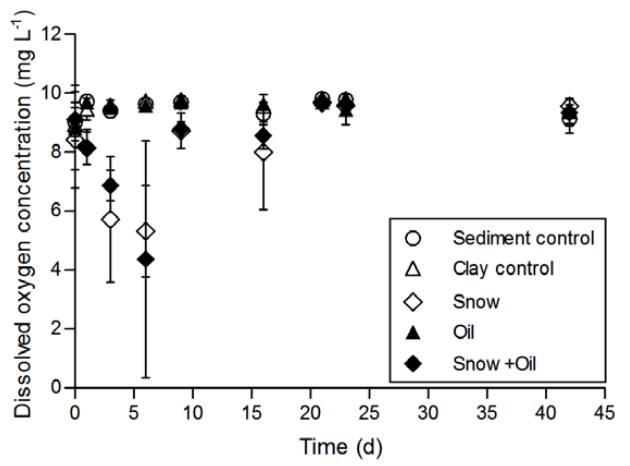

Figure 3.1: Dissolved oxygen concentration at $10 \mathrm{~cm}$ above the sediment layer in the water phase of the microcosms. Average and standard deviation of three microcosm replicates.

The highest oxygen consumption was observed in the Snow+Oil exposure. The oxygen concentration in the water dropped significantly with $52 \%$ from $9 \pm 0.5 \mathrm{mg} \mathrm{L}^{-1}$ to values varying around $4.4 \pm 0.5 \mathrm{mg} \mathrm{L}^{-1}$ in the first 6 days, where after it returned to the initial oxygen concentration within 4 days (Figure 3.1). The $\mathrm{pH}$, temperature and salinity in the water phase remained constant during the incubation time in all the exposures at an average value of $8.5 \pm 0.3$, $14 \pm 1{ }^{\circ} \mathrm{C}$ and $34 \pm 2 \%$, respectively (Annex S3.1).

\subsubsection{C30-hopane normalized n-alkanes (C13-C30) and isoprenoid alkanes}

The batch experiments confirmed the persistence of C30-hopane during our experiments, with average duplicate concentrations of 180 and $210 \mu \mathrm{g}$ of C30-hopane per $\mathrm{g}$ of sediment extracted at $\mathrm{t}=0$ and $\mathrm{t}=42$, respectively. The observed variability (approx. $10 \%$ relative standard deviation) is within the acceptable limit of analytical error accumulated during experimental setup, sampling, sample preparation, GC-MS analysis, and peak integration (CEN, 2012). Therefore, hopane normalized peak areas were further used to determine the relative abundance changes of $n$-alkanes and isoprenoid alkanes.

The C30-hopane normalized peak areas of the $n$-alkanes (C13-C30) and isoprenoid alkanes determined in samples of the exposures Oil and Snow+Oil are presented in Figure 3.2. The results show that 2.5 times more $n$-alkanes and isoprenoid alkanes were degraded in the absence of marine snow $(65 \%)$ than in the presence of marine snow (25\%). Limited degradation of $n$ alkanes and isoprenoid alkanes was observed in the presence of marine snow during the first 30 days (Figure 3.2). After 42 days of incubation of the oil, extended degradation of all individual $n$-alkanes and isoprenoid alkanes occurred (Figure 3.3) in the absence but not in the presence of marine snow. In addition, when looking at the individual removal percentages of the different $n$-alkanes and isoprenoid alkanes, the degradation of the smaller compounds $(<\mathrm{C} 18)$ is far more pronounced in the absence of marine snow (Figure 3.4). 


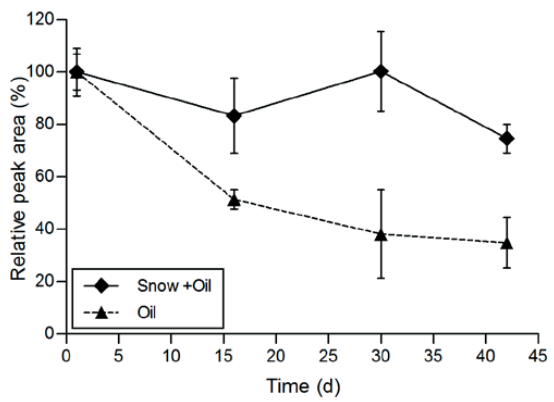

Figure 3.2: Relative peak area of C30-hopane normalized $n$-alkanes (C13-C30) and isoprenoid alkanes (pristane and phytane). Average and standard deviation of three microcosm replicates.
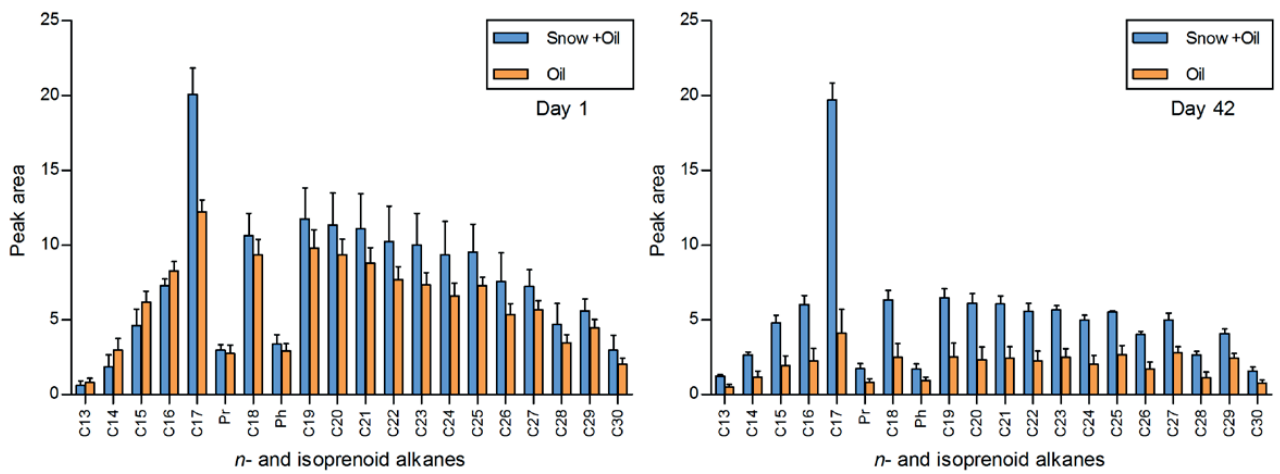

Figure 3.3: C30-hopane normalized peak areas of $n$-alkanes (C13-C30) and isoprenoid alkanes (pristane and phytane) in sediment samples on day 1 (left) and day 42 (right). Average and standard deviation of three microcosm replicates.

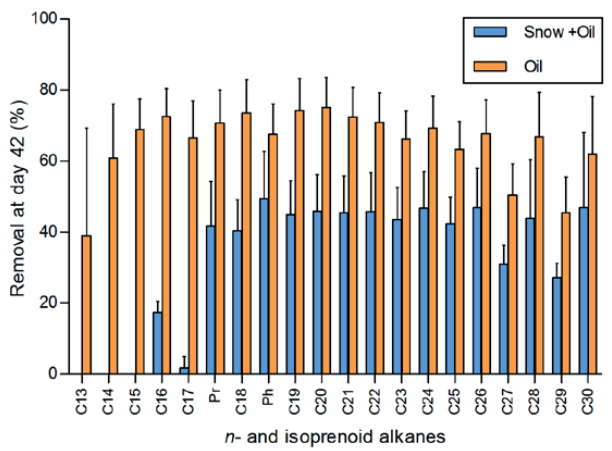

Figure 3.4: Profile of removal percentage of $n$-alkanes (C13-C30) and isoprenoid alkanes (pristane and phytane) in sediment samples at day 42 compared to day 0 . Average and standard deviation of three microcosm replicates. 


\subsection{Discussion}

In this research, we studied the effect of the presence of marine snow on the biodegradation of oil settled on top of a natural sediment layer in microcosms. Our results reveal that marine snow reduces the alkane biodegradation up to $40 \%$. In the presence of marine snow the oxygen concentration in the water $10 \mathrm{~cm}$ above the sediment was up to $52 \%$ after 6 days of incubation (Figure 3.1) despite continuous gentle aeration at the water surface, showing enhanced oxygen consumption due to marine snow degradation. Both our artificial marine snow as well as natural marine snow contains carbon compounds that are easily degradable with concomitant oxygen use. Especially the carbohydrate compounds of marine snow have oxidized groups in their molecular structures, which are readily available for further enzymatic conversions and mineralization (Alldredge, 1998; Bochdansky et al., 2010).

Relative to marine snow, oil is more recalcitrant because of its stable reduced aliphatic or aromatic molecular structures that need to be activated for further mineralization, i.e. through oxygen inclusion by oxygenases (Chikere et al., 2011). As a result, biodegradation of oil components with half lives up to 60 days, depending on the oxygen availability (Reddy et al., 2012), will be slower compared to e.g. marine snow. Therefore, when both marine snow and oil are present, marine snow will be a preferred substrate over oil for the aerobic microbial community. Oil degradation is then further hampered by oxygen depletion as we have seen, especially during the first 6 days of incubation.

In our experiment air was continuously bubbled into the water at $5 \mathrm{~cm}$ below the water surface, but still reduced oxygen concentrations were detected in microcosms with marine snow, especially within the first 6 days of incubation. Follow-up microcosm experiments including ecotoxicological effects on invertebrate organisms also demonstrated oxygen depletion in the sediment layer in the presence of marine snow (Chapter 4 and Chapter 5). At the deep ocean floor, oxygen availability in the water phase nearby the sediment could be limited, depending on the depth and hydrological conditions. Prolonged anaerobic conditions in the deep-sea top sediment layer with often even more than $1 \mathrm{~cm}$ of marine snow-associated oil most likely contributed to the persistence of oil-sediment layers as reported for the DwH oil spill (Khelifa et al., 2005; Montagna et al., 2013; White et al., 2012) as well as the Ixtoc I spill in 1979 (Jernelov and Linden, 1981), for which recently was reported that MOSSFA had occurred as well (Vonk et al., 2015). Also anaerobic conditions were detected in ocean floor sediments after the $\mathrm{DwH}$ oil spill (Ziervogel et al., 2016), suggesting that marine snow may indeed have limited the oil biodegradation in these sediments. A study showed that the intensity of anaerobic conditions in the sediment layer of GoM lasted for up to three years after the DwH spill, likely as a result of excess organic matter and hydrocarbon burial and decomposition in the sediments (Hastings et al., 2016). 
Our results elucidate that the oil biodegradation rate in the sediment layer is influenced by two related factors: carbon source competition and oxygen availability. When high concentrations of marine snow or other easily degradable carbon sources are present, aerobic biodegradation of marine snow is preferred followed by the biodegradation of oil.

The association of oil with marine snow by itself does not mean that the oil biodegradation will decrease. In conditions without oxygen limitation the inclusion of oil in marine snow could even increase the oil biodegradation as has been shown for the water phase (Rahsepar et al., 2017).

This study is a first step in elucidating the effects of marine snow in the deep-sea ecosystem. The laboratory setup of this experiment allowed us to specifically study the biodegradation of marine snow-associated oil on the marine sediment. This fundamental knowledge is highly relevant to understand more complex systems. The limited availability of oxygen in the sediment layer at the ocean sea floor can be enhanced by bioturbation activities of benthic organisms (Pelegrí and Blackburn, 1994). This might further affect the biodegradation rate of oil which we further investigated in a microcosm experiment with representative benthic invertebrates (Chapter 4).

\subsection{Conclusion}

This study shows that biodegradation of marine snow-associated oil in marine sediment is hampered compared to the biodegradation of oil without marine snow. As the excessive EPS formation during the DwH spill was at least partially related to large scale dispersant application in the presence of high phytoplankton densities, the consequence of prolonging oil presence should be taken into account when deciding on an oil spill response.

\section{Acknowledgements}

This research was made possible in part by a grant from The Gulf of Mexico Research Initiative (Grant Contract \#SA 12-10/GoMRI-007) and in part by the Wageningen UR TripleP@Sea innovation Program (KB-14-007). Jagoš R. Radović and Thomas B.P. Oldenburg acknowledge the support from the Canada Foundation for Innovation (CFI), the Natural Sciences and Engineering Research Council of Canada (NSERC) and Canada Research Chairs (CRC), PRG and the University of Calgary. Practical help by Yulia Kuvshinova is gratefully acknowledged. Data are publicly available through the Gulf of Mexico Research Initiative information \& Data Cooperative (GRIIDC) at https://data.gulfresearchinitiative.org (doi:10.7266/N7125QPZ). 


\subsection{Annex to Chapter 3}

S3.1: Water quality measurements

Figure S 3.1 
S 3.1: Water quality measurements
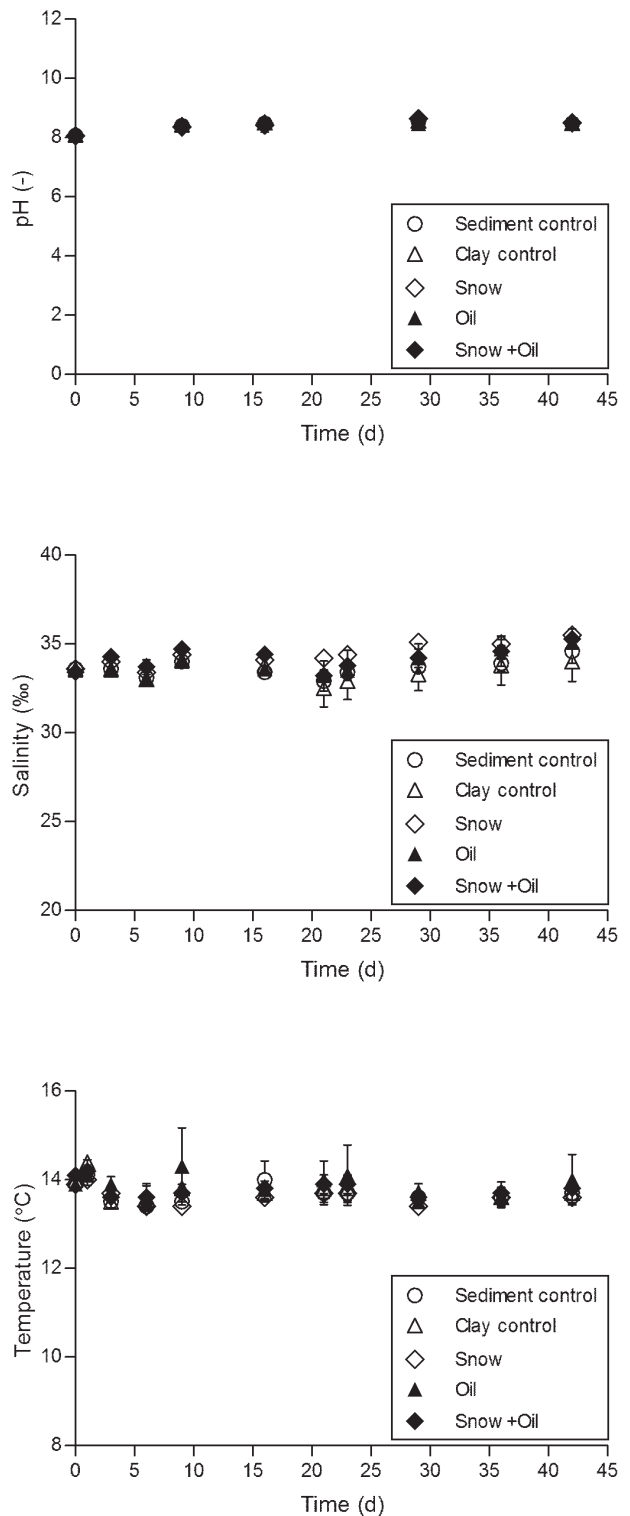

Figure S 3.1: Water column measurements of $\mathrm{pH}$ (top), salinity (middle), and temperature (bottom). Average and standard deviation of three microcosm replicates. 


\section{Chapter 4}

\section{Marine snow enhances the adverse effects of oil on benthic invertebrates}

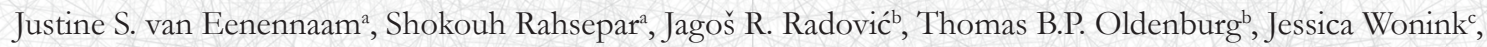
Alette A.M. Langenhoffa, Albertinka J. Murk ${ }^{c}$, Edwin M. Foekema ${ }^{\text {c,d }}$

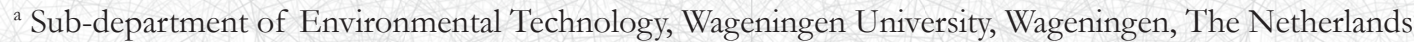

b PRG, Department of Geoscience, University of Calgary, Calgary, Canada

${ }^{\text {c } M a r i n e ~ A n i m a l ~ E c o l o g y ~ G r o u p, ~ W a g e n i n g e n ~ U n i v e r s i t y, ~ W a g e n i n g e n, ~ T h e ~ N e t h e r l a n d s ~}$

${ }^{\mathrm{d}}$ Wageningen Marine Research, Den Helder, The Netherlands

This chapter is based on:

van Eenennaam, J.S., Rahsepar, S., Radović, J.R., Oldenburg, T.B.P., Wonink, J., Langenhoff, A.A.M., Murk, A.J., Foekema, E.M. Marine snow enhances the adverse effects of oil on benthic invertebrates (accepted manuscript). 


\section{Abstract}

After the Deepwater Horizon oil spill, a MOSSFA (Marine Oil Snow Sedimentation and Flocculent Accumulation) event took place, transporting an estimated $14 \%$ of total released oil to the sediment, and smothering the benthic ecosystem. This microcosm study describes the effects of oiled artificial marine snow on benthic macroinvertebrates. Corophium volutator survival was reduced by $80 \%$ in oil-contaminated snow. Hydrobia ulvae survival was reduced by $40 \%$ in oil-contaminated snow, possibly due to consumption of oiled snow. Macoma balthica was sensitive to marine snow, addition of oil slightly decreased survival. This study reveals trait-dependent sensitivity to oil with or without marine snow. The main drivers for organismal response to marine snow and oil are motility, sensitivity to hypoxia and oil toxicity, and feeding habits. Adverse effects of MOSSFA events on the benthic community will have consequence for the benthic-pelagic habitat and food chain, and should receive more attention in oil spill management. 


\subsection{Introduction}

The Deepwater Horizon (DWH) oil spill in the Gulf of Mexico in 2010 was one of the largest marine oil spills in US history. Over a three month time period, 4.9 million barrels of oil leaked into the sea (National Commission on the BP Deepwater Horizon Oil Spill and Offshore Drilling, 2011). The main spill response was the use of 6.8 million liters of dispersants (BP Gulf Science Data, 2017a, c), both applied at the sea surface as well as injected in the sub-sea at the well head.

One of the unexpected events seen during the DWH spill was the unprecedented formation of marine snow, which was probably due to an increased production of extracellular polymeric substances (EPS) by the microbial and phytoplankton community as a biological stress response to dispersants and oil (Passow et al., 2012; van Eenennaam et al., 2016; Ziervogel et al., 2012). Laboratory-induced EPS made by phytoplankton-associated bacteria was found to contain substantial amounts of alginate-like exopolysaccharides (van Eenennaam et al., 2016), and a peak of polysaccharides in sediment from the Gulf of Mexico coincided with the marine snow formation during the spill (Hollander et al., 2016). During the oil spill, there was a large amount of suspended solids due to the flushing of the Mississippi river as a spill response (Bianchi et al., 2011) as well as a phytoplankton bloom (Hu et al., 2011; O'Connor, 2013). Marine snow aggregates, made of dispersed oil, organic debris, phytoplankton, and suspended particles, glued together by the sticky EPS, settled on the ocean floor in a process called MOSSFA: Marine Oil Snow Sedimentation and Flocculent Accumulation (Daly et al., 2016). MOSSFA increased sedimentation rates and caused a downward flux of oil to the sediment (Brooks et al., 2015; Hastings et al., 2016; MOSSFA Steering Committee, 2013). Estimates vary, but as much as 14\% of the total oil released during the DWH oil spill may have ended up on the sediment due to MOSSFA (Daly et al., 2016). Estimates of the total area of sedimentary oil deposition range from $3,200 \mathrm{~km}^{2}$ (Valentine et al., 2014) to $24,000 \mathrm{~km}^{2}$ (Chanton et al., 2015). A review of large historical oil spills has indicated that the MOSSFA process may have occurred during other spills as well, such as the IXTOC-I blowout (Vonk et al., 2015).

The MOSSFA related oil contamination sparked interest in the potential long-term effects of sedimented oil for benthic habitats (Kinner et al., 2014). Benthic organisms, especially those that are sedentary, are particularly at risk for the MOSSFA related oil contamination (Fisher et al., 2016), since they cannot easily escape the contamination. Moderate to severe reduction of macro- and meiofaunal abundance and diversity was found over an area of $172 \mathrm{~km}^{2}$ around the wellhead (Montagna et al., 2013). Persistent reducing conditions in the sediment and the 2-3 fold increase in PAHs reduced benthic foraminiferal diversity and density (Schwing et al., 2016; Schwing et al., 2015).

MOSSFA could affect benthic ecosystems via two mechanisms: 1) direct toxicity of the oil and 2) reduced oxygen availability caused by the microbial degradation of the marine snow. Direct 
oil toxicity to benthic organisms is widely reported, both in experimental studies (e.g., Foekema et al. (1996) and Bhattacharyya et al. (2003)) and in oil spill observations (e.g., Teal and Howarth (1984), Lee and Lin (2013), and Jewett et al. (1999)). The availability of oxygen in deeper layers of the sediment can be increased by the bioturbation activity of many benthic organisms (Pelegrí and Blackburn, 1994). Bioturbation enhances the sediment oxygenation, solute transport, and remineralization of organic matter, and mixes horizontal sediment layers (Levin, 2003). Oxygen consumption by biodegradation of marine snow, the second mechanism, can impact benthic organisms after a MOSSFA event. The accumulation of organic material on the sea floor increased microbial respiration, resulting in decreased oxygen in sediment pore waters (Hastings et al., 2016). In laboratory studies, artificially produced marine snow was found to consume oxygen at a rapid rate (Rahsepar et al., 2017) and this lower oxygen concentration in the sediment is detrimental to benthic invertebrates living in the top layers of the sediment.

Benthic organisms are an important part of the marine food webs in general and of certain species or life stages more specifically. Most oil effect studies are performed with pelagic species, and without marine snow or sediment. This article describes a microcosm experiment revealing the additional effect of marine snow on the ecotoxicity of oil on marine benthic invertebrates. Also the effect of the presence of invertebrates on bioturbation and oil biodegradation is presented. The experiment simulated the effect of marine snow and oil in small scale microcosms with sediment, natural sea water, and four representative species of benthic invertebrates. These invertebrates reflect four different benthic lifestyles and feeding strategies (traits): an infaunal deposit and suspension feeding amphipod, an epifaunal deposit feeding and grazing gastropod, an infaunal deposit and suspension feeding bivalve, and epi- and infaunal deposit and suspension feeding foraminifera.

\subsection{Materials and methods}

\subsubsection{Experimental setup}

The basic experimental design was similar to the experiment described in Chapter 3, but now benthic macroinvertebrates were included. In short, 21 microcosms of $25 \times 25 \times 25 \mathrm{~cm}$ were placed in a climate controlled room at $14{ }^{\circ} \mathrm{C}$, with a day-night light regime of $16 \mathrm{~h}$ light and $8 \mathrm{~h}$ dark. Full glass microcosms were used to avoid the presence of silicone rubber.

Sediment was collected during low tide from the top $10 \mathrm{~cm}$ of an intertidal mudflat in the Dutch Wadden Sea, at approximate location N $52^{\circ} 56.112$ E $004^{\circ} 59.976$, and transported directly to the laboratory of Wageningen Marine Research, Den Helder, The Netherlands. Sediment was subsequently sieved over a $1 \mathrm{~mm}$ sieve to remove large organisms and particles, and thoroughly mixed by hand to create a homogeneous sediment. 
The microcosms were filled with a $5 \mathrm{~cm}$ thick layer of sediment, and a $15 \mathrm{~cm}$ layer of natural sea water $(0.45 \mu \mathrm{m}$ filtered Eastern Scheldt water) on top. The sediment was left to settle for one day prior to the start of the experiment.

The next day, day 0, the treatments as described in Section 4.2.2 were added to the microcosms. One day later (day 1), 40 Corophium volutator (amphipod), 20 Macoma balthica (bivalve), and 20 Hydrobia ulvae (gastropod) were randomly added to each microcosm. These test organisms were collected at the same time and location as the sediment, and were kept in the lab at $14{ }^{\circ} \mathrm{C}$ with natural sea water and aeration. The natural sediment already contained foraminifera.

Air was bubbled via two tubes with glass Pasteur pipette tips per microcosm in the top $5 \mathrm{~cm}$ of the water column, using an aquarium air pump. Microcosms were covered with acrylic plastic covers to minimize evaporation. Approximately once per week the water level was adjusted with demi water to compensate for evaporation.

In order to stimulate biodegradation of the oil, $1 \mathrm{~mL}$ at optical density 0.98 of Rhodococcus qingshengii TUHH-12 (DSMZ No. 46766), an alkane-degrading bacterial culture, and $1 \mathrm{~mL}$ at optical density 0.30 of Pseudomonas putida F1, an aromatic-degrading bacterial culture, were added to the water column of each microcosm at day 0. See Rahsepar et al. (2016) for the culturing procedure.

\subsubsection{Treatments}

Five treatments were tested in triplicate (Table 4.1). The Control treatment consisted of only a sediment layer. The Oil treatment consisted of oil mixed with clay particles to let the oil settle on top of the sediment. As a control for this treatment, a Clay only treatment was included with the same amount of suspended clay. The Snow+Oil treatment included artificial marine snow plus oil mixed with clay. As a control, the Snow treatment was the same but without oil. The clay was needed to make the marine snow and oil negatively buoyant. With the clay no floating oil and/or marine snow were visible neither on the surface nor in the water column. In addition to the five treatments in triplicate as mentioned above, in which invertebrate survival was tested for 16 days, a second set of 6 microcosms was run in parallel with only the Oil and Snow +Oil treatments, used for oil biodegradation sampling. These microcosms in Set 2 had to be separate from the microcosms in Set 1, since taking sediment samples for oil biodegradation analysis from the same microcosms would interfere with the final observations of invertebrate survival. The microcosms in Set 2 ran for 42 days, and samples were taken on day 1, 8, 16, 30, and 42, using the method described in Chapter 3. 
Marine snow enhances the adverse effects of oil on benthic invertebrates

Table 4.1: Test treatments for the Microcosm Experiment. Artificial marine snow was composed of alginate, phytoplankton biomass, and kaolin clay.

\begin{tabular}{|c|c|c|c|c|c|}
\hline & Treatment description & Treatment code & Oil & Kaolin clay & $\begin{array}{c}\text { Alginate and } \\
\text { phytoplankton biomass }\end{array}$ \\
\hline \multirow{5}{*}{$\begin{array}{c}\text { Set 1: } \\
\text { In vivo observations }\end{array}$} & Control & Control & & & \\
\hline & Kaolin clay & Clay & & $\checkmark$ & \\
\hline & Marine snow & Snow & & $\checkmark$ & $\checkmark$ \\
\hline & Oil and kaolin & Oil & $\checkmark$ & $\checkmark$ & \\
\hline & Marine snow and oil & Snow+Oil & $\checkmark$ & $\checkmark$ & $\checkmark$ \\
\hline \multirow{2}{*}{$\begin{array}{c}\text { Set 2: } \\
\text { Biodegradation sampling }\end{array}$} & Oil and kaolin & Oil/B & $\checkmark \checkmark$ & $\checkmark$ & \\
\hline & Marine snow and oil & Snow + Oil/B & $\checkmark$ & $\checkmark$ & $\checkmark$ \\
\hline
\end{tabular}

\subsubsection{Test treatment preparation}

Artificial marine snow was used as an approximation of natural marine snow, since it was not feasible to create natural marine snow in the amounts needed for this study. To mimic the labinduced EPS containing alginate-like exopolysaccharides (van Eenennaam et al., 2016), we used commercially available alginate, a gelling and nontoxic anionic polysaccharide, to create artificial marine snow with the addition of phytoplankton and kaolin clay particles, with or without oil.

Artificial marine snow was prepared for per three replicates as one batch, by slowly adding 22.5 $\mathrm{g}$ alginate (alginic acid sodium salt, CAS 9005-38-3, Arcos Organics; $7.5 \mathrm{~g}$ for each microcosm replicate) to $1.1 \mathrm{~L}$ filtered natural sea water, while stirring. Then, $19 \mathrm{~g}$ fresh weight of phytoplankton biomass (Chlorella paste, Ingepro BV, Borculo, The Netherlands; $6.3 \mathrm{~g}$ for each microcosm replicate) and $9.45 \mathrm{~g}$ kaolin clay (hydrated aluminum silicate, CAS 1332-58-7, Sigma Aldrich; $3.15 \mathrm{~g}$ for each microcosm replicate) were added. Next, 13 liter of a $14.5 \mathrm{~g} \mathrm{~L}^{-1} \mathrm{CaCl}_{2}$ (CAS 10043-52-4, Fluka Analytical) in demi-water solution was quickly added to the alginatephytoplankton-clay mix, and shaken by hand a few times. The calcium caused the alginate to coagulate, incorporating the phytoplankton and clay particles in precipitated marine-snow-like flocks. The overlying liquid was poured off before dividing the marine snow into three equal parts for the microcosm triplicates. For the Snow+Oil treatments, $9.45 \mathrm{~g}$ kaolin clay was first mixed with $1.9 \mathrm{~g}$ oil (0.63 $\mathrm{g}$ for each microcosm replicate) and some demi water into a homogeneous slurry before adding it to the alginate-phytoplankton mix. The marine snow was gently added to the microcosms in order to evenly cover the sediment with a $1 \mathrm{~cm}$ thick layer.

The replicates of the Clay treatment were individually prepared. For this, $3.15 \mathrm{~g}$ kaolin clay was mixed with approximately $500 \mathrm{~mL}$ water from the microcosm and this suspension was then poured into the microcosms. The clay settled homogeneously on top of the sediment in a layer that was $<0.5 \mathrm{~mm}$ thick.

The replicates of the Oil treatment were also individually prepared, by mixing $3.15 \mathrm{~g}$ kaolin clay with $0.63 \mathrm{~g}$ oil and some demi water. Then, the suspensions were added to the microcosms.

In all oil exposures, there was an oil load per microcosm of $0.63 \mathrm{~g}$ per $625 \mathrm{~cm}^{2}$, which is equivalent to $10 \mathrm{~g} \mathrm{~m}^{-2}$. The 'Surrogate Macondo oil' that was used was kindly provided by BP, 64 
and is chemically similar to the oil from the Macondo oil well involved in the DWH oil (BP Gulf Science Data, 2017b). The oil was weathered for $24 \mathrm{~h}$ in the dark at room temperature, while stirring on a magnetic stirrer, to allow evaporation of lighter hydrocarbons. These lighter hydrocarbons, including aromatics, are the main cause for toxicity, therefore weathering reduces the toxicity of the oil (Brils et al., 2002). Since the oil incorporated in marine snow aggregates during the MOSSFA event also have been weathered substantially due to evaporation and dissolution, using weathered oil in the microcosm experiment gives a more realistic toxicity scenario than using fresh oil.

\subsubsection{Water quality parameters}

During the experiment, the following water quality parameters were regularly monitored in the middle of the water column: $\mathrm{pH}(-)$, temperature $\left({ }^{\circ} \mathrm{C}\right)$, salinity $(\% 0)$, dissolved oxygen saturation level (\%). A Mettler Toledo $\mathrm{pH}$ meter was used to measure $\mathrm{pH}$, and the other parameters were measured with a Hach HQ40d multimeter using salinity and dissolved oxygen probes. Both meters were calibrated prior to each measuring day. Oxygen Sensor Spots (PSt3, PreSens Precision Sensing GmbH, Regensburg, Germany) and a handheld Fibox 4 Optical Oxygen Meter (PreSens Precision Sensing GmbH, Regensburg, Germany) were used to monitor local concentrations of dissolved oxygen above and below the sediment-water interphase without disturbing the sediment integrity. Sensor spots were glued to the glass wall at four locations in Snow and Snow+Oil treatments, and because of practical reasons at only three locations in Oil, Clay, and Control.

\subsubsection{Biodegradation sampling}

The method to sample sediment over time for oil biodegradation analysis is the same as described in Chapter 3. In short, a glass tube with a diameter of $2 \mathrm{~cm}$ was inserted into the sediment to the bottom of the microcosm, from which the sediment was collected. The tubes were left in the microcosms until the end of the experiment to minimize disturbance of the surrounding sediment and suspension of sediment particles in the water column. Per sampling four subsamples were combined to get a representative sample per microcosm. After removal of the overlying water, the pooled sediment samples were freeze-dried using a Christ Alpha 2-4 LDplus freeze dryer (Martin Christ Gefriertrocknungsanlagen GmbH, Osterode am Harz, Germany).

\subsubsection{Chemical analysis}

For chemical analysis, $5 \mathrm{~g}$ of freeze-dried sediment was extracted with $8 \mathrm{~mL}$ dichloromethane. An aliquot of the whole extract was first analyzed using GC-MS to check for the presence of the oil fingerprint. Then, the extract was separated to saturate and aromatic fractions, by loading onto a silica gel (0.6 g, 70-230 mesh) column, pre-washed with pentane, and eluting with $2 \mathrm{~mL}$ of pentane to obtain the saturate fraction, followed by elutions with $2 \mathrm{~mL}$ of dichloromethane 
and isopropyl alcohol, respectively, to obtain the aromatic fraction. The temperature program for the GC-MS analysis included a hold of $5 \mathrm{~min}$ at $40{ }^{\circ} \mathrm{C}$, followed by a $4{ }^{\circ} \mathrm{C} \mathrm{min}-1$ ramp up to $325{ }^{\circ} \mathrm{C}$, and finishing with an isothermal hold at $325{ }^{\circ} \mathrm{C}$ for 15 minutes. Separation was performed on a HP-5MS capillary column $(30 \mathrm{~m} \times 0.25 \mathrm{~mm} \times 0.25 \mu \mathrm{m})$, and helium was used as carrier gas, at a flow of $1.0 \mathrm{~mL} \mathrm{~min}^{-1}$. The mass spectrometer was acquiring data in a combined full scan/selected ion monitoring (SIM-SCAN) mode. SIM trace at $m / z, 85$ was used to integrate the areas of $n$-alkanes (C13-C30) and isoprenoid alkanes (pristane and phytane). Integrated areas were then normalized to the area of C30-hopane $(17 \alpha(\mathrm{H}), 21 \beta(\mathrm{H})$-hopane). C30-hopane is considered a conservative biomarker due to its recalcitrance to weathering (Prince et al., 1994). This normalization approach is typically used in oil spill studies to detect and compare compositional changes due to evaporation, biodegradation, and other weathering processes (Aeppli et al., 2014; Radović et al., 2014). Stability of C30-hopane was confirmed in Chapter 3, in batch experiments during 42 days.

\subsubsection{Biological observations and sampling procedure}

During the experiment, behavioral observations of the test organisms were done and photos of the microcosms were made. At day 16, a sample of approximately one table spoon was taken from the top $\mathrm{cm}$ sediment for foraminifera analysis. Then, the entire content of the microcosm was gently sieved over a $1 \mathrm{~mm}$ sieve to collect the test organisms. The organisms were counted and survival was assessed. H. ulvae were put on a glass petri-dish and inspected for movement. M. balthica were put on a glass petri-dish and observed for visible siphons to assess survival. After counting, the organisms were preserved in $4 \%$ formaldehyde buffered with borax (sodium tetraborate decahydrate, Sigma-Aldrich, CAS Number: 1303-96-4). The foraminifera samples were stained with $2.5 \mathrm{~mL}$ of $3.3 \mathrm{mg} \mathrm{L}^{-1}$ rose Bengal (purity 95\%, Sigma-Aldrich, CAS Number: 632-69-9) and preserved in 4\% formaldehyde. Living (stained) and dead (unstained) foraminifera were counted using a binocular microscope.

\subsubsection{Statistical analysis}

GraphPad Prism 5 was used to draw graphs and perform statistical analysis using one-way ANOVA with post-hoc Tukey's test or two-way ANOVA with Bonferroni multiple comparisons post-test.

\subsection{Results}

\subsubsection{Water quality}

The water quality parameters temperature, $\mathrm{pH}$, and salinity were measured in the water column (Figure S 4.1). The temperature remained stable at $14.4 \pm 0.2{ }^{\circ} \mathrm{C}$, without significant differences between any of the treatments. There was no difference in salinity between any of the treatments over the course of the experiment; salinity was stable at $33.5 \pm 0.7 \%$ throughout the experiment. 
Overall, the $\mathrm{pH}$ was stable at $8.26 \pm 0.19$. However, in the Snow and Snow+Oil treatments, $\mathrm{pH}$ was slightly, but statistically significant, lower than in the other treatments on day 3 and 10.

The dissolved oxygen saturation, measured halfway in the water column, was $97.7 \pm 3.8 \%$ in all microcosms during the entire experiment, indicating no oxygen depletion in the water column. However, subtle decreases in the treatments with marine snow were observed on days 3-10 (Figure 4.1): oxygen saturation, expressed relative to the Control treatment at each day, was significantly lower in both marine snow treatments. On day 15 , oxygen saturation was similar again in all microcosms. In addition to dissolved oxygen in the water column, the vertical oxygen profile in the water just above the sediment layer, and in sediment layer itself was measured with Oxygen Sensor Spots on day 1, 8, and 15 (Figure 4.2, Figure S 4.2, Figure S 4.3). In the Snow and Snow+Oil treatments on day 1, the oxygen saturation in the marine snow layer just above the sediment interface was lower than in the Oil treatment: $\sim 40 \%$ vs $\sim 90 \%$. At day 8 and 15 , the oxygen saturation just above the sediment interface in Snow and Snow + Oil increased again to levels comparable to day 1.

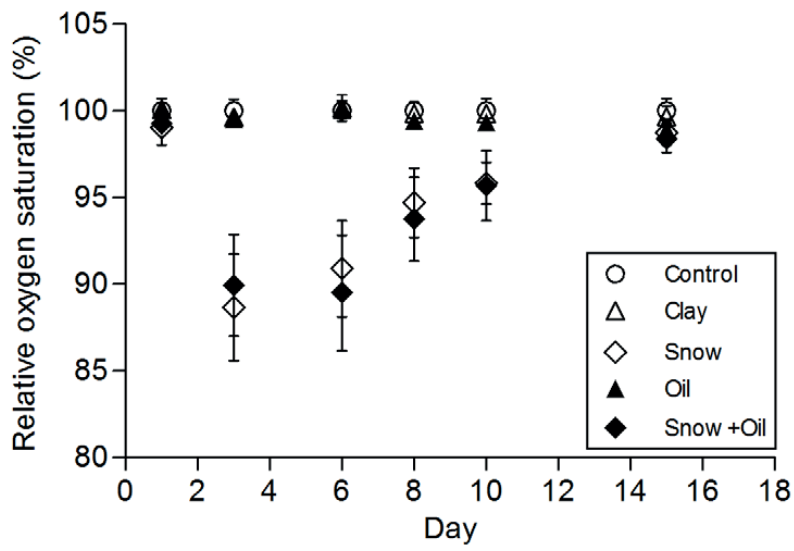

Figure 4.1: Dissolved oxygen saturation (\%) in the water column during the 16 day experiment, relative to Control of each day (average and standard deviation of triplicate microcosms, except Control day 8: duplicate). 


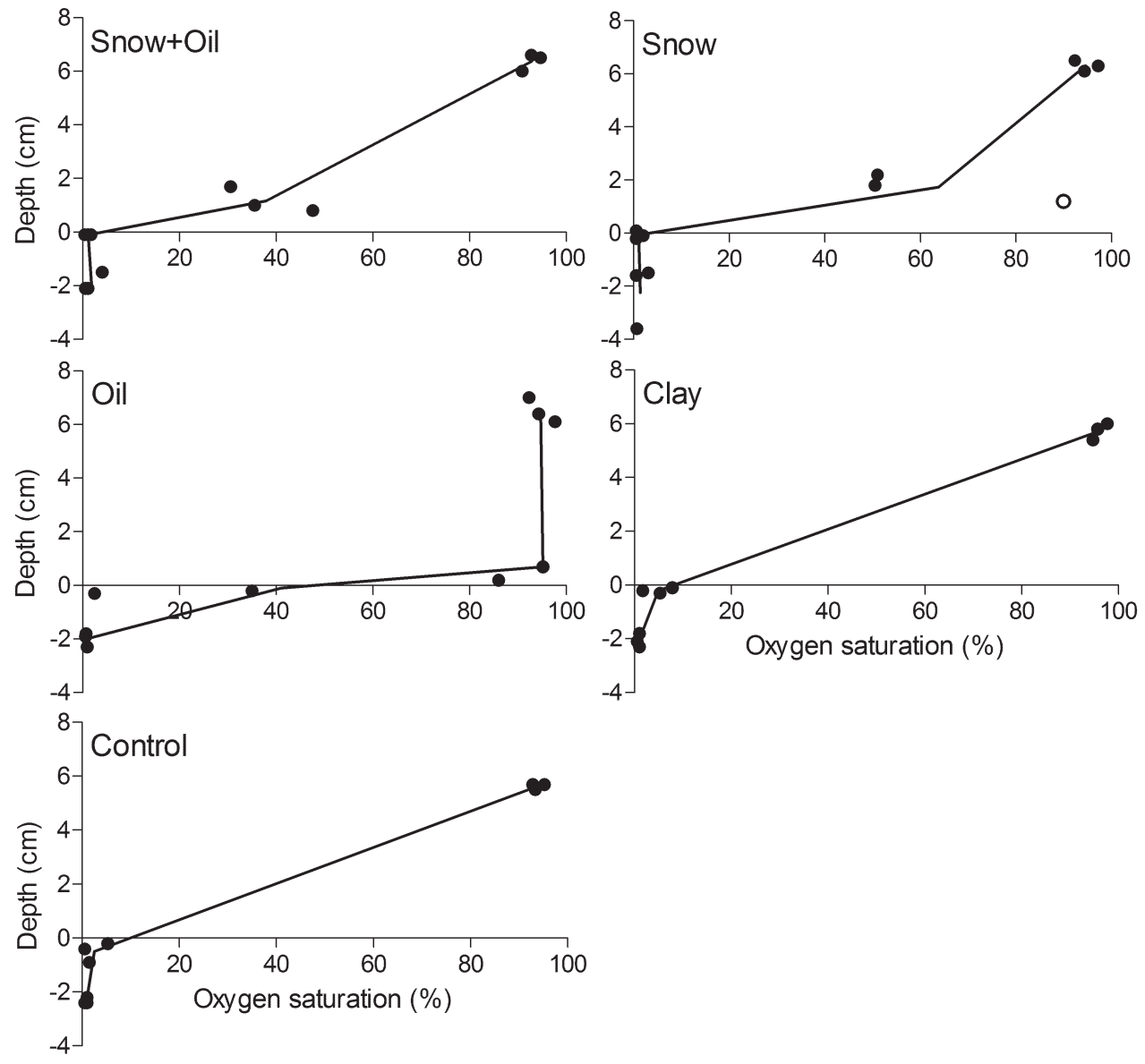

Figure 4.2: Oxygen saturation profiles of the microcosms at day 1. Depth refers to relative position of each Oxygen Sensor Spot to the sediment-water interface at $0 \mathrm{~cm}$. The data points are individual measurements of three replicate microcosms. The black line is the average of the three replicates. The open circle in the Snow graph represents an Oxygen Sensor Spot that was located above the marine snow layer, while the other two Oxygen Sensor Spots at similar depth were inside of the marine snow layer. For this reason, the oxygen saturation at this location was much higher than at the other two locations.

\subsubsection{Chemical analysis}

Clean sediment from the Control treatment contained background levels of $n$-alkanes, however, they were showing distribution characteristic of natural biogenic input (i.e. odd over even preference), such as algae (Gelpi et al., 1970; Weete, 1976). On the contrary, in the oil containing treatments, $n$-alkanes were showing the typical unimodal distribution peaking at $n$-C17, characteristic of light oils, such as Macondo oil (Figure 4.3, Figure S 4.4). There was no difference 
in $n$-alkane and isoprenoid alkane hopane normalized peak areas on day 1 between Snow + Oil and Oil. However, on day 42, the normalized peak areas are much lower for both treatments compared to day 1 and a clear difference between the Snow + Oil and Oil treatments is observed. There is $61 \%$ biodegradation after 42 days in Snow+Oil, compared to $83 \%$ degradation in Oil (Table 4.2), indicating inhibition of oil degradation related to the presence of marine snow. In addition, a preferred degradation of the short chain $n$-alkanes compared to the long chain $n$ alkanes is obvious. In both treatments, the majority of degradation took place between day 8 and day 16 (Table 4.2), with 18\% degradation between day 1 and day 8 in absence of marine snow and hardly any degradation in the presence of marine snow.
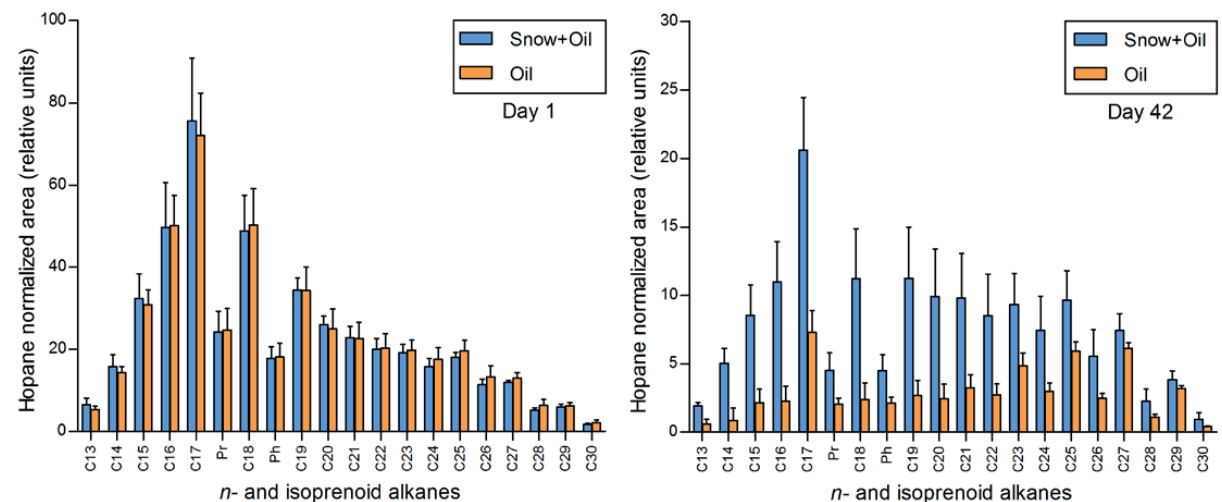

Figure 4.3: Hopane-normalized peak areas for $n$-alkanes and isoprenoid alkanes (pristane and phytane) on day 1 (left) and day 42 (right) (average with standard deviations of triplicates).

Table 4.2: Relative oil biodegradation over four time ranges. Data from this study, and calculated based on data from Chapter 3: a similar microcosm experiment with artificial marine snow, without benthic macroinvertebrates.

\begin{tabular}{lllll}
\hline \multicolumn{5}{c}{ Relative oil biodegradation (as decrease of C13-C30 relative peak areas compared to day 1) } \\
\hline \hline Day range & $\begin{array}{l}\text { Oil } \\
\text { (this study) }\end{array}$ & $\begin{array}{l}\text { Snow+Oil } \\
\text { (this study) }\end{array}$ & $\begin{array}{l}\text { Oil } \\
\text { (Chapter 3) }\end{array}$ & $\begin{array}{l}\text { Snow+Oil } \\
\text { (Chapter 3) }\end{array}$ \\
\hline $\mathbf{1 - 8}$ & $18 \%$ & $1 \%$ & & \\
\hline $\mathbf{8 - 1 6}$ & $51 \%$ & $27 \%$ & $49 \%$ & $9 \%$ \\
\hline $\mathbf{1 - 1 6}$ & $69 \%$ & $28 \%$ & $17 \%$ & $26 \%$ \\
\hline $\mathbf{1 6 - 4 2}$ & $14 \%$ & $33 \%$ & $66 \%$ & \\
\hline \hline $\begin{array}{l}\text { Total oil biodegradation } \\
\text { over 42 days }\end{array}$ & $83 \%$ & $61 \%$ & & $17 \%$ \\
\hline
\end{tabular}




\subsubsection{General in vivo observations}

Throughout the 16 days of the in vivo experiment, the water in the microcosms with Oil stayed clear, while the water in Control and Clay turned turbid after three days. The microcosms with marine snow were more turbid than the others and had a dense fouling layer on the glass. After 6 days, the marine snow layer became thinner and a white and black layer, possibly fungi, covered parts of the surface. After 16 days, the thickness of the oxygenated top layer was relatively thick $(\sim 5 \mathrm{~mm}$ or more, indicated by the yellow box in Figure $4.4 \mathrm{~A})$ in both Clay and Control treatments, with visible bioturbation activity. In contrast, in the Oil treatment the oxygenated layer was thinner $(\sim 2 \mathrm{~mm})$ without visible burrowing behavior and $H$. ulvae tracks on the sediment and the glass microcosm wall (Figure 4.4B). No oxygenated top layer was observed in the microcosms of treatments Snow and Snow+Oil, except where the marine snow layer did not completely cover the sediment due to a non-homogeneous marine snow layer (Figure 4.4C, Annex S 4.4).

\subsubsection{Invertebrate survival}

In the Control treatment, 25 out of 40 C. volutator, 13 out of $28 \mathrm{H}$. ulvae, and 17 out of $19 \mathrm{M}$. balthica were recorded alive after 16 days. For all three species, the survival in the Clay treatment was not significantly different from the Control treatment.

The survival percentage of $C$. volutator was significantly $(\phi<0.05)$ lower in Oil and Snow + Oil treatments, relative to Control ( $9 \%$ and 20\% respectively, Figure 4.5, top panel). Snow without oil also reduced the relative percentage of surviving C. volutator to $69 \%$, but this effect was not statistically significant.

The survival percentage of $H$. ulvae did not differ significantly between treatments (Figure 4.5, middle panel); however there is a trend of lower $H$. ulvae survival in the Snow+Oil treatment, but not in Oil or Snow separately. In the Oil treatment, more H. ulvae were attached to the glass wall or floating at the water surface than in the other treatments.

M. balthica survival was reduced in the Snow and Snow+Oil treatments (Figure 4.5, bottom panel). Survival in Snow+Oil was lower than either Snow or Oil separately (21\% compared to $32 \%$ and $102 \%$, respectively), and was significantly different from the Control treatment $(p=$ 0.041 ) but not from Snow $(p=0.984)$.

The ratio between living and dead foraminifera after 16 days was $0.28 \pm 0.09$ in the Control treatment. This ratio was significantly reduced by $68 \%, 78 \%$ and $90 \%$ in Oil, Snow, and Snow+Oil treatments, respectively, compared to Control (Figure 4.6). 

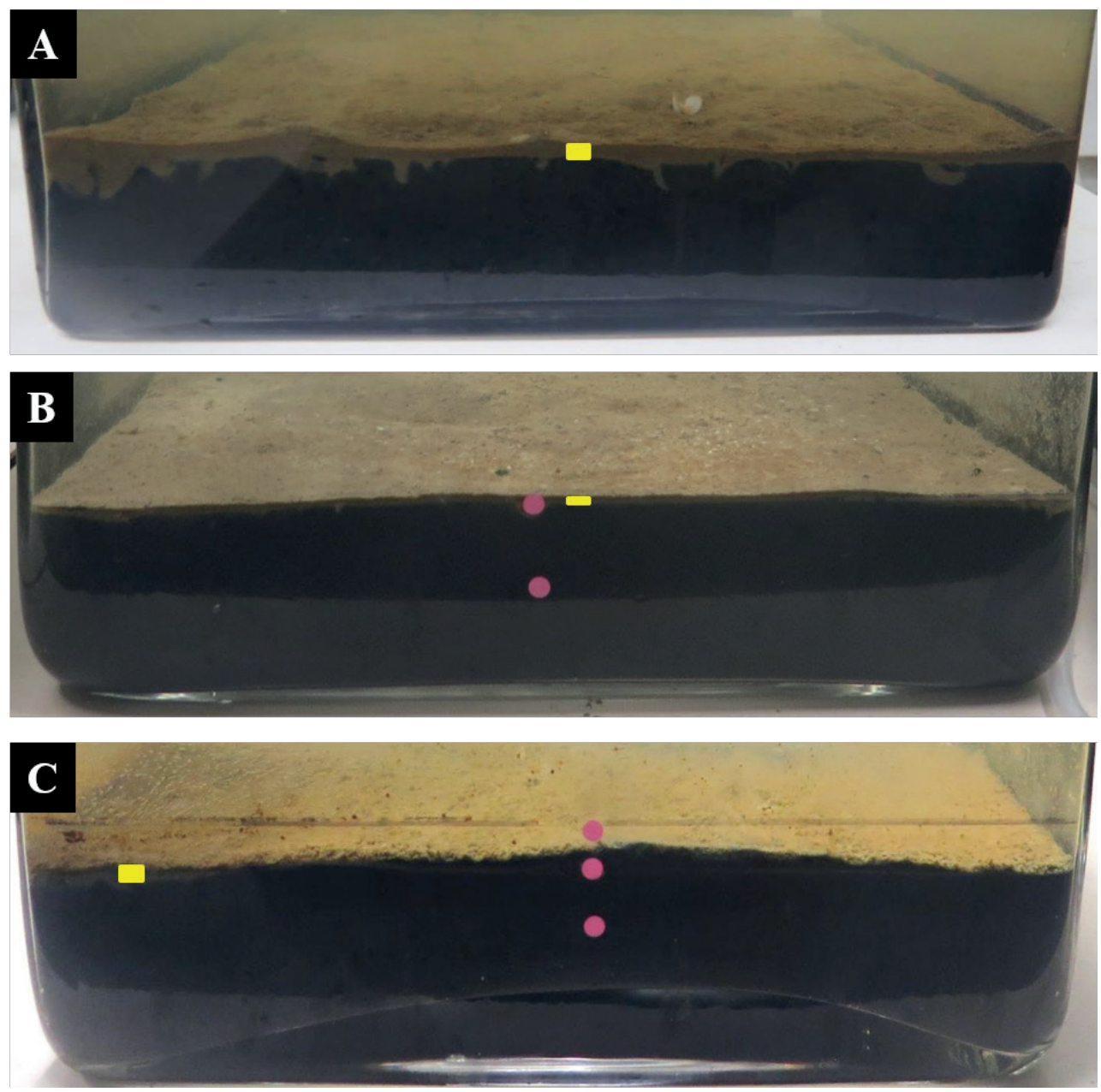

Figure 4.4: Examples (at day 16$)$ of a thick ( $\sim 5 \mathrm{~mm}$ or more) oxygenated layer of a Control microcosm with abundant visible burrowing activity $(\mathrm{A})$, and a thin $(\sim 2 \mathrm{~mm})$ oxygenated layer of an Oil microcosm without visible burrowing activity (B). No oxygenated layer was present in microcosms with Snow + Oil (C), except for a patch in the left corner where no marine snow was accumulated. The height of the yellow boxes indicate the thickness of the oxygenated layer. The pink dots in B and C are the Oxygen Sensor Spots. 


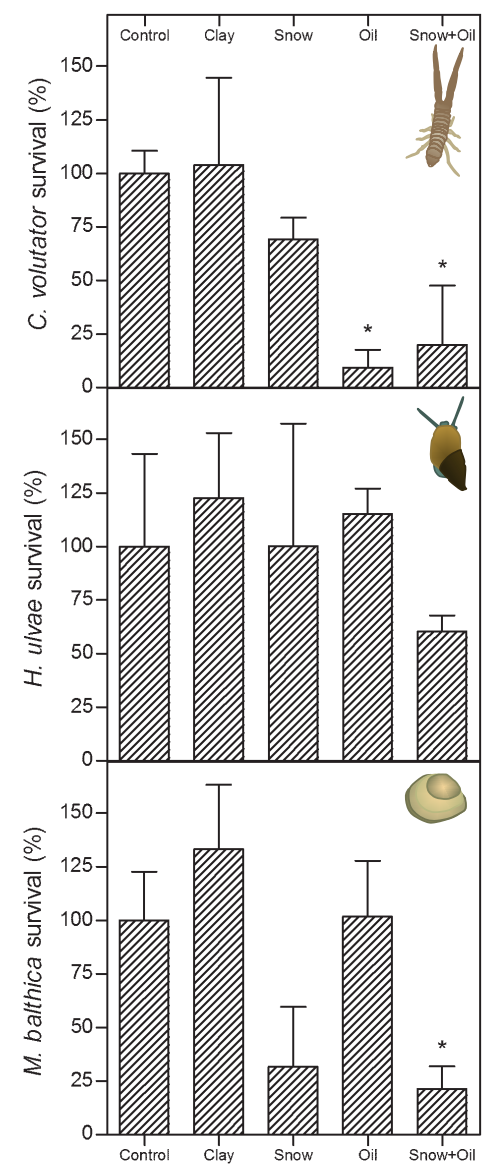

Figure 4.5: Survival of C. volutator (top panel), H. ulvae (middle panel), and M. balthica (bottom panel) after 16 days exposure, compared to Control (100\%) (average and standard deviation of triplicate microcosms. $*$ indicates statistically significant difference from Control at $p<0.05)$.

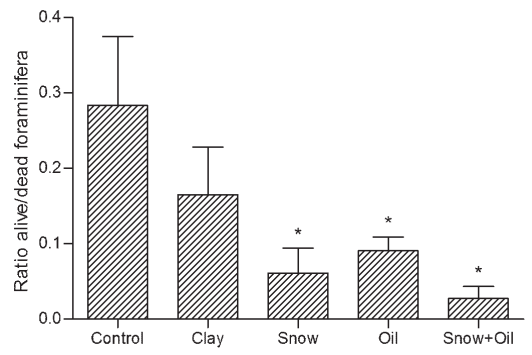

Figure 4.6: Ratio of alive/dead foraminifera after 16 days (average and standard deviation of triplicate microcosms. ${ }^{*}$ indicates statistically significant difference from Control at $\left.p<0.01\right)$. 


\subsection{Discussion}

This study presents the impact of marine snow on the toxic effects of slightly weathered crude oil on marine benthic invertebrates and the biodegradation of the oil. Three single species and one naturally occurring community of species were studied: an infaunal deposit and suspension feeding amphipod (Coropbium volutator), an epifaunal deposit feeding and grazing gastropod (Hydrobia ulvae), an infaunal deposit and suspension feeding bivalve (Macoma balthica), and epiand infaunal deposit and suspension feeding foraminifera. This combination of organisms covers main benthic niches to represent the benthic ecotoxic effects. Our results reveal that the main driving factors for the responses to oil and marine snow are vulnerability for hypoxia, motility, habitat, and feeding habit. The ultimate net effect of oil-contaminated marine snow will be a balance between these different driving factors, determined by differences in traits of the species.

Hypoxia, defined as dissolved oxygen concentrations of generally lower than $2 \mathrm{mg} \mathrm{L}^{-1}$ (Dale et al., 2010), can be caused by degradation of marine snow, which consumes oxygen in the sediment and the water column just above the sediment (Figure 4.2), ultimately resulting in a complete disappearance of an oxygenated top layer (Figure 4.4). Hypoxia did not occur higher in the water column (Figure 4.1), due to the bubbling of air in the top $5 \mathrm{~cm}$ of the water column. The lower $\mathrm{pH}$ and concomitant lower oxygen saturation in the water column in the first 10 days of the exposures with marine snow indicate that there was a slight acidification due to increased respiration.

Motility determines whether the organisms are able to escape unfavorable conditions, like hypoxia and toxicity, which can drive infaunal species, such as $C$. volutator, out of their infaunal habitat into the water column. Sedentary species, such as $M$. balthica, experience more severe effects of oil spills than motile species (Fisher et al., 2016; Lee and Lin, 2013) because of their inability to escape adverse conditions.

Organisms that are likely to use the marine snow as food source could actively expose themselves to the oil by consumption of oil-contaminated marine snow. This was the case in our experiments with $H$. ulvae, who were able to escape the oil by climbing onto the glass wall, but apparently decided to eat the oiled marine snow. The artificial marine snow used in our study consisted of alginate, which is a nontoxic anionic polysaccharide, and phytoplankton biomass plus clay to make it negatively buoyant. Therefore marine snow is a suitable food source for especially grazers and deposit/suspension feeders.

\subsubsection{Differential organismal responses to oil and marine snow}

The four invertebrate species responded in different ways to the benthic exposure to oil and marine snow, related to their biological traits. 
Corophium volutator

The amphipod C. volutator is a deposit and suspension feeder with high motility, and high sensitivity to oil (Foekema et al., 1996; Wake, 2005). In general, crustaceans are more sensitive to oil than other aquatic organisms (Anderson et al., 1974; Gesteira and Dauvin, 2000; Lee et al., 1977; Wake, 2005). C. volutator is sensitive to hypoxia, as was observed both in field as well as in laboratory experiments (Gamenick et al., 1996; van den Heuvel-Greve et al., 2007). The amphipods are typically burrowed in the sediment, but in adverse conditions like low sediment oxygen, they can escape by swimming in the water column. In our experiment, the organisms indeed escaped from the low oxygen saturation at the sediment-water interface due to the presence of marine snow. Even though they escaped the sediment, the survival was still reduced by $31 \%$, to $69 \%$ compared to Control in the treatment with marine snow (Figure 4.5). In contrast, the organisms did not escape to the water column when exposed to only oil, because there was no hypoxia caused by marine snow. As a result, survival was severely reduced to $9 \%$ of Control due to oil toxicity. The combination of oil and marine snow led to a low survival of $20 \%$. Most likely, the organisms escaped the low oxygen situation in the marine snow layer and thus reduced direct exposure to oil. Possibly, the organisms have been feeding on the oilcontaminated marine snow, given the additional 49\% decrease in survival in this treatment compared to the treatment with clean marine snow, although direct contact with the oil cannot be excluded.

\section{Hydrobia ulvae}

The epifaunal deposit feeding and grazing gastropod H. ulvae is motile, highly tolerant to hypoxia (Gamenick et al., 1996), and less sensitive to oil than C. volutator and M. balthica (Wake, 2005). The response of $H$. ulvae in this study is driven by three factors: motility, tolerance to hypoxia, and feeding strategy. Firstly, H. ulvae avoided direct oil toxicity on the sediment by attaching to the glass wall of the microcosm and floating at the water surface, as observed in the treatments with oil. A similar response was observed in a mesocosm study (Chronopoulou et al., 2013) where H. ulvae were seen escaping experimentally oiled cores in mesocosms. Secondly, their high tolerance to hypoxia allowed $H$. ulvae to escape the low oxygen saturation in the marine snow layer, as can be seen by the high survival in the treatment with clean marine snow (Figure 4.5). Thirdly, H. ulvae are grazers and deposit feeders whose diet includes macro- and microalgae and detritus (Aberle et al., 2009) and thus are likely to feed on the marine snow. They will be orally exposed to oil when feeding on oil-contaminated marine snow, as is suggested by the low survival in the treatment with oil-contaminated marine snow: 60\% compared to Control (Figure 4.5). Longer exposure time and internal oil measurements can verify the possible pathway of oil towards organisms via marine snow as food source (Chapter 5).

\section{Macoma balthica}

The bivalve $M$. balthica is a deposit feeder with low motility, high vulnerability to hypoxia (Brafield, 1963), and lower sensitivity to oil than C. volutator (Wake, 2005). In this experiment, M. balthica was more affected by oxygen depletion than by the presence of oil. In our experiment, 
the main driving factor for mortality was the low oxygen saturation in the marine snow layer because of the inability of $M$. balthica to escape adverse conditions due to its low motility. Therefore, $M$. balthica suffered more from the low oxygen saturation in the marine snow layer than the other two, more motile, species (Figure 4.5). The survival in treatments with marine snow $(32 \%)$ and oil $(102 \%)$ separately was higher than in the combination of both: survival in the treatment with oil-contaminated marine snow was only $21 \%$ compared to Control. This indicates a synergistic effect, likely because of internal oil exposure due to the deposit feeding strategy of $M$. balthica. The oil, at $10 \mathrm{~g} \mathrm{~m}^{-2}$, did not reduce survival in the treatment with only oil (Figure 4.5). This is in line with the findings of Shaw et al. (1976), who performed a field mesocosm experiment with a simulated oil slick stranding at two oil loadings: $1.2 \mu \mathrm{cm}^{-2}$ and 5 $\mu \mathrm{cm}^{-2}$. At $1.2 \mu \mathrm{l} \mathrm{cm}^{-2}$, which corresponds to $10 \mathrm{~g} \mathrm{~m}^{-2}$ of oil at relative density 0.838 (BP Gulf Science Data, 2017b), there was no significant mortality to $M$. balthica, while high mortality was found at $5 \mu \mathrm{l} \mathrm{cm}-2\left(42 \mathrm{~g} \mathrm{~m}^{-2}\right)$.

\section{Benthic foraminifera}

Benthic foraminifera are used as indicators for sediment hypoxia because of their high sensitivity to changes in oxygen concentration (Dale et al., 2010). Our finding that oil and marine snow negatively affected the survival of the natural benthic foraminiferal community is in line with field studies in the Gulf of Mexico after the DWH spill, which found that the decrease in benthic foraminiferal diversity and density was related to the spill and the MOSSFA event (Schwing et al., 2016; Schwing et al., 2015). Internal oil measurements in the foraminifera tests could shed more light on the uptake of oil components by these organisms.

\subsubsection{Effects of marine snow and benthic invertebrates on oil biodegradation}

The current study with benthic invertebrates is a follow-up of the microcosm study described in Chapter 3, in which the effect of marine snow on oil biodegradation in the sediment layer was studied. We can now compare biodegradation with and without the influence of invertebrates.

Oil biodegradation in our experiment was reduced in the presence of marine snow (Figure 4.3, Table 4.2), which is in accordance with the results of Chapter 3, in a similar microcosm experiment without invertebrates. Most likely, preferential oxygen consumption by the degrading marine snow competes with oxygen consumption for oil degradation, thus inhibiting oil degradation. In the present study, the majority of the oil biodegradation takes place between day 8 and day 16 (Table 4.2), and a striking difference is visible during day 1-8: hardly any oil degradation takes place in microcosms with marine snow. This is in line with the hypothesis that marine snow consumes oxygen during degradation and thus inhibits oil degradation. Compared to Chapter 3, there is more oil biodegradation in the presence of benthic invertebrates (Figure 4.7, Table 4.2): after 42 days, $83 \%$ of the oil (without marine snow) is degraded in presence of invertebrates, versus $66 \%$ without invertebrates. In the treatment with oil-contaminated marine snow, $61 \%$ of oil is degraded in the presence of the invertebrates, versus $26 \%$ without invertebrates. The reduction in oil biodegradation due to marine snow was $22 \%$ in the present 
study, compared to $40 \%$ in the experiment of Chapter 3. Apparently, the benthic invertebrates stimulate the degradation of oil with and without marine snow. In addition, they partly counterbalance the negative effect of marine snow on oil biodegradation, most likely due to their burrowing behavior. Especially the amphipod C. volutator is an important bioturbator, who thoroughly mixes the top layer of the sediment. Bioturbation enhances oxygen penetration into the sediment and transport of compounds from anoxic layers to the oxic top layer (Pelegrí and Blackburn, 1994).

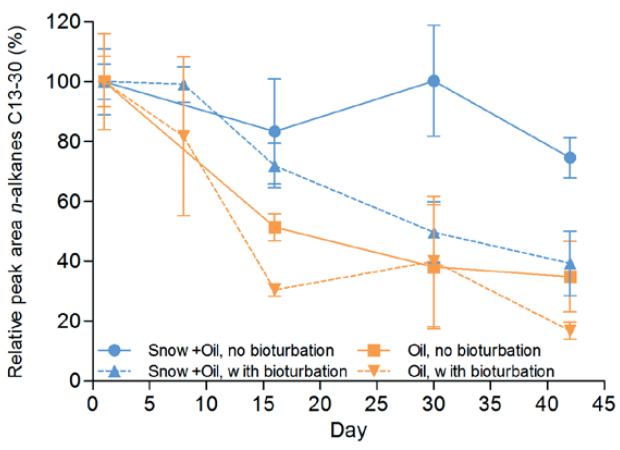

Figure 4.7: Relative peak area of $n$ - and isoprenoid alkanes C13-C30. Solid lines: data from Chapter 3, microcosm experiment with marine snow and oil, no benthic macroinvertebrates. Dotted lines: data from this study, microcosm experiment with marine snow and oil, with benthic macroinvertebrates (average and standard deviation of triplicate microcosms).

C. volutator is able to increase the oxic sediment volume by as much as $150 \%$ at high densities (Hylleberg and Henriksen, 1980). The oxygenated top layer in microcosms with only oil was thinner than in the control microcosms ( $2 \mathrm{~mm}$ vs $5 \mathrm{~mm}$ ), while the layer was completely absent in the microcosms with marine snow, either with or without oil (Figure 4.4). Lower oxygen concentrations in the sediment without benthic invertebrates hamper the oil biodegradation, compared to sediment with invertebrates.

\subsubsection{The field relevance of the artificial marine snow and oil exposure concentration used}

Marine snow is a complex material, including EPS (polysaccharides), organic debris, phytoplankton, and suspended particles. To be able to produce large quantities of reproducible marine snow, we developed a method to create flocks of artificial marine snow that resembled the marine snow that was found in the Gulf of Mexico, using commercially available alginate, phytoplankton paste, and kaolin clay. The artificial marine snow we produced contained all ingredients considered essential in the MOSSFA process in the field situation during the DWH oil spill (Daly et al., 2016): alginate-like exopolysaccharides (van Eenennaam et al., 2016), phytoplankton biomass (Hu et al., 2011; O'Connor, 2013), and mineral particles (Bianchi et al., 2011). 
Interestingly, the homogeneity of the marine snow layer is an important factor that drives organism behavior. Small deviations of homogeneous coverage of sediment with marine snow, led to significant spatial differences in the survival of $C$. volutator. Two of the replicate microcosms in the treatment with oil-contaminated marine snow had just one living $C$. volutator left, while the other replicate had 13 living individuals. The microcosm with the high survival rate had a clearly unequal distribution of the marine snow layer, leaving a patch of approximately $5 \times 5 \mathrm{~cm}$ in one corner uncovered (Annex S 4.4). This served as a refuge for C. volutator to escape the oxygen limiting effects of marine snow and oil. We observed that indeed this patch had an oxygenated top layer and visible burrowing activity of $C$. volutator, while the rest of the microcosm did not (Figure S 4.7). In the field situation, oil deposition by MOSSFA on the sea floor is highly patchy (Daly et al., 2016). Uncovered patches can help organisms avoid the adverse conditions of covered patches thus aiding the survival and later recovery. Less motile species will recover slower than species that can migrate to clean locations. The gastropods in our experiment were able to use the microcosms walls as a refuge, but our results also suggest that they were attracted by the nutritional value of the marine snow, leading to elevated oil exposure.

Approximately $99 \%$ of the oil-contaminated area in the Gulf of Mexico contained less than $1 \mathrm{~g}$ $\mathrm{m}^{-2}$ of oil, and $0.7 \%$ of the area contained $11-43 \mathrm{~g} \mathrm{~m}^{-2}$ (Romero, personal communication). The oil loading we used in the microcosms, $10 \mathrm{~g} \mathrm{~m}^{-2}$, is at the upper limit of what is found in the field, so it is a plausible worst-case scenario. However, in the field situation exposure of organisms will be more chronic than the 16 days exposure in our experiments. It is to be expected that invertebrates that can survival fasting during 2 weeks will start eating oiled marine snow upon fasting for a longer period.

\subsubsection{Ecosystem implications of MOSSFA}

The ecological consequences of the MOSSFA event on an ecosystem scale are not yet fully understood. It is, however, anticipated that the effects will be long-lasting (Bik et al., 2012; Daly et al., 2016). Changes in the benthic microbial communities can reduce the carbon flow to higher trophic levels, which affects zooplankton and fish species (Ortmann et al., 2012) and in turn may lead to long-term effects in higher food webs (Bik et al., 2012).

This study, with representative species of the benthic system, demonstrates that interactions between marine snow and oil on biodegradation can be synergistic, and the impact on benthic organisms depends on their biological traits. Main driving factors for organismal response to marine snow and oil are motility, vulnerability to hypoxia and oil toxicity, and feeding habits. Situations with large amounts of suspended solids and high primary production, such as high river discharge periods and during algae blooms in spring time, are especially vulnerable to triggering a MOSSFA event (Daly et al., 2016), especially when dispersants are used excessively (van Eenennaam et al., 2016). These detrimental additional effects of dispersant application for the benthic ecosystem should be considered when deciding on oil spill response methods. The physical, chemical, and biological circumstances of the marine environment during an oil spill 
should be known to assess whether a MOSSFA event is likely to occur when dispersants are applied. Baseline data on benthic communities and monitoring programs are needed for the assessment of environmental effects of sedimented oil, and to track recovery of ecosystems over time.

\section{Acknowledgments}

This research was made possible in part by a grant from the Gulf of Mexico Research Initiative (Grant Contract \#SA 12-10/GoMRI-007), and in part by the Wageningen UR TripleP@Sea innovation Program (KB-14-007). Jagoš R. Radović and Thomas B.P. Oldenburg also acknowledge the support from the Canada Foundation for Innovation (CFI), the Natural Sciences and Engineering Research Council of Canada (NSERC) and Canada Research Chairs (CRC), PRG and the University of Calgary. Data are publicly available through the Gulf of Mexico Research Initiative Information \& Data Cooperative (GRIIDC) at https://data.gulfresearchinitiative.org/ (doi:10.7266/N7T72FJK). Practical assistance by Yulia Kuvshinova and graphics by Nina Rudigkeit are gratefully acknowledged. 


\subsection{Annex to Chapter 4}

S4.1: Water quality measurements

Figure S 4.1

S4.2: Oxygen saturation profiles

Figures S $4.2-$ S 4.3

S 4.3: Hopane normalized $n$-alkane and isoprenoid alkane peak areas

Figure S 4.4

S 4.4: Photographs of Artificial Marine Snow layer

Figures S 4.5 - S 4.7 
S4.1: Water quality measurements
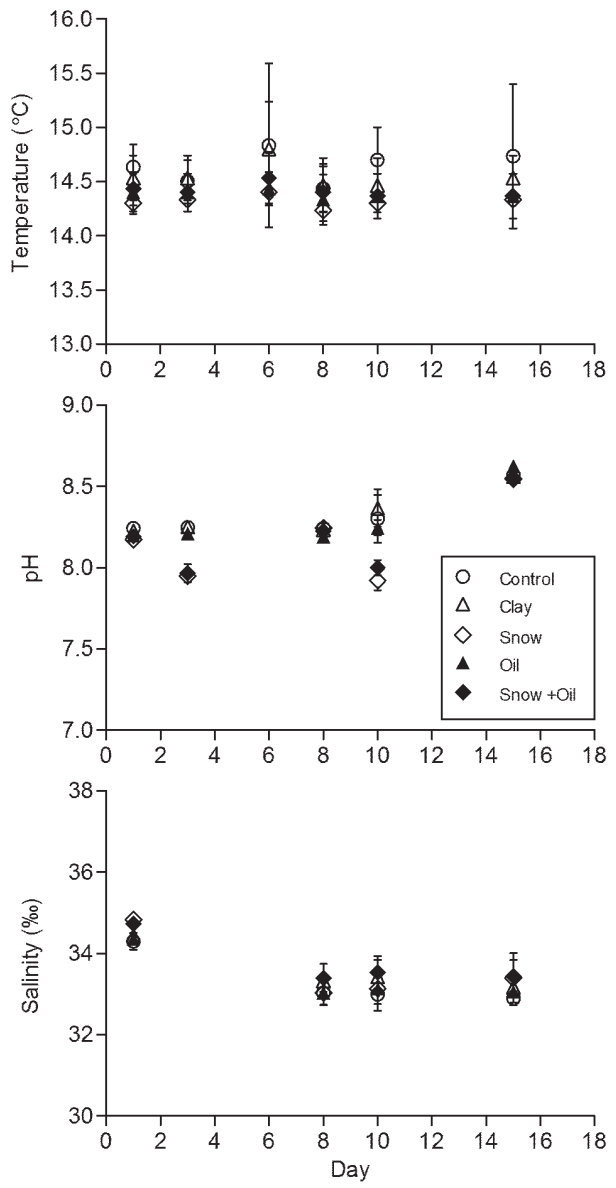

Figure S 4.1: Water column measurements of temperature $\left({ }^{\circ} \mathrm{C}\right.$, top panel), $\mathrm{pH}$ (middle panel), and salinity (\%o, bottom panel). Averages and standard deviation of triplicates. Salinity at day 3 and 6 was measured with an incorrectly calibrated salinity probe, hence the higher values. 
S4.2: Oxygen saturation profiles

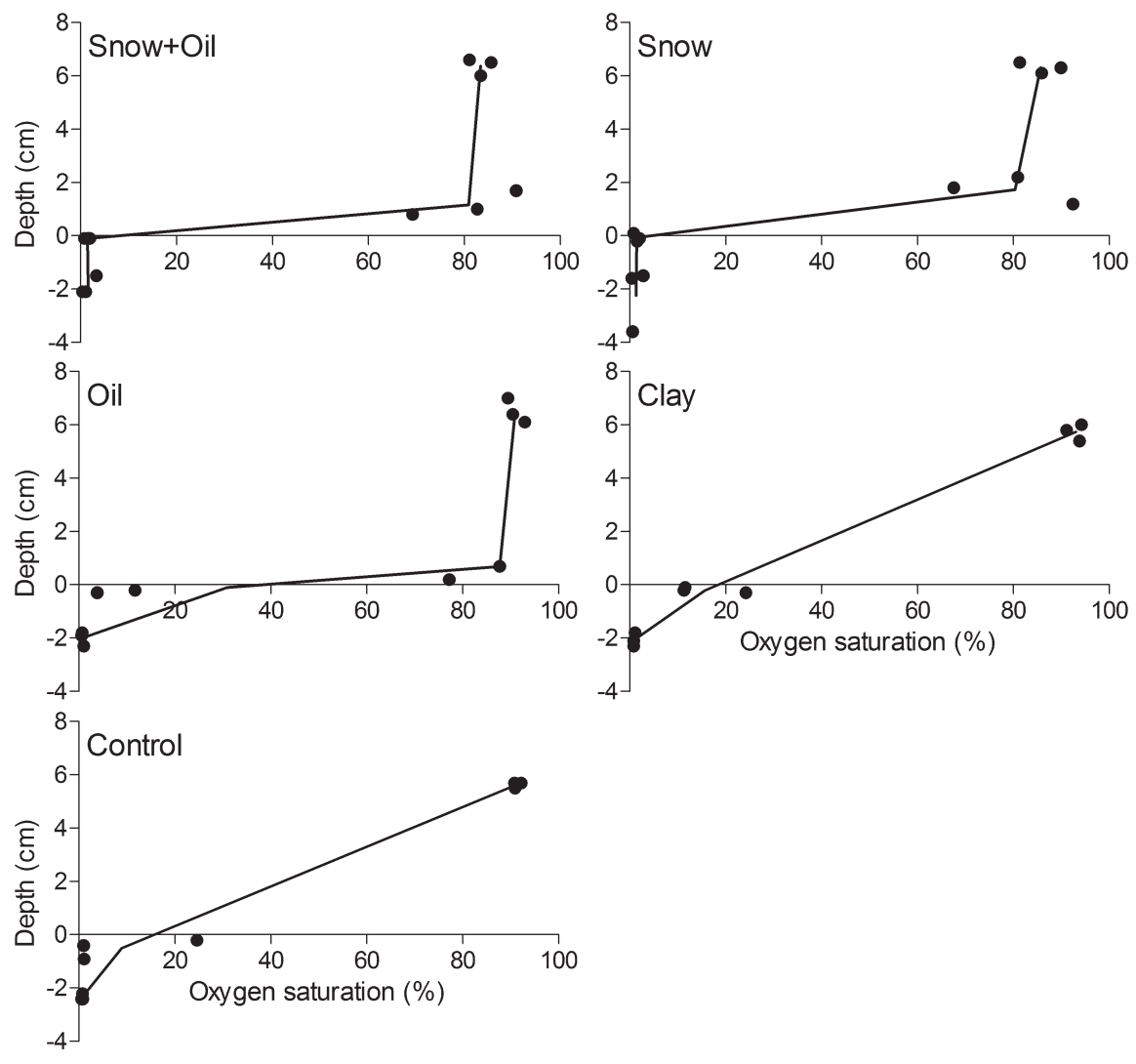

Figure S 4.2: Oxygen saturation profiles of the microcosms at day 8. Depth refers to relative position of each Oxygen Sensor Spot to the sediment-water interface at $0 \mathrm{~cm}$. The data points are individual measurements of three replicate microcosms. The black line is the average of the three replicates. 


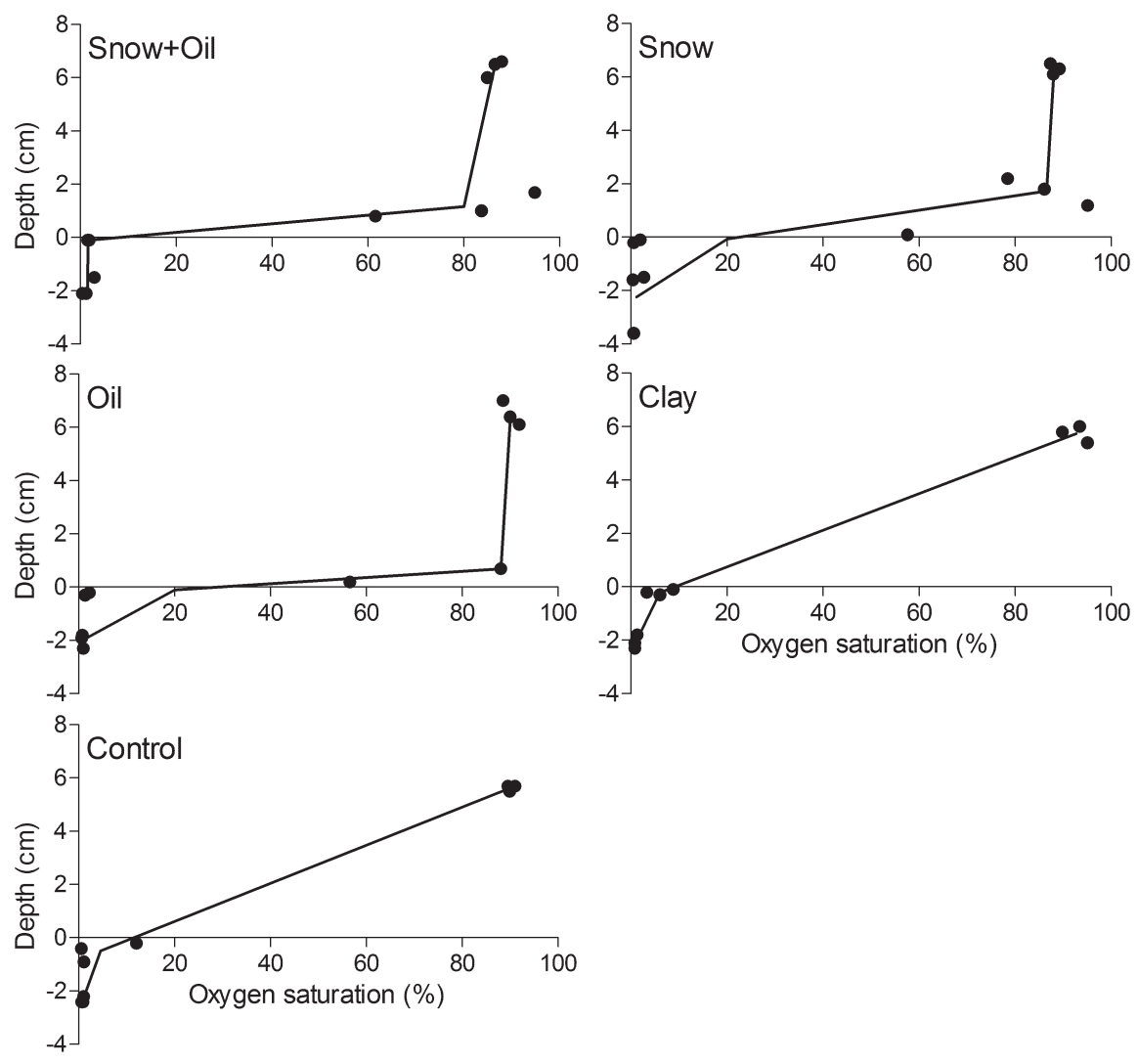

Figure S 4.3: Oxygen saturation profiles of the microcosms at day 15. Depth refers to relative position of each Oxygen Sensor Spot to the sediment-water interface at $0 \mathrm{~cm}$. The data points are individual measurements of three replicate microcosms. The black line is the average of the three replicates. 
S 4.3: Hopane normalized $n$-alkane and isoprenoid alkane peak areas

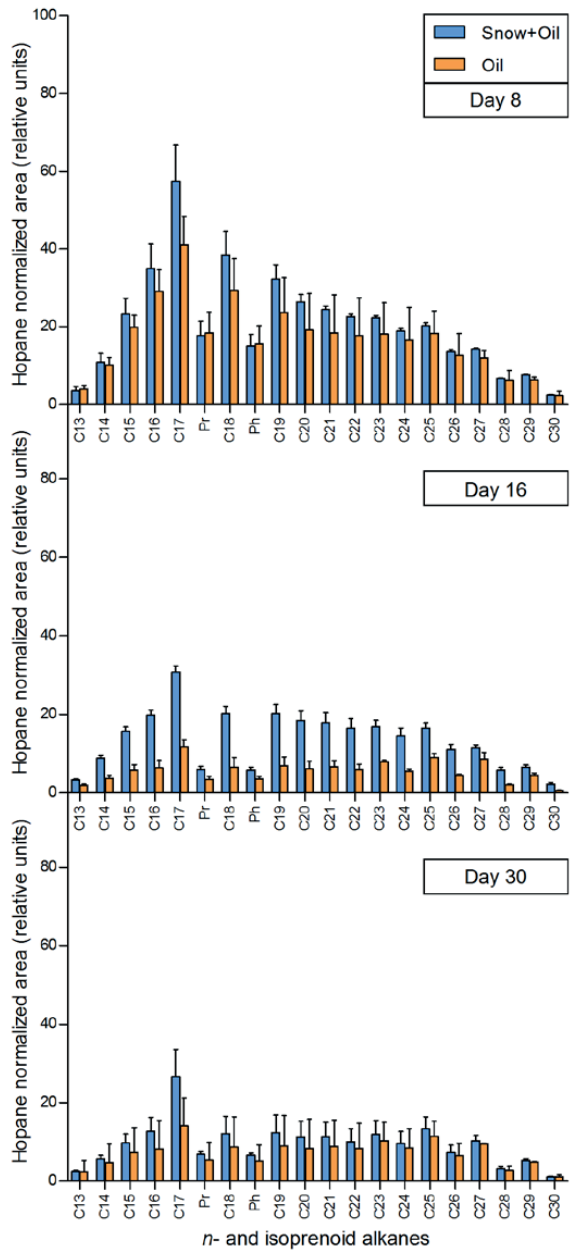

Figure S 4.4: Hopane normalized peak areas for normal and isoprenoid alkanes on day 8 (top panel), day 16 (middle panel), and day 30 (bottom panel). Averages with standard deviations of triplicates. 


\section{S 4.4: Photographs of Artificial Marine Snow layer}

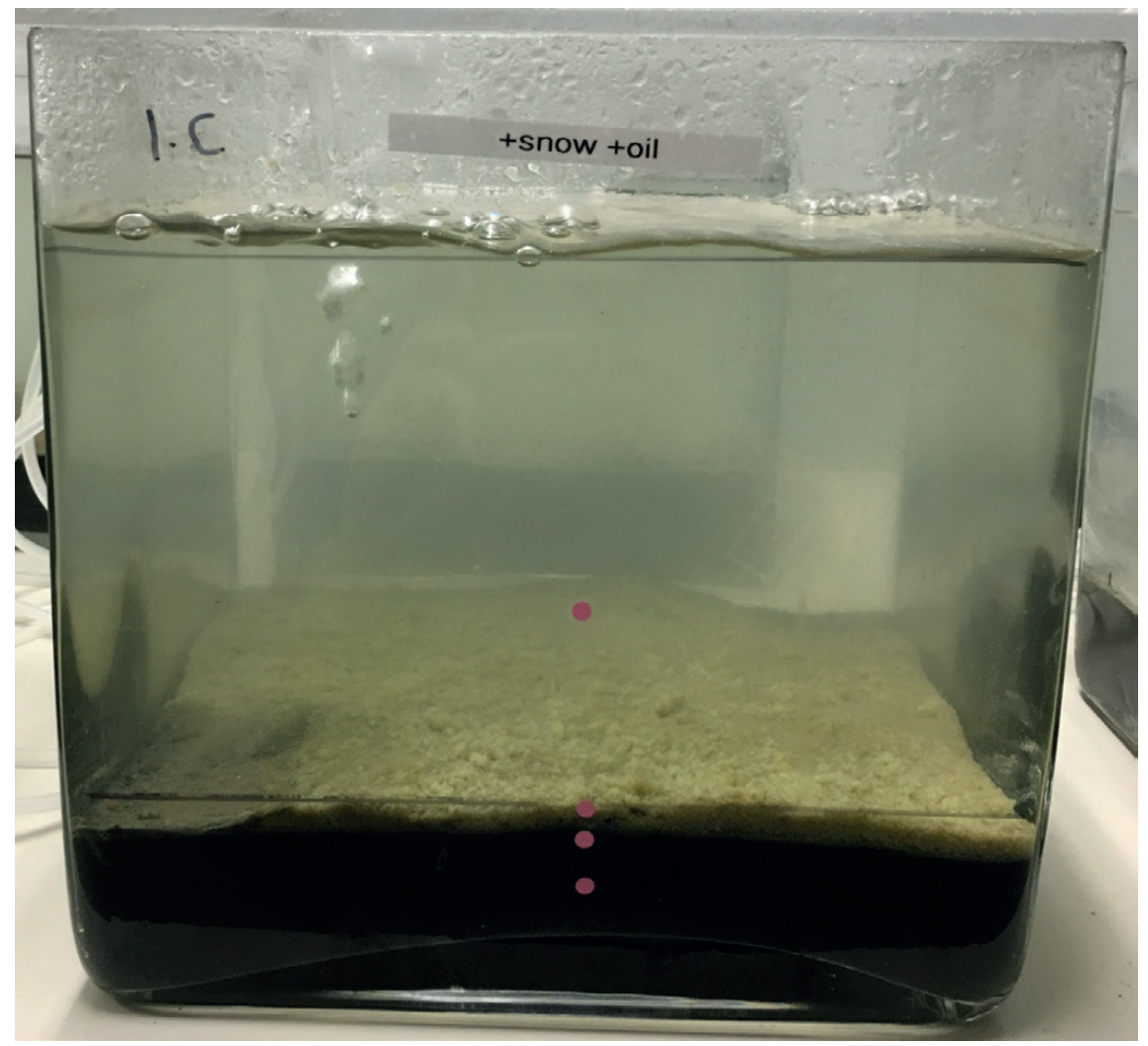

Figure S 4.5: Unequal distribution of artificial marine snow in the lower left corner in microcosm replicate ' $1 \mathrm{C}$ ', with treatment Snow+Oil. A patch of approximately $5 \times 5 \mathrm{~cm}$ is uncovered. This led to a higher survival in this microcosm replicate compared to the other two replicates (13 vs 1 surviving individual Corophium volutator).

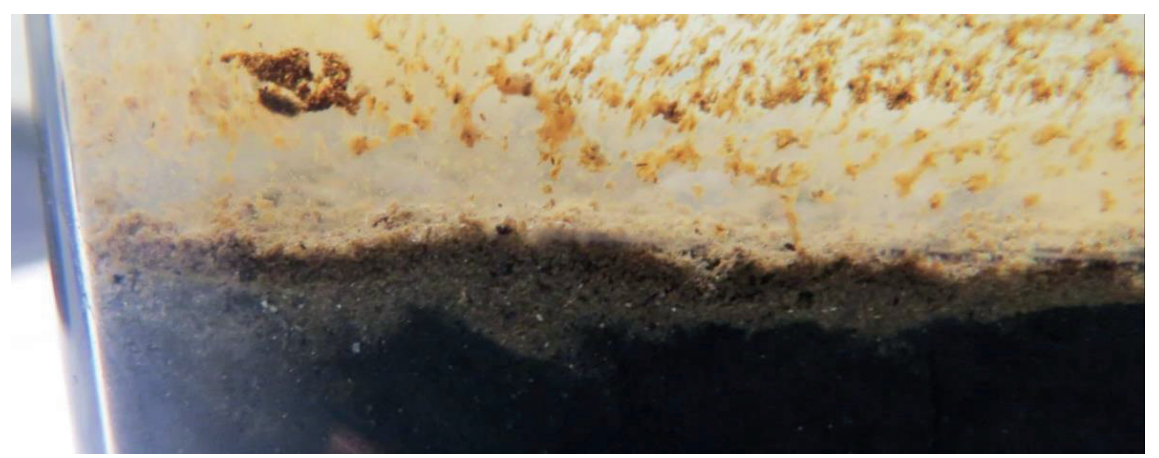

Figure S 4.6: Close up of oxidized layer in microcosm replicate '1C' at day 16. Full view of the entire top layer can be found in Figure 4.4. 


\section{Chapter 4}
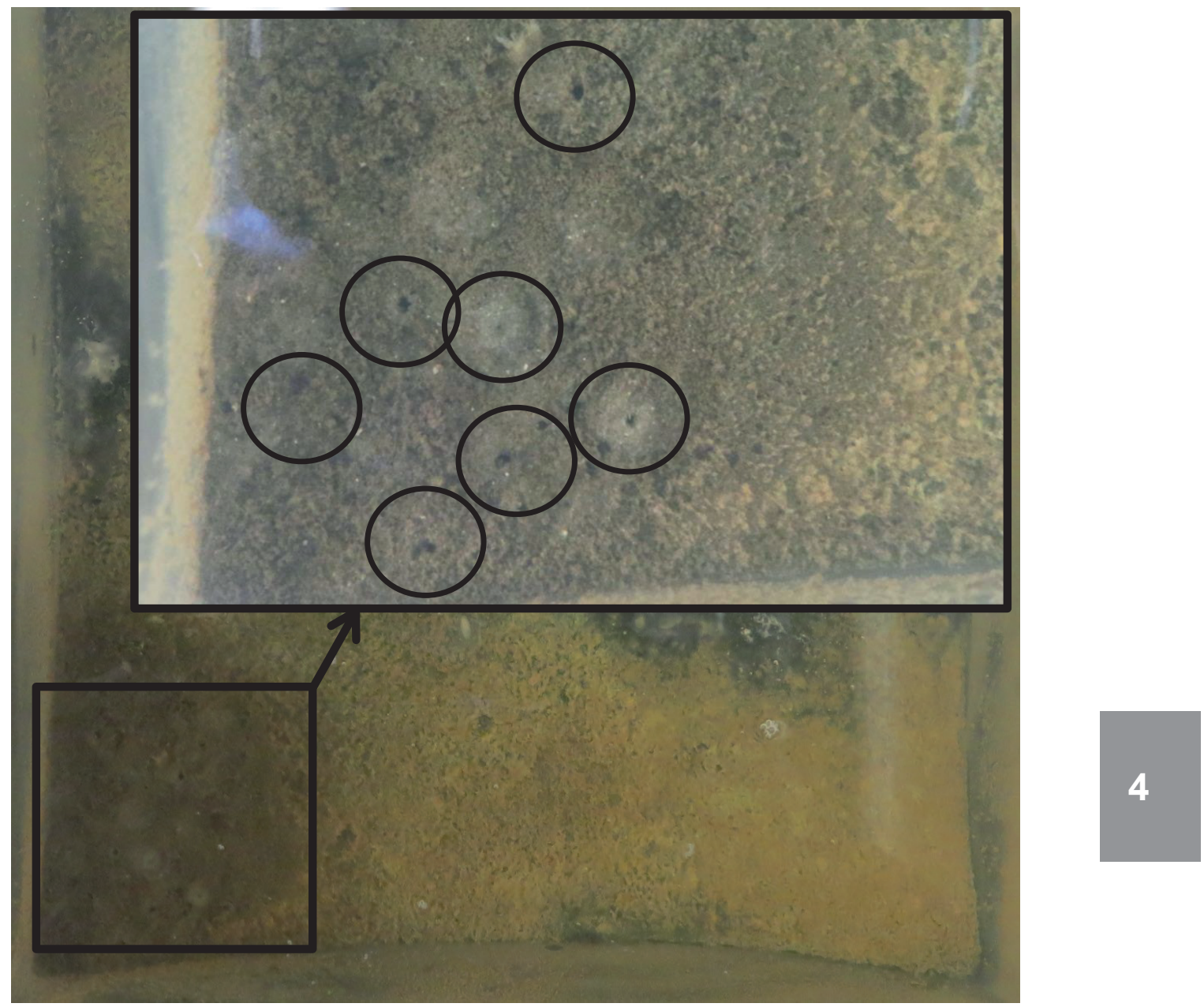

Figure S 4.7: Close up of top of sediment of replicate ' $1 \mathrm{C}$ ' at day 16. The lower left corner had visible burrowing activity. Coropbium volutator burrows were present in this patch (black circles). 


\section{Chapter 5}

\section{Ecotoxicological benthic impacts of experimental oil-contaminated marine snow deposition}

Justine S. van Eenennaamª, Melissa Rohal ${ }^{\mathrm{b}}$, Paul A. Montagna ${ }^{\mathrm{b}}$, Jagoš R. Radovićc, Thomas B.P. Oldenburgc, Isabel C. Romero ${ }^{\mathrm{d}}$, Albertinka J. Murke, Edwin M. Foekema,

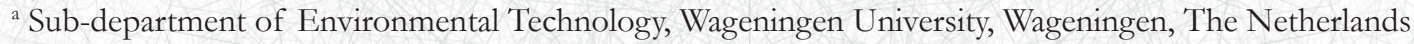

${ }^{b}$ Harte Research Institute for Gulf of Mexico Studies, Texas A\&M University - Corpus Christi, USA

c PRG, Department of Geoscience, University of Calgary, Calgary, Canada

${ }^{\mathrm{d}}$ College of Marine Science, University of South Florida, USA

${ }^{e}$ Marine Animal Ecology Group, Wageningen University, Wageningen, The Netherlands

${ }^{\mathrm{f}}$ Wageningen Marine Research, Den Helder, The Netherlands

Manuscript in preparation. 


\section{Abstract}

Marine Oil Snow Sedimentation and Flocculent Accumulation (MOSSFA) related to oil spills in the marine environment can pose serious threats to the benthic ecosystem. In a microcosm experiment we investigated the effects of oil in combination with artificial marine snow or kaolin clay on two benthic invertebrate species, the burrowing amphipod Corophium volutator and the epibenthic gastropod Hydrobia ulvae, and on benthic meiofauna (copepods and nematodes). Gradual deposition over 4 days of marine snow on the sediment improved survival of motile organisms compared to an instant deposition of the same amount of marine snow, and several indications for the use of marine snow as a food source were found. The presence of marine snow inhibited oil biodegradation on the sediment compared to oil in combination with clay because of extra oxygen consumption for marine snow degradation. C. volutator showed a dosedependent decrease in survival for both oil-contaminated clay and oil-contaminated marine snow. H. ulvae was only affected by the highest concentration of oil-contaminated marine snow and had internal concentrations of PAHs with a similar distribution as found in the oilcontaminated marine snow itself. Benthic copepods showed higher survival in presence of marine snow, either clean or oil-contaminated, most likely because of the nutritional value of the marine snow without exceeding the threshold for adverse oil effects. This study revealed that marine snow on the sediment after oil spills can be a vector for introducing oil into other parts of the food web. 


\subsection{Introduction}

The Deepwater Horizon (DWH) oil spill in 2010 was one of the largest marine oil spills in history, with $\sim 640$ million liter (4.0 million barrels) of crude oil leaking into the Gulf of Mexico in 3 months (Ramseur, 2011; U.S. District Court, 2015). During this time, 6.8 million liters of chemical dispersants were used at the sea surface and injected at the wellhead (BP Gulf Science Data, 2017a, c) to disperse the oil slicks and to avoid the formation of new slicks.

Large amounts of marine snow were observed during the DWH spill (Dell'Amore, 2010; Passow et al., 2012). This unusual marine snow formation was probably the result of a combination of several factors: (dispersed) oil droplets, dispersants, large amounts of suspended solids from the Mississippi river, and increased phytoplankton densities due to algae blooms (Bianchi et al., 2011; Daly et al., 2016; Hu et al., 2011; O'Connor, 2013; Passow et al., 2012; van Eenennaam et al., 2016). The oil and marine snow aggregated and sank to the ocean floor in a depositional process called MOSSFA: Marine Oil Snow Sedimentation and Flocculent Accumulation (MOSSFA Steering Committee, 2013). Sedimentological records showed a 4-10 fold increase in sedimentation rates after the spill when compared to background rates (Brooks et al., 2015; Hastings et al., 2016) and a 2-3 fold increase in sedimentary PAH concentrations in the DeSoto Canyon, located northeast of the DWH wellhead (Romero et al., 2015). Using sedimentary oil indicators, the spatial extent of MOSSFA is estimated to range from $3,200 \mathrm{~km} 2$ (Valentine et al., 2014) to $24,000 \mathrm{~km} 2$ (Chanton et al., 2015). Using increased ${ }^{210} \mathrm{Pbxs}$ flux after 2010, Schwing et al. (2017) estimated the sedimentary spatial extent to range from 12,805-35,425 $\mathrm{km}^{2}$. Hydrocarbon deposition at depths $>200 \mathrm{~m}$ was found in $\sim 76,000 \mathrm{~km}^{2}$ (Romero et al., 2017).

The MOSSFA event was found to have severe impacts on the benthic ecosystem. Benthic foraminiferal density and diversity decreased after the spill (Schwing et al., 2016; Schwing et al., 2015), as did the macro- and meiofaunal abundance and diversity in the study area of at least 172 $\mathrm{km}^{2}$ around the wellhead (Montagna et al., 2013). The effects on benthic macro- and meiofauna persisted at least one year after the spill (Montagna et al., 2017). Deep-sea benthic metazoan meiofauna diversity decreased in severely impacted locations around the DWH wellhead while the nematode to copepod ratio increased 9 times due to decrease of copepod density (Baguley et al., 2015).

Loss of biodiversity in benthic fauna, especially in areas of high biodiversity such as the Gulf of Mexico (Tyler, 2003), can have severe consequences. Danovaro et al. (2008) linked the loss of benthic biodiversity in general to an exponential decline in deep-sea ecosystem functioning, which in turn affects ecological and biogeochemical processes at a global scale. Oil spills and associated MOSSFA events, leading to a loss of biodiversity, may thus have effects that reach further than the immediately impacted locations.

While there is plenty of observational evidence for adverse effects of the DWH oil spill and the associated MOSSFA event, realistic experimental studies into the mechanisms behind the 
impacts on benthic invertebrates and the oil biodegradation in the sediment are lacking. To add to current knowledge about the effects of MOSSFA on the deep-sea benthic ecosystem, we have taken a multi-tiered experimental approach. A series of three experiments was designed, each increasing in complexity and field-relevance. Previously, we have performed two microcosmscale experiments to assess the effect of marine snow on oil biodegradation (Chapter 3) and benthic macroinvertebrate survival (Chapter 4). These first two experiments are important to understand the basic mechanisms of marine snow-related biodegradation and ecosystem effects. This current chapter describes the third and final experiment in the series.

The first experiment (Chapter 3) focused solely on the role of marine snow in the biodegradation of oil, without benthic invertebrates. The experiment showed that marine snow hampers oil biodegradation because it competes with oil for available oxygen for biodegradation.

The second experiment, described in Chapter 4, extended the previous experiment by introducing three species of benthic macroinvertebrates in the natural sediment with a natural foraminifera community. The study showed that oil biodegradation was enhanced compared to the first experiment, most likely because of the bioturbation by benthic invertebrates. The increase in oxygen as a result of bioturbation partly counterbalanced the reduction in oxygen as a result of marine snow biodegradation.

The specific goal of this third experiment is five-fold: 1) determine the impact of gradually build up marine snow with two oil concentrations on benthic organisms, compared to oiled clay. This gradual marine snow exposure creates an exposure scenario that seems more realistic for the field situation; 2) determine the recovery potential of the benthic invertebrates after 6 weeks of oil and marine snow degradation; 3) determine oil biodegradation in presence of marine snow; 4) determine whether marine snow can be used as a food source by invertebrates, leading to enhanced oil uptake; 5) include extra parameters, such as quantification of bioturbation, oxygenated layer thickness, PAH concentration in organism tissues, and meiofaunal analysis, to get a more comprehensive overview of the effects of marine snow and oil on the benthic system.

\subsection{Materials and methods}

As a follow-up of Chapter 3 and Chapter 4, the general set-up of this study was similar to the experiments described in those chapters. Readers are referred to those chapters for details. Below the experimental setup is shortly described, plus specific elaborations in more detail.

\subsubsection{Experimental setup}

Full glass aquaria of $25 \times 25 \times 25 \mathrm{~cm}$ without silicone rubber were used as a basis for the 42 microcosms that were used for this study. The microcosms were placed in two climate controlled 
rooms at $14{ }^{\circ} \mathrm{C}$ and a day-night light regime with $16 \mathrm{~h}$ light and $8 \mathrm{~h}$ dark, using fluorescent tubes on a timer.

Sediment and organisms were collected during low tide from the top $10 \mathrm{~cm}$ of an intertidal mudflat in the Dutch Wadden Sea, at approximate location N $52^{\circ} 56.112$ E $004^{\circ} 59.976$, and transported directly to the laboratory of Wageningen Marine Research, Den Helder, The Netherlands. The sediment (approximately $6 \%$ organic matter) was sieved over a $1 \mathrm{~mm}$ sieve to remove larger organisms and particles, and thoroughly mixed to create a homogeneous sediment. Organisms were kept in the same climate controlled room, in natural sea water with aeration, until use.

The microcosms were filled with a $5 \mathrm{~cm}$ thick layer of sediment and a $15 \mathrm{~cm}$ layer of natural sea water on top $(0.45 \mu \mathrm{m}$ filtered Eastern Scheldt water). The sediment was left to settle for one day prior to introduction of the organisms. The next day, 40 Corophium volutator (an infaunal deposit and suspension feeding amphipod) and 20 Hydrobia ulvae (an epifaunal deposit feeding and grazing gastropod) were introduced randomly in each microcosm and left to acclimatize to their new environment for 4 days before the start of the experiment. Air was bubbled via two tubes with glass tips per microcosm in the top $5 \mathrm{~cm}$ of the water column. Microcosms were covered with acrylic plastic covers to minimize evaporation. Once per week, $25 \%$ of the water in each microcosm was replaced with fresh natural sea water at a low pump rate without disturbing the sediment surface. The water used for refreshment was acclimatized for one week in the same room, with aeration.

On day $0,1,2$, and 3, the test treatments were prepared as described in Section 5.2.3 and added to the microcosms.

\subsubsection{Test treatments}

Seven treatments were tested in six replicates (A-F): Control, Clay C0, Clay C1, Clay C2, Snow C0, Snow C1, Snow C2 (Table 5.1). 'Control' treatments received no additions. 'Snow' refers to treatments with artificial marine snow, 'Clay' refers to treatments with kaolin clay. 'C' refers to the oil concentrations tested. Expressed as the volume of oil per surface area, C0, C1 and C2 refer to 0,3 and $10 \mathrm{~g} \mathrm{~m}^{-2}$ respectively. The highest concentration is similar to the concentration used in Chapter 3 and Chapter 4. Approximately $210 \mathrm{~km}^{2}$ of the oil-contaminated area in the Gulf of Mexico (located at depths $>200 \mathrm{~m}$ ) contained 11-43 $\mathrm{g} \mathrm{oil} \mathrm{m}^{-2}$ (Romero et al., 2017), making $10 \mathrm{~g} \mathrm{~m}^{-2}$ a realistic high concentration and $3 \mathrm{~g} \mathrm{~m}^{-2}$ a realistic lower concentration. Surrogate Macondo MC252 oil, provided by BP, was used for this study and is chemically similar to the oil from the Macondo oil well involved in the Deepwater Horizon oil spill (BP Gulf Science Data, 2013). The oil was slightly weathered for $24 \mathrm{~h}$ at room temperature in the dark while mixing on a magnetic stirrer, to allow evaporation of lighter hydrocarbons as seen previously in the sedimentary environment from the DWH spill or other events (Romero et al., 2016; Romero et al., 2017; Stout and Payne, 2016b). In contrast to Chapter 3 and Chapter 4, no 
oil-degrading bacteria were added. After 42 days, replicates A, B, and C were sampled. Replicates $\mathrm{D}, \mathrm{E}$, and F continued until day 58, when 20 freshly-caught $C$. volutator were added, and the replicates were then continued until the final sampling at day 80 .

Table 5.1: Test treatments for the microcosm experiment

\begin{tabular}{ccccc}
\hline Treatment code & Treatment description & Oil & Kaolin clay & $\begin{array}{c}\text { Alginate and } \\
\text { phytoplankton biomass }\end{array}$ \\
\hline \hline Control & Clean sediment control & & & \\
\hline Clay C0 & Clay without oil & & $\checkmark$ & \\
\hline Clay C1 & Clay with 3 g m oil $^{-2}$ & $\checkmark$ & $\checkmark$ & \\
\hline Clay C2 & Clay with $10 \mathrm{~g} \mathrm{~m}^{-2}$ oil & $\checkmark$ & $\checkmark$ & $\checkmark$ \\
\hline Snow C0 & Marine snow without oil & & $\checkmark$ & $\checkmark$ \\
\hline Snow C1 & Marine snow with 3 g m-2 oil & $\checkmark$ & $\checkmark$ & $\checkmark$ \\
\hline Snow C2 & Marine snow with $10 \mathrm{~g} \mathrm{~m}^{-2}$ oil & $\checkmark$ & $\checkmark$ & \\
\hline
\end{tabular}

\subsubsection{Test treatment preparation}

The same total amount of marine snow $(1 \mathrm{~cm}$ thick layer) as in the previous studies was added, but instead of adding the total amount at once, there was a gradual addition over four days. Each day, a portion of marine snow was freshly prepared for the Snow treatments, and oil was mixed with clay for the Clay treatments, and added to the microcosms.

Since using natural marine snow in the experiment was unfeasible, artificial marine snow was prepared by combining alginate, phytoplankton biomass, and kaolin clay, as described in Chapter 3 and Chapter 4.

For the Snow C0 treatment, clean artificial marine snow was prepared for all six replicates at the same time, by slowly adding $11.3 \mathrm{~g}$ of alginate (alginic acid sodium salt, CAS 9005-38-3, Arcos Organics; $1.88 \mathrm{~g}$ for each mesocosm replicate) to $570 \mathrm{~mL}$ of filtered natural sea water, while stirring. Then, $9 \mathrm{~g}$ fresh weight of algae paste (Chlorella paste, Ingepro BV, Borculo, The Netherlands; $1.5 \mathrm{~g}$ for each microcosm replicate) and $4.7 \mathrm{~g}$ of kaolin clay (hydrated aluminum silicate, CAS 1332-58-7, Sigma Aldrich; $0.78 \mathrm{~g}$ for each microcosm replicate) were added. 6.3 liters of a $14.5 \mathrm{~g} \mathrm{~L}-1 \mathrm{CaCl} 2$ (CAS 10043-52-4, Fluka Analytical) in demi-water solution was quickly added to the alginate-algae mix, and shaken by hand a few times. After this, the marine snow formed and precipitated. The overlying liquid was poured off before dividing the precipitated marine snow into six portions for the microcosm replicates. For the Snow C1 and Snow C2 treatments, $4.7 \mathrm{~g}$ of kaolin clay was first mixed with $0.28 \mathrm{~g}$ and $0.95 \mathrm{~g}$ oil, respectively, and some demi-water into a homogenous slurry before adding to the alginate-algae mix. The marine snow was then added to the microcosms, evenly covering the sediment. After 4 days, the marine snow layer was approximately $1 \mathrm{~cm}$ thick, similar to the thickness of the layer that was produced instantly in the experiments described in Chapter 3 and Chapter 4. 
For each microcosm replicate of Clay C0, $0.78 \mathrm{~g}$ of kaolin clay was mixed with approximately $100 \mathrm{~mL}$ water from the microcosm to form a suspension. For each microcosm replicate of Clay C1 and C2 treatments, $4.7 \mathrm{~g}$ of kaolin clay was mixed with $0.28 \mathrm{~g}$ and $0.95 \mathrm{~g}$ oil, respectively, using some demi water to form a homogenous slurry. The slurry was divided into six parts for the microcosm replicates and then mixed with approximately $100 \mathrm{~mL}$ water from the microcosm to form a suspension. These suspensions were then added back to the microcosm, and once settled formed an even layer on the sediment.

\subsubsection{Water quality parameters}

During the experiment, the following water quality parameters were regularly monitored in the middle of the water column: $\mathrm{pH}(-)$, temperature $\left({ }^{\circ} \mathrm{C}\right)$, salinity $(\% 0)$, dissolved oxygen saturation level (\%). A Mettler Toledo $\mathrm{pH}$ meter was used to measure $\mathrm{pH}$, and the other parameters were measured with a Hach HQ40d multimeter using salinity and dissolved oxygen probes. Both meters were calibrated before use.

\subsubsection{Biological observations and sampling procedure}

During the experiment, behavioral observations of the test organisms were made and photos of the microcosms were taken to observe oxygenated layer thickness and burrow formation. The numbers of $H$. ulvae attached to the side of the microcosms and floating on the water surface were counted. On day 42, the experiment was terminated for replicates A-C, and biodegradation samples were taken as described in Section 5.2.6. For replicates D-F, the experiment was terminated at day 80 , biodegradation samples were taken, and sediment samples for meiofauna analysis were taken using a $25 \mathrm{~mL}$ syringe with the top part cut off. Three replicate cores from all treatments and replicate microcosms were collected for meiofauna analysis resulting in a total of 63 meiofauna samples. However, because of time constraints only one replicate core was analyzed from the following treatments ${ }^{1}$ : Control, Snow C0, Snow C2, Clay C0, and Clay C2. Meiofauna samples were washed over a $45 \mu \mathrm{m}$ sieve and stained with Rose Bengal mixed in $70 \%$ ethanol. The samples were left to stain overnight at $4{ }^{\circ} \mathrm{C}$. All samples were hand-sorted under a dissecting microscope at 120x magnification. Meiofauna and macrofauna were not separated before sorting, therefore both size classes were counted and included in the analysis. After taking the biodegradation and meiofauna samples, the entire contents of the microcosm including water were gently sieved over a $1 \mathrm{~mm}$ sieve to collect the $C$. volutator and $H$. ulvae. The organisms were counted and then freeze-dried (Christ Alpha 1-4 LDplus freeze dryer) for chemical analysis.

\footnotetext{
${ }^{1}$ Additional analyses of meiofaunal samples (replicate cores, and C1 oil concentrations) are currently being performed and will be added to the manuscript for publication.
} 


\subsubsection{Biodegradation sampling}

On day 42 (replicates A-C) and day 80 (replicates D-F), sediment samples were taken from the microcosms for oil biodegradation analysis. A glass tube with a diameter of $1.5 \mathrm{~cm}$ was pushed into the sediment to collect 10 sediment core samples per microcosm. The subsamples were pooled together in glass jars to get a representative sample of one microcosm. The jars were left to settle for three days at $4{ }^{\circ} \mathrm{C}$ in the dark. Then, the overlying water was removed and the sediment samples were freeze-dried.

\subsubsection{Chemical analysis sediment}

For chemical analysis of oil components, $10 \mathrm{~g}$ of freeze-dried sediment from day 42 samples $^{2}$ was extracted with a total of $\sim 75 \mathrm{~mL}$ dichloromethane (DCM). In order to remove elemental sulfur, $\sim 1.5 \mathrm{~g}$ of pre-cleaned copper granules were added to the DCM extract, which was subsequently passed through cotton wool (Blumer, 1957). Desulfurized whole extract was blowdried to small volume, and an aliquot was first analyzed using full scan GC-MS to check if the hydrocarbons were present. Then, the whole extract was separated to saturate and aromatic fractions, by loading onto a silica gel ( $0.6 \mathrm{~g}, 70-230 \mathrm{mesh})$ column, pre-washed with pentane, and eluting with $2 \mathrm{~mL}$ of pentane to obtain the saturate fraction, followed by elutions with $2 \mathrm{~mL}$ of dichloromethane and isopropyl alcohol, respectively, to obtain the aromatic fraction. The temperature program for the GC-MS analysis included a hold of $5 \mathrm{~min}$ at $40{ }^{\circ} \mathrm{C}$, followed by a $4{ }^{\circ} \mathrm{C}$ min $^{-1}$ ramp up to $325^{\circ} \mathrm{C}$, and finishing with an isothermal hold at $325^{\circ} \mathrm{C}$ for 15 minutes. Separation was performed on a HP-5MS capillary column $(30 \mathrm{~m} \times 0.25 \mathrm{~mm} \times 0.25 \mu \mathrm{m})$, and

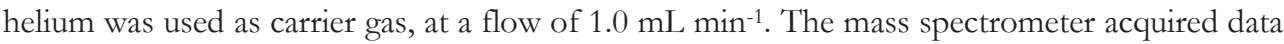
in a combined full scan/selected ion monitoring (SIM-SCAN) mode. SIM trace at $\mathrm{m} / \mathrm{z} 85$ was used to integrate the areas of n-alkanes (C13-C30) and isoprenoid alkanes (pristane and phytane). Integrated areas were then normalized to the area of C30-hopane $(17 \alpha(\mathrm{H}), 21 \beta(\mathrm{H})$-hopane). C30hopane is considered a conservative biomarker due to its recalcitrance to weathering (Prince et al., 1994). This normalization approach is typically used in oil spill studies to detect and compare compositional changes due to evaporation, biodegradation, and other weathering processes (Aeppli et al., 2014; Radović et al., 2014). Stability of C30-hopane was confirmed in the microcosm experiment during 42 days, described in Chapter 3.

\subsubsection{Chemical analysis biota}

Gastropod samples collected on day $42^{3}$ were freeze-dried prior to lipid extraction. Homogenized samples $(\sim 0.04 \mathrm{~g})$ were extracted using an Accelerated Solvent Extraction system

\footnotetext{
2 Additional analyses of day 42 (C1 oil concentration) and day 80 samples are currently being performed and will be added to the manuscript for publication.

3 Additional PAH analyses of gastropods (all replicates, and day 80) and amphipods (day 42 and day 80) are currently being performed and will be added to the manuscript for publication. 
(ASE $200 ®$, Dionex) under high temperature $\left(100{ }^{\circ} \mathrm{C}\right)$ and pressure $(1500 \mathrm{psi})$ with a solvent mixture of 9:1 (v:v) hexane:dichloromethane. Deuterated polycyclic aromatic hydrocarbons (PAHs) were added to samples prior to extraction $\left(\mathrm{d}_{10}\right.$-acenaphthene, $\mathrm{d}_{10}$-phenanthrene, $\mathrm{d}_{10^{-}}$ fluoranthene, $\mathrm{d}_{12}$-benz(a)anthracene, $\mathrm{d}_{12}$-benzo(a)pyrene, $\mathrm{d}_{14}$-dibenz(ah)anthracene). A one-step extraction and clean-up procedure was applied, using a predetermined packing of the extraction cells in an extraction cell of $11 \mathrm{~mL}$. Cells were loaded by inserting a glass fiber filter (precombusted at $450{ }^{\circ} \mathrm{C}$ for $4 \mathrm{~h}$ ) into the cell outlet, followed by $5 \mathrm{~g}$ silica gel (high purity grade, 100-200 mesh, pore size 30A, Sigma Aldrich, USA; pre-combusted at $450{ }^{\circ} \mathrm{C}$ for $4 \mathrm{~h}$, and deactivated $2 \%$ ), then another glass fiber filter, and freeze-dried sample topped with another glass fiber filter. The remaining cell space was filled with sand (pre-combusted at $450{ }^{\circ} \mathrm{C}$ for 4 h). The clean tissue extracts were concentrated to $\sim 2 \mathrm{~mL}$ in a RapidVap (LABONCO RapidVap ${ }^{\circledR}$ Vertex ${ }^{\mathrm{TM}}$ evaporator model 73200 series) and further concentrated to about 100 $300 \mu \mathrm{L}$ by gently blowing with a nitrogen stream. An internal standard was added ( $\mathrm{d}_{14}$-terphenyl) to all samples prior to GC/MS analysis, and two blanks were included for extraction with the samples.

PAHs were quantified using GC/MS/MS multiple reaction monitoring (MRM) on an Agilent 7680B gas chromatograph coupled with an Agilent 7010 triple quadrupole mass spectrometer following modified EPA methods (Method 8270D) and QA/QC protocols. An RXi-5sil chromatographic column was used in splitless injections of $1 \mu \mathrm{L}$ of sample, at a constant flow rate of $1 \mathrm{~mL} \mathrm{~min}^{-1}$, with inlet temperature of $300{ }^{\circ} \mathrm{C}$, and an MS detector temperature of $250{ }^{\circ} \mathrm{C}$. The GC oven temperature program was $60^{\circ} \mathrm{C}$ for $2 \mathrm{~min}, 60^{\circ} \mathrm{C}$ to $200{ }^{\circ} \mathrm{C}$ at a rate of $8{ }^{\circ} \mathrm{C} \mathrm{min}$ ${ }^{1}, 200{ }^{\circ} \mathrm{C}$ to $300{ }^{\circ} \mathrm{C}$ at a rate of $4{ }^{\circ} \mathrm{C} \mathrm{min}-1$ and held for $4 \mathrm{~min}$, and $300{ }^{\circ} \mathrm{C}$ to $325^{\circ} \mathrm{C}$ at a rate of $10{ }^{\circ} \mathrm{C} \mathrm{min}^{-1}$ and held for $5 \mathrm{~min}$. The source electron energy was operated at $70 \mathrm{eV}$, and argon was used as the collision gas at $1 \mathrm{~m}$ Torr pressure. Mass transitions targeted appropriate parent molecular ion masses on Q1 and Q3 for 2-ring to 6-ring PAHs, and their alkylated homologues (C1-C4) as previously reported (Romero et al., 2015; Sørensen et al., 2016). As a reference standard MC252 crude oil (NIST 2779) was used. Recovery of individual PAHs ranged within QA/QC criteria of $50-120 \%$. The limits of quantification were $0.5-1.0 \mathrm{ng} \mathrm{g}^{-1}$ with detection limits below fg $\mathrm{g}^{-1}$ levels. PAH concentrations are expressed on dry weight (dw) basis.

\subsubsection{Statistical analyses and software}

GraphPad Prism 5 was used to make graphs and perform statistical analyses, using one-way ANOVA with post-hoc Tukey's test or two-way ANOVA with Bonferroni multiple comparisons post-test. Meiofauna samples were analyzed using Primer 7. The data was pretreated with an overall square root transformation. A resemblance matrix was generated with Bray-Curtis similarity and then used to create a Non-metric Multi-Dimensional Scaling plot with 1000 restarts. In addition, a cluster analysis was run on the resemblance matrix in order to determine similarity between samples. 


\subsection{Results}

\subsubsection{Water quality}

The water quality parameters $\mathrm{pH}$, salinity, and temperature in the water column can be found in Figure S 5.1. Overall, the $\mathrm{pH}$ increased during the first 20 days. However, in all microcosms with marine snow the $\mathrm{pH}$ decreased during the first week and was significantly lower than in the Controls between day 6 and 13. No difference in salinity between any of the treatments was observed over the course of the experiment; even though salinity increased with time due to evaporation, from $32.5 \pm 0.3 \%$ at day 1 to $35 \pm 0.5 \%$ at day 79 (averages of all treatments). The temperature was stable throughout the experiment, at $14.3 \pm 0.2{ }^{\circ} \mathrm{C}$.

During the entire experiment, the dissolved oxygen saturation in the water column was $91.2 \pm 2.7 \%$ in all microcosms, indicating no oxygen depletion in the water column. However, the oxygen saturation in microcosms of treatments Snow C0, C1, and C2 quickly dropped significantly in the first 10 days to values between $80 \%$ and $85 \%$, but recovered within 20 days (Figure 5.1). At day 13-20, oxygen saturation in Clay C2 also was significantly lower than Control.

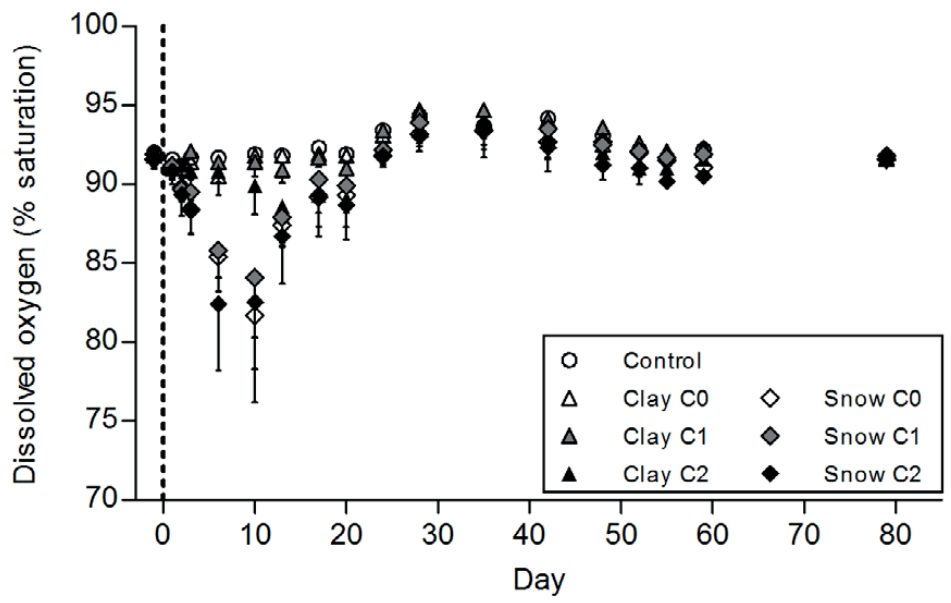

Figure 5.1: Dissolved oxygen saturation (\%) in the water column during the 80 day experiment. Average and standard deviation of replicates A-F until day 42 and replicates D-F on day $42-80$.

\subsubsection{General in vivo observations and analysis}

The invertebrates were introduced into the microcosms four days before the start of the treatments. During these four days, active burrowing of $C$. volutator and an oxygenated top layer were visible in all microcosms. The vast majority of the gastropods $H$. ulvae was present on top of the sediment and only some individuals were attached to the glass sides of the microcosms. After the first day of adding the marine snow treatments, it was noticed that $C$. volutator burrowed 
through the thin layer of marine snow (Figure 5.2). This was not observed in the previous experiment (Chapter 4), where a $1 \mathrm{~cm}$ thick layer of instantly added marine snow prevented the amphipods from making burrows through the marine snow. The number of visible new burrows was counted at day 3 (Figure 5.3), and was statistically significantly lower than control in Clay C1, Clay C2, Snow C1, and Snow C2. Also after the last addition of marine snow C. volutator was still able to make new burrows.

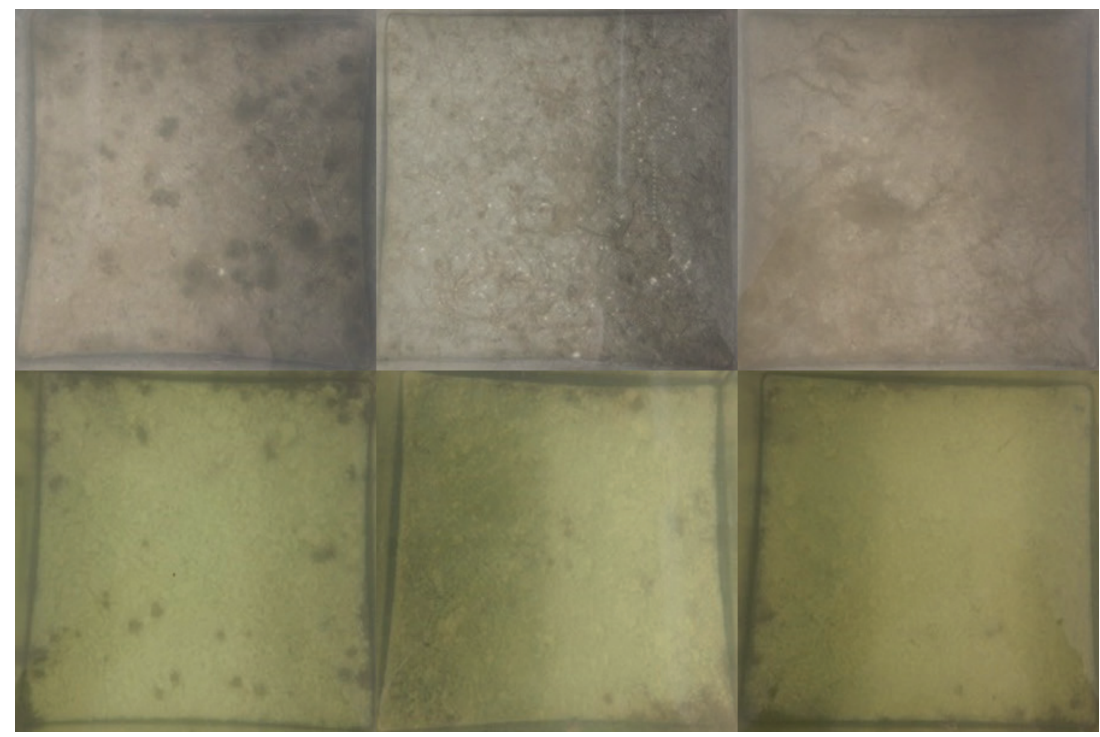

Figure 5.2: Top views of representative microcosms for each treatment. Top row, left to right: Clay C0, Clay C1, Clay C2. Bottom row, left to right: Snow C0, Snow C1, Snow C2. The darker spots indicate where Corophium volutator burrowed through the clay or marine snow layer. Tracks made by Hydrobia ulvae are also visible on top of the sediment in the Clay treatments.

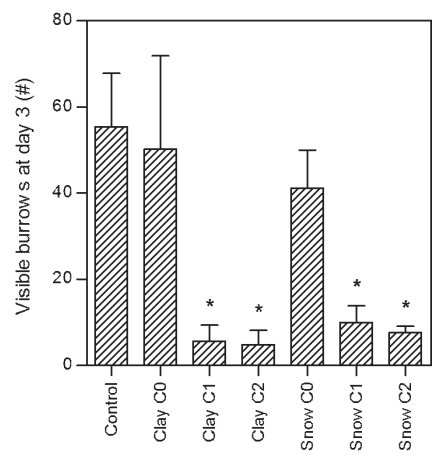

Figure 5.3: Visible burrows on top of the sediment or through the marine snow layer at day 3, just before adding the last portion of the treatments. Average and standard deviation of replicates A-F. * indicates statistically significant difference from Control. 
Figure 5.4 shows the thickness of the oxygenated top layer over time in replicates D-F. Thickness of this layer in Clay C0, C1, and C2 did not differ significantly from Control throughout the experiment, except at day 79 when $\mathrm{C} 1$ and C2 had a thinner oxygenated top layer than Control, indicating a slight effect of oil degradation on oxygen. In all three treatments with marine snow, the oxygenated top layer disappeared after day 3, and returned after day 20, indicating that oxygen depletion is mostly related to the presence and degradation of marine snow and less related to the presence of oil. The thickness of the layer in Snow C2 remained significantly lower than Control throughout the entire experiment.

The number of $H$. ulvae attached to the side of the microcosms or floating at the water surface was counted until day 35 (Figure 5.5). In the first week, there were more gastropods attached to the side in treatments Snow C0 and Snow C1, while Snow C2 followed the general trend of the other treatments after an initial short and small spike. The Clay $\mathrm{C} 2$ treatment also showed a short spike in the number of gastropods right after start of the experiment.

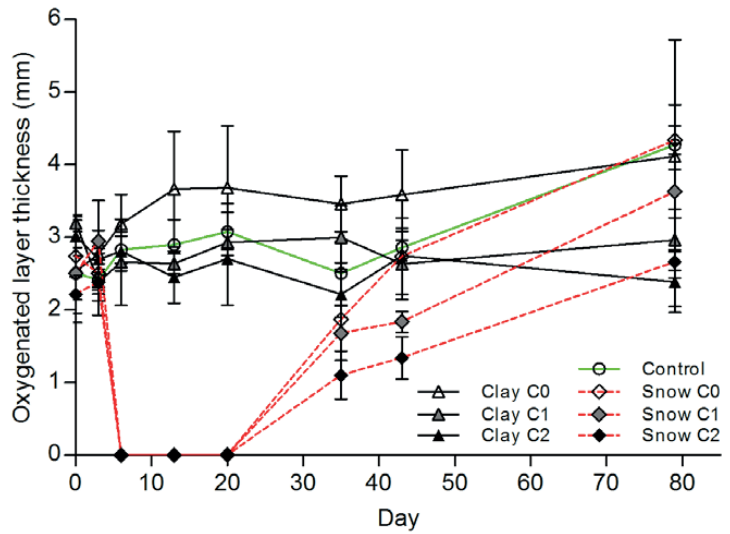

Figure 5.4: Oxygenated layer thickness ( $\mathrm{mm}$ ) over time, measured in replicates D-F (averages with standard deviation).

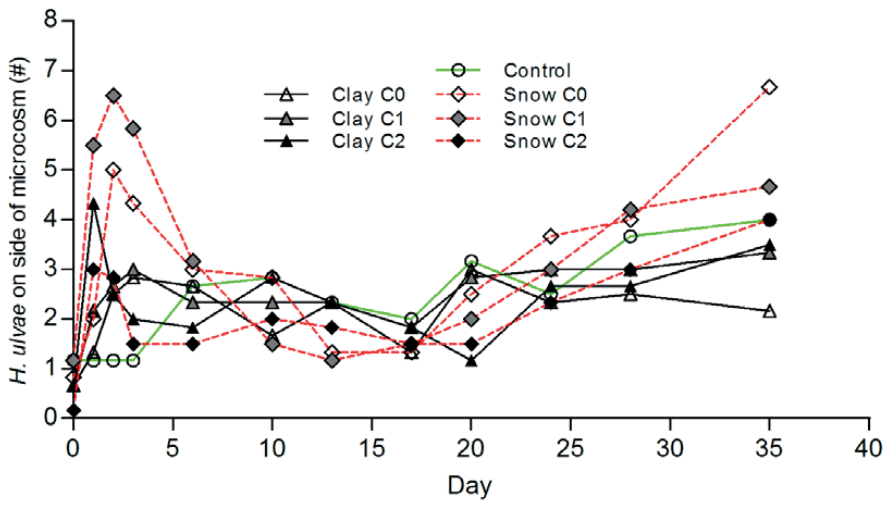

Figure 5.5: Number of gastropod Hydrobia ulvae on the side of the microcosms and floating at the water surface during the first 35 days of the experiment (average of replicates A-F). 


\subsubsection{Invertebrate survival}

In the Control treatment, survival of the initial 40 C. volutator was $73 \pm 3 \%$ after 42 days. Survival in Clay C0 and Snow C0 did not differ from Control (Figure 5.6, top panel), while there was a significant dose-related decrease in survival in Clay C1 and Snow C1 (both $p<0.05$ ) and Clay C2 and Snow C2 (both $p<0.001$ ). Compared to the Control treatment, 52\% survival was observed in Clay C1; 1\% in Clay C2; 60\% in Snow C1; and 18\% in Snow C2.

At day 58, 20 extra C. volutator were added to replicates D-F. Out of theoretically 60 individuals, only 29\% were recovered alive on day 80 in the Control treatment. Survival in Snow C0 was significantly higher than Control (Figure 5.7, top panel), but none of the other treatments were different from Control.

The total number of $H$. ulvae in all microcosms on day 42 was much higher than the 20 individuals which were added at the start. The Control treatment had $131 \pm 8$ individuals. Compared to Control, survival was significantly lower only in Snow C2 (Figure 5.6, bottom panel).

The total number of $H$. ulvae increased even more between day 42 and day 80, with Control at $189 \pm 2$ individuals, and a minimum of 80 in Snow C2 replicate F up to the maximum of 195 in Clay C1 replicate F. Survival was slightly reduced in Snow C0 $(p<0.05)$ and greatly reduced in Snow C2 $(p<0.01)$ (Figure 5.7, bottom panel).

The number of nematodes was similar in all treatments with an average of 33 individuals per $\mathrm{cm}^{2}$ (Figure 5.8). The number of copepods was higher in Snow C0 and Snow C2, although not statistically significant. The N:C ratio was significantly lower than Control in Snow C0 and Clay C2 $(p<0.05)$ and Snow C2 $(p<0.01)$. In general, the Clay and Control treatments were more similar to each other, with the majority of them sharing $80 \%$ similarity (Figure 5.9). The snow treatments grouped out on their own with the exception of Snow C0 replicate B. The N:C ratio was overlaid as a bubble plot to explain the similarities. The Snow treatments all had the lowest $\mathrm{N}$ : C, with the exception of Snow C0 replicate B, because of the higher number of copepods. 


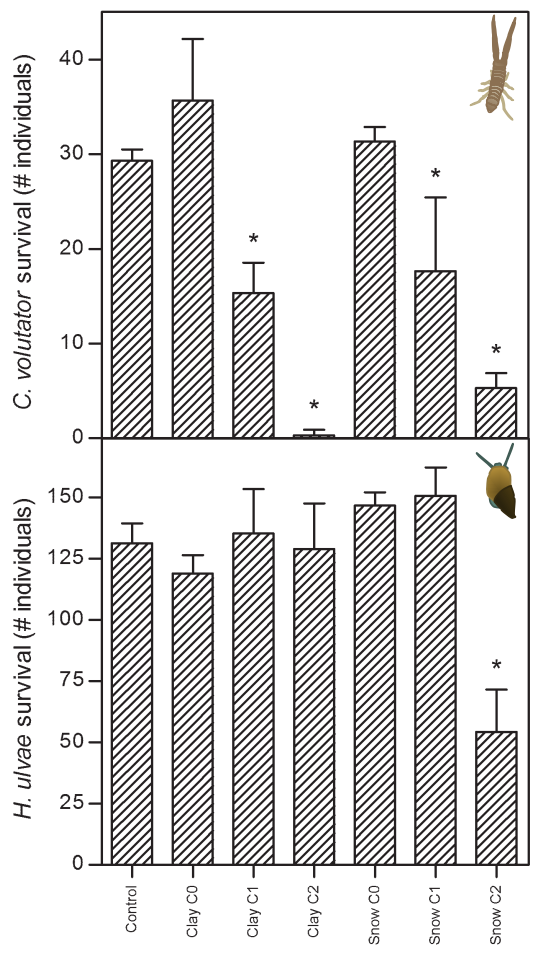

Figure 5.6: Corophium volutator (top panel) and Hydrobia ulvae (bottom panel) survival at day 42. Average and standard deviation of replicates A-C. * indicates statistically significant difference from Control.

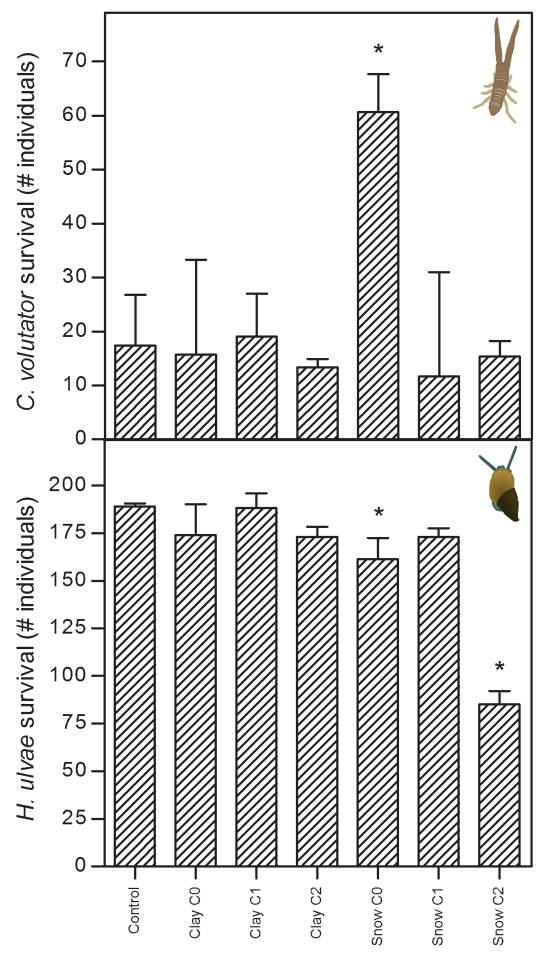

Figure 5.7: Corophium volutator (top panel) and Hydrobia ulvae (bottom panel) survival at day 80 . Average and standard deviation of replicates D-F. * indicates statistically significant difference from Control. 


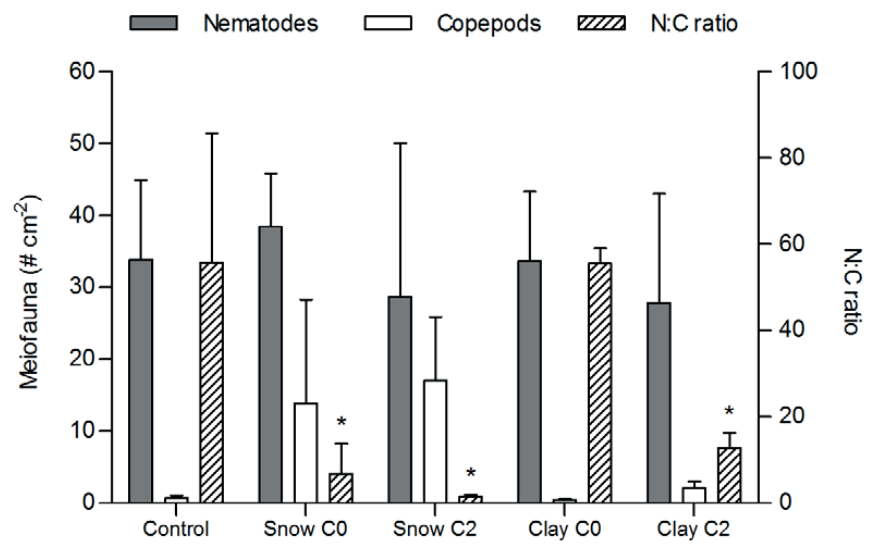

Figure 5.8: Number of meiofauna (nematodes and copepods) per $\mathrm{cm}^{2}$ sediment surface, counted in cores from microcosm replicates D-F at day 80 (left axis). Nematode:copepod ratio (N:C, right axis). ${ }^{*}$ indicates statistically significant difference from Control.

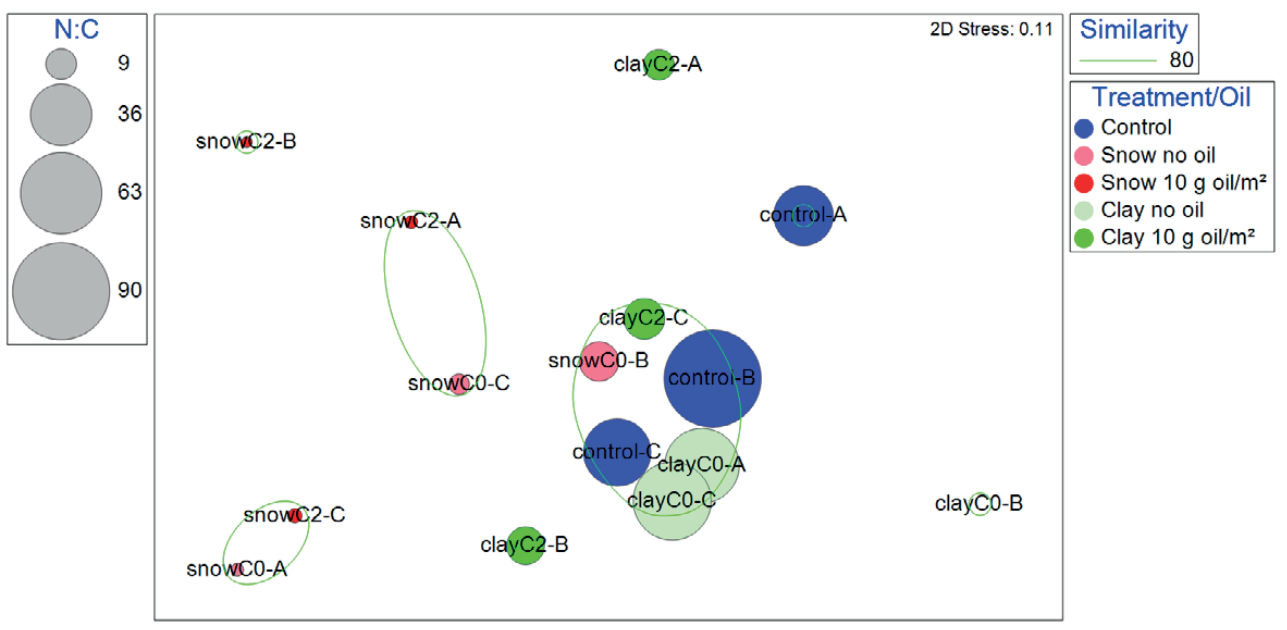

Figure 5.9: Non-metric multi-dimensional scaling (MDS) using all meiofaunal data, with bubble overlay for $\mathrm{N}: \mathrm{C}$ ratio. The green circles depict $80 \%$ similarity between samples.

\subsubsection{Oil analysis}

Sediment samples of day 42 were analyzed for the presence of $n$-alkanes and isoprenoid alkanes. The hopane-normalized peak areas show a difference between the Snow C2 and Clay C2 treatments (Figure 5.10). The peak areas are consistently lower in Clay C2 samples than in Snow C2 samples, especially in the lower molecular weight alkanes. 


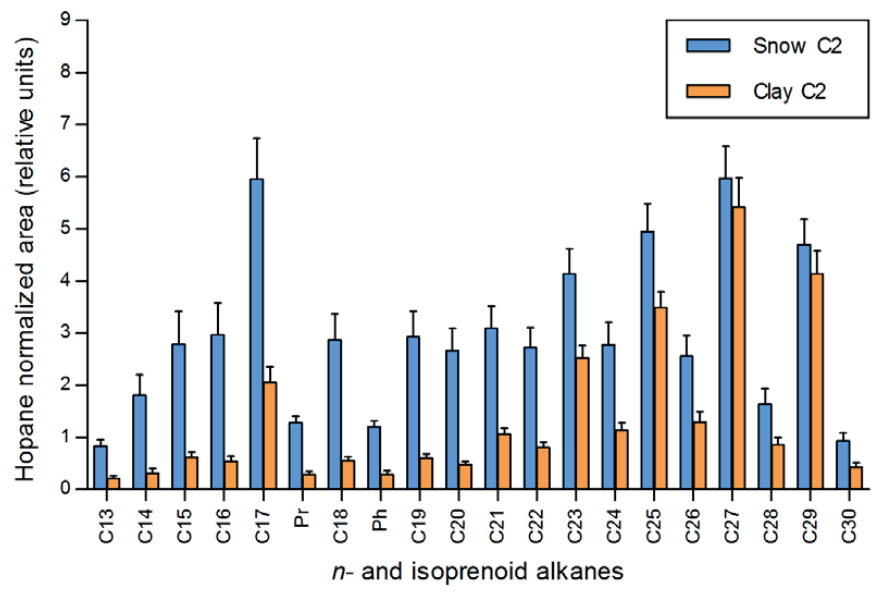

Figure 5.10: Hopane-normalized peak areas for $n$-alkanes and isoprenoid alkanes (pristane and phytane) in Snow C2 and Clay C2 treatments on day 42 (averages with standard deviations of triplicates A-C).

\subsubsection{PAH analysis in gastropods}

Compared to MC252 oil, the oil in a marine snow sample from day 0 contained smaller fractions of low molecular weight (LMW) PAHs (2-ring napthalene and alkylated homologues) and a larger fraction of high molecular weight (HMW) PAHs (3-ring to 6-ring), which is typical of weathered oil (Figure 5.11, top panel). The tissues of H. ulvae from treatments Snow C0 and Clay $\mathrm{C} 0$ contained some background PAHs in the lower molecular weight range, with similar fractions of individual target PAHs (Annex S5.3, Figure S 5.2). The distribution of fractions of PAHs in tissues of H. ulvae from treatments Snow C1 and Clay C1 was similar (Figure 5.11, middle panel), while the concentration of PAHs was higher in Snow C1 gastropods for almost all individual PAHs (Figure 5.11, bottom panel). PAHs in gastropods in Snow C1, but not Clay C1, show a bell-shaped distribution of alkyl homologues for naphthalene $(\mathrm{N})$, phenanthrene $(\mathrm{P})$, and fluoranthene/pyrene (FL/PY) compounds, however not for chrysene/benz(a)anthracene compounds which show a more skewed distribution (Figure 5.11, middle panel). The Total PAH concentration, the sum of all target PAHs, was significantly higher in Clay C2 than in Clay C0 (Figure 5.12). In contrast, in the Snow treatment, the highest levels were found in oil concentration $\mathrm{C} 1$. 

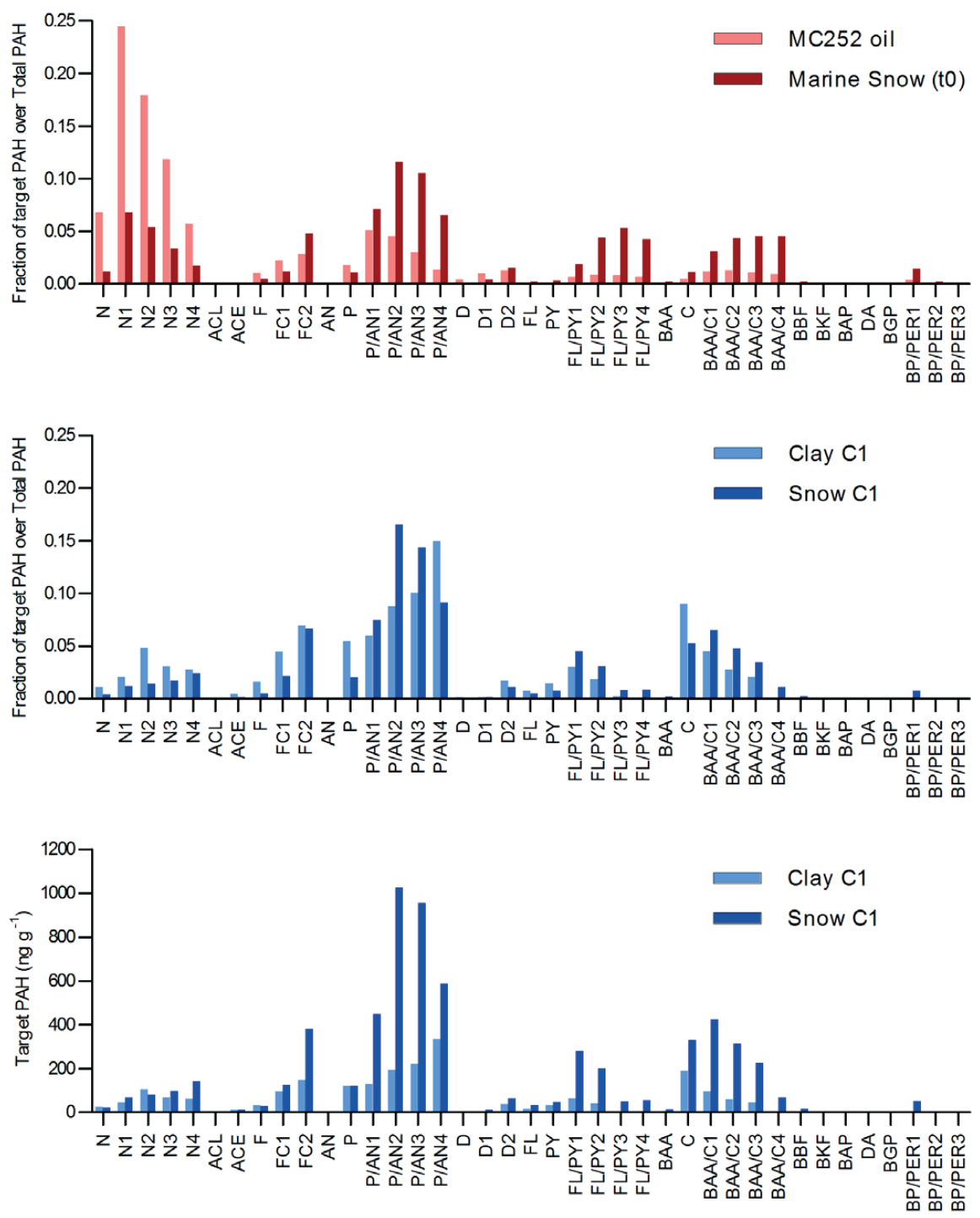

Figure 5.11: Fraction of target PAHs over Total PAH, top panel: MC252 oil and Marine Snow sample at start of experiment ( $\mathrm{t} 0$ ); middle panel: PAHs measured in gastropods from Clay $\mathrm{C} 1$ and Snow $\mathrm{C} 1$ treatments at day 42. Bottom panel: Target PAH concentration (ng g-1 dry weight) measured in gastropods from Clay $\mathrm{C} 1$ and Snow $\mathrm{C} 1$ treatments at day 42. Averages of duplicates A-B. Target PAH labels (x-axis) are as follows: 2-ring PAHs: Naphthalene (N) and alkylated homologues (N 1-4); 3-ring: Acenaphthylene (ACL), Acenaphthene (ACE), Fluorene (F) and alkylated homologues (FC1, FC2), Anthracene (AN), Phenanthrene (P) and Dibenzothiophene (D) and their alkylated homologues (P/AN 1-4, D 1-2), 4-ring: Fluoranthene (FL), Pyrene (PY), Benz[a]anthracene (BAA), Chrysene (C), and their alkylated homologues (FL/PY C1-C4, BAA/C C1-C4), 5-ring: Benzo[b]fluoranthene (BBF), Benzo[k]fluoranthene (BKF), Benzo[a]pyrene (BAP), Dibenz[a,h]anthracene (DA), and alkylated homologues (BP/PER C1-C4), and 6-ring: Benzo[ghi]perylene (BGP). Similar graphs for Clay C2 and Snow C2 can be found in Annex S5.3, Figure S 5.3. 


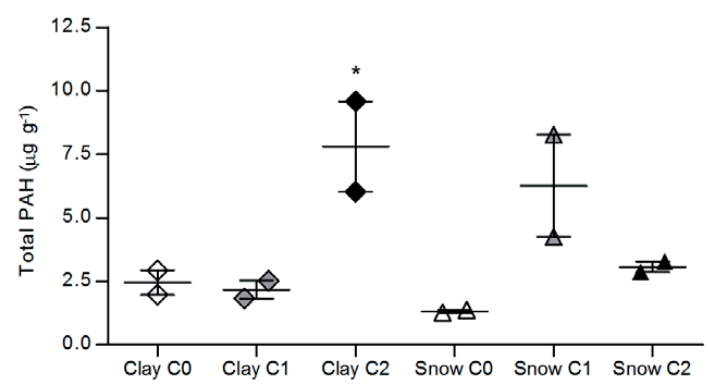

Figure 5.12: Total PAH ( $\mu \mathrm{g} \mathrm{g}^{-1}$ dry weight), measured in gastropods at day 42. Duplicate measurements of microcosms A-B with average, ${ }^{*}$ indicates statistically significantly different than from Clay C0.

\subsection{Discussion}

Our previous experiment (Chapter 4) indicated that the biological traits of organisms (vulnerability for hypoxia, motility, habitat, and feeding habit) determined the effects of oil and marine snow on the organisms. In this experiment, we investigated the effects of oil gradually added with marine snow or clay to Corophium volutator, an infaunal deposit and suspension feeding amphipod, and Hydrobia ulvae, an epifaunal deposit feeding and grazing gastropod.

\subsubsection{Survival and the role of food scarcity}

Survival of C. volutator after 42 days was dose-dependent on oil concentration, and not so much dependent on the presence or absence of marine snow (Figure 5.6): the treatments with oil and marine snow show similar toxicity as the treatments with only oil. The highest concentration of oil in combination with marine snow was slightly less toxic than the highest concentration of only oil. This can be explained by the lower oxygen content in the treatments with marine snow (Figure 5.1 and Figure 5.4), which forces the amphipods out of the sediment layer and into the water column, thereby reducing the exposure to oil. Eventually they will stop swimming to rest on top of the sediment which results in a lower oil exposure compared to burrowing in the contaminated sediment.

Twenty freshly-caught C. volutator were added to replicates D-F on day 58, and survival was assessed on day 80 . Theoretically, if all individuals survived, there would now be 60 C. volutator in one microcosm. However, this is not what was observed (Figure 5.7). In all treatments, except Snow C0, less than 20 individuals on average were found. The triplicate microcosms of Snow C0 had 54, 60, and 68 individuals left. This can indicate that either reproduction took place during the 80 days of the experiment or $C$. volutator smaller than $1 \mathrm{~mm}$ had been present in the sediment that was collected in the field and survived the vigorous sieving and mixing at the start of the experiment. Either way, the significantly higher survival in Snow C0 can point to the 
leading cause of mortality at day 80 : food scarcity. The marine snow can be used as food source, and in the absence of oil the marine snow is adequate to ensure good survival. Most likely, there was food scarcity in all treatments without marine snow, reducing the survival of the organisms. The carrying capacity of those food-scarce systems is 10-20 individuals. There is no difference between the treatments other than Snow C0, indicating that there is no treatment effect anymore: the oil that was present in Clay C2 and Snow C2 did not affect survival of the freshly stocked organisms. Especially the difference between Clay C2 at day 42 and at day 80 is striking. Almost all organisms, except one individual in one of the replicates, were dead at day 42 , but the fact that there were $13 \pm 2$ individuals left at day 80 points to a recovery of the system: apparently, the concentration of toxic oil components had dropped below that of acute toxicity, and oxygen levels were adequate again to sustain the survival of organisms.

Survival of $H$. ulvae in this experiment showed a similar trend as in the previous experiment (Chapter 4, Figure 4.5): only a significantly lower survival in the treatment with marine snow and the highest concentration of oil (Figure 5.6). Our hypothesis is that the marine snow serves as a food source, which will be further discussed in Section 5.4.2. No new H. ulvae were added on day 58 , since the numbers already were so high on day 42 . These high number are most likely due to the presence of individuals smaller than $1 \mathrm{~mm}$ in the sieved sediments at the start, which started to grow during the experiment and were larger than $1 \mathrm{~mm}$ at the sampling times. The same was seen in the previous experiment (Chapter 4). Overall, there was an increase in the number of individuals counted on day 80 , probably due to growth of juveniles that were too small to be removed by sieving at the start of the experiment. Even Snow C2 showed an increase in total numbers ( $54 \pm 17$ at day 42 vs $85 \pm 7$ at day 80 ), although the total number in Snow C2 at day 80 was still significantly lower than in the other treatments (Figure 5.7).

The number of copepods differed between the treatments (Figure 5.8). Copepods were mainly found in the two treatments with marine snow. Again, the marine snow could act as a food source for the organisms. Since benthic harpacticoid copepods are grazers that feed on microalgae, bacteria, and detritus (Rieper, 1982; Vanden Berghe and Bergmans, 1981), it seems likely that the increased bacterial biomass in degrading marine snow and/or the marine snow itself could have served as a food source. Harpacticoid copepods are in general more sensitive to pollution than nematodes (Baguley et al., 2015), and the lack of food probably caused the copepods to be outcompeted by the more opportunistic nematodes that are less sensitive for oxygen depletion and pollution. In contrast to other studies with meiofauna and oil contamination (e.g., Elarbaoui et al., 2015), neither the presence nor the concentration of oil influenced the numbers of surviving copepods or nematodes in this study. Deep-sea meiofaunal analysis after the Deepwater Horizon oil spill showed that nematode abundance increased relative to harpacticoid copepods in areas with oil contamination (Montagna et al., 2013), which could indicate that the DWH spill had a two-fold effect on meiofauna: on the one hand, there was more organic matter on the sediment after MOSSFA, but on the other hand, the copepods were more sensitive to the high oil concentration than the nematodes, which did not decrease in 
numbers. In our experiments, only an enrichment effect occurred by additional food becoming available, but it is important to note that only one replicate core was analyzed for this study.

\subsubsection{Oil exposure of gastropods}

The artificial marine snow used in this experiment contained the polysaccharide alginate as well as phytoplankton biomass. This combination makes it an attractive food source for grazing gastropods, and oil-contaminated marine snow could be a way for them to be orally exposed to the oil. Active avoidance of the sediment surface was observed for the treatments with clean marine snow and marine snow with the lowest oil concentration, but not so clearly in marine snow with the highest oil concentration (Figure 5.5). This could possibly be due to a higher narcotic toxicity of the oil, leading to changes in behavior of the organisms. In the treatments without marine snow, only the Clay C2 treatment showed a short spike in the sediment avoidance during the first few days of the experiment. The differences were not statistically significant, but there is an indication of a trend related to the presence of marine snow on the sediment. When the oxygen concentration starts to increase again (Figure 5.1 and Figure 5.4), the gastropods return to the sediment surface. Active avoidance of oil contamination by $H$. ulvae has been reported before, for example in a mesocosm experiment, where the gastropods escaped experimentally oiled cores (Chronopoulou et al., 2013).

Gastropods are known to have a reduced metabolism for PAHs due to their limited or absent cytochrome P450 activity ((Forbes and Forbes, 1997; Stegeman and Lech, 1991)), therefore the distribution of PAHs observed in the organisms reflects the availability and composition of PAHs in the environment, as can be seen in the oiled snow treatments compared to the marine snow sample (Figure 5.11). The small differences observed in the distribution of PAHs between the oiled snow treatments and the marine snow samples are related to weathering process, as occurred in the environment (e.g. dissolution, degradation, transformation). A shift in the composition of PAHs during weathering (more HMW PAHs relative to LMW PAHs) is consistent with previous reports in environmental samples from the water column and deep-sea sediments (Romero et al., 2016; Romero et al., 2015; Stout et al., 2016). The bell-shaped distribution of alkyl homologues of naphthalene $(\mathrm{N})$, phenanthrene $(\mathrm{P})$, and fluoranthene/pyrene (FL/PY) compounds (Figure 5.11) is in line with observations in the environment, and indicates a petrogenic source of PAHs and weathering processes (Stogiannidis and Laane, 2015; Stout, 2007). This trend was not observed for chrysene/benz(a)anthracene compounds, indicating a more severe weathering of PAHs measured in gastropod tissue relative to the oil-contaminated marine snow sample. Therefore, the composition of PAHs and alkylPAH distributions in gastropods could be used to identify the source of contamination in sediments after oil spills in marine settings. Also, understanding the persistence and toxicity of weathered oil in deep-sea sediments is critical for long-term monitoring and assessment of impacts from oil spills in marine environments. 
Total PAH concentration in gastropods of treatment Snow C1 was higher than in Clay C1, with the same oil concentration (Figure 5.12). Uptake likely occurred via feeding (grazing of marine snow) and not passive dermal uptake (through gills and skin) in the Snow treatment, otherwise PAH concentration in Clay C1 should be similar to concentrations in Snow C1. This is a possible indication for the use of marine snow as food source. Total PAH concentration in gastropods from Snow C1 was higher than in those from Snow C2, even though they actively avoided direct contact with the marine snow on the sediment during the first week of the experiment (Figure 5.5). Later, however, they returned to the sediment surface. The lower survival in Snow C2 (Figure 5.6) can explain why the PAH concentration in gastropods from this treatment is lower than in Snow C1: the analyzed organisms were the ones that did not eat the marine snow, and thus survived, but were not representative for all organisms since only from living animals tissues were extracted and analyzed for PAH levels. The highest PAH concentrations were found in gastropods from Clay C2 (Figure 5.12), however it should be noted that only two replicates were analyzed per treatment. A quite large variation in Total PAH concentration was found in gastropods Clay C2 and Snow C1, which makes it difficult to draw firm conclusions. Our results indicate that marine snow was used as food source by the gastropods, and thus the overall exposure to oil incorporated in marine snow will be higher. Dedicated feeding experiments, in which also fecal pellets are analyzed e.g. with stable isotopes techniques (Dilling and Brzezinski, 2004), could shed more light on whether or not oil is ingested with the marine snow or clay.

\subsubsection{Oil biodegradation}

Compared to the two previous experiments (Chapter 3 and Chapter 4), the sediment of the current experiment contained large amounts of elemental sulfur, even though the sediment was collected at exactly the same location, and an additional cleanup step with activated copper granules was necessary. The results of the chemical analysis in this experiment probably show a mixture of petrogenic hydrocarbons and background levels of biogenic hydrocarbons already present in the sediment. Since the sample matrix of the day 0 marine snow samples, without sediment, was not the same as the sample matrices at the other sampling times, direct comparison between day 0 and day 42 is not possible. The different hydrophobicity of the matrix probably influenced oil retention. In the marine snow samples of day 0 , the lower alkanes are disproportionally depleted compared to the sediment samples of day 42 (data not shown). This hampers calculation of the removal percentage of oil over time in the same way as it could be calculated for the previous two experiments (Table 4.2).

Still, the difference between the hopane-normalized peak areas at day 42 does provide interesting information. The peak areas of Snow C2 and Clay C2 at day 42 (Figure 5.10) showed a similar pattern as was found in the previous two microcosm experiments (Figure 3.3 and Figure 4.3). Since normalization to the recalcitrant biomarker hopane was applied, the absolute peak areas cannot be directly compared between different experiments. However, the trends are the same: in the presence of marine snow, the peak areas are higher than in the absence of marine snow. 
More $n$-alkanes and isoprenoid alkanes disappeared from the samples in the absence of snow, indicating an inhibition of biodegradation by marine snow through the preferential use of oxygen for marine snow biodegradation over oil biodegradation.

\subsubsection{Oxygen depletion}

The thickness of the visibly oxygenated top layer is a good parameter to quantify the effects of oxygen depletion at the sediment surface. Figure 5.4 clearly shows that the oxygenated layer rapidly disappears after addition of marine snow, and it reappears after 20 days. The dissolved oxygen saturation in the water column of these treatments also declined and increased concomitantly with the disappearance and reappearance of the oxygenated layer (Figure 5.1), supporting the results of the quantification of oxygenated layer thickness. Moreover, these observations are in line with our previous microcosm experiment, where no oxygenated layer was seen in microcosms with marine snow after 16 days and the dissolved oxygen saturation was lower in the treatments with marine snow (Chapter 4.3.3, Figure 4.1). The presence of the same artificial marine snow also was shown to deplete oxygen during oil biodegradation in an experimental setting (Rahsepar et al., 2017). Our results are in accordance with field observations, showing decreased pore-water oxygen concentrations in deep-sea sediments covered with marine snow (Hastings et al., 2016).

\subsubsection{Gradual exposure to marine snow}

In contrast to our previous experiments (Chapter 3 and Chapter 4), the layer of marine snow was added over 4 consecutive days. This reflects a somewhat more realistic exposure scenario than adding a $1 \mathrm{~cm}$ layer all at once. We recognize that adding a $1 \mathrm{~cm}$ layer over 4 days still gives a much higher accumulation rate than was observed in the deep-sea, where accumulation rates of $\sim 1 \mathrm{~cm}$ in $4-5$ months were estimated, which is 4-10 fold higher than background sedimentation rates (Brooks et al., 2015). Still, we could observe markedly greater burrowing activity in the experiment with the more gradual marine snow accumulation compared to the instant deposition (Chapter 4). C. volutator were seen burrowing through each newly added thin layer, while no burrowing was observed in the instant deposition of the thicker layer, showing the detrimental effect of large quantities of marine snow on survival of this species. The obvious effect of the presence of oil (Figure 5.3) indicates that the thickness of the added marine snow was not the only factor determining burrowing behavior. Since $C$. volutator are quite sensitive to oil (Evers et al., 1997; Foekema et al., 1996; Wake, 2005), this can lead to synergistic effects between oil and marine snow followed by a reduced oil degradation rate. The reduced burrowing shown in Figure 5.3 was mirrored in the reduced survival as well (Figure 5.6).

Overall, based on this experiment, the direct adverse effects of oil and the indirect adverse effect of marine snow through sediment oxygen depletion disappeared after 80 days, and the food availability then determines survival of benthic invertebrates. Benthic invertebrate species with high motility are more likely to recover after a MOSSFA event, since they are better capable of 
dealing with the adverse effects and recolonization will be faster. Oil contamination in the deepsea benthic ecosystem can pose threats to other parts of the ecosystem through food web effects as well.

\section{Acknowledgements}

This research was made possible in part by a grant from the Gulf of Mexico Research Initiative (Grant Contract \#SA 12-10/GoMRI-007), and in part by the Wageningen UR TripleP@Sea Innovation Program (KB-14-007). Jagoš R. Radović and Thomas B.P. Oldenburg also acknowledge the support from the Canada Foundation for Innovation (CFI), the Natural Sciences and Engineering Research Council of Canada (NSERC) and Canada Research Chairs (CRC), PRG and the University of Calgary. Data will become publicly available through the Gulf of Mexico Research Initiative Information \& Data Cooperative (GRIIDC) at https://data.gulfresearchinitiative.org/data/R4.x267.181:0005 (doi:10.7266/N7BG2M2F). Practical assistance by Babette Bontes, Sofia Kolkman, and Suzanne Woltheus is gratefully acknowledged. 


\subsection{Annex to Chapter 5}

S5.1: Water quality measurements

Figure S 5.1

S5.2: PAHs in Hydrobia ulvae

Figure S 5.2, Figure S 5.3 
S5.1: Water quality measurements
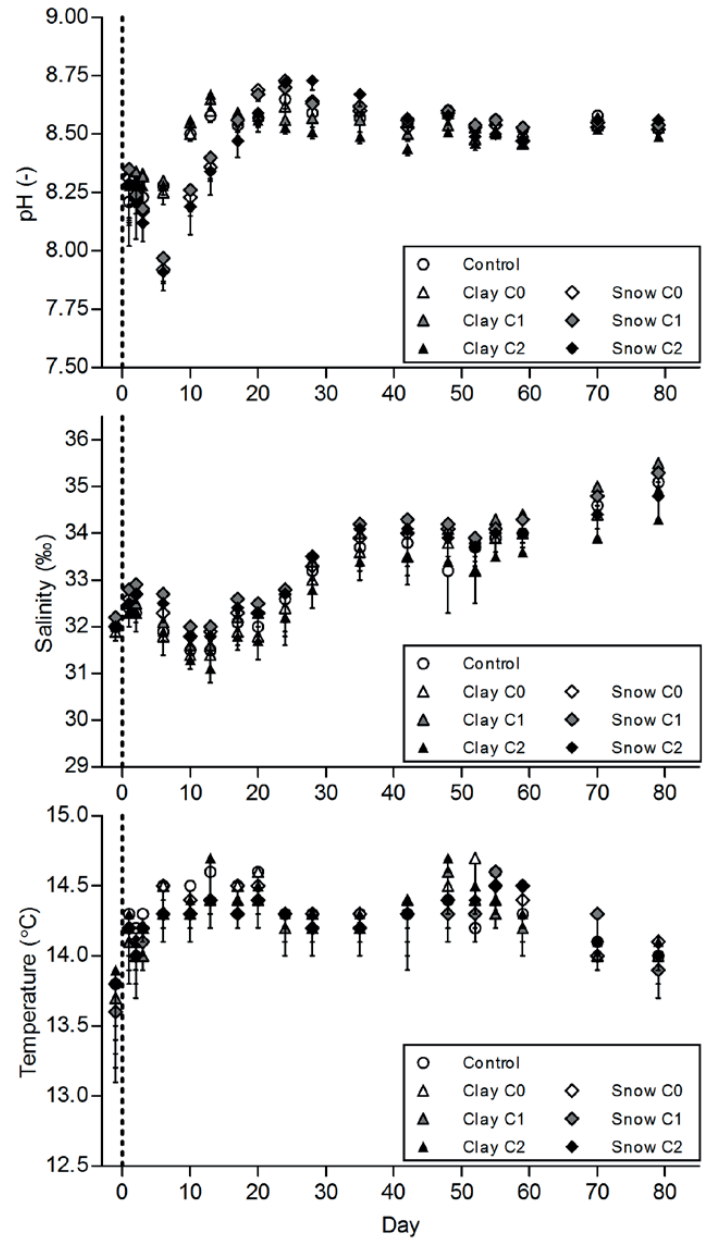

Figure S 5.1: Water column measurements of $\mathrm{pH}$ (top panel), salinity (\%o, middle panel), and temperature $\left({ }^{\circ} \mathrm{C}\right.$, bottom panel). Average and standard deviation of replicates A-F until day 42 and replicates D-F on day $42-80$. 

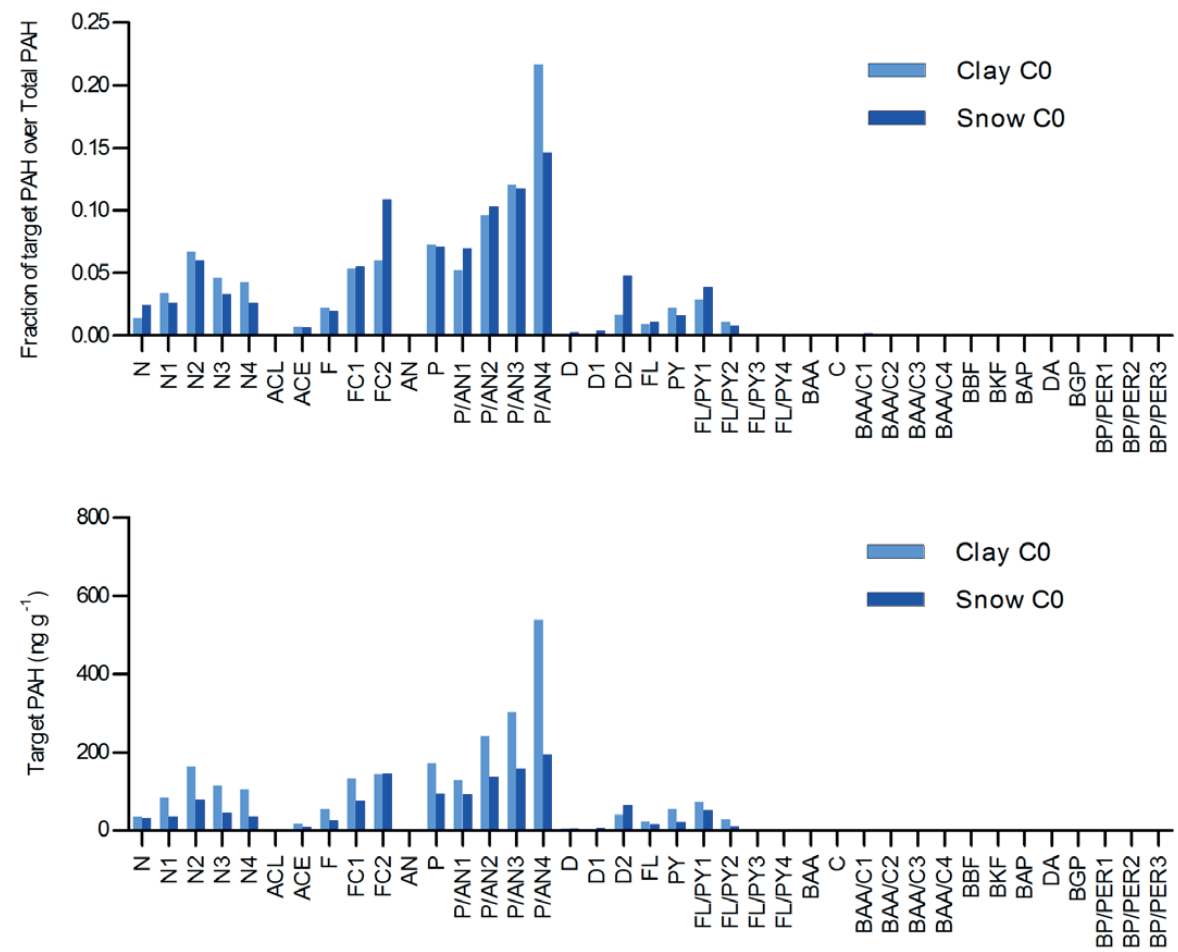

Figure S 5.2: Fraction of target PAHs over Total PAH, measured in gastropods from Snow C0 and Clay C0 treatments at day 42 (top panel), and target PAH concentration (ng g-1 dry weight) measured in gastropods from Snow C0 and Clay C0 treatments at day 42 (bottom panel). Averages of duplicates A-B. Target PAH labels (x-axis) are as follows: 2-ring PAHs: Naphthalene $(\mathrm{N})$ and alkylated homologues (N 14); 3-ring: Acenaphthylene (ACL), Acenaphthene (ACE), Fluorene (F) and alkylated homologues (FC1, FC2), Anthracene (AN), Phenanthrene (P) and Dibenzothiophene (D) and their alkylated homologues (P/AN 1-4, D 1-2), 4-ring: Fluoranthene (FL), Pyrene (PY), Benz[a]anthracene (BAA), Chrysene (C), and their alkylated homologues (FL/PY C1-C4, BAA/C C1-C4), 5-ring: Benzo[b]fluoranthene (BBF), Benzo[k]fluoranthene (BKF), Benzo[a]pyrene (BAP), Dibenz[a,h]anthracene (DA), and alkylated homologues (BP/PER C1-C4), and 6-ring: Benzo[ghi]perylene (BGP). 

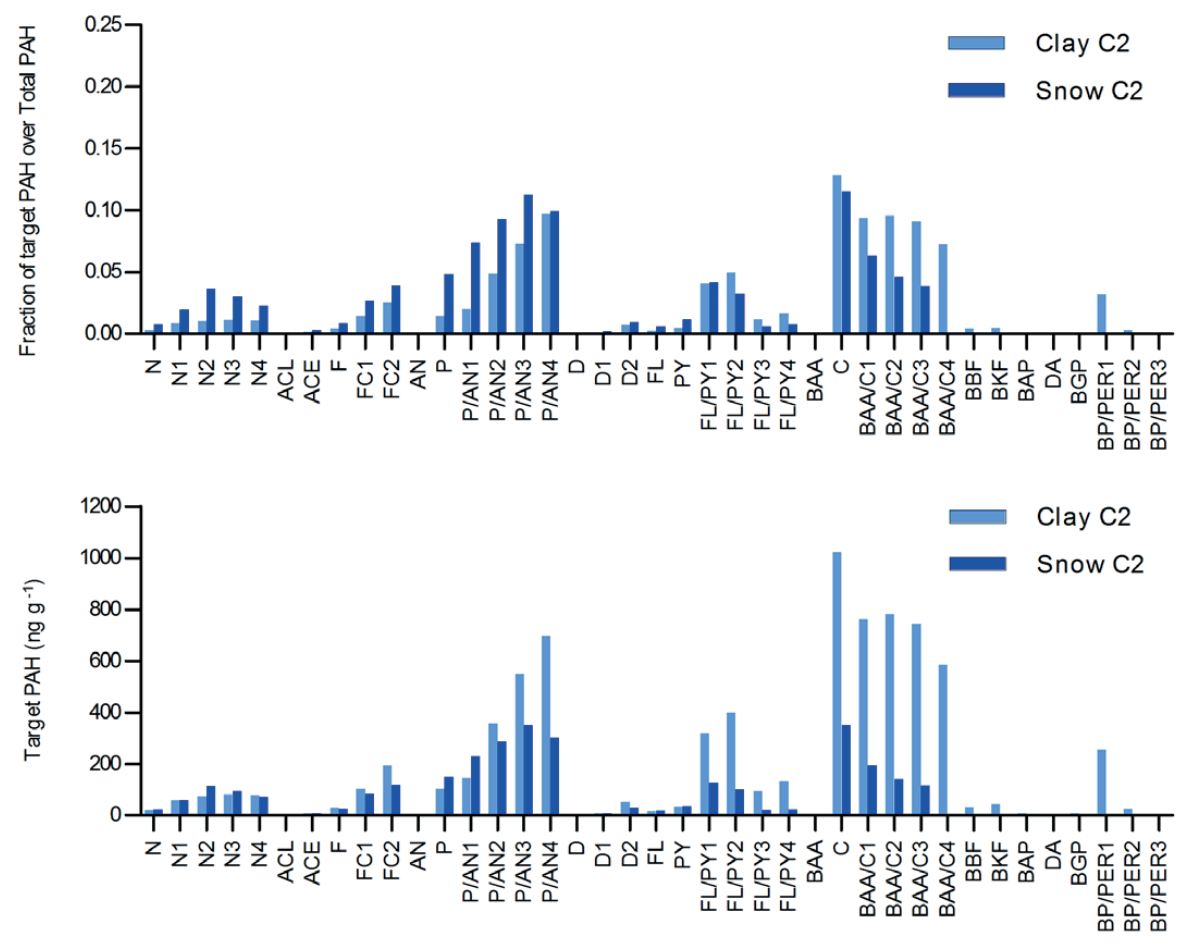

Figure S 5.3: Fraction of target PAHs over Total PAH, measured in gastropods from Snow C2 and Clay $\mathrm{C} 2$ treatments at day 42 (top panel), and target PAH concentration (ng g $\mathrm{g}^{-1}$ dry weight) measured in gastropods from Snow C2 and Clay C2 treatments at day 42 (bottom panel). Averages of duplicates A-B. Target PAH labels (x-axis) are as follows: 2-ring PAHs: Naphthalene (N) and alkylated homologues (N 14); 3-ring: Acenaphthylene (ACL), Acenaphthene (ACE), Fluorene (F) and alkylated homologues (FC1, FC2), Anthracene (AN), Phenanthrene (P) and Dibenzothiophene (D) and their alkylated homologues (P/AN 1-4, D 1-2), 4-ring: Fluoranthene (FL), Pyrene (PY), Benz[a]anthracene (BAA), Chrysene (C), and their alkylated homologues (FL/PY C1-C4, BAA/C C1-C4), 5-ring: Benzo[b]fluoranthene (BBF), Benzo[k]fluoranthene (BKF), Benzo[a]pyrene (BAP), Dibenz[a,h]anthracene (DA), and alkylated homologues (BP/PER C1-C4), and 6-ring: Benzo[ghi]perylene (BGP). 


\section{Chapter 6}

General discussion 


\subsection{Introduction}

The Deepwater Horizon (DWH) oil spill in 2010 was one of the largest oil spills in history, with an unprecedented use of chemical oil spill dispersants. Even after seven years, the overall environmental damage cannot be fully assessed yet. One of the unexpected outcomes of the spill and the spill response operations was the massive formation of marine snow. A phenomenon called MOSSFA, Marine Oil Snow Sedimentation and Flocculent Accumulation, brought approximately $21 \%$ of the total discharged oil down to the benthic ecosystem on the ocean floor (Romero et al., 2017). MOSSFA was likely not unique for the DWH spill, but probably also happened during other spills in the past, and might happen again in the future (Vonk et al., 2015).

This thesis focusses first on the cause of the marine snow formation, and then more in depth on the additional ecotoxicological consequences of this process during oil spills for the benthic ecosystem. First, the role of chemical oil spill dispersants in the formation of Extracellular Polymeric Substances (EPS), one of the main ingredients of marine snow, was examined (Chapter 2). This study revealed that dispersants can induce the formation of EPS by phytoplankton-associated bacteria. The microcosm experiment that followed (Chapter 3) showed that the presence of marine snow on the sediment can cause oxygen depletion when the marine snow is degraded by microorganisms. This lack of oxygen, perhaps in combination with a preference of the microorganisms for marine snow above oil as a food source, hampers oil biodegradation. In the next microcosm experiment (Chapter 4), it was shown that bioturbation by invertebrates can partly counterbalance the inhibitory effect of marine snow on oil biodegradation. This experiment further showed that marine snow reduces survival of some benthic invertebrate species, as does oil itself. Oxygen depletion near the sediment surface seemed to be the main reason for the observed adverse effects of the marine snow, but also indications were found that some invertebrate species were exposed to oil by using the oilcontaminated marine snow as food source. In this way, the presence of marine snow increased the risk of oil exposure for these species. To better mimic the natural situation of marine snow deposition, the (oil-contaminated) marine snow was added more gradually in the final microcosm experiment (Chapter 5). The direct impact of the marine snow itself was less clear, probably because motile animals had more opportunity to climb on top of the marine snow before they suffocated, although oxygen depletion occurred again. This experiment further indicated that benthic invertebrate species with high motility have a higher potential to survive after a MOSSFA event when they are not smothered by the marine snow deposition. Several lines of evidence are presented to indicate that oil-contaminated marine snow can be used as food source resulting in a higher oil exposure, which is further discussed in Section 6.5. 


\subsection{The role of dispersants in marine snow formation}

The marine snow formation as was seen during the DWH spill was most likely facilitated by a combination of (dispersed) oil, phytoplankton, suspended sediments, and EPS. EPS can be produced in natural sea water exposed to dispersed, undispersed, fresh, or weathered oil (Fu et al., 2014; Passow, 2016; Suja et al., 2017). Chapter 2 described how chemical dispersants can induce the formation of EPS in the presence of marine phytoplankton. Using a green algae species and a diatom species treated with antibiotics, it was revealed that the bacteria associated with the phytoplankton cultures were responsible for the dispersant-induced formation of EPS. This EPS contained substantial amounts of polysaccharides and proteins. Indications were found that in absence of light, and thus of photosynthesis by the phytoplankton, less EPS was produced (own unpublished data). This implies that the symbiosis between the phytoplankton and its associated bacterial community provided the bacteria with energy to produce the EPS. Knowing what factors play a role in the formation of EPS is relevant in the field situation, because this means that MOSSFA is more likely to occur if an oil spill happens at a time of high phytoplankton densities, such as during spring algal blooms, which will also harbor large amounts of associated bacteria.

Chemical analysis of the EPS produced by the phytoplankton-associated bacteria in Chapter 2 showed that the EPS contained carbohydrates and proteins, in line with other studies that found these compounds in EPS (Bælum et al., 2012; Gutierrez et al., 2013; Han et al., 2014; Sohm et al., 2011). Increased amounts of polysaccharides in sediment cores after the DWH spill indicate that marine snow was indeed deposited on the sediment (Fridrik et al., 2017; Hollander et al., 2016).

\subsection{To what extent does marine snow affect oil biodegradation?}

\subsubsection{The role of oxygen in oil biodegradation}

The biodegradation of oil was hampered by the presence of marine snow (Figure 4.7), most likely because of oxygen consumption by the degradation of marine snow. Previous experiments with similar artificial marine snow as was used in the present experiments, showed indeed that oxygen was consumed more rapidly in the presence of artificial marine snow (Rahsepar et al., 2017). Oil biodegradation is a predominantly aerobic process and as such relies on the availability of dissolved oxygen. Therefore, if oxygen is consumed by the degradation of marine snow, it will no longer be available for the degradation of oil. Marine snow contains more easily degradable compounds than oil, so it is preferentially degraded first. Only a very limited amount of oil was degraded in the presence of marine snow in the first week of the microcosm experiment (Chapter 4, Table 4.2), and oil degradation increased with an concomitant increase in dissolved oxygen after the first week. During the first week, there was substantial oil biodegradation in absence of marine snow (Table 4.2), but the oil-degrading microorganisms did 
not consume enough oxygen to lower the dissolved oxygen concentrations in the treatments without marine snow (Figure 3.1, Figure 4.1).

Oxygen consumption in the presence of marine snow, as was observed in Chapters 3-5, was also observed in the deep-sea after the DWH spill: respiration of deposited organic material through MOSSFA lead to a decrease in pore-water oxygen concentrations and a shallower redoxcline in sediment cores around the DWH wellhead (Hastings et al., 2016). The consumption of oxygen is probably not due to biodegradation of oil alone: even though the deep-sea plume of dissolved oil which formed during the DWH spill (Hazen et al., 2010) created an oxygen anomaly (Kessler et al., 2011), microbial respiration in the plume was not induced to such an extent that oxygen depletion was to be expected (Camilli et al., 2010).

\subsubsection{The role of benthic invertebrates in oil biodegradation}

In absence of benthic invertebrates, the top layer of the sediment only becomes oxygenated by passive oxygen diffusion from the overlying water into the sediment. The thickness of the oxygenated sediment layer is thus the resultant of the oxygen concentration of the overlying water, the diffusion rate of the oxygen from the water into the sediment, and the consumption of the oxygen in the sediment by microbial activity, which depends on the presence of biodegradable organic matter. Bioturbation by invertebrates increases the permeability of the sediment and thus creates a thicker oxygenated top layer and well-oxygenated burrows in the sediment (Figure 4.4A). The thickness of the oxygenated layer rapidly decreased when marine snow was deposited on top (Figure 5.4), and the oxygenated layer returned when dissolved oxygen increased after marine snow was degraded (Figure 5.1). Bioturbation increased sediment oxygen concentration and thereby enhanced oil biodegradation, compared to the experiment without macro-invertebrates (Figure 4.7). After 42 days, the inhibitory effect of marine snow on oil biodegradation was substantially counterbalanced by the stimulatory effect of the bioturbation.

\subsection{To what extent does marine snow affect benthic invertebrate survival?}

The survival of the benthic invertebrates was related to their biological traits, such as motility and sensitivity to hypoxia and oil toxicity. In Chapter 4 and Chapter 5, three different benthic invertebrate species were exposed to marine snow with or without oil, and to oil attached to kaolin clay. The marine snow and oil were added all at once to the microcosms in Chapter 4, while in Chapter 5 they were added gradually over four days. The gradual addition of marine snow better mimics the natural situation during a MOSSFA event, while addition of a $1 \mathrm{~cm}$ thick layer of marine snow at once may not be realistic, and probably overestimates the adverse effects of marine snow because of smothering (Chapter 4). The main difference in effect between the two methods of marine snow addition was observed in Chapter 5, where the amphipod Corophium volutator was able to burrow through the newly added thinner layers (Figure 5.2, Figure 
5.3), which was not observed in the experiment of Chapter 4. The bivalve Macoma balthica, a relatively sedentary species that can only move small distances, showed a severely reduced survival when all marine snow was added at once (Figure 4.5). Unfortunately, this species could not be included in the last experiment (Chapter 5) due to practical limitations. However, given its slight motility, it might have been able to escape the thinner layer of marine snow that was added each day, compared to the thick layer of marine snow, and thus survival may have been higher.

In the microcosms, which were continuously aerated near the water surface, oxygen saturation levels in the water column never decreased to levels deemed detrimental to aerobic organisms (Figure 4.1, Figure 5.1): in sea water, an oxygen saturation level of $<30 \%$ is considered insufficient for most larger aerobic organisms like benthic invertebrates (Rabalais and Turner, 2013). However, these low values were reached just above and in the top layer of the sediment in microcosms containing marine snow (Figure 4.2). Foraminifera were clearly affected by the lower oxygen conditions in the second microcosm experiment (Figure 4.6), although many hypoxia-tolerant species of foraminifera exist as well (Platon and Sen Gupta, 2013).

The experiment described in Chapter 4 provided indications that marine snow could be used as food source by the benthic invertebrates. The gastropod $H$. ulvae showed a reduced survival when exposed to oil-contaminated marine snow (Figure 4.5), but not when exposed to oil or marine snow separately. In the next experiment, this trend became even more prominent (Figure 5.6), and chemical analyses of PAH content suggested that the gastropods were exposed to oil via consumed marine snow (Section 5.4.2). The experiments described in this thesis provide several lines of evidence for the use of oil-contaminated marine snow as food source, which will be further discussed in Section 6.5.

\subsubsection{Consequences of low sediment oxygen concentration in the field situation}

The consequences of low sediment oxygen concentration in the experiments described in Chapter 4 and Chapter 5 was different for the various test species. Depending on their sensitivity to hypoxia and their motility, organisms might be more or less capable of dealing with low oxygen concentrations in the sediment. Corophium volutator, Hydrobia ulvae, and Macoma balthica are intertidal species, collected from a shallow intertidal mudflat in The Netherlands. Since intertidal organisms are regularly exposed to widely varying oxygen concentrations, they are in general quite tolerant of reduced oxygen levels and have efficient compensatory mechanisms (McMahon, 1988). However, of the three species used in the experiment described in Chapter 4, only H. ulvae is considered very tolerant of hypoxia (Gamenick et al., 1996). Ocean sediments are often going through seasonal cycles of oxic and hypoxic conditions (Morse and Eldridge, 2007; Rabalais et al., 2013), and the large bioturbating and burrowing organisms appear and disappear with these cycles as well (Gutiérrez et al., 2008). Enhanced macrofaunal activity due to higher oxygen levels can turn fully laminated sediments into highly bioturbated sediments with no distinct horizontal layers (Levin et al., 2009). Vice-versa, the sudden appearance of 
laminations in sediments can point to an abrupt end of bioturbation, as was seen in sediment cores from the Gulf of Mexico around the DWH wellhead (Brooks et al., 2015; Schwing et al., 2015). These sediment cores also showed a clear decline in benthic foraminifera (Schwing et al., 2015) and decreased pore-water oxygen concentrations, most likely due to the respiration of marine snow (Hastings et al., 2016) and possibly also oil.

However, low sediment oxygen concentrations in the microcosm experiments cannot directly be translated to the field situation. In our experiments, the layer of marine snow was $1 \mathrm{~cm}$ thick, while in the field layers of several centimeters were observed (Hollander et al., 2016). Oxygen penetration from the overlying water into this thicker layer will be slower and less deep than in our experiment. Moreover, the water in the microcosms was continuously aerated, which is not the case in deep-sea waters, where low bottom water oxygen levels can occur.

\subsection{Marine snow as food source and food web implications of MOSSFA}

Marine snow in the water column and on the sediment can be used as food source by many kinds of organisms, such as zooplankton, echinoderms, polychaeates, and fish (Alldredge and Silver, 1988; Asgaard and Bromley, 2008; Guidi et al., 2008; Turner, 2002; Wu et al., 2013). In freshwater streams, bacterial EPS and flocculent aggregates play a large role in the carbon cycling via benthic invertebrates (Hall and Meyer, 1998). As mentioned in Section 6.4, the experiments described in this thesis revealed multiple indications that marine snow and EPS on the sediment can be used by benthic organisms as food source and can be a vector for oil towards other parts of the ecosystem. Four indications of marine snow as food source are discussed below.

First, chemical analysis of the EPS produced by the phytoplankton-associated bacteria in Chapter 2 showed that the EPS contained carbohydrates and proteins, as mentioned in Section 6.2. Carbohydrates and proteins are suitable food sources for many zooplankton and fish species (Decho, 1990; Wotton, 2004a), as well as for bacteria (Arnosti et al., 2015), and could make marine oil snow attractive to eat.

Second, after 80 days of exposure, there was a significantly higher survival of the detritus feeding amphipod Corophium volutator in the treatment with clean artificial marine snow compared to the controls without marine snow (Chapter 5). In the clean marine snow group, approximately 60 individuals survived, close to the theoretical maximum number, while less than 20 animals were found in the control situation (Figure 5.7). The higher survival in the presence of clean marine snow can be explained by the use of marine snow as food, while there was food scarcity in the microcosms of the other treatments.

Third, reduced survival of Hydrobia ulvae in treatments with oil-contaminated marine snow (Figure 4.5, Figure 5.6, Figure 5.7) can indicate that the gastropods, which are grazers and deposit feeders, use the marine snow as food source. They are highly motile and thus can escape adverse 
conditions like oil contamination and hypoxia, so they do not need to be exposed to oil if they choose not to. The organisms could escape the oil on the sediment in treatments with only oil by sticking to the glass wall of the microcosms, and survival in these treatments was similar to the control situation. Clean marine snow, or marine snow with a low oil concentration, does not affect the survival either. However, $H$. ulvae from the treatment with marine snow and low oil concentration did show a higher PAH body burden than the treatment with the same oil concentration without marine snow (Figure 5.12). This suggests that the gastropods consumed oil-contaminated marine snow, but a toxic body burden was not reached. In the marine snow treatment with high oil concentration more animals died, but the remaining living animals did not have a higher PAH body burden than the gastropods from the marine snow with low oil concentration.

Fourth, the higher number of benthic copepods in treatments with marine snow, either clean or with the highest oil concentration (Figure 5.8), indicates that the conditions in these two treatments were more suitable for these copepods and the presence of oil was not relevant. Considering the feeding habits of benthic copepods (Rieper, 1982; Vanden Berghe and Bergmans, 1981), it is likely that marine snow can be used as food source, while there was not enough food in the other treatments to support a large copepod population. Competition between copepods and nematodes could also play a role: copepods are outcompeted by the less sensitive nematodes for food, so when more food is available they are able to coexist.

Consumption of oil-contaminated marine snow by the benthic organisms may have a wider reaching effect than only impacts on the benthic ecosystem. The benthic organisms themselves are food source for many other marine species. Food web effects after the DWH spill were observed from plankton (Graham et al., 2010) all the way up to top predators like common bottlenose dolphins (Schwacke et al., 2014). Tarnecki and Patterson (2015) revealed that red snapper, an ecologically and economically important fish species in the northern Gulf of Mexico, shifted diet from pelagic prey towards benthic prey and was found to have elevated levels of PAH metabolites of petrogenic origin in bile after the DWH spill (Murawski et al., 2014). Golden tilefish, a demersal fish living in close contact with sediments, had prolonged higher biliary PAH concentrations compared to red snapper and king snake eel, which are less closely associated with sediments (Snyder et al., 2015). This shows that oil-contaminated sediments after a MOSSFA event can have consequences in other parts of the food web as well, not just in the benthos.

\subsection{Recovery of the benthic ecosystem after MOSSFA in the field situation}

Chapter 5 showed that in our experimental setting, the direct adverse effects of oil and the indirect adverse effect of marine snow through sediment oxygen depletion disappear after 80 days, and the food availability then determines survival of benthic invertebrates. Direct extrapolation to the field situation is difficult, since the microcosms were discrete artificial 
systems with well-defined boundaries. Apart from the newly introduced amphipods at day 58, there was no recruitment from outside, and organisms could also not escape to other places, although the gastropods were often seen climbing the glass walls. Due to their motility, both the amphipod and the gastropod would be expected to escape, either by swimming or floating, to locations with less adverse conditions in the field situation. The most recent estimate puts the total spatial extent of sedimentary oil deposition at $\sim 76,000 \mathrm{~km}^{2}$ (Romero et al., 2017). However, the distribution of the deposition is likely to be patchy since the export of aggregates to deep water is spatially heterogeneous (Daly et al., 2016; Guidi et al., 2008; Passow and Ziervogel, 2016). Advective transport of sediments over horizontal distances also affects the depositional pattern of oil-contaminated aggregates (Brooks et al., 2015), moving oil-contaminated aggregates to previously clean locations. The patchiness would allow escape of benthic organisms at the boundaries of these contaminated patches to more or less oil-free refuges, when other locations are not inhabitable because of oil toxicity or hypoxia. From there, surviving organisms could recolonize other parts when the conditions become favorable again. Species that are best able to cope with any remaining oil and relatively low oxygen levels, can best take advantage of the added food sources, have highly motile life stages, and have fast reproduction are expected to recolonize the contaminated areas first. This can be opportunistic species with pelagic larvae, like polychaetes (Dauer et al., 1992).

Deposition of clean sediments on top of the contaminated sediments could speed up recovery of the benthic ecosystem, especially in case of high deposition rates. The benthic recovery time might in that case be shorter because the oil contamination is covered with clean material, which is a suitable habitat for recolonization. However, if deposition rates are low, benthic recovery might take longer as oil has to be degraded before the habitat is suitable for benthic species again.

Field studies of benthic recovery after the DWH spill indicate that recovery rates of abundance and diversity of benthic species are different (Table 6.1). While abundance of benthic foraminifera and meiofauna recovers in 1-3 years, diversity of meiofauna and macrofauna takes more than 4 years to recover (Schwing and Montagna, 2017; Schwing et al., In Review). Longer time series and better baseline studies will improve the prediction of benthic recovery, as will identifying the ultimate depocenters of MOSSFA material where oil-contaminated sediments and marine snow will eventually be deposited by vertical and advective sediment transport (Schwing et al., 2017). Retrospective analysis of IXTOC I data can also improve predictions of DWH recovery. Even after more than 30 years, oil can still be found in layers of sediment affected by the 1979 IXTOC I blowout in the southern Gulf of Mexico (Hollander et al., 2016). Petrocarbon is also found in planktonic foraminifera at sedimentary depths related to the blowout (Fridrik et al., 2017; Machain-Castillo et al., 2017; Schwing and Montagna, 2017). Given the similarities between the IXTOC I and DWH blowouts, scientists are now studying the ecological recovery in the southern Gulf of Mexico after the IXTOC I blowout, to learn more about the mechanisms of recovery in the northern Gulf of Mexico (Hollander et al., 2016). 
Table 6.1: Observed years to benthic recovery after the DWH oil spill (data from (Schwing and Montagna, 2017), from sediment cores around the DWH; max. distance from wellhead: $177 \mathrm{~km}$ )

\begin{tabular}{lll}
\hline Group & Abundance & Diversity \\
\hline Foraminifera & $1-3$ & $3-4$ \\
Meiofauna & 1 & $>4$ \\
Macrofauna & 4 & $>4$ \\
\hline
\end{tabular}

\subsection{Relevance of MOSSFA in shallow waters}

The conditions in the experiments presented in this thesis clearly cannot be considered duplicates of the conditions in the deep-sea of the Gulf of Mexico. The aim was to investigate mechanisms of formation and possible effects of MOSSFA. The fundamental insights are expected to be applicable, with some specific refinements, to other environments as well. Although the MOSSFA phenomenon was not unique to the DWH spill, it was the only time it was observed and documented during a spill. Retrospective analyses indicate that it also happened during the IXTOC I spill in 1979, and most likely in some other situations as well (Hollander et al., 2016; Vonk et al., 2015). This makes it highly likely that under specific conditions MOSSFA could occur again, both in deep-sea as well as in coastal regions (Daly et al., 2016).

Important similarities between the DWH spill and the IXTOC I spill are that they were both marine blowouts releasing huge quantities of oil in deltaic regions, occurring during periods of phytoplankton blooms (Hu et al., 2011; Jernelov and Linden, 1981) and high suspended solids input, either due to flushing of the river system (Bianchi et al., 2011) or high river discharge after heavy rainfall (Jernelov and Linden, 1981). Planktonic foraminiferal accumulation rates (PFAR) in cores around the IXTOC I well showed a 1-3 fold increase, similar to the 3-4 fold increase in the PFAR around the DWH well, with a concomitant increase in diatom 16S RNA and bulk polysaccharides found in both cases (Fridrik et al., 2017). One of the main differences between IXTOC I and DWH is the depth at which the blowout occurred: the Macondo well was at 1,500 $\mathrm{m}$ below sea level, while the IXTOC I well was only at $56 \mathrm{~m}$. This indicates that MOSSFA is not restricted to deep-water systems. Shallow waters in deltaic systems often have high suspended solids input due to river inflow. The marine snow can be formed at the surface followed by settling onto the sediment, but during a blowout EPS can also be formed in the deep-sea by oildegrading microorganisms. The route to the benthic system, however, highly determines the composition of the oil. In shallow waters, the oil will still contain a higher percentage of the more toxic (more water soluble) compounds because of lower dissolution due to the shorter residence time in the water column. On the other hand, more volatile oil components will evaporate faster on the water surface. Both evaporation and dissolution will weather the oil and thus affect the toxicity. When less weathered oil will be deposited via MOSSFA, it will be more toxic to the benthic ecosystem. Of course, under high pressure in the deep sea physico-chemical 
properties of oil are different, such as oil dissolution, and chemical repartitioning between gasliquid-water phases (Gros et al., 2016). At the pressure and temperature of the deep-sea, hydrocarbons larger than C14 may crystallize into waxy solids and rapid gas expansion of dissolved methane may cause gas bubble formation inside the oil droplets (Thibodeaux et al., 2011). Methane hydrates, a solid phase of methane gas trapped in a crystal structure, can also be formed once methane gas encounters cold water at high pressure (Camilli et al., 2012; Johansen, 2003). These differences between deep-sea and shallow waters in oil chemistry and phasepartitioning will affect the fate and effects of the spilled oil. In the experiments described in Chapters 3-5, slight weathering was simulated by evaporating the oil for $24 \mathrm{~h}$ at room temperature prior to the start of the experiments. This allows a more generalized mechanistic approach, but it would be very interesting to perform a comparable study the added effects of marine snow under high-pressure conditions with more or less weathered oil.

\subsection{Future perspective: MOSSFA in the Arctic}

It is not really a question if another large oil spill like the DWH spill will occur, it is rather a matter of when and where, and whether we are better prepared now. Because of the intensive study of the DWH spill and its aftermath, there is now more knowledge about spill prevention, spill response, and preparation in case of large oil spills. The knowledge gained during the DWH spill can also be applied in other situations, with different regional characteristics, such as the Arctic. For many years, oil exploration in the Arctic region was limited by the ice coverage, but extended ice-free seasons in the Beaufort Sea and Chukchi Sea have opened opportunities for oil exploration (Gardiner et al., 2013; Larsen et al., 2014). Because of the expansion of oil and gas exploration towards the Arctic regions, the possible occurrence of MOSSFA in these regions should be considered in oil spill contingency plans.

The Arctic ecosystem is largely dependent on the primary production in spring phytoplankton blooms, which occurs after breakup of the sea ice, and fuels high secondary production (Dünweber et al., 2010). The main drivers of MOSSFA are presence of EPS producing biomass, suspended solids, and (dispersed) oil (Daly et al., 2016). It is likely that this specific combination of factors occurs in Arctic regions in spring, and thus MOSSFA could occur. Actually, EPS and marine oil snow formation was previously reported in Arctic, Antarctic, and subarctic waters in experimental settings (Krembs and Engel, 2001; Mancuso Nichols et al., 2004; Suja et al., 2017), but not yet observed during oil spills. Climate change is expected to increase plankton biomass in the Arctic (Zhang et al., 2010), and also increased suspended particle densities can occur due to increased sediment fluxes from rivers and melting land ice masses, leading to a temporary increase in runoff with high sediment load (Lewis and Lamoureux, 2010; Moore et al., 2009). Also, coastal erosion could increase due to wave action on open waters and coasts without ice cover (Larsen et al., 2014). Of course, the lower temperatures will influence the chemical-physical composition of spilled oil in another way compared to warmer conditions, for example reduced 
surface evaporation and higher viscosity. Overall, because of the potential risk for MOSSFA formation in the Arctic and the expansion of oil and gas exploration in these regions, more research into the possible effects of MOSSFA in cold climates is necessary, and oil spill contingency plans should take the possible benthic effects of oil spills into account.

\subsection{General conclusions}

The focus of this thesis was on the additional ecotoxicological consequences of MOSSFA during oil spills for the benthic ecosystem. Dispersant-induced formation of EPS by phytoplanktonassociated bacteria is one of the important ingredients leading to a MOSSFA event during an oil spill. MOSSFA transports oil to the benthic ecosystem in association with marine snow. This study showed that presence of marine snow on sediment inhibits oil biodegradation via competition for oxygen during degradation. This also reduced survival of less motile benthic invertebrates. When bioturbation by benthic invertebrates was possible, this partly counterbalanced the inhibitory effect of marine snow on oil biodegradation. Some species were specifically exposed to marine snow-associated oil by using this as food source. Overall, the presence of marine snow adds to the risk of spilled oil via reducing oil biodegradation, suffocating benthic organisms and acting as a vector for oil towards the food web. 
References 
Aberle, N., Malzahn, A.M., Grey, J., Hillebrand, H., Wiltshire, K.H., 2009. Altered complementary feeding strategies of the consumers Hydrobia ulvae and Idotea emarginata via passive selectivity. Helgoland Marine Research 63, 189197. http://dx.doi.org/10.1007/s10152-009-0148-9

Adams, J., Sweezey, M., Hodson, P.V., 2014. Oil and oil dispersant do not cause synergistic toxicity to fish embryos. Environmental Toxicology and Chemistry 33, 107-114. http://dx.doi.org/10.1002/etc.2397

Aeppli, C., Nelson, R.K., Radović, J.R., Carmichael, C.A., Valentine, D.L., Reddy, C.M., 2014. Recalcitrance and degradation of petroleum biomarkers upon abiotic and biotic natural weathering of Deepwater Horizon oil. Environmental Science \& Technology 48, 6726-6734. http://dx.doi.org/10.1021/es500825q

Ahmed, A.E.R., Labavitch, J.M., 1978. A simplified method for accurate determination of cell wall uronide content. Journal of Food Biochemistry 1, 361-365. http://dx.doi.org/10.1111/j.1745-4514.1978.tb00193.x

Al-Halbouni, D., Dott, W., Hollender, J., 2009. Occurrence and composition of extracellular lipids and polysaccharides in a full-scale membrane bioreactor. Water Research 43, 97-106. https://doi.org/10.1016/i.watres.2008.10.008

Alexander, C.R., Hooper, M.J., Cacela, D., Smelker, K.D., Calvin, C.S., Dean, K.M., Bursian, S.J., Cunningham, F.L., Hanson-Dorr, K.C., Horak, K.E., Isanhart, J.P., Link, J., Shriner, S.A., Godard-Codding, C.A.J., 2017. CYP1A protein expression and catalytic activity in double-crested cormorants experimentally exposed to deepwater Horizon Mississippi Canyon 252 oil. Ecotoxicology and Environmental Safety 142, 79-86. http://dx.doi.org/10.1016/i.ecoenv.2017.02.049

Alldredge, A., 1998. The carbon, nitrogen and mass content of marine snow as a function of aggregate size. Deep Sea Research Part I: Oceanographic Research Papers 45, 529-541. http://dx.doi.org/10.1016/S09670637(97)00048-4

Alldredge, A.L., Passow, U., Logan, B.E., 1993. The abundance and significance of a class of large, transparent organic particles in the ocean. Deep Sea Research Part I: Oceanographic Research Papers 40, 1131-1140. http://dx.doi.org/10.1016/0967-0637(93)90129-Q

Alldredge, A.L., Silver, M.W., 1988. Characteristics, dynamics and significance of marine snow. Progress in Oceanography 20, 41-82. http://dx.doi.org/10.1016/0079-6611(88)90053-5

Almeda, R., Wambaugh, Z., Wang, Z., Hyatt, C., Liu, Z., Buskey, E.J., 2013. Interactions between Zooplankton and Crude Oil: Toxic Effects and Bioaccumulation of Polycyclic Aromatic Hydrocarbons. PLoS ONE 8. http://dx.doi.org/10.1371/journal.pone.0067212

Anderson, J.W., Neff, J.M., Cox, B.A., Tatem, H.E., Hightower, G.M., 1974. Characteristics of dispersions and watersoluble extracts of crude and refined oils and their toxicity to estuarine crustaceans and fish. Marine Biology 27, 75-88. http://dx.doi.org/10.1007/bf00394763

Arnosti, C., Ziervogel, K., Yang, T., Teske, A., 2015. Oil-derived marine aggregates - hot spots of polysaccharide degradation by specialized bacterial communities. Deep Sea Research Part II: Topical Studies in Oceanography. http://dx.doi.org/10.1016/i.dsr2.2014.12.008

Asgaard, U., Bromley, R.G., 2008. Echinometrid sea urchins, their trophic styles and corresponding bioerosion, in: Wisshak, M., Tapanila, L. (Eds.), Current Developments in Bioerosion. Springer Berlin Heidelberg, Berlin, Heidelberg, pp. 279-303. http://dx.doi.org/10.1007/978-3-540-77598-0_15

Atlas, R.M., Hazen, T.C., 2011. Oil Biodegradation and Bioremediation: A Tale of the Two Worst Spills in U.S. History. Environmental Science \& Technology 45, 6709-6715. http://dx.doi.org/10.1021/es2013227

Atlas, R.M., Stoeckel, D.M., Faith, S.A., Minard-Smith, A., Thorn, J.R., Benotti, M.J., 2015. Oil Biodegradation and OilDegrading Microbial Populations in Marsh Sediments Impacted by Oil from the Deepwater Horizon Well Blowout. Environmental Science \& Technology 49, 8356-8366. http://dx.doi.org/10.1021/acs.est.5b00413

Aurand, D., Coelho, G., 2005. Cooperative Aquatic Toxicity Testing of Dispersed Oil and the "Chemical Response to Oil Spills: Ecological Effects Research Forum (CROSERF).". Ecosystem Management \& Associates, Inc., Lusby, MD. Technical Report 07-03, p105.

Bælum, J., Borglin, S., Chakraborty, R., Fortney, J.L., Lamendella, R., Mason, O.U., Auer, M., Zemla, M., Bill, M., Conrad, M.E., Malfatti, S.A., Tringe, S.G., Holman, H.-Y., Hazen, T.C., Jansson, J.K., 2012. Deep-sea bacteria enriched by oil and dispersant from the Deepwater Horizon spill. Environmental Microbiology 14, 24052416. http://dx.doi.org/10.1111/j.1462-2920.2012.02780.x

Baguley, J.G., Montagna, P.A., Cooksey, C., Hyland, J.L., Bang, H.W., Morrison, C., Kamikawa, A., Bennetts, P., Saiyo, G., Parsons, E., Herdener, M., Ricci, M., 2015. Community response of deep-sea soft-sediment metazoan meiofauna to the Deepwater Horizon blowout and oil spill. Marine Ecology Progress Series 528, 127-140. http://dx.doi.org/10.3354/meps11290

Barata, C., Calbet, A., Saiz, E., Ortiz, L., Bayona, J.M., 2005. Predicting single and mixture toxicity of petrogenic polycyclic aromatic hydrocarbons to the copepod Oithona davisae. Environmental Toxicology and Chemistry 24, 2992-2999. http://dx.doi.org/10.1897/05-189r.1 
Beaulieu, S.E., 2002. Accumulation and fate of phytodetritus on the sea floor, in: Gibson, R.N., Barnes, M., Atkinson, R.J.A. (Eds.), Oceanography and Marine Biology: an Annual Review. Taylor \& Francis, pp. 171-232.

Bennett, B., Larter, S.R., 2000. Quantitative separation of aliphatic and aromatic hydrocarbons using silver ion-silica solid-phase extraction. Analytical Chemistry 72, 1039-1044. http://dx.doi.org/10.1021/ac9910482

Beyer, J., Trannum, H.C., Bakke, T., Hodson, P.V., Collier, T.K., 2016. Environmental effects of the Deepwater Horizon oil spill: A review. Marine Pollution Bulletin 110, 28-51. http://dx.doi.org/10.1016/j.marpolbul.2016.06.027

Bhattacharyya, S., Klerks, P.L., Nyman, J.A., 2003. Toxicity to freshwater organisms from oils and oil spill chemical treatments in laboratory microcosms. Environmental Pollution 122, 205-215. http://dx.doi.org/10.1016/S0269-7491(02)00294-4

Bianchi, T.S., Cook, R.L., Perdue, E.M., Kolic, P.E., Green, N., Zhang, Y., Smith, R.W., Kolker, A.S., Ameen, A., King, G., Ojwang, L.M., Schneider, C.L., Normand, A.E., Hetland, R., 2011. Impacts of diverted freshwater on dissolved organic matter and microbial communities in Barataria Bay, Louisiana, U.S.A. Marine Environmental Research 72, 248-257. http://dx.doi.org/10.1016/i.marenvres.2011.09.007

Bik, H.M., Halanych, K.M., Sharma, J., Thomas, W.K., 2012. Dramatic Shifts in Benthic Microbial Eukaryote Communities following the Deepwater Horizon Oil Spill. PLoS ONE 7, e38550. http://dx.doi.org/10.1371/journal.pone.0038550

Blumer, M., 1957. Removal of Elemental Sulfur from Hydrocarbon Fractions. Analytical Chemistry 29, 1039-1041. http://dx.doi.org/10.1021/ac60127a014

Bochdansky, A.B., van Aken, H.M., Herndl, G.J., 2010. Role of macroscopic particles in deep-sea oxygen consumption. Proceedings of the National Academy of Sciences 107, 8287-8291. http://dx.doi.org/10.1073/pnas.0913744107

Bolt, H.M., Roos, P.H., 2008. Chapter 2 Generation of Reactive Intermediates by Cytochromes P450, in: Ioannides, C. (Ed.), Cytochromes P450: Role in the Metabolism and Toxicity of Drugs and other Xenobiotics. The Royal Society of Chemistry, pp. 46-94. 10.1039/9781847558428-00046

BP, 2010. Mississippi Canyon 252 Weathered Crude Oil (Louisiana Light Sweet Crude) Material Safety Data Sheet. p7.

BP Gulf Science Data, 2013. MC 252 Oil Characterization from parent sample collected from the Q4000 Well Intervention vessel on June 19, 2010. https://data.gulfresearchinitiative.org/data/BP.x750.000:0004.

BP Gulf Science Data, 2017a. Application of dispersants to surface oil slicks by aircraft and by boat in approved areas of the Gulf of Mexico from April 22, 2010 to final application on July 19, 2010. Distributed by: Gulf of Mexico Research Initiative Information and Data Cooperative (GRIIDC), Harte Research Institute, Texas A\&M University-Corpus Christi. Available from: http://data.gulfresearchinitiative.org/data/BP.x750.000:0017.

BP Gulf Science Data, 2017b. Chemical analysis and physical properties of weathered, unweathered, and surrogate crude oils from the Deepwater Horizon accident in the Gulf of Mexico, July 2010 to January 2011. Distributed by: Gulf of Mexico Research Initiative Information and Data Cooperative (GRIIDC), Harte Research Institute, Texas A\&M University-Corpus Christi. Available from: http://data.gulfresearchinitiative.org/data/BP.x750.000:0003.

BP Gulf Science Data, 2017c. Subsea Dispersant Application records collected during the Deepwater Horizon (DWH) accident near the Mississippi Canyon block 252 wellhead from April 30 to July 22, 2010. Distributed by: Gulf of Mexico Research Initiative Information and Data Cooperative (GRIIDC), Harte Research Institute, Texas A\&M University-Corpus Christi. Available from: http://data.gulfresearchinitiative.org/data/BP.x750.000:0018.

Brafield, A.E., 1963. The effects of oxygen deficiency on the behaviour of Macoma balthica (L.). Animal Behaviour 11, 345-346. http://dx.doi.org/10.1016/S0003-3472(63)80122-0

Brils, J.M., Huwer, S.L., Kater, B.J., Schout, P.G., Harmsen, J., Delvigne, G.A.L., Scholten, M.C.T., 2002. Oil effect in freshly spiked marine sediment on Vibrio fischeri, Corophium volutator, and Echinocardium cordatum. Environmental Toxicology and Chemistry 21, 2242-2251. http://dx.doi.org/10.1002/etc.5620211031

Brooks, G.R., Larson, R.A., Schwing, P.T., Romero, I., Moore, C., Reichart, G.-J., Jilbert, T., Chanton, J.P., Hastings, D.W., Overholt, W.A., Marks, K.P., Kostka, J.E., Holmes, C.W., Hollander, D., 2015. Sedimentation Pulse in the NE Gulf of Mexico following the 2010 DWH Blowout. PLoS ONE 10, e0132341. https://doi.org/10.1371/journal.pone.0132341

Brummer, Y., Cui, S.W., 2005. Understanding Carbohydrate Analysis, in: Cui, S.W. (Ed.), Food Carbohydrates. CRC Press, Boca Raton, FL, USA. http://dx.doi.org/10.1201/9780203485286.ch2

Bursian, S.J., Alexander, C.R., Cacela, D., Cunningham, F.L., Dean, K.M., Dorr, B.S., Ellis, C.K., Godard-Codding, C.A., Guglielmo, C.G., Hanson-Dorr, K.C., Harr, K.E., Healy, K.A., Hooper, M.J., Horak, K.E., Isanhart, J.P., Kennedy, L.V., Link, J.E., Maggini, I., Moye, J.K., Perez, C.R., Pritsos, C.A., Shriner, S.A., Trust, K.A., Tuttle, P.L., 2017. Overview of avian toxicity studies for the Deepwater Horizon Natural Resource Damage 
$\begin{array}{lllll}\text { Assessment. Ecotoxicology and } \quad \text { Environmental } & \text { Safety }\end{array}$ http://dx.doi.org/10.1016/i.ecoenv.2017.03.046

Butler, R.G., Harfenist, A., Leighton, F.A., Peakall, D.B., 1988. Impact of Sublethal Oil and Emulsion Exposure on the Reproductive Success of Leach's Storm-Petrels: Short and Long-Term Effects. Journal of Applied Ecology 25, 125-143. http://dx.doi.org/10.2307/2403614

C-IMAGE, 2017. C-IMAGE web page. Retrieved from http://www.marine.usf.edu/c-image/

Camilli, R., Di Iorio, D., Bowen, A., Reddy, C.M., Techet, A.H., Yoerger, D.R., Whitcomb, L.L., Seewald, J.S., Sylva, S.P., Fenwick, J., 2012. Acoustic measurement of the Deepwater Horizon Macondo well flow rate. Proceedings of the National Academy of Sciences 109, 20235-20239. http://dx.doi.org/10.1073/pnas.1100385108

Camilli, R., Reddy, C.M., Yoerger, D.R., Van Mooy, B.A.S., Jakuba, M.V., Kinsey, J.C., McIntyre, C.P., Sylva, S.P., Maloney, J.V., 2010. Tracking Hydrocarbon Plume Transport and Biodegradation at Deepwater Horizon. Science 330, 201-204. http://www.jstor.org/stable/40931813

Campo, P., Venosa, A.D., Suidan, M.T., 2013. Biodegradability of Corexit 9500 and Dispersed South Louisiana Crude Oil at 5 and $25 \quad{ }^{\circ} \mathrm{C}$. Environmental Science \& Technology 47, 1960-1967. http://dx.doi.org/10.1021/es303881h

Carrales Jr., M., Martin, R.W., 1975. Sulfur content of crude oils. U.S. Bureau of Mines, Washington. Information Circular 8676, p61.

CEN, 2012. Oil spill identification - waterborne petroleum and petroleum products - part 2: Analytical pethodology and interpretation of results. PD CEN/TR 15522-2:2012.

Chanton, J., Zhao, T., Rosenheim, B.E., Joye, S., Bosman, S., Brunner, C., Yeager, K.M., Diercks, A.R., Hollander, D., 2015. Using Natural Abundance Radiocarbon To Trace the Flux of Petrocarbon to the Seafloor Following the Deepwater Horizon Oil Spill. Environmental Science \& Technology 49, 847-854. http://dx.doi.org/10.1021/es5046524

Chikere, C.B., Okpokwasili, G.C., Chikere, B.O., 2011. Monitoring of microbial hydrocarbon remediation in the soil. 3 Biotech 1, 117-138. http://dx.doi.org/10.1007/s13205-011-0014-8

Chronopoulou, P.M., Fahy, A., Coulon, F., Païssé, S., Goñi-Urriza, M., Peperzak, L., Alvarez, L.A., McKew, B.A., Lawson, T., Timmis, K.N., Duran, R., Underwood, G.J.C., McGenity, T.J., 2013. Impact of a simulated oil spill on benthic phototrophs and nitrogen-fixing bacteria in mudflat mesocosms. Environmental Microbiology 15, 242-252. http://dx.doi.org/10.1111/j.1462-2920.2012.02864.x

Clark, J.R., Bragin, G.E., Febbo, E.J., Letinski, D.J., 2001. Toxicity Of Physically And Chemically Dispersed Oils Under Continuous And Environmentally Realistic Exposure Conditions: Applicability To Dispersant Use Decisions In Spill Response Planning. International Oil Spill Conference Proceedings 2001, 1249-1255. http://dx.doi.org/10.7901/2169-3358-2001-2-1249

Coelho, G., Clark, J., Aurand, D., 2013. Toxicity testing of dispersed oil requires adherence to standardized protocols to assess potential real world effects. Environmental Pollution 177, 185-188. https://doi.org/10.1016/i.envpol.2013.02.004

Conklin-Brittain, N.L., Dierenfeld, E.S., Wrangham, R.W., Norconk, M., Silver, S.C., 1999. Chemical Protein Analysis: A Comparison of Kjeldahl Crude Protein and Total Ninhydrin Protein from Wild, Tropical Vegetation. Journal of Chemical Ecology 25, 2601-2622. http://dx.doi.org/10.1023/a:1020835120701

Corzo, A., Morillo, J.A., Rodríguez, S., 2000. Production of transparent exopolymer particles (TEP) in cultures of Chaetoceros calcitrans under nitrogen limitation. Aquatic Microbial Ecology 23, 63-72. http://dx.doi.org/10.3354/ame023063

Couillard, C.M., Lee, K., Légaré, B., King, T.L., 2005. Effect of dispersant on the composition of the wateraccommodated fraction of crude oil and its toxicity to larval marine fish. Environmental Toxicology and Chemistry 24, 1496-1504. http://dx.doi.org/10.1897/04-267r.1

Czaczyk, K., Myszka, K., 2007. Biosynthesis of Extracellular Polymeric Substances (EPS) and Its Role in Microbial Biofilm Formation. Pol. J. Environ. Stud. 16, 799-806.

Dale, V.H., Kling, C.L., Meyer, J.L., Sanders, J., Stallworth, H., Armitage, T., Wangsness, D., Bianchi, T., Blumberg, A., Boynton, W., Conley, D.J., Crumpton, W., David, M., Gilbert, D., Howarth, R.W., Lowrance, R., Mankin, K., Opaluch, J., Paerl, H., Reckhow, K., Sharpley, A.N., Simpson, T.W., Snyder, C.S., Wright, D., 2010. Hypoxia in the Northern Gulf of Mexico. Springer, New York. http://dx.doi.org/10.1007/978-0-38789686-1

Daly, K.L., Passow, U., Chanton, J., Hollander, D., 2016. Assessing the impacts of oil-associated marine snow formation and sedimentation during and after the Deepwater Horizon oil spill. Anthropocene 13, 18-33. http://dx.doi.org/10.1016/i.ancene.2016.01.006 
Danovaro, R., Gambi, C., Dell'Anno, A., Corinaldesi, C., Fraschetti, S., Vanreusel, A., Vincx, M., Gooday, A.J., 2008. Exponential Decline of Deep-Sea Ecosystem Functioning Linked to Benthic Biodiversity Loss. Current Biology 18, 1-8. http://dx.doi.org/10.1016/j.cub.2007.11.056

Das, N., Chandran, P., 2011. Microbial Degradation of Petroleum Hydrocarbon Contaminants: An Overview. Biotechnology Research International 2011, 941810. http://dx.doi.org/10.4061/2011/941810

Dauer, D.M., Rodi, A.J., Ranasinghe, J.A., 1992. Effects of Low Dissolved Oxygen Events on the Macrobenthos of the Lower Chesapeake Bay. Estuaries 15, 384-391. http://dx.doi.org/10.2307/1352785

Davis, S., 2003. LegalOil.com Information Paper No. 2 Fingerprinting Oil.

De Philippis, R., Vincenzini, M., 1998. Exocellular polysaccharides from cyanobacteria and their possible applications. FEMS Microbiology Reviews 22, 151-175. http://dx.doi.org/10.1111/i.1574-6976.1998.tb00365.x

Decho, A.W., 1990. Microbial exopolymer secretions in ocean environments: their role(s) in food webs and marine processes, in: Barnes, M. (Ed.), Oceanography and Marine Biology: An Annual Review. Aberdeen University Press, pp. 73-153.

Decho, A.W., Gutierrez, T., 2017. Microbial Extracellular Polymeric Substances (EPSs) in Ocean Systems. Frontiers in Microbiology 8. http://dx.doi.org/10.3389/fmicb.2017.00922

Dell'Amore, C., 2010. "Sea Snot" Explosion Caused by Gulf Oil Spill? Retrieved from http://news.nationalgeographic.com/news/2010/09/100916-sea-snot-gulf-bp-oil-spill-marine-snowscience-environment/

DeMarini, D.M., 2011. Overview of the Toxicity of the Oil Dispersant Corexit. Environmental and Molecular Mutagenesis 52, S30. http://dx.doi.org/10.1002/em.20693

Dilling, L., Brzezinski, M.A., 2004. Quantifying marine snow as a food choice for zooplankton using stable silicon isotope tracers. Journal of Plankton Research 26, 1105-1114. https://doi.org/10.1093/plankt/fbh103

Diniz, G., Barbarino, E., Oiano-Neto, J., Pacheco, S., Lourenço, S., 2001. Gross Chemical Profile and Calculation of Nitrogen-to-Protein Conversion Factors for Five Tropical Seaweeds. American Journal of Plant Sciences 2, 287-296. http://dx.doi.org/10.4236/ajps.2011.23032

Dünweber, M., Swalethorp, R., Kjellerup, S., Nielsen, T.G., Arendt, K.E., Hjorth, M., Tönnesson, K., Møller, E.F., 2010. Succession and fate of the spring diatom bloom in Disko Bay, western Greenland. Marine Ecology Progress Series 419, 11-29. https://doi.org/10.3354/meps08813

Elarbaoui, S., Richard, M., Boufahja, F., Mahmoudi, E., Thomas-Guyon, H., 2015. Effect of crude oil exposure and dispersant application on meiofauna: an intertidal mesocosm experiment. Environmental Science: Processes \& Impacts 17, 997-1004. http://dx.doi.org/10.1039/c5em00051c

Englyst, H.N., Cummings, J.H., 1984. Simplified method for the measurement of total non-starch polysaccharides by gas - liquid chromatography of constituent sugars as alditol acetates. The Analyst 109, 937-942. http://dx.doi.org/10.1039/AN9840900937

Evers, E.H.G., Dulfer, J.W., Schobben, H.P.M., 1997. Oil and oil constituents : an analysis of problems associated with oil in the aquatic environment. RIKZ, Den Haag.

FAO, 2003. Food energy - methods of analysis and conversion factors. Report of a Technical Workshop, Rome, 3-6 December 2002.

Finch, B.E., Marzooghi, S., Toro, D.M.D., Stubblefield, W.A., 2017. Phototoxic potential of undispersed and dispersed fresh and weathered Macondo crude oils to Gulf of Mexico marine organisms. Environmental Toxicology and Chemistry, n/a-n/a. http://dx.doi.org/10.1002/etc.3808

Fingas, M., 2011a. Chapter 3 - Introduction to Oil Chemistry and Properties, in: Fingas, M. (Ed.), Oil Spill Science and Technology. Gulf Professional Publishing, Boston, pp. 51-59. https://doi.org/10.1016/B978-1-85617-9430.10003-6

Fingas, M., 2011b. Chapter 15 - Oil Spill Dispersants: A Technical Summary, in: Fingas, M. (Ed.), Oil Spill Science and Technology. Gulf Professional Publishing, Boston, pp. 435-582. https://doi.org/10.1016/B978-1-85617943-0.10015-2

Fingas, M., 2011c. Chapter 23 - An Overview of In-Situ Burning, in: Fingas, M. (Ed.), Oil Spill Science and Technology. Gulf Professional Publishing, Boston, pp. 737-903. https://doi.org/10.1016/B978-1-85617-943-0.10023-1

Fingas, M., 2011d. Chapter 28 - Introduction to Oil Spill Contingency Planning and Response Initiation, in: Fingas, M. (Ed.), Oil Spill Science and Technology. Gulf Professional Publishing, Boston, pp. 1027-1031. https://doi.org/10.1016/B978-1-85617-943-0.10028-0

Fingas, M., 2016. Oil Spills and Response, in: Dhanak, M.R., Xiros, N.I. (Eds.), Springer Handbook of Ocean Engineering. Springer International Publishing, Cham, pp. 1067-1094. http://dx.doi.org/10.1007/978-3319-16649-0_43

Fisher, C.R., Hsing, P.-Y., Kaiser, C.L., Yoerger, D.R., Roberts, H.H., Shedd, W.W., Cordes, E.E., Shank, T.M., Berlet, S.P., Saunders, M.G., Larcom, E.A., Brooks, J.M., 2014. Footprint of Deepwater Horizon blowout impact 
to deep-water coral communities. Proceedings of the National Academy of Sciences 111, 11744-11749. http://dx.doi.org/10.1073/pnas.1403492111

Fisher, C.R., Montagna, P.A., Sutton, T.T., 2016. How did the Deepwater Horizon oil spill impact deep-sea ecosystems? Oceanography 29, 182-195. http://dx.doi.org/10.5670/oceanog.2016.82

Foekema, E.M., Schobben, H.P.M., Marquenie, J., Scholten, M.C.T., 1996. A Comparison between the Toxicity of Porduced Oil and Gas Condensate Using a New Sediment Bioassay for Deposited Oil, in: Reed, M., Johnsen, S. (Eds.), Produced Water Seminar. Environmental Science Research, Trondheim, Norway, pp. 61-68.

Forbes, V.E., Forbes, T.L., 1997. Dietary absorption of sediment-bound fluoranthene by a deposit-feeding gastropod using the 14C:51Cr dual-labeling method. Environmental Toxicology and Chemistry 16, 1002-1009. http://dx.doi.org/10.1002/etc.5620160520

FOSC, 2011. On scene coordinator report : Deepwater Horizon oil spill. U.S. Dept. of Homeland Security, U.S. Coast Guard, https://lccn.loc.gov/2012427375, p244.

Fridrik, E., Schwing, P.T., Larson, R., Brooks, G., hollander, D., Lincoln, S., Overholt, W.A., 2017. Planktic Foraminiferal Records of MOSSFA and Petrocarbon Incorporation Following the Ixtoc-1 and DWH Blowouts, 2017 Gulf of Mexico Oil Spill and Ecosystem Science Conference, New Orleans, LA, USA.

Fu, J., Gong, Y., Zhao, X., O'Reilly, S.E., Zhao, D., 2014. Effects of oil and dispersant on formation of marine oil snow and transport of oil hydrocarbons. Environmental Science \& Technology 48, 14392-14399. http://dx.doi.org/10.1021/es5042157

Gamenick, I., Jahn, A., Vopel, K., Giere, O., 1996. Hypoxia and sulphide as structuring factors in a macrozoobenthic community on the Baltic Sea shore: Colonisation studies and tolerance experiments. Marine Ecology Progress Series 144, 73-85. http://dx.doi.org/10.3354/meps144073

García, M.T., Campos, E., Marsal, A., Ribosa, I., 2009. Biodegradability and toxicity of sulphonate-based surfactants in aerobic and anaerobic aquatic environments. Water Research 43, 295-302. http://dx.doi.org/10.1016/i.watres.2008.10.016

Gardiner, W.W., Word, J.Q., Word, J.D., Perkins, R.A., McFarlin, K.M., Hester, B.W., Word, L.S., Ray, C.M., 2013. The acute toxicity of chemically and physically dispersed crude oil to key arctic species under arctic conditions during the open water season. Environmental Toxicology and Chemistry 32, 2284-2300. http://dx.doi.org/10.1002/etc. 2307

Gelpi, E., Schneider, H., Mann, J., Oró, J., 1970. Hydrocarbons of geochemical significance in microscopic algae. Phytochemistry 9, 603-612. http://dx.doi.org/10.1016/S0031-9422(00)85700-3

Geng, X., Boufadel, M.C., Wrenn, B., 2013. Mathematical modeling of the biodegradation of residual hydrocarbon in a variably-saturated sand column. Biodegradation 24, 153-163. http://dx.doi.org/10.1007/s10532-012-9566$\underline{5}$

George-Ares, A., Clark, J.R., 2000. Aquatic toxicity of two Corexit ${ }^{\circledR}$ dispersants. Chemosphere 40, 897-906. http://dx.doi.org/10.1016/S0045-6535(99)00498-1

Gesteira, J.L.G., Dauvin, J.C., 2000. Amphipods are Good Bioindicators of the Impact of Oil Spills on Soft-Bottom Macrobenthic Communities. Marine Pollution Bulletin 40, 1017-1027. http://dx.doi.org/10.1016/S0025$\underline{326 X(00) 00046-1}$

Glover, C.M., Mezyk, S.P., Linden, K.G., Rosario-Ortiz, F.L., 2014. Photochemical degradation of Corexit components in ocean water. Chemosphere 111, 596-602. http://dx.doi.org/10.1016/i.chemosphere.2014.05.012

GoMRI, 2011. \$112.5 Million Awarded to Research Consortia Studying Effects of Deepwater Horizon Oil Spill on Gulf of Mexico. Retrieved from http://gulfresearchinitiative.org/112-5-million-awarded-research-consortiastudying-effects-deepwater-horizon-oil-spill-gulf-mexico/

Gong, Y., Zhao, X., Cai, Z., O’Reilly, S.E., Hao, X., Zhao, D., 2014. A review of oil, dispersed oil and sediment interactions in the aquatic environment: Influence on the fate, transport and remediation of oil spills. Marine Pollution Bulletin 79, 16-33. http://dx.doi.org/10.1016/j.marpolbul.2013.12.024

Graham, W.M., Condon, R.H., Carmichael, R.H., D’Ambra, I., Patterson, H.K., Linn, L.J., Hernandez Jr., F.J., 2010. Oil carbon entered the coastal planktonic food web during the Deepwater Horizon oil spill. Environmental Research Letters 5, 045301. https://doi.org/10.1088/1748-9326/5/4/045301

Gray, J.L., Kanagy, L.K., Furlong, E.T., Kanagy, C.J., McCoy, J.W., Mason, A., Lauenstein, G., 2014. Presence of the Corexit component dioctyl sodium sulfosuccinate in Gulf of Mexico waters after the 2010 Deepwater Horizon oil spill. Chemosphere 95, 124-130. http://dx.doi.org/10.1016/j.chemosphere.2013.08.049

Gros, J., Reddy, C.M., Nelson, R.K., Socolofsky, S.A., Arey, J.S., 2016. Simulating Gas-Liquid-Water Partitioning and Fluid Properties of Petroleum under Pressure: Implications for Deep-Sea Blowouts. Environmental Science \& Technology 50, 7397-7408. http://dx.doi.org/10.1021/acs.est.5b04617

Guidi, L., Gorsky, G., Claustre, H., Miquel, J.C., Picheral, M., Stemmann, L., 2008. Distribution and fluxes of aggregates $>100 \mu \mathrm{m}$ in the upper kilometer of the South-Eastern Pacific. Biogeosciences 5, 1361-1372. http://dx.doi.org/10.5194/bg-5-1361-2008 
Gullett, B.K., Aurell, J., Holder, A., Mitchell, W., Greenwell, D., Hays, M., Conmy, R., Tabor, D., Preston, W., George, I., Abrahamson, J.P., Vander Wal, R., Holder, E., 2017. Characterization of emissions and residues from simulations of the Deepwater Horizon surface oil burns. Marine Pollution Bulletin 117, 392-405. https://doi.org/10.1016/i.marpolbul.2017.01.083

Gutiérrez, D., Enríquez, E., Purca, S., Quipúzcoa, L., Marquina, R., Flores, G., Graco, M., 2008. Oxygenation episodes on the continental shelf of central Peru: Remote forcing and benthic ecosystem response. Progress in Oceanography 79, 177-189. https://doi.org/10.1016/i.pocean.2008.10.025

Gutierrez, T., Berry, D., Yang, T., Mishamandani, S., McKay, L., Teske, A., Aitken, M.D., 2013. Role of Bacterial Exopolysaccharides (EPS) in the Fate of the Oil Released during the Deepwater Horizon Oil Spill. PLoS ONE 8, e67717. http://dx.doi.org/10.1371/journal.pone.0067717

Gutierrez, T., Mulloy, B., Black, K., Green, D.H., 2007. Glycoprotein emulsifiers from two marine Halomonas species: chemical and physical characterization. Journal of Applied Microbiology 103, 1716-1727. http://dx.doi.org/10.1111/j.1365-2672.2007.03407.x

Hahn, M.E., 1998. The aryl hydrocarbon receptor: A comparative perspective. Comparative Biochemistry and Physiology Part C: Pharmacology, Toxicology and Endocrinology 121, 23-53. https://doi.org/10.1016/S0742-8413(98)10028-2

Hahn, M.E., 2002. Aryl hydrocarbon receptors: Diversity and evolution. Chemico-Biological Interactions 141, 131-160. http://dx.doi.org/10.1016/s0009-2797(02)00070-4

Hall, R.O., Meyer, J.L., 1998. The Trophic Significance of Bacteria in a Detritus-Based Stream Food Web. Ecology 79, 1995-2012. http://dx.doi.org/10.1890/0012-9658(1998)079[1995:ttsobi]2.0.co;2

Han, P.P., Sun, Y., Jia, S.R., Zhong, C., Tan, Z.L., 2014. Effects of light wavelengths on extracellular and capsular polysaccharide production by Nostoc flagelliforme. Carbohydrate Polymers 105, 145-151. https://doi.org/10.1016/i.carbpol.2014.01.061

Hastings, D.W., Schwing, P.T., Brooks, G.R., Larson, R.A., Morford, J.L., Roeder, T., Quinn, K.A., Bartlett, T., Romero, I.C., Hollander, D.J., 2016. Changes in sediment redox conditions following the BP DWH blowout event. Deep-Sea Research Part II: Topical Studies in Oceanography 129, 167-178. http://dx.doi.org/10.1016/i.dsr2.2014.12.009

Hay, I.D., Rehman, Z.U., Ghafoor, A., Rehm, B.H.A., 2010. Bacterial biosynthesis of alginates. Journal of Chemical Technology and Biotechnology 85, 752-759. http://dx.doi.org/10.1002/jctb.2372

Hazen, T.C., Dubinsky, E.A., DeSantis, T.Z., Andersen, G.L., Piceno, Y.M., Singh, N., Jansson, J.K., Probst, A., Borglin, S.E., Fortney, J.L., Stringfellow, W.T., Bill, M., Conrad, M.E., Tom, L.M., Chavarria, K.L., Alusi, T.R., Lamendella, R., Joyner, D.C., Spier, C., Baelum, J., Auer, M., Zemla, M.L., Chakraborty, R., Sonnenthal, E.L., D’haeseleer, P., Holman, H.-Y.N., Osman, S., Lu, Z., Van Nostrand, J.D., Deng, Y., Zhou, J., Mason, O.U., 2010. Deep-Sea Oil Plume Enriches Indigenous Oil-Degrading Bacteria. Science 330, 204-208. http://dx.doi.org/10.1126/science.1195979

Head, I.M., Jones, D.M., Roling, W.F.M., 2006. Marine microorganisms make a meal of oil. Nature Reviews Microbiology 4, 173-182. http://dx.doi.org/10.1038/nrmicro1348

Hill, D.R., Peat, A., Potts, M., 1994. Biochemistry and structure of the glycan secreted by desiccation-tolerant Nostoc commune (Cyanobacteria). Protoplasma 182, 126-148. http://dx.doi.org/10.1007/bf01403474

Hollander, D.J., Flower, B., Larson, R., Brooks, G., Romero, I., Zinzola, N., Means, Z., 2012. Deposition, distribution and fate of Macondo oil in the sediments of the northeastern Gulf of Mexico, Ocean Sciences Meeting, Salt Lake City, USA.

Hollander, D.J., Machain-Castillo, M.-L., Gracia, A., Alexander-Valdés, H.A., Brooks, G.R., Chanton, J., EscobarBriscon, E., Hastings, D.W., Kostka, J., Larson, R.A., Romero, I.C., Ruiz-Fernández, A.C., Sánchez-Cabeza, J., Schwing, P.T., Lincoln, S., Oldenburg, T.B.P., Freeman, K., Montagna, P.A., 2016. Marine Oil Snow Sedimentation \& Flocculent Accumulation MOSSFA Events-The Rule or the Exception to the Rule? Comparative Analysis of the Deepwater Horizon \& IXTOC-1 Blowouts, Where did the oil go? Sea GrantNOAA Symposium. https://gulfseagrant.files.wordpress.com/2016/03/oilspillseminar-wheredidtheoilgohollander.pdf, Mobile, AL.

Hollander, D.J., Romero, I.C., Schwing, P.T., Brooks, G.R., Kostka, J., 2014. Disentangling The Roles Of River Discharge, Productivity, Oil Burning \& Dispersant On The Marine Oil-Snow Deposition (MOSSFA) Event Following The DWH Blowout Ocean Sciences Meeting, Honolulu, Hawaii USA.

Hollebone, B., 2011. Chapter 4 - Measurement of Oil Physical Properties, in: Fingas, M. (Ed.), Oil Spill Science and Technology. Gulf Professional Publishing, Boston, pp. 63-86. https://doi.org/10.1016/B978-1-85617-943$\underline{0.10004-8}$

Hsing, P.-Y., Fu, B., Larcom, E., Berlet, S., Shank, T., Govindarajan, A., Lukasiewicz, A., Dixon, P., Fisher, C.R., 2013. Evidence of lasting impact of the Deepwater Horizon oil spill on a deep Gulf of Mexico coral community. Elementa: Science of the Anthropocene 1, 12. http://dx.doi.org/10.12952/journal.elementa.000012 
Hu, C., Weisberg, R.H., Liu, Y., Zheng, L., Daly, K.L., English, D.C., Zhao, J., Vargo, G.A., 2011. Did the northeastern Gulf of Mexico become greener after the Deepwater Horizon oil spill? Geophysical Research Letters 38, L09601. http://dx.doi.org/10.1029/2011g1047184

Hylleberg, J., Henriksen, K., 1980. The central role of bioturbation in sediment mineralization and element re-cycling. Ophelia Suppl. 1, 1-16.

IARC, 2017. Agents Classified by the IARC Monographs, Volumes 1-118. International Agency for Research on Cancer, http://monographs.iarc.fr/ENG/Classification/ClassificationsAlphaOrder.pdf, p36.

IMO, 2017. International Convention for the Prevention of Pollution from Ships (MARPOL). Retrieved from http://www.imo.org/en/About/Conventions/ListOfConventions/Pages/International-Convention-forthe-Prevention-of-Pollution-from-Ships-\%28MARPOL\%29.aspx

Jaligama, S., Chen, Z., Saravia, J., Yadav, N., Lomnicki, S.M., Dugas, T.R., Cormier, S.A., 2015. Exposure to Deepwater Horizon Crude Oil Burnoff Particulate Matter Induces Pulmonary Inflammation and Alters Adaptive Immune Response. Environmental Science \& Technology 49, 8769-8776. http://dx.doi.org/10.1021/acs.est.5b01439

Jernelov, A., Linden, O., 1981. Ixtoc I: A case study of the world's largest oil spill. Ambio 10, 299-306. http://www.jstor.org/stable/4312725

Jewett, S.C., Dean, T.A., Smith, R.O., Blanchard, A., 1999. 'Exxon Valdez' oil spill: impacts and recovery in the softbottom benthic community in and adjacent to eelgrass beds. Marine Ecology Progress Series 185, 59-83. http://dx.doi.org/10.3354/meps185059

Jia, C., Li, X., Zhang, L., Francis, D., Tai, P., Gong, Z., Liu, W., 2017. Extracellular Polymeric Substances from a Fungus Are More Effective than Those from a Bacterium in Polycyclic Aromatic Hydrocarbon Biodegradation. Water, Air, and Soil Pollution 228. http://dx.doi.org/10.1007/s11270-017-3330-8

Jochens, A.E., Bender, L.C., DiMarco, S.F., Morse, J.W., Kennicutt II, M.C., Howard, M.K., Nowlin Jr., W.D., 2005. Understanding the processes that maintain the oxygen levels in the deep Gulf of Mexico: Synthesis report. U.S. Dept. of the Interior, Minerals Management Service, Gulf of Mexico OCS Region, New Orleans, LA. , OCS Study MMS 2005-032, p142.

Johansen, Ø., 2003. Development and verification of deep-water blowout models. Marine Pollution Bulletin 47, 360368. https://doi.org/10.1016/S0025-326X(03)00202-9

Joshi, N., Ngwenya, B.T., French, C.E., 2012. Enhanced resistance to nanoparticle toxicity is conferred by overproduction of extracellular polymeric substances. Journal of Hazardous Materials 241-242, 363-370. http://dx.doi.org/10.1016/i.jhazmat.2012.09.057

Joye, S.B., MacDonald, I.R., Leifer, I., Asper, V., 2011. Magnitude and oxidation potential of hydrocarbon gases released from the BP oil well blowout. 4, 160-164. http://dx.doi.org/10.1038/ngeo1067

Joye, S.B., Teske, A.P., Kostka, J.E., 2014. Microbial Dynamics Following the Macondo Oil Well Blowout across Gulf of Mexico Environments. BioScience 64, 766-777. http://dx.doi.org/10.1093/biosci/biu121

Kessler, J.D., Valentine, D.L., Redmond, M.C., Du, M., Chan, E.W., Mendes, S.D., Quiroz, E.W., Villanueva, C.J., Shusta, S.S., Werra, L.M., Yvon-Lewis, S.A., Weber, T.C., 2011. A Persistent Oxygen Anomaly Reveals the Fate of Spilled Methane in the Deep Gulf of Mexico. Science 331, 312-315. http://dx.doi.org/10.1126/science.1199697

Khelifa, A., Stoffyn-Egli, P., Hill, P.S., Lee, K., 2005. Effects of salinity and clay type on oil-mineral aggregation. Marine Environmental Research 59, 235-254. http://dx.doi.org/10.1016/i.marenvres.2004.05.003

King, S.M., Leaf, P.A., Olson, A.C., Ray, P.Z., Tarr, M.A., 2014. Photolytic and photocatalytic degradation of surface oil from the Deepwater Horizon spill. Chemosphere 95, 415-422. http://dx.doi.org/10.1016/i.chemosphere.2013.09.060

Kinner, N.E., Belden, L., Kinner, P., 2014. Unexpected Sink for Deepwater Horizon Oil May Influence Future Spill Response. Eos 95, 176-176. http://dx.doi.org/10.1002/2014eo210005

Krembs, C., Engel, A., 2001. Abundance and variability of microorganisms and transparent exopolymer particles across the ice-water interface of melting first-year sea ice in the Laptev Sea (Arctic). Marine Biology 138, 173-185. http://dx.doi.org/10.1007/s002270000396

Kujawinski, E.B., Kido Soule, M.C., Valentine, D.L., Boysen, A.K., Longnecker, K., Redmond, M.C., 2011. Fate of Dispersants Associated with the Deepwater Horizon Oil Spill. Environmental Science \& Technology 45, 1298-1306. http://dx.doi.org/10.1021/es103838p

Larsen, J.N., Anisimov, O.A., Constable, A., Hollowed, A.B., Maynard, N., Prestrud, P., Prowse, T.D., Stone, J.M.R., 2014. Polar regions, in: Barros, V.R., Field, C.B., Dokken, D.J., Mastrandrea, M.D., Mach, K.J., Bilir, T.E., Chatterjee, M., Ebi, K.L., Estrada, Y.O., Genova, R.C., Girma, B., Kissel, E.S., Levy, A.N., MacCracken, S., Mastrandrea, P.R., White, L.L. (Eds.), Climate Change 2014: Impacts, Adaptation, and Vulnerability. Part B: Regional Aspects. Contribution of Working Group II to the Fifth Assessment Report of the 
Intergovernmental Panel of Climate Change. Cambridge University Press, Cambridge, United Kingdom and New York, NY, USA, pp. 1567-1612.

Larson, R.A., Hunt, L.L., Blankenship, D.W., 1977. Formation of toxic products from a \#2 fuel oil by photooxidation. Environmental Science \& Technology 11, 492-496. http://dx.doi.org/10.1021/es60128a002

Lee, K., Boufadel, M., Chen, B., Foght, J., Hodson, P., Swanson, S., Venosa, A., 2015. Expert Panel Report on the Behaviour and Environmental Impacts of Crude Oil Released into Aqueous Environments. Royal Society of Canada, Ottawa, ON, Canada.

Lee, K., Stoffyn-Egli, P., Owens, E.H., 2002. The OSSA II pipeline oil spill: Natural mitigation of a riverine oil spill by oil-mineral aggregate formation. Spill Science \& Technology Bulletin 7, 149-154. http://dx.doi.org/10.1016/S1353-2561(02)00056-7

Lee, L.-H., Lin, H.-J., 2013. Effects of an oil spill on benthic community production and respiration on subtropical intertidal sandflats. Marine Pollution http://dx.doi.org/10.1016/j.marpolbul.2013.05.006

Lee, W.Y., Welch, M.F., Nicol, J.A.C., 1977. Survival of two species of amphipods in aqueous extracts of petroleum oils. Marine Pollution Bulletin 8, 92-94. http://dx.doi.org/10.1016/0025-326X(77)90197-7

Lehr, B., Bristol, S., Possolo, A., 2010. Oil Budget Calculator Deepwater Horizon Technical Documentation, A Report to the National Incident Command. The Federal Interagency Solutions Group, Oil Budget Calculator Science and Engineering Team, p217.

Lessard, R.R., DeMarco, G., 2000. The Significance of Oil Spill Dispersants. Spill Science \& Technology Bulletin 6, 5968. http://dx.doi.org/10.1016/S1353-2561(99)00061-4

Levin, L.A., 2003. Oxygen minimum zone benthos: adaptation and community response to hypoxia, in: Gibson, R.N., Atkinson, R.J.A. (Eds.), Oceanography and Marine Biology: an Annual Review Volume 41. Taylor \& Francis, pp. 1-45.

Levin, L.A., Whitcraft, C.R., Mendoza, G.F., Gonzalez, J.P., Cowie, G., 2009. Oxygen and organic matter thresholds for benthic faunal activity on the Pakistan margin oxygen minimum zone (700-1100 m). Deep-Sea Research Part II: Topical Studies in Oceanography 56, 449-471. http://dx.doi.org/10.1016/j.dsr2.2008.05.032

Lewis, T., Lamoureux, S.F., 2010. Twenty-first century discharge and sediment yield predictions in a small high Arctic watershed. Global and Planetary Change 71, 27-41. https://doi.org/10.1016/i.gloplacha.2009.12.006

Lin, Y., de Kreuk, M., van Loosdrecht, M.C.M., Adin, A., 2010. Characterization of alginate-like exopolysaccharides isolated from aerobic granular sludge in pilot-plant. Water Research 44, 3355-3364. http://dx.doi.org/10.1016/i.watres.2010.03.019

Lin, Y.M., Sharma, P.K., van Loosdrecht, M.C.M., 2013. The chemical and mechanical differences between alginate-like exopolysaccharides isolated from aerobic flocculent sludge and aerobic granular sludge. Water Research 47, 57-65. http://dx.doi.org/10.1016/j.watres.2012.09.017

Liu, H., Buskey, E.J., 2000. Hypersalinity enhances the production of extracellular polymeric substance (EPS) in the Texas brown tide alga, Aureoumbra lagunensis (Pelagophyceae). Journal of Phycology 36, 71-77. http://dx.doi.org/10.1046/i.1529-8817.2000.99076.x

Lourenço, S.O., Barbarino, E., Lavín, P.L., Lanfer Marquez, U.M., Aidar, E., 2004. Distribution of intracellular nitrogen in marine microalgae: Calculation of new nitrogen-to-protein conversion factors. European Journal of Phycology 39, 17-32. http://dx.doi.org/10.1080/0967026032000157156

Machain-Castillo, M.-L., Gracia, A., Ruiz-Fernández, A.C., Sanchez-Cabeza, J.A., Rodríguez-Ramírez, A., AlexanderValdés, H.M., Nava-Fernández, X.A., Gómez-Lizárraga, L.E., Schwing, P.T., Hollander, D.J., 2017. Assessing the Role of Benthic Foraminifera as Indicators of the Benthic Ecosystem Health and Evolution after the IXTOC-I Oil Spill, Gulf of Mexico Oil Spill and Ecosystem Science Conference, New Orleans, Louisiana, USA.

Managi, S., Opaluch, J.J., Jin, D., Grigalunas, T.A., 2005. Technological change and petroleum exploration in the Gulf of Mexico. Energy Policy 33, 619-632. https://doi.org/10.1016/i.enpol.2003.09.007

Mancuso Nichols, C.A., Garon, S., Bowman, J.P., Raguénès, G., Guézennec, J., 2004. Production of exopolysaccharides by Antarctic marine bacterial isolates. Journal of Applied Microbiology 96, 1057-1066. http://dx.doi.org/10.1111/j.1365-2672.2004.02216.x

Mariotti, F., Tomé, D., Mirand, P.P., 2008. Converting Nitrogen into Protein-Beyond 6.25 and Jones' Factors. Critical Reviews in Food Science and Nutrition 48, 177-184. http://dx.doi.org/10.1080/10408390701279749

Market Research Store, 2015. Global Petrochemical Market is Expected to Reach Around USD 890 Billion by 2020. Retrieved from http://www.marketresearchstore.com/news/global-petrochemical-market-is-expected-toreach-around-83

Mason, O.U., Scott, N.M., Gonzalez, A., Robbins-Pianka, A., Balum, J., Kimbrel, J., Bouskill, N.J., Prestat, E., Borglin, S., Joyner, D.C., Fortney, J.L., Jurelevicius, D., Stringfellow, W.T., Alvarez-Cohen, L., Hazen, T.C., Knight, 
R., Gilbert, J.A., Jansson, J.K., 2014. Metagenomics reveals sediment microbial community response to Deepwater Horizon oil spill. The ISME Journal 8, 1464-1475. http://dx.doi.org/10.1038/ismej.2013.254

Masuko, T., Minami, A., Iwasaki, N., Majima, T., Nishimura, S.I., Lee, Y.C., 2005. Carbohydrate analysis by a phenolsulfuric acid method in microplate format. Analytical Biochemistry 339, 69-72. http://dx.doi.org/10.1016/i.ab.2004.12.001

McFarlin, K.M., Prince, R.C., Perkins, R., Leigh, M.B., 2014. Biodegradation of Dispersed Oil in Arctic Seawater at $1^{\circ} \mathrm{C}$. PLoS ONE 9, e84297. https://doi.org/10.1371/journal.pone.0084297

McMahon, B.R., 1988. Physiological Responses to Oxygen Depletion in Intertidal Animals. American Zoologist 28, 3953. http://www.jstor.org/stable/3883218

McNutt, M.K., Camilli, R., Crone, T.J., Guthrie, G.D., Hsieh, P.A., Ryerson, T.B., Savas, O., Shaffer, F., 2012. Review of flow rate estimates of the Deepwater Horizon oil spill. Proceedings of the National Academy of Sciences 109, 20260-20267. http://dx.doi.org/10.1073/pnas.1112139108

McSwain, B.S., Irvine, R.L., Hausner, M., Wilderer, P.A., 2005. Composition and distribution of extracellular polymeric substances in aerobic flocs and granular sludge. Applied and Environmental Microbiology 71, 1051-1057. http://dx.doi.org/10.1128/AEM.71.2.1051-1057.2005

Mendelssohn, I.A., Andersen, G.L., Baltz, D.M., Caffey, R.H., Carman, K.R., Fleeger, J.W., Joye, S.B., Lin, Q., Maltby, E., Overton, E.B., Rozas, L.P., 2012. Oil Impacts on Coastal Wetlands: Implications for the Mississippi River Delta Ecosystem after the Deepwater Horizon Oil Spill. BioScience 62, 562-574. http://dx.doi.org/10.1525/bio.2012.62.6.7

Metzger, U., Lankes, U., Fischpera, K., Frimmel, F., 2009. The concentration of polysaccharides and proteins in EPS of Pseudomonas putida and Aureobasidum pullulans as revealed by 13C CPMAS NMR spectroscopy. Applied Microbiology and Biotechnology 85, 197-206. http://dx.doi.org/10.1007/s00253-009-2218-y

Michel, J., Owens, E.H., Zengel, S., Graham, A., Nixon, Z., Allard, T., Holton, W., Reimer, P.D., Lamarche, A., White, M., Rutherford, N., Childs, C., Mauseth, G., Challenger, G., Taylor, E., 2013. Extent and Degree of Shoreline Oiling: Deepwater Horizon Oil Spill, Gulf of Mexico, USA. PLoS ONE 8, e65087. http://dx.doi.org/10.1371/journal.pone.0065087

Miller, I., Serchi, T., Murk, A.J., Gutleb, A.C., 2014. The Added Value of Proteomics for Toxicological Studies. Journal of Toxicology and Environmental Health, Part B 17, 225-246. http://dx.doi.org/10.1080/10937404.2014.904730

Mishra, A., Jha, B., 2009. Isolation and characterization of extracellular polymeric substances from micro-algae Dunaliella salina under salt stress. Bioresource Technology 100, 3382-3386. http://dx.doi.org/10.1016/i.biortech.2009.02.006

Moerschbaecher, M., Day Jr., J.W., 2011. Ultra-Deepwater Gulf of Mexico Oil and Gas: Energy Return on Financial Investment and a Preliminary Assessment of Energy Return on Energy Investment. Sustainability 3, 2009. http://dx.doi.org/10.3390/su3102009

Montagna, P.A., Baguley, J.G., Cooksey, C., Hartwell, I., Hyde, L.J., Hyland, J.L., Kalke, R.D., Kracker, L.M., Reuscher, M., Rhodes, A.C.E., 2013. Deep-Sea Benthic Footprint of the Deepwater Horizon Blowout. PLoS ONE 8, e70540. http://dx.doi.org/10.1371/journal.pone.0070540

Montagna, P.A., Baguley, J.G., Cooksey, C., Hyland, J.L., 2017. Persistent impacts to the deep soft-bottom benthos one year after the Deepwater Horizon event. Integr Environ Assess Manag 13, 342-351. http://dx.doi.org/10.1002/ieam.1791

Moore, R.D., Fleming, S.W., Menounos, B., Wheate, R., Fountain, A., Stahl, K., Holm, K., Jakob, M., 2009. Glacier change in western North America: influences on hydrology, geomorphic hazards and water quality. Hydrol. Process. 23, 42-61. http://dx.doi.org/10.1002/hyp.7162

Morse, J.W., Eldridge, P.M., 2007. A non-steady state diagenetic model for changes in sediment biogeochemistry in response to seasonally hypoxic/anoxic conditions in the "dead zone" of the Louisiana shelf. Marine Chemistry 106, 239-255. https://doi.org/10.1016/i.marchem.2006.02.003

MOSSFA Steering Committee, 2013. Marine Oil Snow Sedimentation and Flocculent Accumulation (MOSSFA) Workshop October 22-23, 2013 Florida State University, Tallahassee, Florida.

Mullin, J.V., Champ, M.A., 2003. Introduction/Overview to In Situ Burning of Oil Spills. Spill Science \& Technology Bulletin 8, 323-330. https://doi.org/10.1016/S1353-2561(03)00076-8

Murawski, S.A., Hogarth, W.T., Peebles, E.B., Barbeiri, L., 2014. Prevalence of External Skin Lesions and Polycyclic Aromatic Hydrocarbon Concentrations in Gulf of Mexico Fishes, Post-Deepwater Horizon. Transactions of the American Fisheries Society 143, 1084-1097. http://dx.doi.org/10.1080/00028487.2014.911205

Myklestad, S.M., 1995. Release of extracellular products by phytoplankton with special emphasis on polysaccharides. Science of The Total Environment 165, 155-164. http://dx.doi.org/10.1016/0048-9697(95)04549-G

Nalco, 2005. Material Safety Data Sheet Corexit(r) 9500 version number 1.6.

Nalco, 2008. Material Safety Data Sheet Corexit(r) EC9527A version number 1.7. 
National Commission on the BP Deepwater Horizon Oil Spill and Offshore Drilling, 2011. Deep Water: The Gulf Oil Disaster and the Future of Offshore Drilling, Report to the President. National Commission on the BP Deepwater Horizon Oil Spill and Offshore Drilling,

National Research Council, 2003. Oil in the Sea III: Inputs, Fates, and Effects. Committee on Oil in the Sea: Inputs, Fates, and Effects, Ocean Studies Board and Marine Board, Divisions of Earth and Life Studies and Transportation Research Board, National Research Council, Washington, D.C.

Nemkov, T., D’Alessandro, A., Hansen, K., 2015. Three-minute method for amino acid analysis by UHPLC and highresolution quadrupole orbitrap mass spectrometry. Amino Acids, 1-13. http://dx.doi.org/10.1007/s00726015-2019-9

NRDC, 2015. Summary of Information concerning the Ecological and Economic Impacts of the BP Deepwater Horizon Oil Spill Disaster.

O'Connor, B., 2013. Impacts of the Anomalous Mississippi River Discharge and Diversions on Phytoplankton Blooming in Northeastern Gulf of Mexico. University of South Florida, http://scholarcommons.usf.edu/etd/4736/.

Okey, A.B., Riddick, D.S., Harper, P.A., 1994. The Ah receptor: Mediator of the toxicity of 2,3,7,8-tetrachlorodibenzop-dioxin (TCDD) and related compounds. Toxicology Letters 70, 1-22. http://dx.doi.org/10.1016/0378$\underline{4274(94) 90139-2}$

Ortmann, A.C., Anders, J., Shelton, N., Gong, L., Moss, A.G., Condon, R.H., 2012. Dispersed Oil Disrupts Microbial Pathways in Pelagic Food Webs. PLoS ONE 7, e42548. http://dx.doi.org/10.1371/journal.pone.0042548

Passow, U., 2002. Transparent exopolymer particles (TEP) in aquatic environments. Progress in Oceanography 55, $287-$ 333. http://dx.doi.org/10.1016/S0079-6611(02)00138-6

Passow, U., 2016. Formation of rapidly-sinking, oil-associated marine snow. Deep Sea Research Part II: Topical Studies in Oceanography 129, 232-240. http://dx.doi.org/10.1016/i.dsr2.2014.10.001

Passow, U., Alldredge, A.L., 1994. Distribution, size and bacterial colonization of transparent exopolymer particles (TEP) in the ocean. Marine Ecology Progress Series 113, 185-198.

Passow, U., Ziervogel, K., 2016. Marine snow sedimented oil released during the Deepwater Horizon spill. Oceanography 29, 118-125. http://dx.doi.org/10.5670/oceanog.2016.76

Passow, U., Ziervogel, K., Asper, V., Diercks, A., 2012. Marine snow formation in the aftermath of the Deepwater Horizon oil spill in the Gulf of Mexico. Environmental Research Letters 7, 035301. http://dx.doi.org/10.1088/1748-9326/7/3/035301

Pelegrí, S.P., Blackburn, T.H., 1994. Bioturbation effects of the amphipod Corophium volutator on microbial nitrogen transformations in marine sediments. Marine Biology 121, 253-258. http://dx.doi.org/10.1007/bf00346733

Perkins, M.J., Joye, S.B., Field, J.A., 2017. Selective quantification of DOSS in marine sediment and sediment-trap solids by LC-QTOF-MS. Analytical and Bioanalytical Chemistry 409, 971-978. http://dx.doi.org/10.1007/s00216016-0010-2

Peterson, C.H., Rice, S.D., Short, J.W., Esler, D., Bodkin, J.L., Ballachey, B.E., Irons, D.B., 2003. Long-Term Ecosystem Response to the Exxon Valdez Oil Spill. Science 302, 2082-2086. http://dx.doi.org/10.1126/science.1084282

Peterson, D.R., 1994. Calculating the aquatic toxicity of hydrocarbon mixtures. Chemosphere 29, 2493-2506. http://dx.doi.org/10.1016/0045-6535(94)90052-3

Pietroski, J.P., White, J.R., DeLaune, R.D., 2015. Effects of dispersant used for oil spill remediation on nitrogen cycling in Louisiana coastal salt marsh soil. Chemosphere 119, 562-567. http://doi.org/10.1016/i.chemosphere.2014.07.050

Platon, E., Sen Gupta, B.K., 2013. Benthic Foraminiferal Communities in Oxygen-Depleted Environments of the Louisiana Continental Shelf, in: Rabalais, N.N., Turner, R.E. (Eds.), Coastal Hypoxia: Consequences for Living Resources and Ecosystems. American Geophysical Union, pp. 147-163. http://dx.doi.org/10.1029/CE058

Prince, R.C., Elmendorf, D.L., Lute, J.R., Hsu, C.S., Halth, C.E., Senius, J.D., Dechert, G.J., Douglas, G.S., Butler, E.L., 1994. $17 \alpha(\mathrm{H}), 21 \beta(\mathrm{H})$-hopane as a conserved internal marker for estimating the biodegradation of crude oil. Environmental Science \& Technology 28, 142-145. http://dx.doi.org/10.1021/es00050a019

Rabalais, N.N., Smith, L.E., Harper, D.E., Justic, D., 2013. Effects of Seasonal Hypoxia on Continental Shelf Benthos, in: Rabalais, N.N., Turner, R.E. (Eds.), Coastal Hypoxia: Consequences for Living Resources and Ecosystems. American Geophysical Union, pp. 211-240. http://dx.doi.org/10.1029/CE058

Rabalais, N.N., Turner, R.E., 2013. Hypoxia in the Northern Gulf of Mexico: Description, Causes and Change, in: Rabalais, N.N., Turner, R.E. (Eds.), Coastal Hypoxia: Consequences for Living Resources and Ecosystems. American Geophysical Union, pp. 1-36. http://dx.doi.org/10.1029/CE058

Radović, J.R., Aeppli, C., Nelson, R.K., Jimenez, N., Reddy, C.M., Bayona, J.M., Albaigés, J., 2014. Assessment of photochemical processes in marine oil spill fingerprinting. Marine Pollution Bulletin 79, 268-277. http://dx.doi.org/10.1016/i.marpolbul.2013.11.029 
Rahsepar, S., Langenhoff, A.A.M., Smit, M.P.J., van Eenennaam, J.S., Murk, A.J., Rijnaarts, H.H.M., 2017. Oil biodegradation: interactions of marine snow, clay particles, oil and chemical dispersants in a marine environment. Marine Pollution Bulletin in press.

Rahsepar, S., Smit, M.P.J., Murk, A.J., Rijnaarts, H.H.M., Langenhoff, A.A.M., 2016. Chemical dispersants: Oil biodegradation friend or foe? Marine Pollution Bulletin 108, 113-119. http://dx.doi.org/10.1016/i.marpolbul.2016.04.044

Ramseur, J.L., 2011. Deepwater Horizon Oil Spill: The Fate of the Oil. Congressional Research Service, R41531, p22.

Raposo, M., de Morais, R., Bernardo de Morais, A., 2013. Bioactivity and Applications of Sulphated Polysaccharides from Marine Microalgae. Marine Drugs 11, 233-252. http://dx.doi.org/10.3390/md11010233

Reddy, C.M., Arey, J.S., Seewald, J.S., Sylva, S.P., Lemkau, K.L., Nelson, R.K., Carmichael, C.A., McIntyre, C.P., Fenwick, J., Ventura, G.T., Van Mooy, B.A.S., Camilli, R., 2012. Composition and fate of gas and oil released to the water column during the Deepwater Horizon oil spill. Proceedings of the National Academy of Sciences 109, 20229-20234. http://dx.doi.org/10.1073/pnas.1101242108

Remminghorst, U., Rehm, B.H.A., 2006. Bacterial alginates: From biosynthesis to applications. Biotechnology Letters 28, 1701-1712. http://dx.doi.org/10.1007/s10529-006-9156-x

Rico-Martínez, R., Snell, T.W., Shearer, T.L., 2013. Synergistic toxicity of Macondo crude oil and dispersant Corexit $9500 \mathrm{~A}{ }^{\circledR}$ to the Brachionus plicatilis species complex (Rotifera). Environmental Pollution 173, 5-10. http://dx.doi.org/10.1016/i.envpol.2012.09.024

Rieper, M., 1982. Feeding preferences of marine harpacticoid copepods for various species of bacteria. Marine Ecology Progress Series 7, 303-307.

Romero, I.C., Özgökmen, T., Snyder, S., Schwing, P., O'Malley, B.J., Beron-Vera, F.J., Olascoaga, M.J., Zhu, P., Ryan, E., Chen, S.S., Wetzel, D.L., Hollander, D., Murawski, S.A., 2016. Tracking the Hercules 265 marine gas well blowout in the Gulf of Mexico. J. Geophys. Res. Oceans 121, 706-724. http://dx.doi.org/10.1002/2015jc011037

Romero, I.C., Schwing, P.T., Brooks, G.R., Larson, R.A., Hastings, D.W., Ellis, G., Goddard, E.A., Hollander, D.J., 2015. Hydrocarbons in deep-sea sediments following the 2010 Deepwater Horizon blowout in the northeast Gulf of Mexico. PLoS ONE 10. http://dx.doi.org/10.1371/iournal.pone.0128371

Romero, I.C., Toro-Farmer, G., Diercks, A.-R., Schwing, P., Muller-Karger, F., Murawski, S., Hollander, D.J., 2017. Large-scale deposition of weathered oil in the Gulf of Mexico following a deep-water oil spill. Environmental Pollution 228, 179-189. https://doi.org/10.1016/j.envpol.2017.05.019

Schedler, M., Hiessl, R., Valladares Juárez, A.G., Gust, G., Müller, R., 2014. Effect of high pressure on hydrocarbondegrading bacteria. AMB Express 4, 77. http://dx.doi.org/10.1186/s13568-014-0077-0

Schmidt-Etkin, D., 2011. Chapter 2 - Spill Occurrences: A World Overview, in: Fingas, M. (Ed.), Oil Spill Science and Technology. Gulf Professional Publishing, Boston, pp. 7-48. https://doi.org/10.1016/B978-1-85617-943$\underline{0.10002-4}$

Schmidt, C.W., 2010. Between the Devil and the Deep Blue Sea Dispersants in the Gulf of Mexico. Environ. Health Perspect. 118, 338-344. http://dx.doi.org/10.1289/ehp.118-a338

Schrope, M., 2013. Dirty blizzard buried Deepwater Horizon oil. Retrieved from http://www.nature.com/news/dirtyblizzard-buried-deepwater-horizon-oil-1.12304

Schwacke, L.H., Smith, C.R., Townsend, F.I., Wells, R.S., Hart, L.B., Balmer, B.C., Collier, T.K., De Guise, S., Fry, M.M., Guillette, L.J., Lamb, S.V., Lane, S.M., McFee, W.E., Place, N.J., Tumlin, M.C., Ylitalo, G.M., Zolman, E.S., Rowles, T.K., 2014. Health of Common Bottlenose Dolphins (Tursiops truncatus) in Barataria Bay, Louisiana, Following the Deepwater Horizon Oil Spill. Environmental Science \& Technology 48, 93-103. http://dx.doi.org/10.1021/es403610f

Schwenzfeier, A., 2013. Physico-chemical and techno-functional properties of proteins isolated from the green microalgae Tetraselmis sp., Laboratory of Food Chemistry. Wageningen University, Wageningen, The Netherlands.

Schwenzfeier, A., Wierenga, P.A., Gruppen, H., 2011. Isolation and characterization of soluble protein from the green $\begin{array}{lllll}\text { microalgae Tetraselmis sp. Bioresource } & \text { Technology } & 102, & 9121-9127 .\end{array}$ http://dx.doi.org/10.1016/j.biortech.2011.07.046

Schwing, P.T., Brooks, G.R., Larson, R., Holmes, C., O'Malley, B., Hollander, D.J., 2017. Constraining the spatial extent of Marine Oil Snow Sedimentation and Flocculent Accumulation (MOSSFA) following the Deepwater Horizon Event using an excess ${ }^{210} \mathrm{~Pb}$ flux approach. Environmental Science \& Technology 521, 5962-5968. http://dx.doi.org/10.1021/acs.est.7b00450

Schwing, P.T., Montagna, P.A., 2017. Benthic Footprint, Ecological Impacts and Long-term Recovery from a MOSSFA Event, MOSSFA Workshop, Gulf of Mexico Oil Spill \& Ecosystem Science Conference, New Orleans, LA, USA. 
Schwing, P.T., O’Malley, B.J., Hollander, D.J., In Review. Recovery of Benthic Foraminifera in the Northern Gulf of Mexico Following the Deepwater Horizon Event (2010-2015). PLoS ONE.

Schwing, P.T., O’Malley, B.J., Romero, I.C., Martínez-Colón, M., Hastings, D.W., Glabach, M.A., Hladky, E.M., Greco, A., Hollander, D.J., 2016. Characterizing the variability of benthic foraminifera in the northeastern Gulf of Mexico following the Deepwater Horizon event (2010-2012). Environmental Science and Pollution Research, 1-16. http://dx.doi.org/10.1007/s11356-016-7996-z

Schwing, P.T., Romero, I.C., Brooks, G.R., Hastings, D.W., Larson, R.A., Hollander, D.J., 2014. Characterizing the Deep Sea Benthic Foraminifera Impact and Response to the Deepwater Horizon Blowout in the Northeastern Gulf of Mexico. International Oil Spill Conference Proceedings 2014, 299744. http://dx.doi.org/10.7901/2169-3358-2014-1-299744.1

Schwing, P.T., Romero, I.C., Brooks, G.R., Hastings, D.W., Larson, R.A., Hollander, D.J., 2015. A Decline in Benthic Foraminifera following the Deepwater Horizon Event in the Northeastern Gulf of Mexico. PLoS ONE 10, e0120565. http://dx.doi.org/10.1371/journal.pone.0120565

Shaw, D.G., Paul, A.J., Cheek, L.M., Feder, H.M., 1976. Macoma balthica: An indicator of oil pollution. Marine Pollution Bulletin 7, 29-31. http://dx.doi.org/10.1016/0025-326X(76)90307-6

Shell, 2016. Stones project. Retrieved from http://www.shell.com/about-us/major-projects/stones.html

Sheridan, M., 2006. California Crude Oil Production and Imports. California Energy Commission, CEC-600-2006-006, p15.

Shigenaka, G., 2011. Chapter 27 - Effects of Oil in the Environment, in: Fingas, M. (Ed.), Oil Spill Science and Technology. Gulf Professional Publishing, Boston, pp. 985-1024. https://doi.org/10.1016/B978-1-85617943-0.10027-9

Simon, M., Grossart, H.-P., Schweitzer, B., Ploug, H., 2002. Microbial ecology of organic aggregates in aquatic ecosystems. Aquatic Microbial Ecology 28, 175-211. http://dx.doi.org/10.3354/ame028175

Singer, M.M., George, S., Lee, I., Jacobson, S., Weetman, L.L., Blondina, G., Tjeerdema, R.S., Aurand, D., Sowby, M.L., 1998. Effects of Dispersant Treatment on the Acute Aquatic Toxicity of Petroleum Hydrocarbons. Archives of Environmental Contamination and Toxicology 34, 177-187. http://dx.doi.org/10.1007/s002449900302

Smith, D.C., Steward, G.F., Long, R.A., Azam, F., 1995. Bacterial mediation of carbon fluxes during a diatom bloom in a mesocosm. Deep-Sea Research Part II: Topical Studies in Oceanography 42, 75-97. http://dx.doi.org/10.1016/0967-0645(95)00005-B

Snyder, S.M., Pulster, E.L., Wetzel, D.L., Murawski, S.A., 2015. PAH Exposure in Gulf of Mexico Demersal Fishes, Post- Deepwater Horizon. Environmental Science \& Technology 49, 8786-8795. http://dx.doi.org/10.1021/acs.est.5b01870

Sohm, J., Edwards, B., Wilson, B., Webb, E., 2011. Constitutive Extracellular Polysaccharide (EPS) Production by Specific Isolates of Crocosphaera watsonii. Frontiers in Microbiology 2. http://dx.doi.org/10.3389/fmicb.2011.00229

Solomon, G.M., Janssen, S., 2010. Health effects of the Gulf oil spill. JAMA: The Journal of the American Medical Association 304, 1118-1119. http://dx.doi.org/10.1001/jama.2010.1254

Sørensen, L., Meier, S., Mjøs, S.A., 2016. Application of gas chromatography/tandem mass spectrometry to determine a wide range of petrogenic alkylated polycyclic aromatic hydrocarbons in biotic samples. Rapid Commun. Mass Spectrom. 30, 2052-2058. http://dx.doi.org/10.1002/rcm.7688

Staats, N., Stal, L.J., Mur, L.R., 2000. Exopolysaccharide production by the epipelic diatom Cylindrotheca closterium: effects of nutrient conditions. Journal of Experimental Marine Biology and Ecology 249, 13-27. http://dx.doi.org/10.1016/S0022-0981(00)00166-0

Stegeman, J.J., Lech, J.J., 1991. Cytochrome P-450 monooxygenase systems in aquatic species: carcinogen metabolism and biomarkers for carcinogen and pollutant exposure. Environ. Health Perspect. 90, 101-109.

Stegeman, J.J., Livingstone, D.R., 1998. Introduction Forms and functions of cytochrome P450. Comparative Biochemistry and Physiology Part C: Pharmacology, Toxicology and Endocrinology 121, 1-3. http://dx.doi.org/10.1016/S0742-8413(98)10025-7

Stoderegger, K.E., Herndl, G.J., 1999. Production of exopolymer particles by marine bacterioplankton under contrasting turbulence conditions. Marine Ecology Progress Series 189, 9-16. http://dx.doi.org/10.3354/meps189009

Stogiannidis, E., Laane, R., 2015. Source Characterization of Polycyclic Aromatic Hydrocarbons by Using Their Molecular Indices: An Overview of Possibilities, in: Whitacre, D.M. (Ed.), Reviews of Environmental Contamination and Toxicology. Springer International Publishing, Cham, pp. 49-133. http://dx.doi.org/10.1007/978-3-319-10638-0_2

Stout, S.A., 2007. Characterization and Source of Unknown "Tar-Like Material" and "Slag" in a Former Oil Field in Compton, California. Environmental Forensics 8, 265-282. http://dx.doi.org/10.1080/15275920701506540 
Stout, S.A., Payne, J.R., 2016a. Chemical composition of floating and sunken in-situ burn residues from the Deepwater Horizon oil spill. Marine Pollution Bulletin 108, 186-202. http://dx.doi.org/10.1016/i.marpolbul.2016.04.031

Stout, S.A., Payne, J.R., 2016b. Macondo oil in deep-sea sediments: Part 1 - sub-sea weathering of oil deposited on the seafloor. Marine Pollution Bulletin 111, 365-380. https://doi.org/10.1016/i.marpolbul.2016.07.036

Stout, S.A., Payne, J.R., Ricker, R.W., Baker, G., Lewis, C., 2016. Macondo oil in deep-sea sediments: Part 2 Distribution and distinction from background and natural oil seeps. Marine Pollution Bulletin 111, 381-401. https://doi.org/10.1016/j.marpolbul.2016.07.041

Suja, L.D., Summers, S., Gutierrez, T., 2017. Role of EPS, Dispersant and Nutrients on the Microbial Response and MOS Formation in the Subarctic Northeast Atlantic. Frontiers in Microbiology 8, 676. http://dx.doi.org/10.3389/fmicb.2017.00676

Tamis, J.E., Jongbloed, R.H., Karman, C.C., Koops, W., Murk, A.J., 2012. Rational application of chemicals in response to oil spills may reduce environmental damage. Integr Environ Assess Manag 8, 231-241. http://dx.doi.org/10.1002/ieam.273

Tarnecki, J.H., Patterson, W.F., 2015. Changes in Red Snapper Diet and Trophic Ecology Following the Deepwater Horizon Oil Spill. Marine and Coastal Fisheries 7, 135-147. http://dx.doi.org/10.1080/19425120.2015.1020402

Tarr, M.A., Zito, P., Overton, E.B., Olson, G.M., Adhikari, P.L., Reddy, C.M., 2016. Weathering of oil spilled in the marine environment. Oceanography 29, 126-135. http://dx.doi.org/10.5670/oceanog.2016.77

Teal, J.M., Howarth, R.W., 1984. Oil spill studies: A review of ecological effects. Environmental Management 8, 27-43. http://dx.doi.org/10.1007/bf01867871

Thibodeaux, L.J., Valsaraj, K.T., John, V.T., Papadopoulos, K.D., Pratt, L.R., Pesika, N.S., 2011. Marine Oil Fate: Knowledge Gaps, Basic Research, and Development Needs; A Perspective Based on the Deepwater Horizon Spill. Environmental Engineering Science 28, 87-93. http://dx.doi.org/10.1089/ees.2010.0276

Turner, J.T., 2002. Zooplankton fecal pellets, marine snow and sinking phytoplankton blooms. Aquatic Microbial Ecology 27, 57-102. http://dx.doi.org/10.3354/ame027057

Tyler, P.A., 2003. The peripheral deep seas, in: Tyler, P.A. (Ed.), Ecosystems of the Deep Oceans, Volume 28. Elsevier Science, Amsterdam.

U.S. District Court, 2015. Findings of facts and Conclusions of Law - Phase Two Trial. Case 2: 10-md-02179-CJB-SS, Document 14021. Filed Jan. 15, 2015, New Orleans, Louisiana, USA, pp. 1-44.

U.S. EPA, 1995. COREXIT® EC9500A TECHNICAL PRODUCT BULLETIN \#D-4. Retrieved from http://www.epa.gov/emergency-response/corexitr-ec9500a

Valentine, D.L., Fisher, G.B., Bagby, S.C., Nelson, R.K., Reddy, C.M., Sylva, S.P., Woo, M.A., 2014. Fallout plume of submerged oil from Deepwater Horizon. Proceedings of the National Academy of Sciences 111, 1590615911. http://dx.doi.org/10.1073/pnas.1414873111

van den Heuvel-Greve, M., Postma, J., Jol, J., Kooman, H., Dubbeldam, M., Schipper, C., Kater, B., 2007. A chronic bioassay with the estuarine amphipod Corophium volutator: Test method description and confounding factors. Chemosphere 66, 1301-1309. http://dx.doi.org/10.1016/i.chemosphere.2006.07.022

van Eenennaam, J.S., Wei, Y., Grolle, K.C.F., Foekema, E.M., Murk, A.J., 2016. Oil spill dispersants induce formation of marine snow by phytoplankton-associated bacteria. Marine Pollution Bulletin 104, 294-302. http://dx.doi.org/10.1016/j.marpolbul.2016.01.005

Vanden Berghe, W., Bergmans, M., 1981. Differential food preferences in three co-occurring species of Tisbe (Copepoda, Harpacticoida). Marine Ecology Progress Series 4, 213-219.

Vonk, S.M., Hollander, D.J., Murk, A.J., 2015. Was the extreme and wide-spread marine oil-snow sedimentation and flocculent accumulation (MOSSFA) event during the Deepwater Horizon blow-out unique? Marine Pollution Bulletin 100, 5-12. http://dx.doi.org/10.1016/i.marpolbul.2015.08.023

Vrabie, C.M., Candido, A., van den Berg, H., Murk, A.J., van Duursen, M.B.M., Jonker, M.T.O., 2011. Specific in vitro toxicity of crude and refined petroleum products: 3. Estrogenic responses in mammalian assays. Environmental Toxicology and Chemistry 30, 973-980. http://dx.doi.org/10.1002/etc.463

Vrabie, C.M., Candido, A., van Duursen, M.B.M., Jonker, M.T.O., 2010. Specific in vitro toxicity of crude and refined petroleum products: II. Estrogen $(\alpha$ and $\beta$ ) and androgen receptor-mediated responses in yeast assays. Environmental Toxicology and Chemistry 29, 1529-1536. http://dx.doi.org/10.1002/etc.187

Vrabie, C.M., Jonker, M.T.O., Murk, A.J., 2009. Specific in vitro toxicity of crude and refined petroleum products. 1. Aryl hydrocarbon receptor-mediated responses. Environmental Toxicology and Chemistry 28, 1995-2003. http://dx.doi.org/10.1897/08-624.1

Wake, H., 2005. Oil refineries: a review of their ecological impacts on the aquatic environment. Estuarine, Coastal and Shelf Science 62, 131-140. http://dx.doi.org/10.1016/j.ecss.2004.08.013 
Wang, Z., Fingas, M., Blenkinsopp, S., Sergy, G., Landriault, M., Sigouin, L., Foght, J., Semple, K., Westlake, D.W.S., 1998. Comparison of oil composition changes due to biodegradation and physical weathering in different oils. Journal of Chromatography A 809, 89-107. https://doi.org/10.1016/S0021-9673(98)00166-6

Weete, J.D., 1976. Algal and fungal waxes, in: Kolattukudy, P.E. (Ed.), Chemistry and biochemistry of natural waxes. Elsevier, Amsterdam, pp. 349-418.

White, H.K., Hsing, P.-Y., Cho, W., Shank, T.M., Cordes, E.E., Quattrini, A.M., Nelson, R.K., Camilli, R., Demopoulos, A.W.J., German, C.R., Brooks, J.M., Roberts, H.H., Shedd, W., Reddy, C.M., Fisher, C.R., 2012. Impact of the Deepwater Horizon oil spill on a deep-water coral community in the Gulf of Mexico. Proceedings of the National Academy of Sciences 109, 20303-20308. http://dx.doi.org/10.1073/pnas.1118029109

White, H.K., Lyons, S.L., Harrison, S.J., Findley, D.M., Liu, Y., Kujawinski, E.B., 2014. Long-Term Persistence of Dispersants following the Deepwater Horizon Oil Spill. Environmental Science \& Technology Letters 1, 295-299. http://dx.doi.org/10.1021/ez500168r

White, P.A., 2002. The genotoxicity of priority polycyclic aromatic hydrocarbons in complex mixtures. Mutation Research/Genetic Toxicology and Environmental Mutagenesis 515, 85-98. https://doi.org/10.1016/S1383$\underline{5718(02) 00017-7}$

Wingender, J., Neu, T.R., Flemming, H.-C., 1999. What are Bacterial Extracellular Polymeric Substances?, in: Wingender, J., Neu, T.R., Flemming, H.-C. (Eds.), Microbial Extracellular Polymeric Substances. Springer Berlin Heidelberg, pp. 1-19. http://dx.doi.org/10.1007/978-3-642-60147-7_1

Wise, C.F., Wise, J.T.F., Wise, S.S., Thompson, W.D., Wise Jr, J.P., Wise Sr, J.P., 2014. Chemical dispersants used in the Gulf of Mexico oil crisis are cytotoxic and genotoxic to sperm whale skin cells. Aquatic Toxicology 152, 335340. http://dx.doi.org/10.1016/j.aquatox.2014.04.020

Wotton, R.S., 2004a. The Essential Role of Exopolymers (EPS) in Aquatic Systems, in: Gibson, R.N., Atkinson, R.J.A., Gordon, J.D.M. (Eds.), Oceanography and Marine Biology: an Annual Review. CRC Press, pp. 57-94. http://dx.doi.org/10.1201/9780203507810.ch3

Wotton, R.S., 2004b. The ubiquity and many roles of exopolymers (EPS) in aquatic systems. Scientia Marina 68, 13-21.

Wu, J.-Y., Lin, S.-Y., Chen, Y.-J., S-H, P., Hung, J.-J., Chen, C.-T.A., L-L, L., 2013. Food sources for benthos in shallow hydrothermal vent and non-vent ecosystems, in: Cheng, Y.-C. (Ed.), NSYSU-KU Seminar on Agriculture and Fishery Sciences. National Sun Yat-sen University, Kagoshima University, Kaohsiung, Taiwan, pp. 7-8.

Yang, T., Speare, K., McKay, L., MacGregor, B.J., Joye, S.B., Teske, A., 2016. Distinct Bacterial Communities in Surficial Seafloor Sediments Following the 2010 Deepwater Horizon Blowout. Frontiers in Microbiology 7. http://dx.doi.org/10.3389/fmicb.2016.01384

Zeinstra-Helfrich, M., Koops, W., Dijkstra, K., Murk, A.J., 2015a. Quantification of the effect of oil layer thickness on entrainment of surface oil. Marine Pollution Bulletin 96, 401-409. http://dx.doi.org/10.1016/j.marpolbul.2015.04.015

Zeinstra-Helfrich, M., Koops, W., Murk, A.J., 2015b. The NET effect of dispersants - a critical review of testing and modelling of surface oil dispersion. Marine Pollution Bulletin 100, 102-111. https://doi.org/10.1016/j.marpolbul.2015.09.022

Zhanfei, L., Jiqing, L., Qingzhi, Z., Wei, W., 2012. The weathering of oil after the Deepwater Horizon oil spill: insights from the chemical composition of the oil from the sea surface, salt marshes and sediments. Environmental Research Letters 7, 035302. https://doi.org/10.1088/1748-9326/7/3/035302

Zhang, J., Spitz, Y.H., Steele, M., Ashjian, C., Campbell, R., Berline, L., Matrai, P.C.C., 2010. Modeling the impact of declining sea ice on the Arctic marine planktonic ecosystem. J. Geophys. Res. Oceans 115. http://dx.doi.org/10.1029/2009jc005387

Ziervogel, K., Joye, S.B., Arnosti, C., 2016. Microbial enzymatic activity and secondary production in sediments affected by the sedimentation pulse following the Deepwater Horizon oil spill. Deep Sea Research Part II: Topical Studies in Oceanography 129, 241-248. https://doi.org/10.1016/j.dsr2.2014.04.003

Ziervogel, K., McKay, L., Rhodes, B., Osburn, C.L., Dickson-Brown, J., Arnosti, C., Teske, A., 2012. Microbial Activities and Dissolved Organic Matter Dynamics in Oil-Contaminated Surface Seawater from the Deepwater Horizon Oil Spill Site. PLoS ONE 7, e34816. http://dx.doi.org/10.1371/journal.pone.0034816 
Summary 
The Deepwater Horizon (DWH) oil spill in the Gulf of Mexico in 2010 was one of the largest oil spills in history. For three months, oil leaked from the Macondo well at 1,500 $\mathrm{m}$ depth into the Gulf. As one of the spill responses, an unprecedented amount of dispersants were applied, both at the sea surface and, for the first time ever, directly injected into the wellhead. During the spill, unusually large amounts of marine snow, including Extracellular Polymeric Substances (EPS), were formed. Oil-contaminated marine snow aggregates were formed by aggregation of EPS with 1) the large amounts of suspended solids due to flushing of the Mississippi River, 2) phytoplankton cells due to the spring bloom, and 3) the dispersed oil droplets. The marine snow sank through the water column and settled on the ocean floor. This process was named MOSSFA: Marine Oil Snow Sedimentation and Flocculent Accumulation. The GoMRI (Gulf of Mexico Research Initiative) research revealed that MOSSFA was an important pathway of transferring oil to the deep-sea, and $14-21 \%$ of the total discharged oil is estimated to have settled on the sediment, where it impacted the benthic ecosystem. This thesis focused first on the mechanism of EPS snow formation, and then more in depth on the additional ecotoxicological consequences of marine snow formation during oil spills for the benthic ecosystem.

Chapter 2 describes the role of chemical dispersants in the presence of phytoplankton in the formation of EPS, one of the main ingredients of marine snow. Two marine phytoplankton species (the green algae Dunaliella tertiolecta and the diatom Phaeodactylum tricornutum) produced EPS within days of exposure to the dispersant Corexit 9500, one of the dispersant types applied during the DWH oil spill. When the phytoplankton cultures were treated with antibiotics to remove the associated bacterial community, no EPS was produced. This implies that phytoplankton-associated bacteria were responsible for the EPS formation, and the symbiosis between the phytoplankton and its associated bacterial community provided the bacteria with energy to produce the EPS. Chemical analysis of the composition of EPS showed that it consisted of proteins and polysaccharides, similar to the marine snow that was formed during the Deepwater Horizon spill. The results have implications for the application of chemical dispersants during high phytoplankton densities in deltaic systems, since this combination might trigger a MOSSFA event.

To further investigate the effects of (oil-contaminated) marine snow on the benthic ecosystem, three consecutive microcosm experiments were performed, each gradually more complex. All three experiments had the same basic setup of $15 \mathrm{~L}$ glass microcosms with a layer of natural sediment and sea water. The insight into the chemical composition of EPS in Chapter 2 was used to create artificial marine snow, consisting of alginate (a non-toxic, gelling polysaccharide), phytoplankton biomass, and kaolin clay, to which oil could be added to create oil-contaminated artificial marine snow. This artificial marine snow was used in all three microcosm experiments to enhance comparability and consistency. In order to investigate the effect of oil without the organic fraction of the marine snow, treatments with oil-contaminated clay were included using the same amount of clay and oil as was present in the marine snow. 
First, the experiment in Chapter 3 investigated the effect of marine snow on oil biodegradation in microcosms without benthic macroinvertebrates. Marine snow, with or without oil, and oil mixed with kaolin clay, were added to the microcosms all at once, as a layer on top of the sediment. The layer of snow was about $1 \mathrm{~cm}$ thick, the layer of clay was far less than $1 \mathrm{~mm}$. Results showed that marine snow hampers oil biodegradation: the presence of marine snow reduced the depletion of oil alkanes by $40 \%$, most likely due to the high biodegradability of marine snow organics compared to the oil. Biodegradation of marine snow resulted in anaerobic conditions in the top of the sediment layer. This reduced the oil biodegradation. Marine snow thus prolongs the residence time of oil in the benthic ecosystem.

The next experiment, described in Chapter 4, investigated the effects of oil-contaminated marine snow on benthic macroinvertebrates, and the effect of macroinvertebrates on oil biodegradation. In this experiment, marine snow was again added all at once as a $1 \mathrm{~cm}$ thick layer. Bioturbation by the invertebrates increased the oxygenated top layer of the sediment and partly counterbalanced the inhibition of oil biodegradation due to oxygen consumption by marine snow. Survival of the amphipod Corophium volutator was reduced by $80 \%$ in oil-contaminated marine snow, while the survival of the gastropod Hydrobia ulvae was reduced by $40 \%$ in oilcontaminated marine snow. Also clean marine snow reduced survival of C. volutator by $31 \%$, while it did not reduce survival of $H$. ulvae, which climbed onto the glass side of the microcosms. The bivalve Macoma balthica was most sensitive to the marine snow presence, with $70 \%$ and $80 \%$ reduced survival in presence of clean and oil-contaminated marine snow, respectively. Oxygen depletion near the sediment surface seemed to be the main reason for the observed adverse effects of the marine snow. In addition, indications were found that some species used the marine snow as food source, even when it was oil-contaminated. In this way, the presence of marine snow can increase the oil intake. This revealed that MOSSFA has additional adverse effects on the benthic community.

In the last microcosm experiment, described in Chapter 5, two benthic invertebrate species (the amphipod C. volutator and the gastropod H. ulvae) were first monitored over a period of 42 days after which new animals were introduced and observed for an additional period of 22 days. The (oil-contaminated) marine snow was added more gradually, over four consecutive days, to better mimic a MOSSFA event. Marine snow degradation again resulted in lower dissolved oxygen concentrations in the water column, which inhibited oil biodegradation on the sediment compared to oil in combination with clay. The oxygenated top layer of the sediment disappeared, and recovered after $\sim 20$ days. The impact of the lower oxygen concentration on benthic invertebrates was less than in the previous experiment. C. volutator were able to burrow through the gradually added thinner layer of marine snow without any mortality in case of clean marine snow, and showed a dose-dependent decrease in survival for both oil-contaminated clay and oilcontaminated marine snow. At the end of the experiment, $H$. ulvae from the treatments with oiled marine snow had higher PAH concentrations in their tissues than the animals from the treatments with the same amount of oil in clay only. This, and additional observations, confirmed 
that marine snow can be used as food source, and that oil-contaminated marine snow on the sediment due to MOSSFA can be a vector for oil towards other parts of the food web. The experiment further showed that benthic invertebrate species with high motility are more likely to survive a MOSSFA event because they are less vulnerable for the oxygen depletion as a result of biodegrading marine snow.

Overall, oil-contaminated marine snow on the ocean sediment can negatively affect benthic ecosystems, and can hamper oil biodegradation and ecosystem recovery. The additional consequences of MOSSFA during oil spills and spill responses should be taken into account in oil spill response planning. 
Samenvatting 
De Deepwater Horizon (DWH) olieramp in de Golf van Mexico in 2010 was één van de grootste olierampen in de geschiedenis. Gedurende drie maanden lekte er olie uit de $1500 \mathrm{~m}$ diepe Macondo bron. Een van de oliebestrijdingstechnieken was het gebruik van een tot dusver ongekende hoeveelheid chemische dispergeermiddelen, die zowel aan het zeeoppervlak werden toegepast als direct in de bron geïnjecteerd werden. Dit laatste was nog nooit eerder gedaan. Gedurende de olielekkage werd er een abnormaal grote hoeveelheid zeesneeuw gevormd, waaronder Extracellulaire Polymere Stoffen (EPS). Aggregaten van olieverontreinigde zeesneeuw werden gevormd door de samenklontering van EPS met 1) de grote hoeveelheid gesuspendeerde kleideeltjes als gevolg van doorspoeling van de Mississippi Rivier, 2) fytoplanktoncellen als gevolg van de algenbloei in de lente, en 3) de gedispergeerde oliedruppels. De zeesneeuw zonk door de waterkolom naar beneden en kwam op de bodem van de oceaan terecht. Dit hele proces wordt MOSSFA genoemd: Marine Oil Snow Sedimentation and Flocculent Accumulation. Onderzoek door GoMRI (Gulf of Mexico Research Initiative) liet zien dat MOSSFA een belangrijke wijze was waarop olie naar de diepzee getransporteerd kon worden. Naar schatting is $14-21 \%$ van de totale gelekte olie zo op de zeebodem terecht gekomen, alwaar de olie het bentische ecosysteem beïnvloedde. Dit proefschrift richtte zich allereerst op het mechanisme achter de vorming van EPS en zeesneeuw, en daarna in meer detail op de additionele ecotoxicologische consequenties van vorming van zeesneeuw gedurende olierampen voor het bentische ecosysteem.

In Hoofdstuk 2 wordt de rol beschreven die chemische dispergeermiddelen spelen in de vorming van EPS, in de aanwezigheid van fytoplankton. EPS is één van de hoofdingrediënten van zeesneeuw. Twee soorten mariene fytoplankton (de groenalg Dunaliella tertiolecta en de diatomee Phaeodactylum tricornutum) bleken binnen enkele dagen na blootstelling aan het dispergeermiddel Corexit 9500 EPS te vormen. Corexit 9500 was één van de twee gebruikte dispergeermiddelen tijdens de DWH olieramp. EPS werd niet gevormd indien de fytoplanktonkweek was behandeld met antibiotica, die de bijbehorende bacteriën verwijderden. Dit wijst er op dat de bacteriën behorende bij het fytoplankton zorgden voor de vorming van EPS. Ook werden aanwijzingen gevonden dat de benodigde energie voor de vorming van EPS voortkwam uit de symbiose tussen het fytoplankton en de bacteriën. Chemische analyse van de samenstelling van de EPS toonde aan dat dit uit proteïnen en polysachariden bestond. De zeesneeuw die in de DWH olieramp gevormd werd bestond ook uit deze bestanddelen. Deze resultaten hebben gevolgen voor de toepassing van chemische dispergeermiddelen gedurende hoge algendichtheid in deltaecosystemen, omdat deze combinatie van factoren een MOSSFA gebeurtenis in gang kunnen zetten.

Om de effecten van (olieverontreinigde) zeesneeuw op het bentische ecosysteem verder te onderzoeken zijn drie opeenvolgende microcosm experimenten uitgevoerd, elke meer uitgebreid dan de voorgaande. Alle drie de experimenten hadden dezelfde opzet, van $15 \mathrm{~L}$ glazen microcosms met een laag natuurlijk sediment en zeewater. De inzichten in de chemische samenstelling van de EPS, uit Hoofdstuk 2, zijn gebruikt om een kunstmatige zeesneeuw te 
Samenvatting

maken, bestaande uit alginaat (een niet-toxische, gelerende polysacharide), fytoplankton biomassa, en kaolien klei. Door toevoeging van olie is ook olieverontreinigde kunstmatige zeesneeuw gemaakt. Deze kunstmatige zeesneeuw is in alle drie de microcosm experimenten gebruikt, waardoor de experimenten onderling goed vergelijkbaar zijn. Om de effecten van olie zonder de organische fractie uit zeesneeuw te kunnen onderzoeken zijn behandelingen met olieverontreinigde kaolien klei gebruikt, die dezelfde hoeveelheid olie en klei bevatten als de zeesneeuw.

Allereerst werd in het experiment uit Hoofdstuk 3 onderzocht wat het effect is van zeesneeuw op olieafbraak in microcosms zonder bentische macro-invertebraten. Zeesneeuw, met of zonder olie, en olie gemengd met kaolien klei, werden in één keer toegevoegd aan de microcosms, zodat er een laag bovenop het sediment gevormd werd. De laag zeesneeuw was ongeveer $1 \mathrm{~cm}$ dik, en de laag klei was minder dan $1 \mathrm{~mm}$ dik. De resultaten toonden aan dat zeesneeuw de olieafbraak hindert: de aanwezigheid van zeesneeuw verlaagde de afbraak van alkanen uit olie met $40 \%$, waarschijnlijk door de hoge afbreekbaarheid van organisch materiaal in zeesneeuw in vergelijking met de afbreekbaarheid van de olie. Biologische afbraak van zeesneeuw leidde tot anaerobe omstandigheden in de toplaag van het sediment, wat de olieafbraak verminderde. Zeesneeuw verlengt derhalve de verblijftijd van olie in het bentische ecosysteem.

In het volgende experiment, beschreven in Hoofdstuk 4, werd bekeken wat de effecten zijn van olieverontreinigde zeesneeuw op bentische macro-invertebraten en wat het effect is van macroinvertebraten op olieafbraak. Zeesneeuw werd in dit experiment wederom in één keer toegevoegd zodat er een $1 \mathrm{~cm}$ dikke laag ontstond. Bioturbatie door de invertebraten vergrootte de geoxideerde bovenste laag van het sediment, en compenseerde deels de verhindering van olieafbraak veroorzaakt door het zuurstofgebruik door de afbraak van zeesneeuw. Overleving van de amphipode Corophium volutator was met $80 \%$ gereduceerd in de behandeling met olieverontreinigde zeesneeuw, terwijl de overleving van de gastropode Hydrobia ulvae met $40 \%$ gereduceerd was in de behandeling met olieverontreinigde zeesneeuw. Schone zeesneeuw reduceerde de overleving van $C$. volutator met $31 \%$, terwijl de overleving van $H$. ulvae niet afnam, omdat deze slakjes tegen de glazen wand van de microcosms op konden klimmen en zo de olie en de zeesneeuw konden ontwijken. De tweekleppige Macoma balthica was het meest gevoelig voor de aanwezigheid van zeesneeuw, met $70 \%$ en $80 \%$ gereduceerde overleving in de behandeling met respectievelijk schone of olieverontreinigde zeesneeuw. Zuurstoftekort nabij het sedimentoppervlak was de hoofdreden voor de geobserveerde nadelige gevolgen van de zeesneeuw. Er waren tevens indicaties dat sommige soorten macro-invertebraten de zeesneeuw als voedselbron konden gebruiken, zelfs als het olieverontreinigd was. De aanwezigheid van zeesneeuw kan op deze manier de opname van olie bevorderen. MOSSFA heeft op deze wijze additionele nadelige gevolgen voor de bentische gemeenschap.

In het laatste microcosm experiment, beschreven in Hoofdstuk 5, werden twee soorten bentische invertebraten (de amphipode C. volutator en de gastropode $H$. ulvae) eerst geobserveerd 
gedurende 42 dagen na de start van de behandeling. Na deze periode werden nieuwe dieren werden geïntroduceerd en geobserveerd voor nog eens 22 dagen. Voor een betere benadering van een MOSSFA gebeurtenis, werden de (olieverontreinigde) zeesneeuw en klei in dit experiment geleidelijk toegevoegd gedurende vier opeenvolgende dagen. Afbraak van zeesneeuw leidde wederom tot lagere opgeloste zuurstofconcentraties in de waterkolom, wat de olieafbraak op het sediment verhinderde ten opzichte van het experiment met olie in combinatie met klei. De geoxideerde bovenste laag van het sediment verdween en herstelde na $\sim 20$ dagen. De invloed van de lagere zuurstofconcentratie op bentische invertebraten was in dit experiment minder duidelijk dan in het vorige experiment. C. volutator kon nog door de geleidelijk toegevoegde dunnere laag schone zeesneeuw graven zonder sterfte, maar er was een dosis-afhankelijke afname in overleving in zowel de olieverontreinigde klei als de olieverontreinigde zeesneeuw. Aan het einde van het experiment hadden $H$. ulvae uit de behandeling met olieverontreinigde zeesneeuw hogere PAK concentraties in hun weefsels dan de dieren uit de behandeling met dezelfde hoeveelheid olie gemengd met klei zonder zeesneeuw. Deze en andere observaties bevestigden aan dat zeesneeuw gebruikt kan worden als voedselbron, en dat olieverontreinigde zeesneeuw op het sediment als gevolg van MOSSFA een vector kan zijn voor olie naar andere delen van het voedselweb. Tevens liet het experiment zien dat bentische invertebraten die in hoge mate beweeglijk zijn een hogere overlevingskans hebben in het geval van een MOSSFA gebeurtenis, omdat ze minder kwetsbaar zijn voor zuurstofdepletie als gevolg van biologische afbraak van zeesneeuw.

Afsluitend kan gesteld worden dat olieverontreinigde zeesneeuw op de bodem van de oceaan een negatief effect heeft op bentische ecosystemen en dat olieafbraak en herstel van ecosystemen gehinderd kunnen worden. De additionele consequenties van MOSSFA gedurende olierampen en tijdens de bestrijding daarvan moeten meegenomen worden in de besluitvorming en planning van oliebestrijding. 
Acknowledgements 


\section{"Everything is hard before it is easy" (Johann Wolfgang von Goethe)}

U bent nu aangekomen bij het deel van het proefschrift dat de meeste mensen wél lezen: het dankwoord. Ze zeggen weleens dat dit het moeilijkste deel is om te schrijven, want je wil vooral niemand vergeten. Ik zal mijn best doen om iedereen te bedanken die op enigerlei wijze heeft bijgedragen aan het feit dat dit boekje bestaat. Als je naam er onverhoopt toch niet bij staat: sorry, en uiteraard alsnog bedankt.

Allereerst mijn promotor Tinka. Nadat ik bij Toxicologie mijn masterscriptie had geschreven, bood je mij de mogelijkheid om een promotieonderzoek te gaan doen binnen het C-IMAGE project. Bedankt voor je vertrouwen, je ondersteuning, en je optimisme. Je zag altijd nog wel ergens mogelijkheden, als ik het zelf even niet meer zag zitten. Het was zeker geen makkelijk traject, maar mede door jouw pragmatische aanpak is het allemaal gelukt en heb ik ontzettend veel geleerd.

Edwin, mijn grote dank gaat uit naar jou. Ik ben blij dat je als co-promotor bij mijn project betrokken was, en dat ik jouw eerste promovendus mocht zijn. Jouw ervaring met het doen van experimenteel ecotoxicologisch werk was van onschatbare waarde tijdens de drie grote experimenten in Den Helder. Bedankt voor je kritische blik, je open houding, en de gezellige gesprekken tijdens het werk, over wat vissen nou zo leuk maakt (ik snap dat misschien nog steeds niet helemaal), Bruce Springsteen ( $\mathrm{ja}$, ik ben nog steeds jaloers dat jij wel naar het concert ging en ik in Den Helder aan de experimenten moest werken), en het nut van speciale conferentieschoenen. De opmaak van dit proefschrift is losjes gebaseerd op de opmaak van Edwins proefschrift, waarvoor dank aan zijn vrouw Gerda.

Huub, bedankt voor je vertrouwen in het C-IMAGE project, en bedankt dat ik volledig werd opgenomen binnen Milieutechnologie toen ik daarnaartoe verhuisde. Mijn overige collega's binnen C-IMAGE wil ik ook bedanken voor de goede samenwerking: Alette, Martijn en Wierd, en natuurlijk mijn C-IMAGE sisters Marieke, Shokouh en Sophie.

The American C-IMAGE team is gratefully acknowledged for their support: David Hollander, Steven Murawski, Sherryl Gilbert and Benjamin Pruitt. My thanks also go to fellow C-IMAGE members Jagoš Radović, Thomas Oldenburg, Isabel Romero, Patrick Schwing, Melissa Rohal and Paul Montagna, for the fruitful collaborations which were incredibly valuable for our experiments and my $\mathrm{PhD}$ thesis.

Grote dank aan de lab-medewerkers en studenten van IMARES Den Helder (thans Wageningen Marine Research) die meegeholpen hebben aan de experimenten: Babette, Cor, Erika, Evelien, Jessica, Siem, Sofia, Suzanne, Yulia en ZQ. Also a big thank you to my MSc students Adi, Xenia, Gladys and Park, and to Celia for helping out with the analyses for the first publication. Park and Celia, I wish you all the best for your own PhDs! 
My friends and colleagues at Toxicology: Agata, Ans, Arif, Artem, Aziza, Barae, Bert, Hans, Henrique, Hequn, Jochem, Jonathan, Judith, Karsten, Laura, Linda, Marcia, Marije, Marta, Merel, Myrthe, Myrto, Nacho, Nynke, Reiko, Rozaini, Rung, Samantha, Si, Sunday, Suzanne and Wasma. Thanks for making the first one and a half year at Tox very memorable! I enjoyed our lunches, the PhD trip to the UK, pizza Tuesdays, coffee breaks, and whenever someone shouted “it's beer o'clock, let's go?". I was sad I had to leave you, but I am grateful that I was still included in your social activities, and was considered an honorary Tox-family member.

After moving from Toxicology to Environmental Technology, I was introduced to a whole different kind of scientific field, where apparently everyone (except me) knew what a UASB was. Thanks for putting up with this strange ecotox-student, and for making the 'second part' of my $\mathrm{PhD}$ very enjoyable. I especially enjoyed the conversations during coffee breaks, when the best ideas seem to pop up, the Sinterklaas poems, the hugely successful WE-days, the Veluweloop, the weekly and monthly borrels, the department trips, the insane amounts of cakes and cookies, and the togetherness of ETE. A big thank you to my friends and colleagues, both $\mathrm{PhD}$ and staff: Alette, Anita, Annemerel, Arnoud, Azie, Bruna, Dainis, Dandan, Darja, Delaram, Els, Emilius, Gunther, Hans, Ilse, Ilse, Indra, Ingo, Jean, Jess, Joeri, Judith, Kamonashish, Kasper, Katja, Koen, Laura, Lei, Leire, Livio, Lucia, Marjo, Mark, Miriam, Momo, Nora, Pim, Pradip, Rosanne, Sanne, Shokouh, Sophie, Thomas, Tiemen, Tim, Viola, Wenbo, Yujie and Yvonne.

Geen enkele PhD bij ETE zou succesvol afgerond kunnen worden zonder de hoeksteen van de afdeling: het secretariaat. Liesbeth en Gea, bedankt voor alles wat jullie voor ETE doen! Het labteam van ETE verdient ook een groot applaus. Ik weet dat het ecotox-gebeuren in het begin een beetje lastig in te passen was bij de rest van het ETE onderzoek, bedankt voor alle hulp!

Naast mijn studie en PhD heb ik van 2007 tot 2016 bij de vrijwillige brandweer van Wageningen gewerkt. In het najaar van 2016 besloot ik te stoppen als vrijwilliger omdat m'n proefschrift toch echt een keertje af moest zijn. Collega's, bedankt! In het bijzonder wil ik hier Inge en Patrick noemen, mijn maatjes vanaf het eerste uur.

Anneke, Daniëlle en Marina, mijn BSc-genootjes, en daarna PhD-lotgenoten: bedankt voor de gezelligheid tijdens etentjes, drankjes, spelletjes, pubquizzen, concerten, etc. Laura, bedankt voor al het voorgaande én alle keren dat je op Muffin hebt gepast! Femke, bedankt voor onze fijne gesprekken en kopjes thee en koffie. Mijn festivalvriendjes Sander \& Marieke, Maurice, Anne en de andere Lowlandsgangers: bedankt voor de gezelligheid en de knakworst-ontbijtjes.

Twee mensen die een speciaal bedankje verdienen zijn mijn paranimfen Martijn en Yvonne: ik ben ontzettend blij dat jullie op de dag van de verdediging samen met mij op het podium zullen staan. Martijn, bedankt voor de bemoedigende woorden op de momenten dat het moeilijk was. Jij had het allemaal al meegemaakt, dus je wist precies hoe lastig het soms kan zijn. Ik was ontzettend trots op jou toen jij je eigen proefschrift verdedigde; ik hoop dat je nu net zo trots op je zusje kunt zijn! Yvonne, jij hebt me door de laatste schrijffase heen gesleept en bent mijn 
schouder om op uit te huilen geweest. Ik weet zeker dat mijn mentale gesteldheid de laatste twee maanden van het schrijven niet had overleefd zonder onze kopjes thee, biertjes, chocola, goede gesprekken, de mantra "nog eventjes" blijven herhalen, gedeelde smart, en het vieren van kleine succesjes.

Mijn familie wil ik graag bedanken voor het enorme gevoel van thuiskomen, elke keer dat ik naar Twente kwam. Dat was in de laatste fase van mijn $\mathrm{PhD}$ niet meer zo heel erg vaak wegens tijdgebrek, maar ik ben van plan dat in te halen hoor! Mama, sorry voor elke keer dat ik je weer afkapte als je geïnteresseerd vroeg hoe het met m'n onderzoek ging, maar ik het daar gewoon eventjes niet over wilde hebben. Papa, bedankt dat je altijd klaarstaat. Mijn brusjes Martijn, Suzanne, en Marjolein, en alle aanhang: Team Rocket is sneller dan het licht! Bedankt dat ik me bij jullie nooit zo raar voel, omdat we met z'n allen raar zijn.

De laatste woorden in dit proefschrift richt ik aan mijn favoriete persoon, Velda: everything is awesome, everything is cool when you're part of a team. Jij ziet altijd mijn goede kanten, of je vindt mijn mindere kanten in ieder geval niet zo erg. Je hebt van dichtbij meegemaakt hoe een promotieonderzoek erin kan hakken, en door alle dingen die gedurende dezelfde tijd ook nog zijn gebeurd in onze privélevens, was het niet altijd heel makkelijk. Bedankt dat je er altijd voor me bent. Er gaan na deze periode behoorlijk wat dingen veranderen in ons leven, maar ik weet dat wij dat samen wel aan kunnen. Jij en ik, zo moet het zijn. 
About the author 
Justine Sophie van Eenennaam was born on July 14, 1986, in Nijmegen, the Netherlands. She finished her secondary education (VWO) at Twents Carmel College locatie Lyceumstraat in Oldenzaal in 2004, after which she started her Bachelor's study Bodem, Water en Atmosfeer at Wageningen University. Justine completed her Bachelor's degree with a thesis at the Aquatic Ecology group, and then continued with her Master's study in the Hydrology and Water Quality program in 2007, specializing in Aquatic Ecology and Water Quality Management. Her Master's

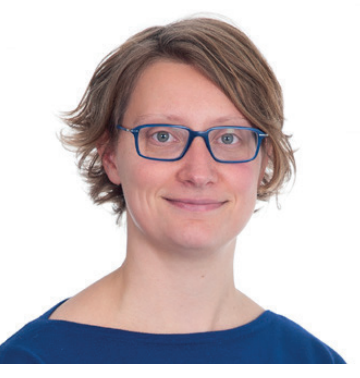
thesis was completed at the Aquatic Ecology group, and she did an internship at Universidade Federal do Rio Grande do Norte in Natal, Brazil. In 2010, she started a second Master's study in the Aquaculture and Marine Resources Management program, specializing in Marine Resources and Ecology. Her Master's thesis was completed at the Department of Toxicology. In 2012, Justine started her PhD research under supervision of Prof. Dr Tinka Murk and Dr Edwin Foekema, first at the Department of Toxicology and from 2013 at the Environmental Technology group. During her $\mathrm{PhD}$, she followed the Postgraduate Education Toxicology program. Starting September 2017, Justine is employed as Regulatory Affairs Officer at Charles River Laboratories in Den Bosch. 


\section{SENSE}

Netherlands Research School for the

Socio-Economic and Natural Sciences of the Environment

\section{I P L O M A}

For specialised PhD training

The Netherlands Research School for the Socio-Economic and Natural Sciences of the Environment (SENSE) declares that

\section{Justine Sophie van Eenennaam}

born on 14 July 1986 in Nijmegen, The Netherlands

has successfully fulfilled all requirements of the Educational Programme of SENSE.

Wageningen, 10 October 2017

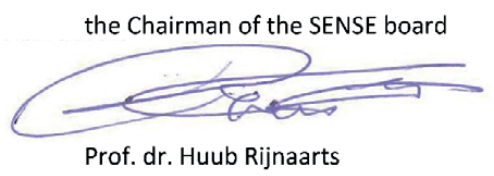

the SENSE Director of Education

The SENSE Research School has been accredited by the Royal Netherlands Academy of Arts and Sciences (KNAW)

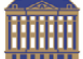

$\begin{array}{llllllllllllllllllllll}K & O & N & I & N & K & L & I & J & K & E & N & E & D & E & R & L & A & N & D & S & E\end{array}$

$\begin{array}{lllllllllllllllllllllllll}\text { A } & K & A & D & E & M & \text { I } & \text { E } & \text { V } & \text { A } & N & \text { W } & \text { E } & T & \text { E } & N & S & C & H & A & P & P & E & N\end{array}$ 


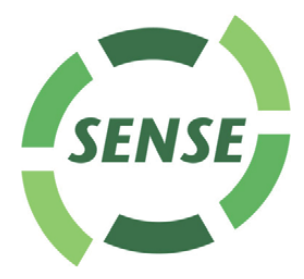

The SENSE Research School declares that Ms Justine van Eenennaam has successfully fulfilled all requirements of the Educational PhD Programme of SENSE with a work load of $50 \mathrm{EC}$, including the following activities:

\section{SENSE PhD Courses}

- Environmental research in context (2013)

- SENSE Writing Week (2014)

- Research in context activity: 'Co-organising the SENSE Writing Week' (2015)

\section{Other PhD and Advanced MSc Courses}

- Course supervising MSc students, Wageningen University (2013)

- Scientific Writing, Wageningen University (2014)

- Pathobiology, Risk Communication, Medical and Forensic Toxicology, Postgraduate Education in Toxicology (2014)

- MSc Introduction to Epidemiology and Public Health, Wageningen University (2015)

- MSc Food Toxicology, Wageningen University (2015)

- Molecular Toxicology, Introductory course in Laboratory Animal Science, Risk Assessment, Organ Toxicology, Postgraduate Education in Toxicology (2015)

- Cell Toxicology, Postgraduate Education in Toxicology (2016)

\section{Management and Didactic Skills Training}

- Teaching in the BSc course 'Introductie omgevingswetenschappen' (2012-2013)

- Supervising Master's thesis projects of four MSc students (2013-2014)

- Teaching in the MSc course 'Environmental Toxicology' and 'Environmental Quality and Governance' (2013-2015)

- Member of the Lab Committee at the Environmental Technology Group (2015-2017)

\section{Oral Presentations}

- Rational application of chemicals in response to oil spills to reduce environmental damage: ecotoxicological aspects. $1^{\text {st }}$ Symposium on Deep-Sea Oil Spills, 4-6 September 2013, Hamburg, Germany

- Marine snow enhances the adverse effects of oil on benthic invertebrates. Gulf of Mexico Oil Spill \& Ecosystem Science Conference, 6-9 February 2017, New Orleans, United States

SENSE Coordinator PhD Education 
This research was made possible in part by a grant from the Gulf of Mexico Research Initiative as an effort of the C-IMAGE consortium (Grant Contract \#SA 12-10/GoMRI-007), and in part by the Wageningen UR TripleP@Sea innovation program (KB-14-007).

Financial support from Wageningen University for printing this thesis is gratefully acknowledged. 
Cover image: "Inside a Snowflake", Vlad Studio, www.vladstudio.com

Layout and printing: ProefschriftMaken, www.proefschriftmaken.nl

This thesis is printed on FSC certified paper. 